
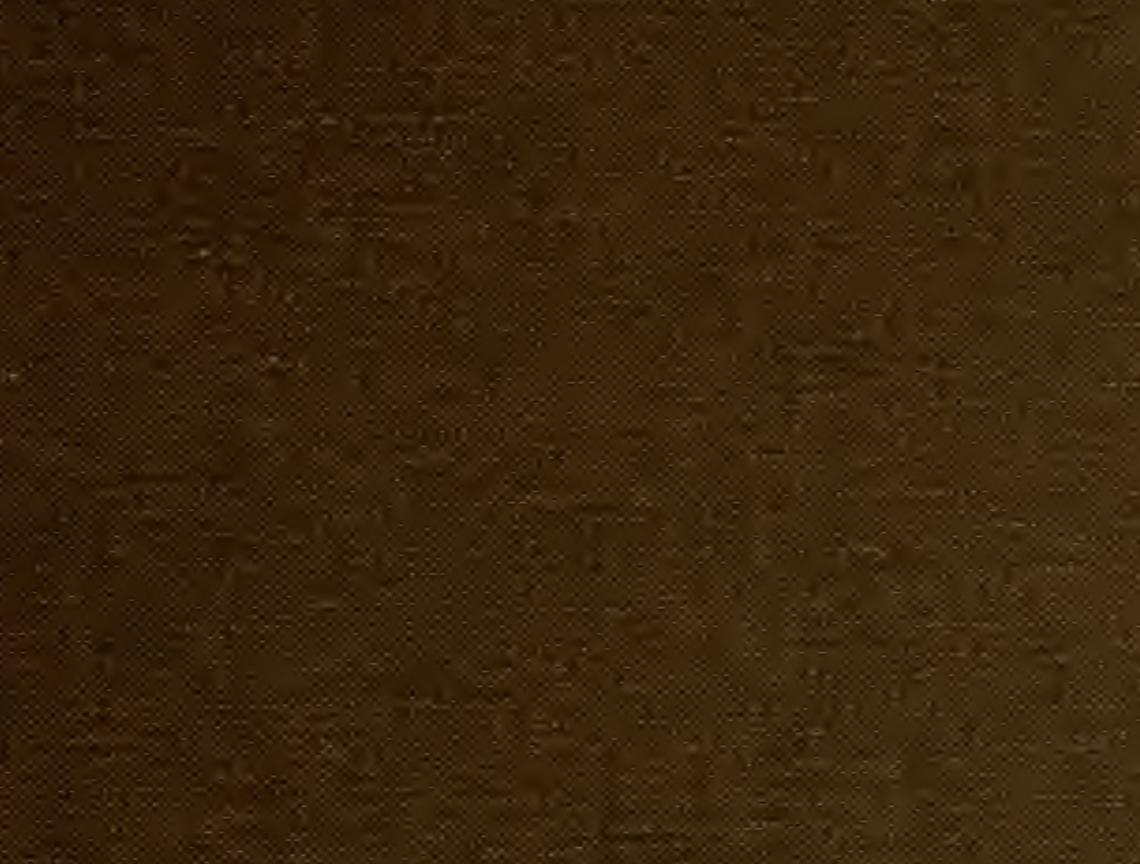

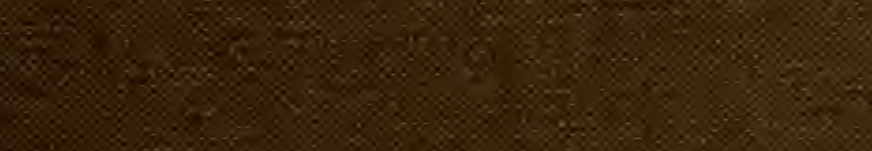

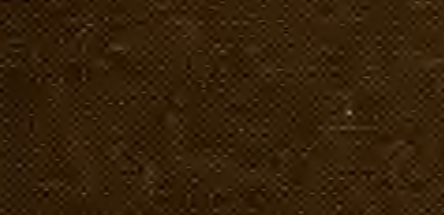

$88^{8}$

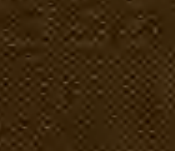

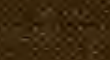
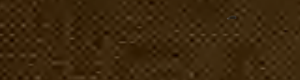

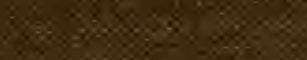

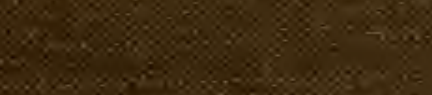

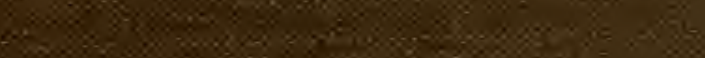

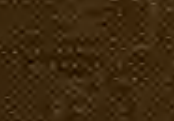

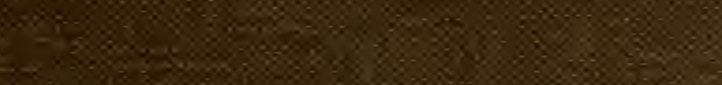

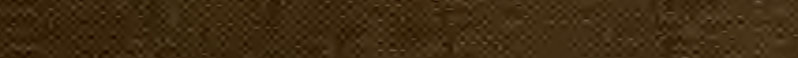

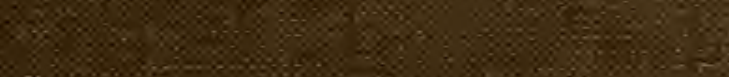

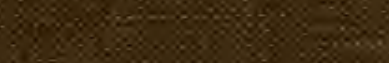
2808 308 8 


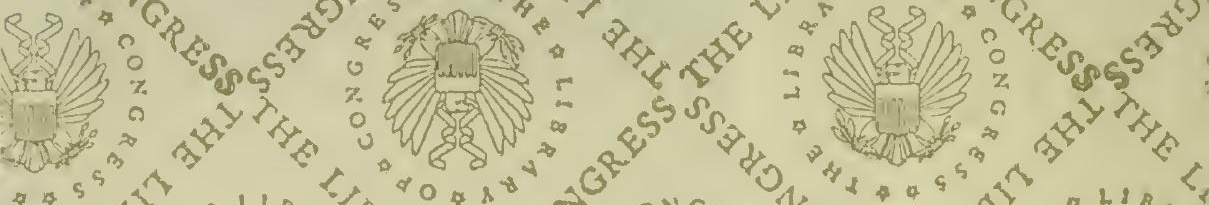

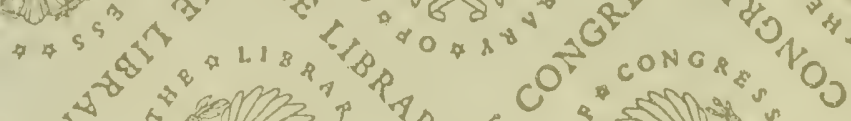

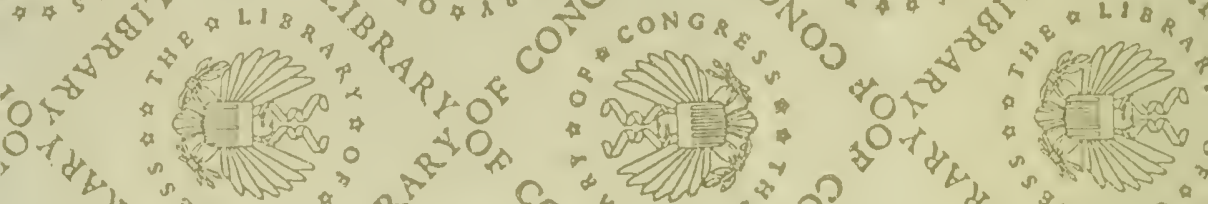
$a^{2}$

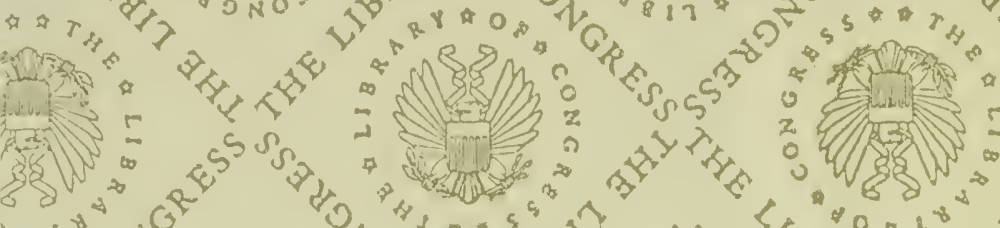

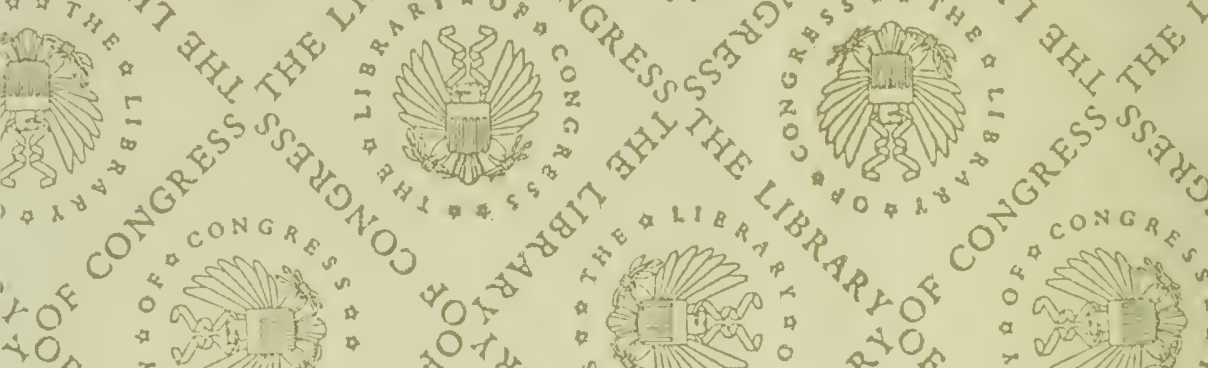

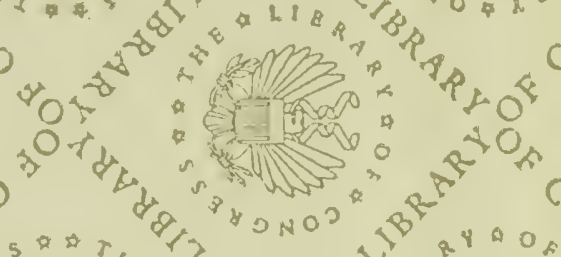

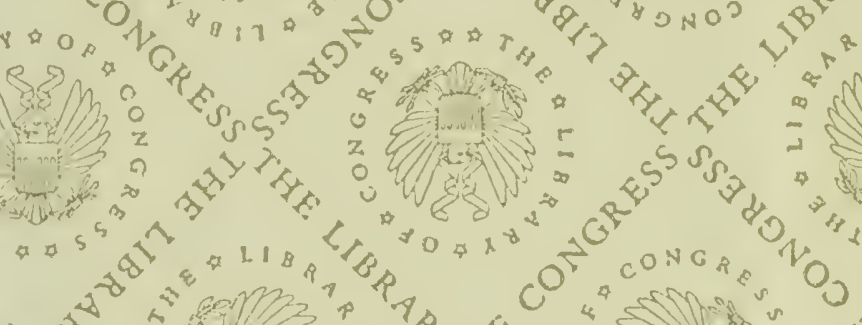

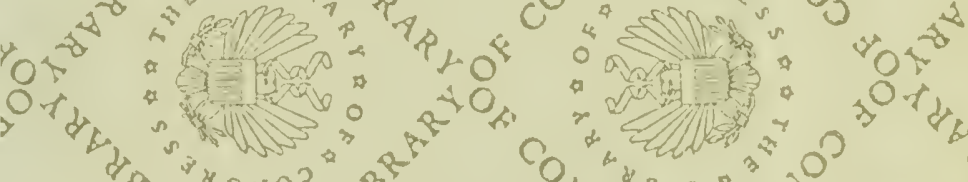
$\mathrm{A}^{2}$

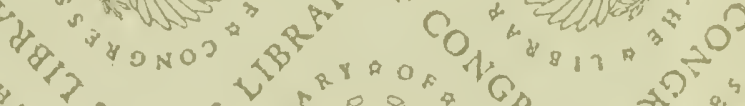

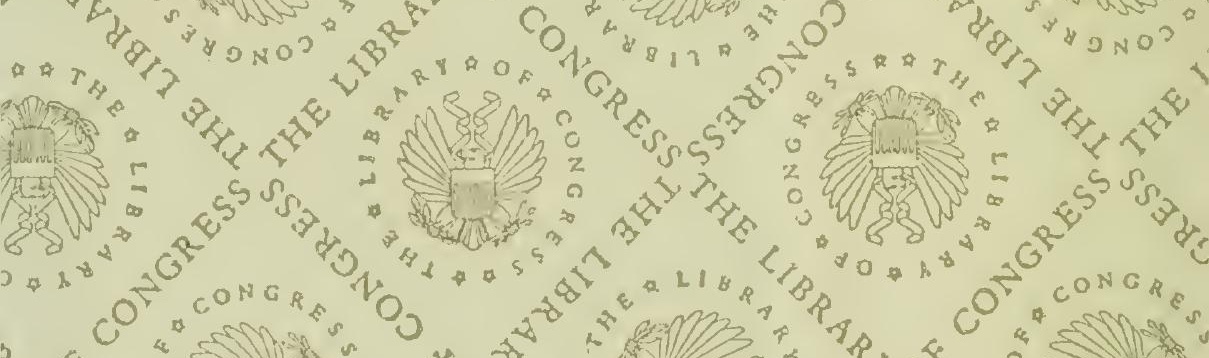
30 01010

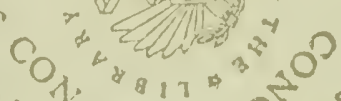

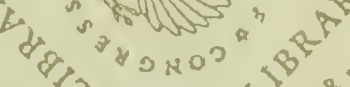
C. als axositis

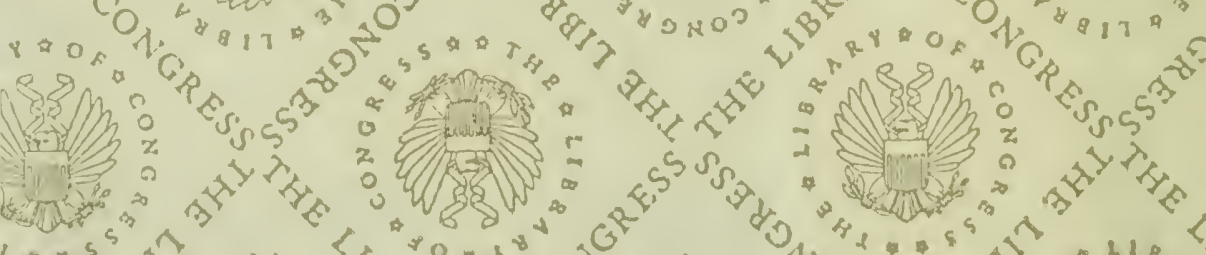





\section{ORIGINAL}

\section{HANDBOOK FOR RIDERS}

A Complete Guide to Modern Horsemanship

BY

M. C. GRIMSGAARD, K.W.O., G.M.E.H.S.

Captain of Horse, Royal Norwegian Cavalry

Translated by the Author

Revised and Corrected by The Berlitz School of Languages

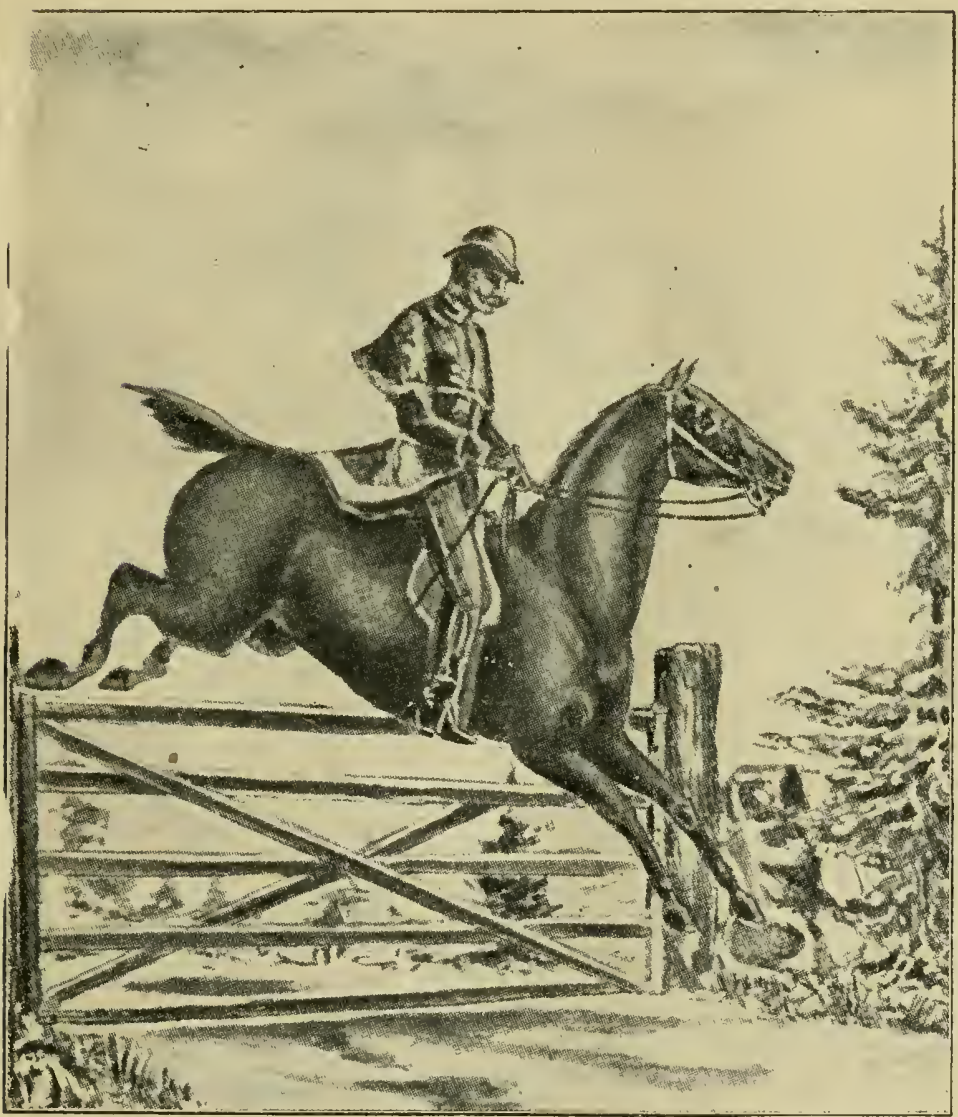

WITH ILLUSTRATIONS 


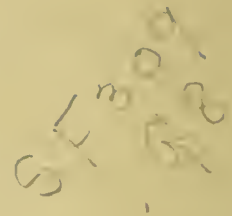

Copyright, 1911

By M. C. GRIMSGAARD

The Winthrop Press

New York, N. Y., U. S. A.

(C) CI.A259551 



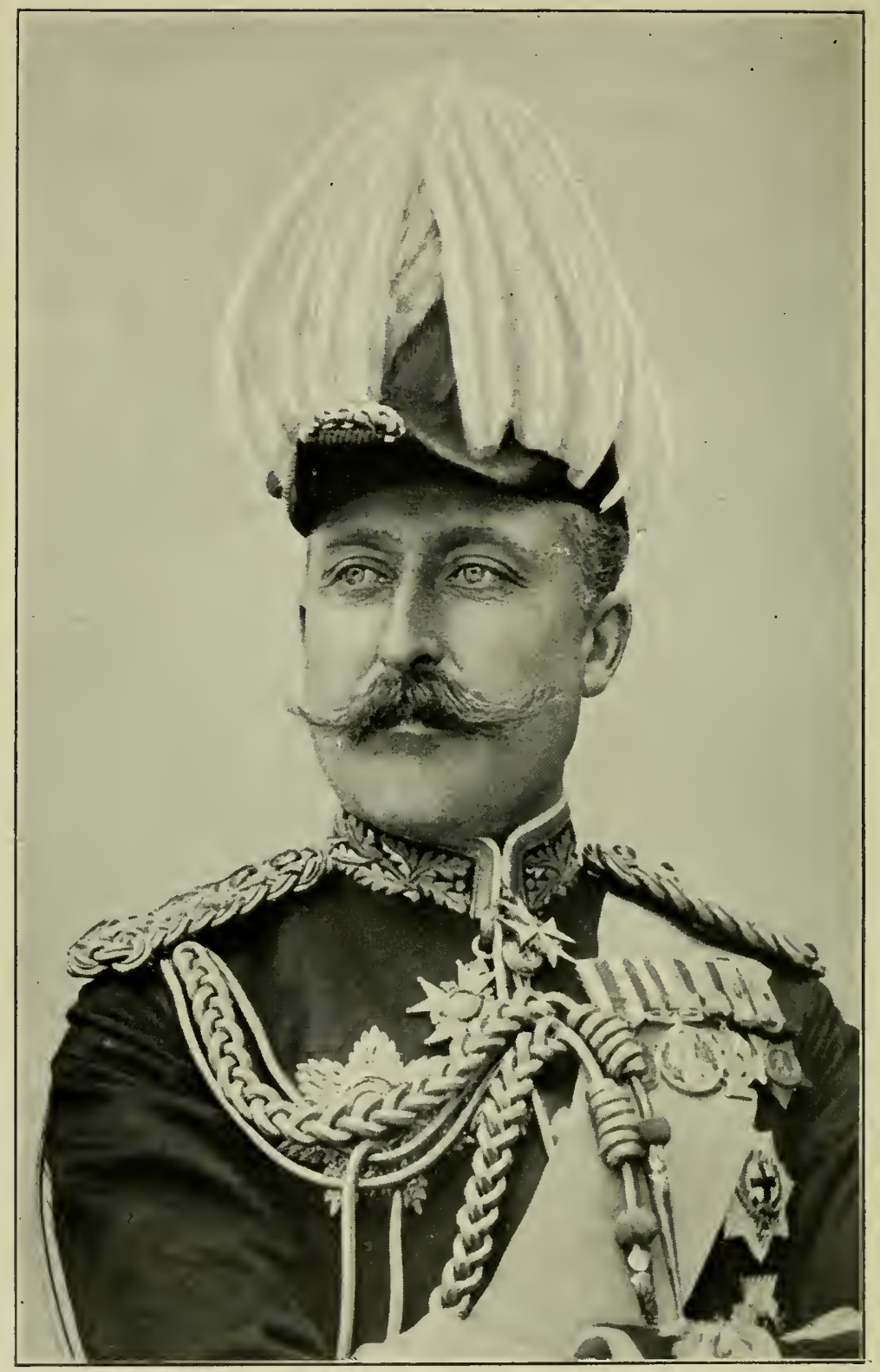

H. R. H. THE DUKE OF CONNAUGHT. 
To

Field-Marshal

His Royal Highness

ARTHUR WILLIAM PATRICK ALBERT,

Duke of Connaught and Strathearn, K.G., K.T., K.P., G.C.B., G.C.S.I., G.C.M.G., G.C.I.E., G.C.V.O.

This

\section{HANDBOOK FOR RIDERS}

is most humbly dedicated in grateful remembrance of the honour bestowed upon the author in having been granted the privilege of inspecting the Aldershot Division of the English Army, then under command of His Royal Highness. 



\section{Preface.}

Having been frequently asked by my pupils for some simple work on horsemanship, which they might study in connection with their practical riding lessons, I have undertaken to supply that apparent want by writing this book. It contains nothing new to the fully experienced rider; those less experienced will, it is hoped, find in it the necessary assistance. If so, my purpose will be achieved, and still more so, if it may lead to a more rational and humane treatment of our most noble domestic animal, the Horse. 



\section{CONTENTS.}

First Part.

Page

The Rider's Dress . . . . . . . . . I

The Riding Horse . . . . . . . . . . . 5

The Stable and its Management . . . . . . 16

Feeding and Watering . . . . . . . 25

Shoeing . . . . . . . . . . . . 30

Saddlery and its Care . . . . . . . . $3_{3} 8$

Saddling and Bridling . . . . . . . . 46

Unsaddling and Unbridling . . . . . . . 52

Packing the Saddle . . . . . . . . 53

Grooming and Care of Horses . . . . . . $5^{8}$

The Riding-Schюol . . . . . . . . . . 67

Second Part. Riding Instruction.

73

Leading the Horse, Dismounted or Mountel . . . 77

I. Riding with Snaflle . . . . . . . . . . 80

Mounting and Dismounting . . . . . . . . 8 I

The Rider's Position when Mounted . . . . . 90

Handling the Reins . . . . . . . . . . 95

Saluting on Horseback . . . . . . . . . 100

The Aids in Horsemanship . . . . . . . . 103

How, when and where to Punish Horses . . . . 109

The Various Paces . . . . . . . . . . II4

Carriage of the Horse when Mounted . . . . . 122

Riding in Classes . . . . . . . . . . 128

To Put the Horse into a Walk . . . . . . . I32

To Pass from the Walk to the Trot . . . . . I33

To Pass from the Trot to the Walk . . . . ${ }^{\mathrm{I}} 35$

To Halt from the Walk . . . . . . . . I 35

Turning Corners . . . . . . . . . . 136

Turning Diagonally Across the School . . . . . ${ }_{3} 8$

The Medium Trot . . . . . . . . . . . 139

Turning on Forehand with Horse's Head to the Front I 40

Bending the Horse's Neck at the Stand and while in

Motion . 
Bending the Horse's Head at the Stand and while in Motion

Backing

The Extended Trot

Collecting the Horse

152

Halts

Bending the Horse

Turning on Forehand with Horse's Head Bent Sideways 162

The Great Circle

Turning while in Motion

Change in Crossing the Great Circle

Yielding Sideways to the Rider's Leg

Side-Gaits

Turning on Haunches .

Diminishing and Resuming the Great Circle I 65 I 68 I 69 I 7 I I 84 Small Circles I 86 The Gallop

Obstacle Riding I 88 I9I 201 Rising to the Trot

II. Riding with Curb

Mounting and Dismounting 220

Handling the Reins 224

The Lessons 230

III. Measures Adapted to Special Cases

\section{Supplement.}

Outdoor Riding

The Full Gallop (The Carrière) .

Method of Swimming a Horse

Long Distance Rides 25 I

Exercising and Longeing

Transportation of Horses

Treatment of Sick Horses

Quadrille Riding

Ladies' Riding .

Schooling the Horse (Breaking)

Horse-Gymnastics (The Modern Fquine High School)

Ieu de Barre

Memorandum 




\section{First Part.}

\section{The Rider's Dress.}

"Dress properly and you may learn to ride properly."

The rider's costume has much to do with his firmness and comfort in the saddle; it should be plain and well cut; trimming of every kind and conspicuous colours should be carefully avoided.

A hat or cap, which, when riding, feels as if it were falling off every moment, is troublesome; it is not unusual to see inexperienced riders lose their balance in efforts to hold their hats; nor should the headwear be too tight, a condition which may easily cause headache when riding. A small cap of cloth or silk is recommended during lessons and on long distance rides, but it is not considered comme il faut for promenade riding, when a silk hat or a Derby is preferable.

The riding-coat for summer wear or in the school should be single breasted and fitted to the figure; the skirts cut off in front and so short as not to touch the back of the horse (Fig. I). The overcoat for riding should also be single breasted, of the "fly front" shape shown in Fis. 2, and should have several pockets.

I - Ilandbook for Riders. 
Riding-breeches should fit well up in the crotch and be low in the waist, especially in front. Trousers with straps may also be worn; they should not be made of too elastic material nor fit

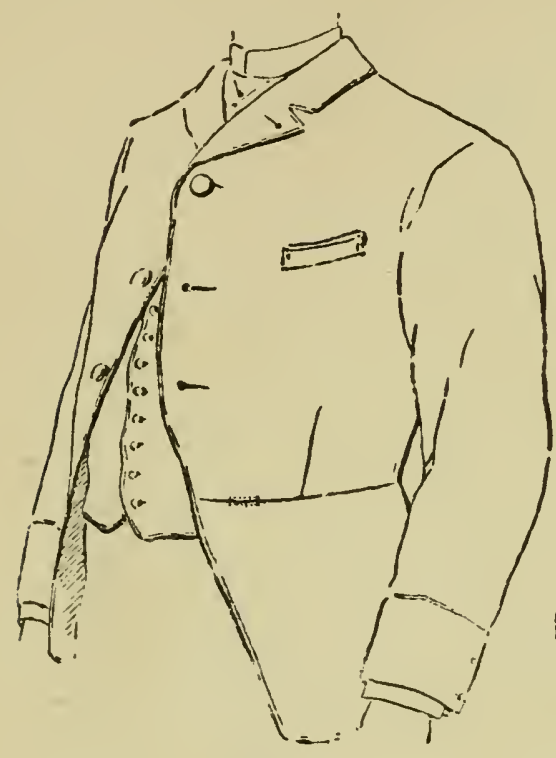

Fig. I.

too closely. The material of riding-breeches should be elastic; they may be baggy or close-fitting, according to taste, but should always be close-fit-

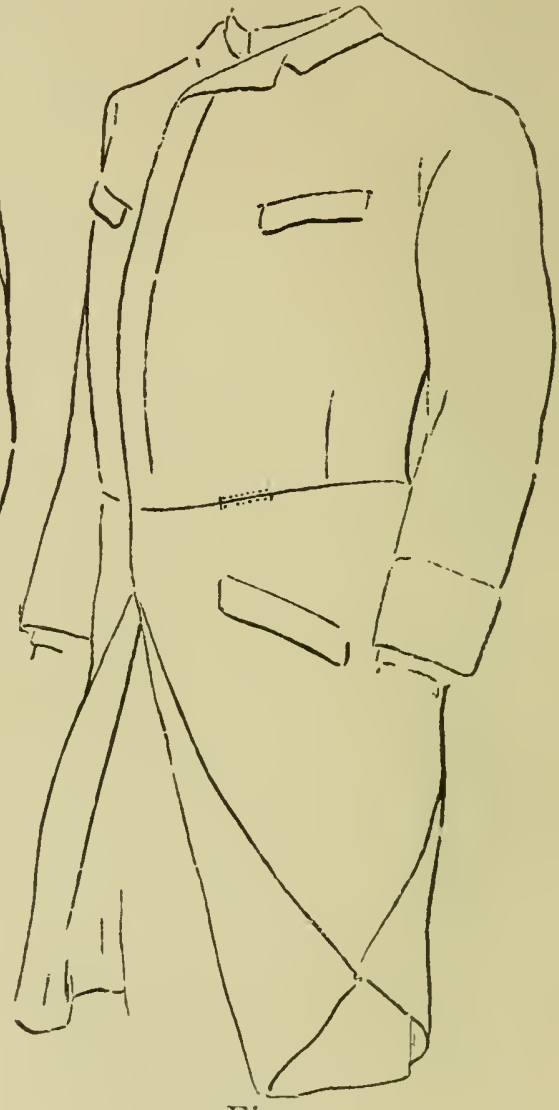

Fig. 2. ting around and below the knee (Fig. 3). When riding-trousers or breeches are double seated the material should be of the same softness as that of the garment; therefore chamois skin or leather may not always be suitable. It is advisable to 
provide a sufficient quantity of the material for use in repairing the seat, when worn out. If the rider should feel uncomfortable from the double thickness of cloth, the inner material may be removed. The front seam should be on the inside of the leg, just clearing but not'coming over the knee.

For trousers, the so-called whipcord is recommended; and for breeches the same or softer materials may be used.

With trousers, low boots are used with elastics at the sides, and the spurs should be fastened in the heels. Riding-boots, of whatever shape they may be, should be sufficiently wide and soft at the ankle as not to interfere with the play of the ankle and instep $\rightarrow$ a most important consideration in preserving a supple seat. The soles should not be thick nor should they break off under the middle of the foot. When drawn on, the tops of the boots must not catch in the

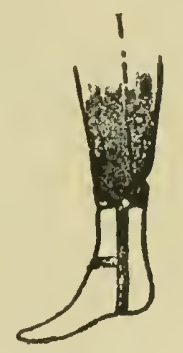

Fig. 3 . skirts of the saddle, as that would prevent the rider from freely using his legs-a most annoying thing, though easily remedied by having leather straps on the inside of the boot-legs, fastened by buttons on the breeches, thus keeping the boot-leg always in place. With riding-boots, it is preferable to wear loose spurs with straps buckled on the outside. To prevent the spurs from sliding down, a small leather knob is usually placed on the boot-heel.

Riding-gloves should be of soft dogskin or wash-leather (deerskin) and should be very loose. 
A tight-fitting glove must inevitably cause rigidity of the wrist, as the effort of closing the fingers reacts on the wrist, depriving the hand of its most important attribute, pliancy.

The short English crop is excellent for road and country riding, but the ordinary long ridingwhip is preferable during lessons, particularly for schooling a horse.

Everyone, who has ridden in very cold weather, knows that, as a rule, the feet suffer most from cold. Even the best protection, applied inside the boots, will in time fail to keep the feet warm.

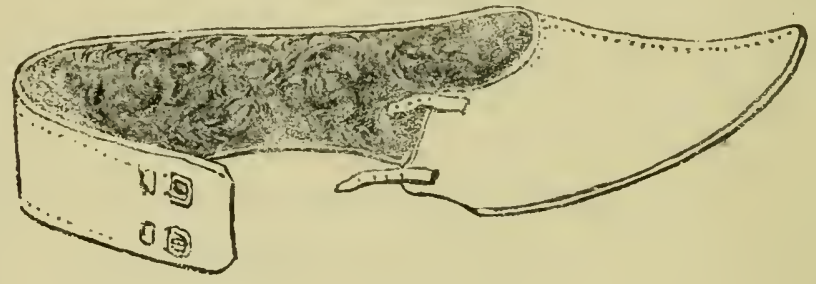

Fig. 4 .

Fur riding-socks (Fig. f) worn outside the boots have proved to be the best protection. Overshoes of this kind are usually made of strong sheepskin with short black wool turned inside, thus forming a sort of hood for the foot, the inner side being so formed as to permit drawing around the heel and buckling on the outside of the foot. They are trimmed with thin skin, blackened and soled with thin leather. When worn, the back of the overshoe rests on the spur. With trousers a pair of gaiters should be worn; with ridingboots, long. stockings; the rider will then be prepared 
for the severest cold. Another and not less important advantage of the overshoes is that by their use one may wear the same kind of boots in winter and summer.*

\section{The Riding Horse.}

"My kingdom for a horse."

It goes without saying that a rider $\mathrm{s} \mathrm{hou} 1 \mathrm{~d}$ at least know the name of the more important external parts of the horse.

These are (Fig. 5, A):

I. Fore part, that is: head, neck, withers, chest, shoulders and fore legs.

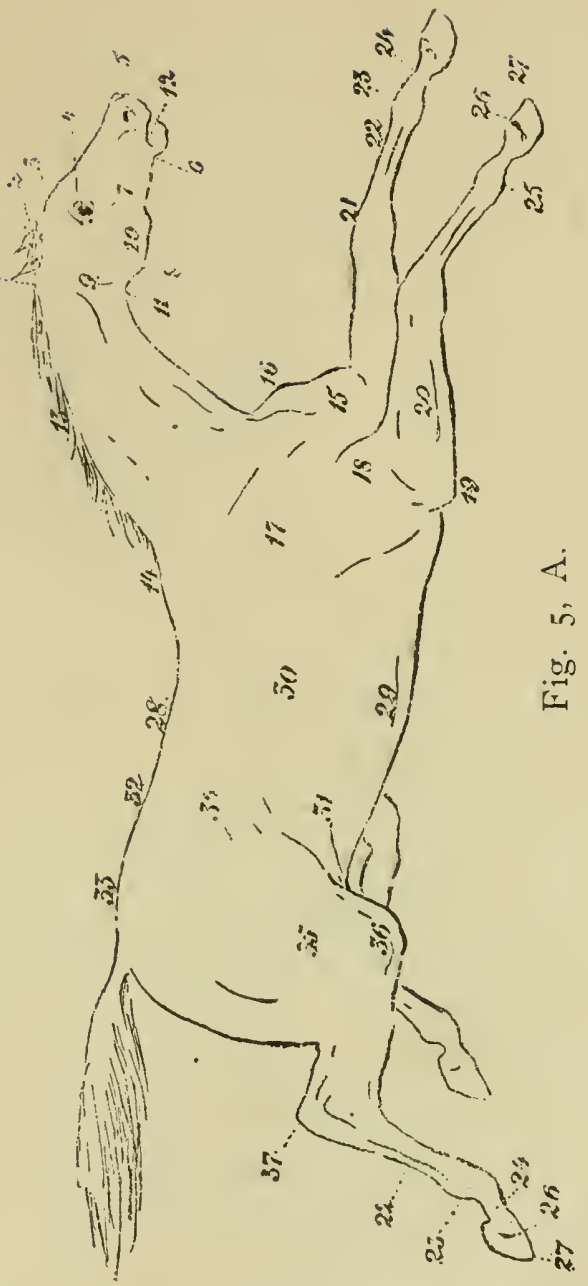

I. Poll.

2. Forelock.

3. Forehead.

4. Eyebrows.

5. Nostril.

6. Chin groove.

7. Cheek bone.

8. Edge of jaw (ganache).

9. Parotid gland.

*The reader will find in the back of this book the addresses of some reliable places of interest to horsemen. 


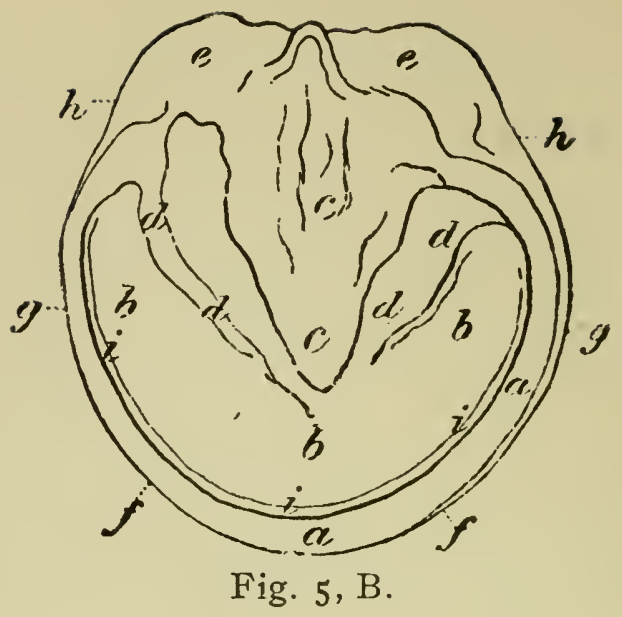

Io. Jowl.

I . Throat groove or throttle.

I2. Mouth (the toothless part of the lower jaw is called the interdental space or bar).

I3. Crest.

I4. Withers.

I 5. Chest (breast).

r6. Shoulder point.

I 7. Shoulder ?

I8. Arm.

blade The

shoulder.

I9. Elbow.

20. Forearm.

2 I. Ḱnee.

22. Shank (canon bone and back tendons).
23. Fetlock (pastern joint).

24. Pastern.

25. Fetlock (tuft).

26. Coronet.

27. Hoof or foot (Fig. $5, B)$ consisting of (a) plantar surface of wall; (b) sole; (c) frog; (d) bar; (e) bulb of heel; toe; $(f g)$ wall; $(g / l)$ quarter, and (i) the white line.

\section{Middle part.}

28. Back.

29. Belly.

30. Sides.

3r. Flanks. 


\section{$-7-$}

32. Loin.

III. Hind part.

33. Croup.

34. Point of the hip.
35. Thigh.

36. Stifle.

37. Hock.

36 to 37 . Lower thigh or gaskin.

Fig. 6 shows a fore hoof, Fig. 7 a hind hoof.

Riding, to be of any service or pleasure, must, of course, depend in great part on the horse. A faultless looking animal may, on account of its disposition and behaviour, become a plague to the rider. Inasmuch as tastes differ so widely, I would advise every rider, who has the opportunity,

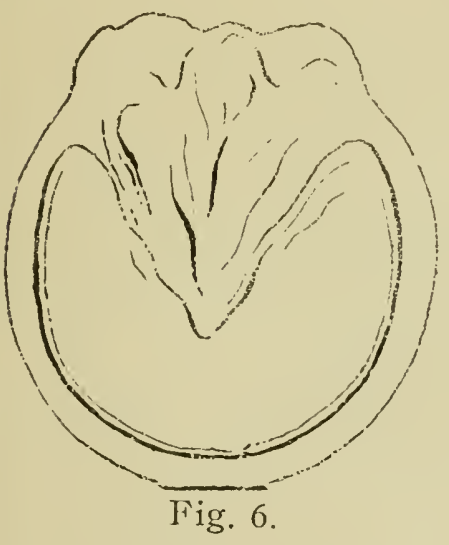

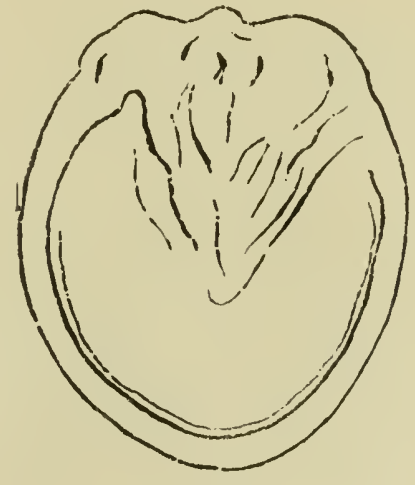

Fig. 7 .

to try his proposed mount himself, before he decides thereon. If obliged to use the judgment of another, it is preferable that the person making the choice should have ridden a horse, meeting the approval of his principal. The animal should always be tried by actual riding; for, even during mounting, it may display tendencies which would not please its prospective rider. 
The paces of a riding horse should be sure and progressive, but of a slow tempo; short stepping horses are a great nuisance. The riding horse should have a lively but gentle temper and be free from nervousness. The eyes and ears are good indications of its disposition.

One must not forget to study the horse when in its stall and at different times and under different conditions; for example, when it is groomed, fed and saddled.

The height of the horse should be in some proportion to that of his rider, to avoid too great lack of harmony in appearance. The measurement of a horse should be taken from the ground to the highest point of the withers and is reckoned by hands and inches or by centimeters-one hand (4 inches) being equal to $10.2 \mathrm{~cm}$.

In appearance the riding horse should conform substantially to the following rules:

The head should be light but not too short, as it is the lever on which the reins act.

The eyes should be large, clear, and have a lively but steady and kindly look. Eyes in which much of the white shows indicate bad temper. Wall-eyes are those in which the iris is dull white.

The ears should be lean, narrow and upright; hanging ears are, as a rule, a sign of sluggishness. Vicious horses turn their ears backward. Those which shy show a nervous twitching of the ears.

The space between the branches of the lower jaws should be wide, the jowl not too broad and 
the parotid glands short, narrow and standing out plainly.

The poll, that is the joint between the first vertebra of the neck and the head, must not be too thick or broad, and the upper line formed by it and the neck, i.e., the crest, should be a continuous one, of which the top of the head, i.e., the poll, should be the highest point.

The neck should be broadest at the shoulder, decrease gradually towards the poll and have a sharp edge. Long and thin, as well as short and thick, necks are undesirable. A neck is said to be lopping over when the crest, on account of the weight of the neck, hangs over to one side.

The withers should be prominent and rather inclined to slant evenly off towards the back than to be short and high.

The shoulder should be long and sloping, the chest deep but not too broad. The fore legs should stand straight up and down with muscular forearm, dry and clean cannon bone and back tendons. The pasterns should slant at an angle of about 45 degrees and should not be too long. The joints should be strong and broad.

The back should be short and straight, the loin broad and from the back pass imperceptibly to the croup, which, in turn, should be broad, long and, when viewed from behind, rounded. It should not be pointed and sloping. The tail should be placed high and hang freely down, not pinched in between the hind legs, nor be in a continual nervous motion. The hind legs must 
neither be behind the horse nor too far under him. The hocks should be strong and broad and neither bent outward nor inward. A horse with hocks bent inward is called cownucked. The same distance between fore feet as between hind feet is most desirable.

In a well shaped hoof the line from the coronet down to the toe should form an angle of 45 degrees with the ground on which it stands; at the quarters it should be wide, and the colour of the horn dark; light coloured horn is, as a rule, brittle and shelly.

The age of a horse may be judged in part from its appearance; as years pass the grooves over the eyes become deeper, grey hairs show themselves on the head, the underlip hangs, and the formerly rounded parts of the body become sharp.

The lifetime of a healthy, strong, and in every respect well treated horse of good breed, may be divided into three periods:

I. The development, which lasts until and including the 6th year.

2. The powerful age from the $7^{\text {th }}$ through the I 4 th year.

3. The age in which it gradually, declines, beginning with the I 5 th year.

The surest signs of the age of the horse are the teeth. These are of two kinds: temporary or milk-teeth, and those which are permanent and are called horse-teeth. The difference lies in their size, shape and colour; the permanent teeth being 
larger, the crown nearly of the same breadth as the bottom and with grooves alongside, and of a darker colour than the milk-teeth.

The fully developed horse has 12 incisors (nippers), 24 molars (grinders) and 4 tusks (bridle teeth). The last are, as a rule, only found in the male animal; they are placed between the nippers and the grinders and are not changed. (Fig. 8).

The age of a horse is judged by the growth, appearance and position of the nippers. The foal within a few days of its birth gets its first pair of nippers (the centrals), about five weeks later the next pair (the laterals) appear and after the fifth month the last pair (the corner teeth). At the

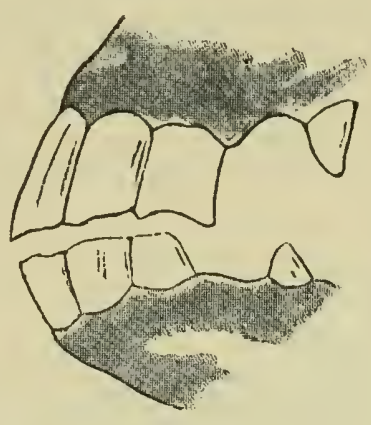

Fig. 8 . age of one year the foal has all its nippers, but the number of molars is as yet only $\mathrm{I} 2$.

After that time and until the age of $4 \frac{1}{2}$ years it is the changing of teeth in combination with their wear, which indicates the age of the animal.

In glancing at the table surface of the crown of a nipper, we find in its middle a dark groove, called the "mark"; it is the presence of this on the different teeth and in a different degree which is the surest sign of the age of the horse. As the tooth grows and its surface wears off, the mark becomes smaller and at last disappears, leaving but a white ring. The mark disappears first from 
the oldest teeth; it has on the top the same shape as the tooth, and it is this last named point, together with the want of the ring of enamel, that surrounds the mark, which makes it possible to

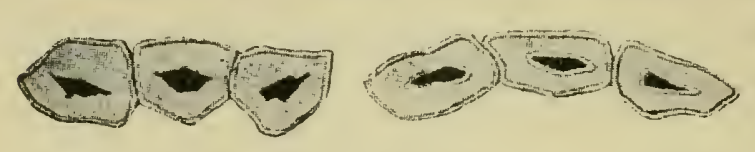

Fig. 9. easily discover frauds (bishoping) through artificially produced marks (Fig. 9). Sometimes efforts are also made to make a horse look older than he is in reality; this is done by pulling out one or another pair of milk-teeth, as by such an operation the permanent teeth may appear earlier.

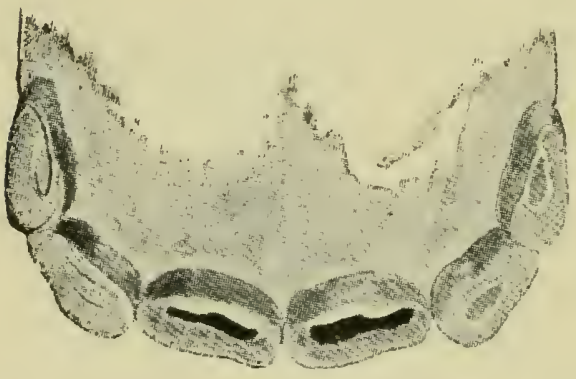

Fig. Io.

In the case of cribbers the age may be decided by the corner teeth, which do not wear off by biting the crib.

At the age of 2 years the mark has disappeared from the middle teeth and partly from the laterals, but on the corner teeth is yet visible.

At the age of $2 \frac{1}{2}$ years the mark has disappeared from the nippers, the centrals fall out and are replaced by permanent teeth (Fig. IO), which grow so rapidly that they already show wear at the age of 3 years (Fig. II).

At the age of $3 \frac{1}{2}$ years the laterals are changed (Fig. I2); the horse thus has at the age 
of 4 years four permanent teeth, which already have commenced to wear off. Six months later, as a rule, the corner teeth change (Fig. I3) and the tusks appear. At the age of 5 years the front of the corner teeth commence to wear and they present a shelllike condition, though it is possible that a single milk corner tooth may yet be left.

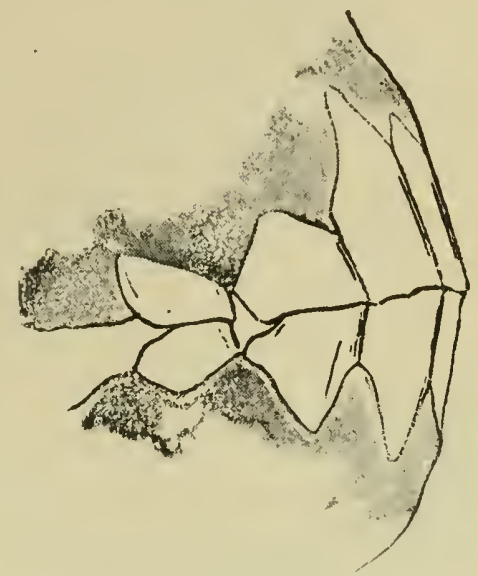

Ustially at the age of 6 years the mark on Fig. I I. the centrals has disappeared and the corner teeth are in wear throughout the whole table surface (Fig. I4).

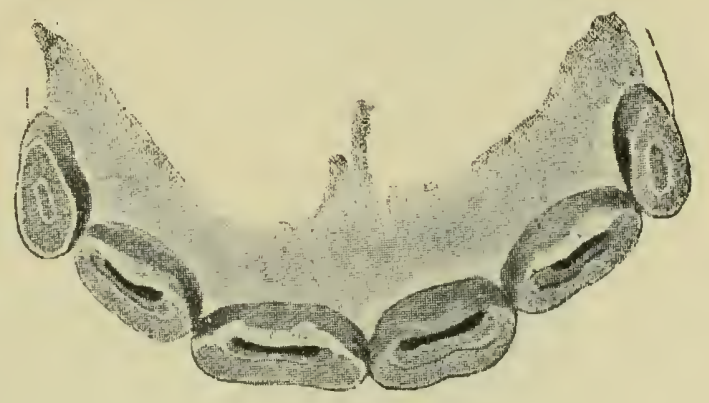

Fig. I 2.

On a 7-yearold horse the mark has quite disappeared from the centrals and only shows in a small spot on the laterals (Fig. I5). Often

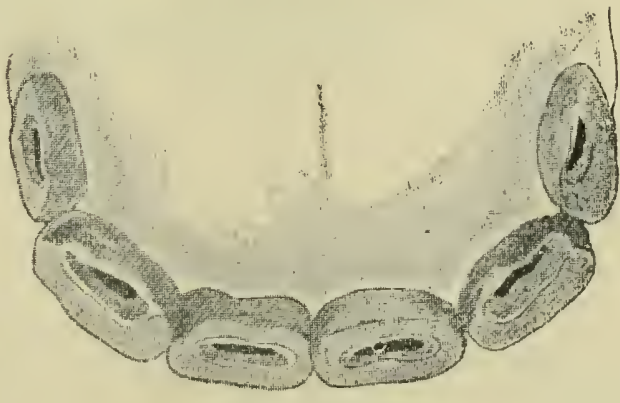

Fig. I3. 


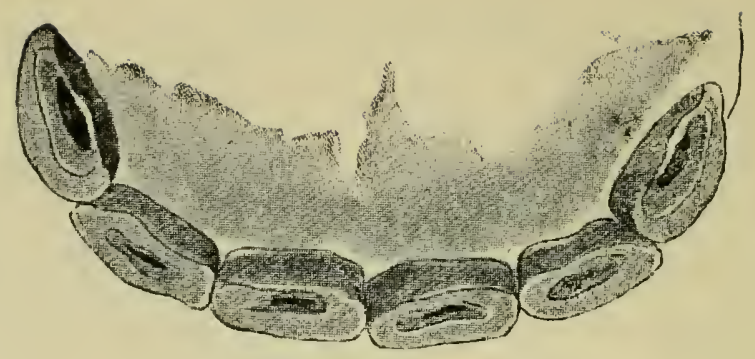

Fig. I4.

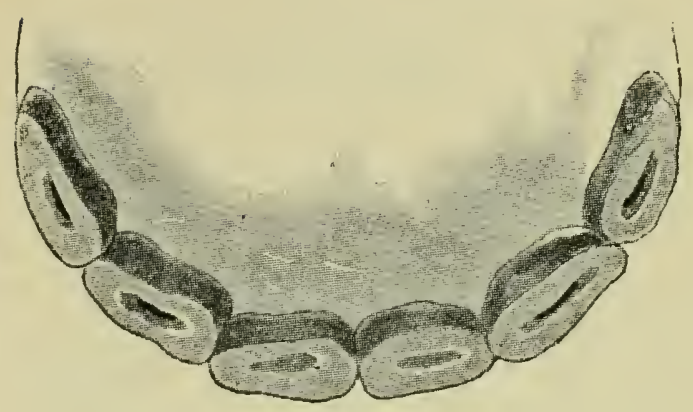

Fig. I 5 .

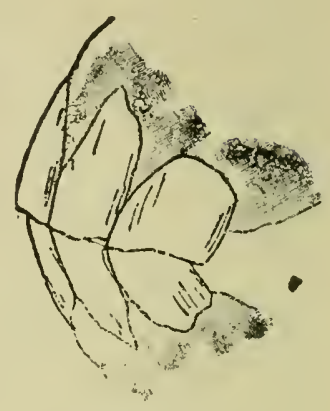

Fig. 16.

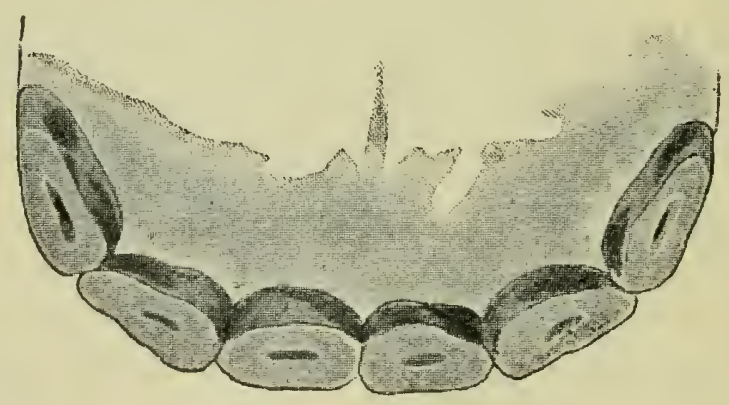

Fig. I 7 .

at this age the corner teeth in the upper jaw commence forming a small hook (Fig. IO).

At the age of 8 years the mark has quite disappeared from the laterals and nearly from the corner teeth (Fig. I7). 
After the 8th year the age of the horse can not be decided with any great degree of certainty. As signs of the more advanced age of the horse may be noted: The increasing length of the teeth, their rounded surface and their dull, yellow colour; still further the semi-circular row of teeth gradually tends towards forming a straight line and the jaws begin to form towards each other a very acute angle (Fig. I8).

In order to examine the teeth of the horse, talk gently to him and, while stroking his forehead and nose, try to open his lips. If the animal snatches its head back, do not use force, but start quietly in the same manner again. To make the horse open his mouth one may also seize it around the under jaw with one hand, and with the other seize the tongue behind the nippers : and pull it out at the side.

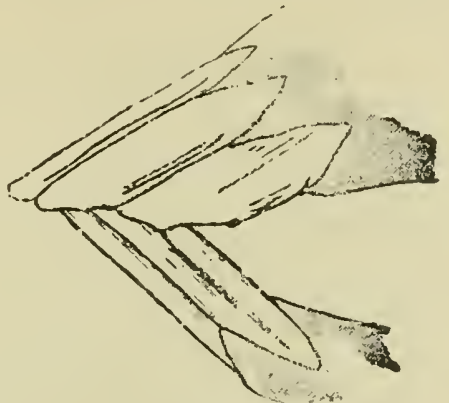

Fig. I8.

In examining the teeth, the nature of the bars should also be ascertained; if they are uneven and scarred, or if the underlip is folded over them (double bars), it is a sign of "dead month," that is, that the horse is hard-mouthed.

The defects most frequently found in riding horses will be hereinafter described under "Treatment of Sick Horses."

As those qualities, which are required in a good riding horse, principally are found in well-bred 
animals, it is difficult to understand why anybody should take the risk of disappointment and give the trainer unnecessary difficulty by acquiring a riding horse that is not well bred.

In examining and judging riding horses, one ought to consult not only a capable veterinarian but an experienced rider as well; but be warned against listening to all the good advice so frequently offered to one, for human nature is not yet perfect. It was a horsedealer who once made the remark: "In horse-dealing nobody is to be trusted; at that time I scarcely trust myself."

\section{The Stable and its Management.}

As riding horses, as a rule, during the greater part of the year, are kept in the stable from $2 \mathrm{I}$ to 22 hours out of the 24 , it must be understood how necessary it is that the stable be arranged as appropriately as possible.

Sufficient space, fresh air, light and absence of draught and damp are the principal conditions for the welfare of the horse in the stable.

As stables frequently fail to meet these requirements, and at the same time one may be put to the necessity of using them, I shall, in the following paragraphs, give some information and quite ordinary advice, through which their defects may be partly remedied.

A spacious stall is one in which the horse can lie on his side at full length, with his legs stretched 
out and his neck and head resting on the floor without kllocking the poll against the wall of the stall. For a riding horse of ordinary size a width of 6 feet to 6 feet 6 inches is required and a length of about ro feet 6 inches. The floor behind the stalls ought to be 6 feet 6 inches in width. The walls of the stall should be of the same length as its floor and at the head high enough to prevent the horse, when tied, from taking hold of the upper edge with his teeth, which occasionally develops "cribbers."

In old stables the walls and floor have to be examined to see if they are tight, and the latter if it be sufficiently strong to prevent the horse from treading through.

It frequently happens that the stall-floor in old stables is saturated with ammonia gradually accumulated, through a long period, from the heaped-up manure. In such a case, it may be necessary to take up the planks, thoroughly scour, air and dry them, or if they be rotten, replace with new. The foundation should also be scoured and sprinkled with chloride of lime, crushed charcoal and tanbark, whereupon the planks, after being tarred, are placed on two or three pieces of wood crossways, that they may not rest too close to the foundation save at the back. For draining, the floor of the stall should be given a slight slant ( $\mathrm{I}$ in Ioo), and in the passageway, close behind the stalls, holes should be made about $1 / 2$ inch in diameter and lined with zinc.

2 - Handbook for Riders. 
It must be remembered that all these preparations are intended for old stables, where drainage has been neglected or does not exist.

I believe it to be an advantage to be without rack and fixed manger, as a bare wall does not afford any temptation to the horse to learn bad habits or injure himself. Added to this, as the horse by nature takes his food from the ground, it would seem more rational to have the food placed on the floor than up on the wall. If the floor be clean and if the horse get no more hay than he can eat, he will soon learn to be careful with the food and to waste nothing. When oats are fed, a loose manger of wood is used which is placed on the floor in front of the horse and which should be taken away as soon as the food is eaten. Such mangers are lined on the inside and over the edge with plates of zinc and should be wide but not so deep as to prevent the animal from easily reaching its food.

If the horse kicks against the walls, through which capped hock is easily developed, straw mats, or still better, canvas with straw-tilling are applied. By such an arrangement the rubbing of the porint of the hip is also prevented, shotild the animal be disposed to that halit.

If the accumulation of manure in cellars under the stable can be aroided, at least during the warmer weather, it will greatly improve the purity of the usual stable air. If there be no ventilation in the roof, an air-pipe, niade of four boards and with shutter underneath, should be 
run through the roof. By opening or closing the shutter the changing of air can be regulated. The air-pipe is placed above the passageway and not above the stalls.

The light should not fall from the sirles nor directly into the eyes of the animal, but preferably from above or from behind.

\section{If the hay be kept} in the loft over the stable, a trap door, through which it may be thrown down, should be placed above the passageway and not right above the head of the horse; this arrangement will prevent the dust and seed, which follows the hay, from falling on the head and into the eyes of the animal or being inhaled by it.

The constant standing and usual hard work during use, from which, in particular, riding

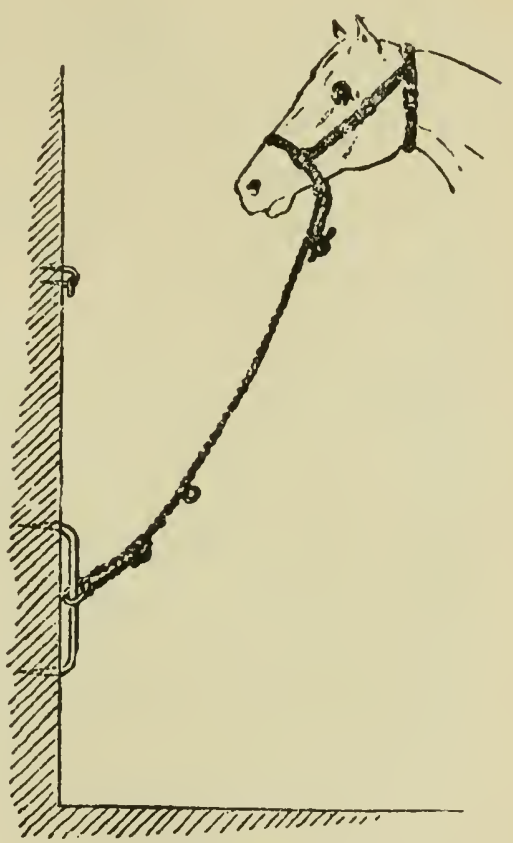

Fig. I9. horses' legs suffer, should lead us to provide as much rest for them as may be possible; this may be obtained by tying the animal in the stable so that it can stand up or lie down as it pleases. Fig. I9 shows such a method of tying a horse: An iron staple is driven well into the front wall about 
I 2 inches from the floor and midway between the walls; through an iron ring on the staple the halter-rope is fastened. If the horse, tied in this manner, gets his fore leg over the rope he will usually be able to free the leg without help. During gronming and sardling, to prevent the horse from biting or interfering with the groom, an iron ring is

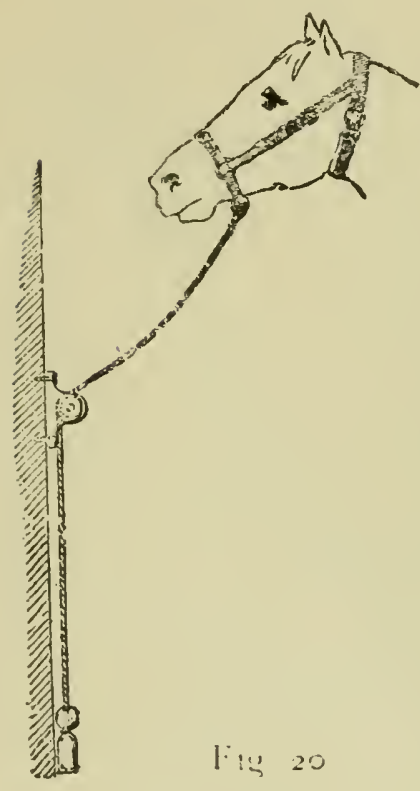
fastened to the wall above the staple and about level with the nose of the animal; through this ring the rope may be passed.

Precautions should be taken with animals that are in the habit of opening the fastening with their lips.

If the horse is in the habit of frequently putting his leg over the rope and, while so doing, becoming very nervous, the method pictured in

Fig. 20 is preferable; the rope is then placed over an iron pulley, which is fastened to the wall with strong screws; to the lower end of the rope is fastened a leather bag filled with lead or sanc?. To prevent the bag from sticking fast, if the horse should pull violently upon the rope, a wooden ball is strung on the rope. If the borse is in the habit of pawing much with his fore feet so as to 
damage the rope and the leather hag, these may either be put through a wooden shaft with well rounded edges, or the rope may be passed through a hole in the wall so as to bring the lower part thereof and the weight on the other side.

If the horse is in the habit of turning around in the stall, two ropes have to be usedone on each side of the halter.

The surest and most practical means of preventing the horse from biting the crib is to take away from the stall everything which might furnish a grip for the teeth.

The muzzle is ordinarily used as a protection against biting the crib; its advantages and defects seem to speak for themselves.

I have seen cribbers take a grip with their teeth even on the toe of a fore hoof. In such case a muzzle is the only means of prevention.

I have tried almost every imaginable cure for biting the crib but all without success; the horse bit through the sheep's wool nailed on, enjoyed licking the tar and aloes with which I had everything painted over and bit the crib nevertheless, etc. To punish the animal every time it bites the crib will only result in it becoming vicious in the stable. Only by removing from the stall everything which might furnish a grip for the teeth have I succeeded in preventing, but not curing, this habit of crib biting.

For horses that champ the air without taking a grip with the teeth, there is scarcely any remedy. Standing still to the horse is like idleness to 
the human being- "the root of all evil"; for this reason the animal should have plenty of exercise in the fresh air and occupation in the stall. The latter may be provided by giving it many meals and by giving it plenty of good straw for bedding. For occupation cribbers are also given the so-called bit with keys.

Horses, with such a ravenous appetite that they eat most of their straw bedding, should, instead of being tied short (which is cruel), have muzzle on.

Muzzles must be kept clean.

On horses, that bite their stable-cloths to pieces, a piece of stiff leather may be fastened around the under jaw to the noseband of the halter (Fig. 2I).

Manure ought to be taken away from the stall as soon as it has fallen; at all events this must be done at every feeding time. If the manure cannot be taken out of the

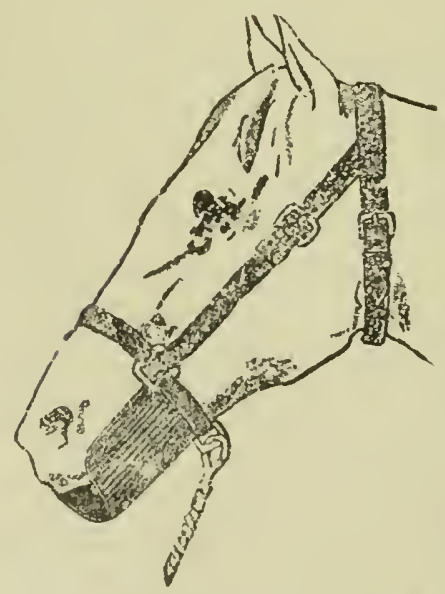

Fig. 2 I. stable directly, it must in every case be done morning, noon and evening. When the horse is taken out for use, the stall should be well cleaned before his return. During the warm season and in dry weather it will do no harm occasionally to scour the floor of the stall. The holes made in the floor for the purpose of draining are always to be kept open. 
In the morning, after the cleaning of the crib and after the first feed of oats has been given, and before the horse is groomed, the bedding should be taken from under the horse, and the stall and passageway swept. If the temperature permits, and especially if the stable is badly ventilated, the doors and windows should be kept open, and also during the grooming. After every grooming the stable should be well swept and the stall strewn with sawdust.

If the hay be given on the floor, the latter must be thoroughly swept beforehand.

After the horse has finished his first work for the day, or in any case before noon, he should have plenty of straw bedding, to be partly renewed in the evening with fresh straw, the dirty and wet bedding being taken away. At the same time the fastening of the tie is examined.

Upon going into the stable early in the morning, you will find the greater part of the bedding lying in the passageway behind the horse; therefore the straw, when first laid down, should be placed well forward in the stall. To prevent the straw from slipping behind the horse during the night, a board may be placed at the back and set down in grooves on the stall posts; in the daytime this board is taken away; such an arrangement requires sufficient length of stail.

The cleanliness of the stable is greatly improved by frequently strewing the floors with sawdust or wood shavings, especially after removing the manure. 
Where peatmoss can be easily had, it is cheaper than straw, as well as air purifying, and a warm and beneficial bedding for the legs and hoofs of the horse; the animal soon becomes familiar with the odour which comes from peatmoss directly after it is put down. When used for bedding the peatmoss should be dry and without lumps. However, it has the disadvantage of impeding the grooming of the horse, whereas sawdust and shavings facilitate it.

In stables where no permanent attendant is kept and where strange horses may be placed, there should be movable safety-bars behind the stalls or across the passageway from the stall posts over to the opposite wall, according to whether it is a stable with a single or a double row. These safety-bars are arranged in such a manner as to prevent loose horses from lifting them up by placing their necks thereunder.

No matter how well a stall may be arranged, there is nothing so good for the riding horse as the box-stall about I 3 feet square and with walls sufficiently high to prevent the animal from reaching the top with its teeth. The upper part of the walls should be an open partition.

During the dark part of the year the stable should be lighted from dusk until the stable is arranged for the night. In the morning the stable should be lighted until daylight. 


\section{Feeding and Watering.}

Fodder for the riding horse should consist of hay, oats, straw, and occasionally bran.

The hay should be absolutely dry, not too fine, have a fresh green colour and an aromatic odour. Timothy mixed with flowery species of grass is considered good horsefeed. New hay, especially if it is not quite dry, should be avoided. Before the hay is given to the horse, the dust and seed should be well shaken out and the hay afterwards put together in bundles.

When green fodder can be obtained it is advisable to give the riding horse a few handfuls of it daily, but the grass must be fresh, not wet and not entirely clover. To turn riding horses out to pasture is risky, and it should only be done for the sake of their health-when recommended by the Veterinarian-and then only when there is full security for the particular instructions being complied with. A riding horse turned out on grass should not have less than 3 quarts of oats per day; he must have ample supply of fresh water, shelter against the weather and not be in want of grooming.

Good oats should be well cleaned, dry, free from mouldy smell and weigh about $40 \mathrm{lbs}$. per bushel. The colour has little to do with regard to the quality of the oats; black may be as good as yellow, but they must not be mottled. Just before the oats are given to the horse, they should be dampened with fresh water. Crushed oats are considered very economical, as the feed is better assimilated, but it has the disadvantage of weakening 
the functions of the stomach and it may injure the functions of the lungs, and is frequently swallowed without being masticated, in this way not being mixed with the saliva; this is not the case with bruised oats which compel the animal to masticate. Crushed or bruised oats may be serviceable for very old or sick horses, when much unmasticated grain is found in the droppings.

The straw should be dry, free from dust, rust and mouldy odour. The best straw for fodder comes from barley or oats. As fodder the straw is used either in the shape of chaff or in its natural form. The chaff should be about the same length as the grains of the oats and be cut evenly; it is given together with the oats, and, like these, it should be dampened; a riding horse ought not to have more than a handful of it to each portion of oats. If the horse masticates the oats properly, leaving but little or nothing appearing as undigested, the chaff may be completely done away with and especially so if the horse is inclined to nibble the straw from the bedding.

Rye- and wheat-straw being of the least nutritive value, it is generally used for bedding.

Hay, as well as oats and straw, should have been kept some time after harvesting before being used as fodder.

When used in small quantities carrots are beneficial to the digestion. In case of sickness, when the animal loses its appetite, for instance, catarrh, typhoid fever, pneumonia, jaundice and other diseases, carrots have proved to be an 
excellent feed; five or six medium-sized carrots a day have proved able to keep up the strength of the patient during quite a long time, not only because they in themselves contain a good deal of easily-digested nutritive material, but also because by that means the appetite for other fodder is stimulated. Instead of bread and sugar, with which lovers of horses like to reward their animals, carrots are much to be preferred; they should be well cleaned from earth and be cut in thin slices before they are given.

The quantity of fodder depends upon the size of the horse and the work which is required of him. The times for feeding should, as a rule, always be the same. Supposing a riding horse of medium size, well developed and broken in, gets sufficient exercise, that is to say, 2 to 3 hours daily, the ration per day may be put at:

Io qts. of oats, ro lbs. of hay and 7 lbs. of stran; on I to 2 hours' daily exercise:

9 qts. of oats, 9 lbs. of hay and 7 lbs. of straw; and on I hour's daily exercise:

7 qts. of oats, 8 lbs. of hay and 7 lbs. of straw; (the straw principally used for bedding).

During training even up to 18 or 20 qts. of oats may be given daily, and there have been cases, during very hard riding, when horses have eaten up to 28 qts. a day ( 24 hours) and have stood it well; under such circumstances the quantity of oats might very well be arranged according to the appetite of the animal, but the ration of hay ought, as a rule, not to exceed ro lbs. 
Feeding the animal just before and after being used should, if possible, be avoided, and then especially the latter. It is advisable not to give hay just before and oats just after the ride; at all events not the latter before the breathing is slowed down to about ro respirations a minute. If, for some reason or other, the horse does not eat up all the fodder which is given him, the leavings should be taken away; mixing the new with the old fodder has generally shown that the animal touches neither of them. Altogether it is of importance to keep the feed boxes clean, as it stimulates the appetite and is economical of the food.

The water that is given to the horse should be clean and fresh, but not too cold. Running waternot containing much mineral matter-or fresh rain-water is the best for horses. Unclean water should be filtered, and in water containing mineral substances is put a small quantity of muriatic acid (about a teaspoonful to a pail of water) before it is given the horse to drink. The temperature of the water should be about $48 \mathrm{~F}$.; the water being colder should be made warmer by letting it stand for a while in fresh, warm air or by applying a small quantity of hot water. The water must not be made warmer by being allowed to remain any time in the stable.

The horse must not get water just after he has come back to the stable after being used, but when he has been cooled and the breathing has become normal. During riding, and then especially in strong sunshine and dust, the horse may be allowed, 
even if he is a little warm, occasionally to drink a few mouthfuls. To give water just before the horse is taken out for use ought to be avoided if possible.

As a rule, the water should be given before feeding. During short rests on long and fatiguing rides, however, a small portion of hay may begiven before the watering, upon which the feeding with oats should follow. On long rides the horse should, if possible, have some water while on the road and shortly before reaching the place for the intended rest, the animal will then start eating sooner and better.

When in the stable it is sufficient to give water three times a day. To ascertain whether the groom has so far done his duty, it is only necessary to turn on the watertap or rattle with the pail; if the animal is thirsty, it will directly show it by whinnying and by turning the head.

As an example the following feed table may be appended:

At 5 A. M. 2 qts. of oats.

$\begin{array}{lcl}\text { “ } & 6-\text { Water and } 3 \text { lbs. of hay. } \\ \text { “ } & 9-3 \text { qts. of oats. } \\ \text { “ } 2 \text { M. } & \text { Water and } 3 \text { lbs. of hay. } \\ \text { “ } & 3 \text { P. M. } & 2 \text { qts. of oats. } \\ \text { " } & 6-3 \text { qts. of oats. } \\ & 8- & \text { Water and } 4 \text { lbs. of hay. }\end{array}$

(The oats given with or without chaff.)

Otherwise the hours for feeding should be arranged according to the time the horse is at work and may very well be diminished to five for horses that are much in use, but as for horses that "stand" 
much and for cribbers, frequent feeding and smaller portions at a time are preferable.

In preparing (training) a horse for long rides, at the same time increasing the quantity of food, the number of feeding times should be diminished, because during such rides the animal will have to eat principally morning and evening, that is to say, fewer times and more at a time.

\section{Shoeing.}

Those readers who wish a more comprehensive knowledge of horseshoeing can easily find it, as the literature on this subject is very rich; for this reason I shall only explain the shoeing of the sound hoof.

Reasoning from the fact that shoes are injurious to the hoofs and legs of the horse, this must especially be the case with the riding horse, as the pressure of the hoof on the ground is considerably increased on account of the weight of the rider. It seems, then, to be of great advantage to save the riding horse as much as possible from shoeing, especially so with young horses until the hoof has reached its full development, which does not occur before the $5^{\text {th }}$ year.

It is of great advantage during the schooling of the horse to let him go bare-footed; by saving the hoofs from the weight of the shoe it makes the horse a better stayer, and his movements more free; also the injuries, which the horse might cause by interfering, are considerably 
diminished when the hoof is without shoe. In such cases, of course, the hoof should at times be trimmed by rasping off at the lower margin of the wall if it, for want of wear, grows too long.

In order to facilitate the shoeing and to diminish its injurious effects on the hoof, the horn should be kept moist and tough; the daily cleaning of the hoofs contributes greatly to this; if the horn should still become hard and brittle, it is advisable, before having the horse shod, to let him stand for some time on moist sawdust or moss without shoes on. It is particularly the fore hoof which is most liable to become dry. To prevent the moisture, which in this manner is applied to the hoofs, from evaporating too soon and thereby causing the horn to contract, a smearing with some greasy substance may be used, or what is better-glycerine.

In order to pare and shoe the hoof of the horse, his foot has to be taken up; and to do it in the right manner should be known by every rider, as the reluctance of many horses to having their legs raised comes originally from an ignorant and violent manner of doing it. Caution, soothing words and no higher raising of the foot than necessary are especially to be recommended.

The fore leg is taken up in the following manner:

Place yourself by and a little in front of the leg which is to be lifted, stroke the horse with your hands several times on the neck, shoulder and leg all the way down to the fetlock. If the 
animal quietly submits to it, then seize with your right (or left) hand from the front of and around the left (or right) pastern and, while pressing your elbow against the back of the horse's knee, lift the leg and with your own shoulder push the weight of the horse over on the standing leg, and call out a short and distinct "foot," after which the other hand also seizes the pastern, and the bent knee of the horse is kept resting against your thigh.

If the hind leg is to be taken up, place yourself by the left (or right) side of the horse facing to the rear; stroke him repeatedly with your hands over the back, the loin, the thigh and the hock down towards the pastern. If the animal quietly submits to it, then seize with your right (or left) hand from behind just under the fetlock and round the left (or right) pastern; the leg is lifted, while the other hand, pressed against the hip of the horse, brings the weight of the animal over on the standing leg, and the word "foot" is pronounced in a short and sharp tone. Then place your left (or right) knee forward under the lifted leg of the horse, after which both your hands seize the pastern by passing your left (or right) arm over and along the inside of the lifted leg, which is supported against your thigh. The lifted hind leg must not be stretched unnecessarily far backwards, as this would cause the animal pain, and generally ends by its starting to kick every time a hind leg is to be taken up. If the horse seems unwilling to have his leg held up 
main force should not be used, but he should be allowed to put his leg down again, and then the above-described method is repeated until he quietly submits to it; the usual result of such a method is that the horse at last raises the leg of himself that is indicated to him.

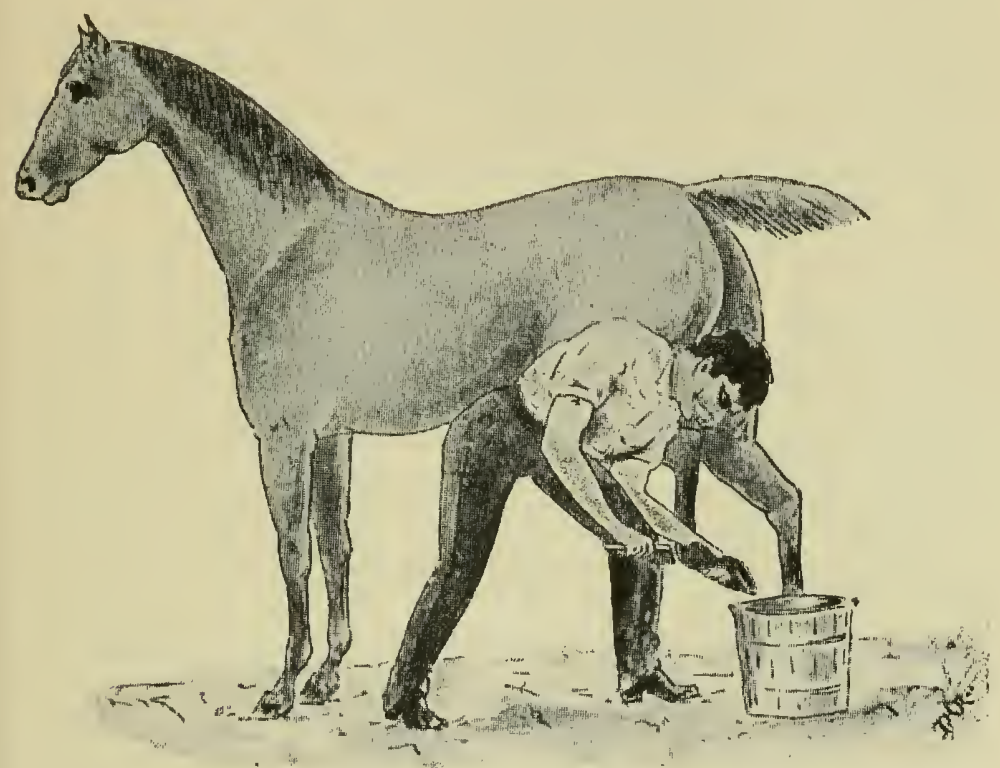

Fig. 22.

If the same person who holds the leg up is also to do the work on the hoof, he can, of course, only "hold up" with one of his hands, which always is done during the daily cleaning of the hoofs (Fig. 22). The leg of the horse must not be kept up longer than absolutely necessary.

When the lifted leg is again put down, it should be done carefully, while the man slowly

3 - Handbook for Riders. 
draws his foot back; to let the leg go suddenly and jump to the side is wrong.

The horse should, as a rule, be reshod every $4^{\text {th }}$ week. If the shoes by this time are not worn out, the same shoes may be replaced after the hoof is pared and the shoes again fitted; this is called resetting.

On the paring of the hoof, the fitting and putting on of the shoe, the surety and preservation of the horse's legs depend to such an extent that every rider should at least possess some knowledge of it.

It should be observed in the paring of the hoof that it gets its natural position, which is easily found out by letting the horse for some time go without shoes and on even ground, rather on fine sand; in so doing the hoof will wear into its natural position towards the ground. It may then easily be ascertained at every shoeing that the position of the hoof is exactly the same. If the toe is shortened too much, the horse is liable to kmuckle over; on the other hand, if the quarters are pared down too much, the position of the pastern becomes too slanting, and the horse will then lower the fetlock too much, by which the flexors of the leg are injured.

The part of the hoof to be pared is the plantarsurface and the sole; the bars and the frog should not be touched with the exception of loose hanging pieces of horn and dead horn, which are to be taken off; the perioplic membrane of the wall should not be rasped off. Trimming the hoof, in 
order to make it look small, is as injurious to the horse as the pinching in of the foot by too small footwear is to man. The proportion between the height of the hoof at the quarters and at the toe should, as a rule, be as I to 3. On shod hoofs the horn grows about $1 / 2$ inch in 5 weeks.

To the ready and correctly pared hoof the shoe should be fitted, observing that the shoe lies close to the whole plantarsurface, not pressing on the sole and the frog, not reaching outside the hoof except a very little at the outside quarters, and the branches of the shoe reaching about $\frac{1}{12}$ inch beyond the corners of the quarters.

It is injurious to the hoof to fit the shoe, when it is so hot that it singes the horn.

In the application of the shoe it should be observed that during the nailing on it does not get displaced, and especially so on the inner side of the hoof, not allowing it to reach outside the edge of the hoof, and that nails are driven in rightly. If the nail penetrates the horn very easily, or if the horse snatches the foot back, it is to be feared that the nail has been put in wrongly, and it ought then to be drawn out immediately; if the extracted nail is bloody, it is advisable not to use the same nail-hole. The ends of the nails are looked after, especially on the inner side, if they are properly clenched. The edge of the hoof must be rounded and the edge of the shoe even.

To obtain a little knowledge in shoeing it is recommended to the reader to make some visits to the shop of an experienced and clever farrier; 
in doing so you might learn to drive in a nail to a certain degree correctly, and the time will not have been wasted.

In northern climates it is necessary to have different shoes for summer and for winter.

As summer shoeing the flat shoe is generally used, that is the shoe without calks and toepiece (Fig. 23); still, when the ground is very slippery

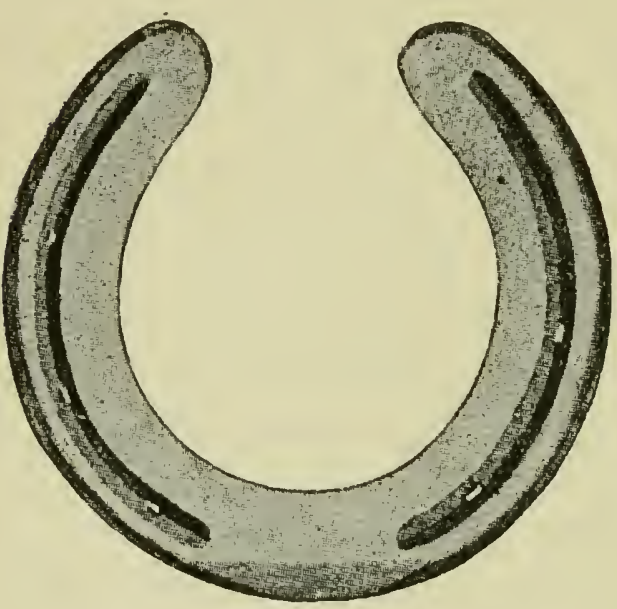

Fig. 23. and hilly, shoes with low calks should be used; whereas riding horses are better without the toepiece. When using shoes with calks and without toepiece it has to be taken in to consideration in the paring of the hoof.

The winter

shoe is generally provided with sharp toepiece and sharp calk on the outside; but on the inside the calk must not be sharpened. Also on winter shoeing the riding horse is better off without the toepiece and especially so on the hind feet.

Putting in frostnails means that a couple of ordinary nails are replaced by nails with high and tempered heads. On the hind legs of riding horses frostnails must not be put in the toe. 
The clip is a turned-up plate hammered out from a portion of the shoe. By bending it over the edge of the hoof and hammering it into a groove pared out on the wall of the hoof, the shoe is prevented from being displaced and the hoof is protected. Ordinarily the clip is made at the toe (toeclip). On horses that are in the habit of kicking with the hind hoofs against the stall posts, it answers the purpose best to have the clip placed on the outside (quarterclip).

The outside edge of the shoe should be rounded and slant inwards to the ground surface of the shoe. Fig. 24 shows the section of a horseshoe, the shaded parts representing the iron of the branches.

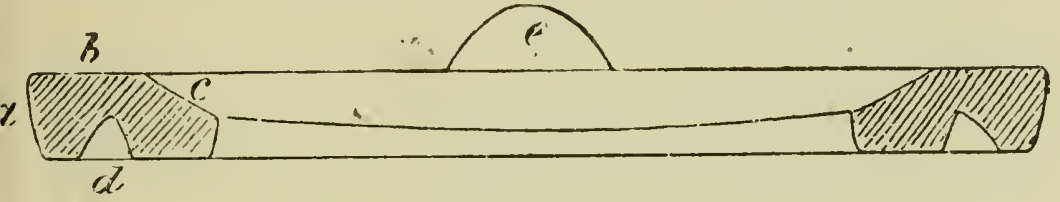

Fig. 24.

a. Outside edge.

b. Upper surface.

c. Seat.

d. Fuller.

e. Toeclip.

When the horn of the hoof is good it may be sufficient for summer shoeing to apply 5 nails in each shoe, 3 on the outside and 2 on the inside, but for winter shoeing, as a rule, 6 or 7 are required.

The shoes should be as light as is consistent with the work required of the horse.

Some time after the horse has been shod, and especially if used much on hard roads, it may 
occur that the ends of the nails have worked their way through so as to stand out from the surface of the wall, by which the animal may easily injure itself, principally on the inside of the legs. This should be adjusted as soon as possible.

\section{Saddlery and its Care.}

The English saddle (Fig. 25), covered with pigskin, is acknowledged by horsemen as "the saddle;" it consists of the following parts:
a. Saddle panel.
b. Seat (Cantle being the hindpart).
c. Pommel.
d. Open gullet (Channel).

ee. Flap, skirt.

f. Knee roll.

g. Stirrup leather.

h. Stirrup iron.
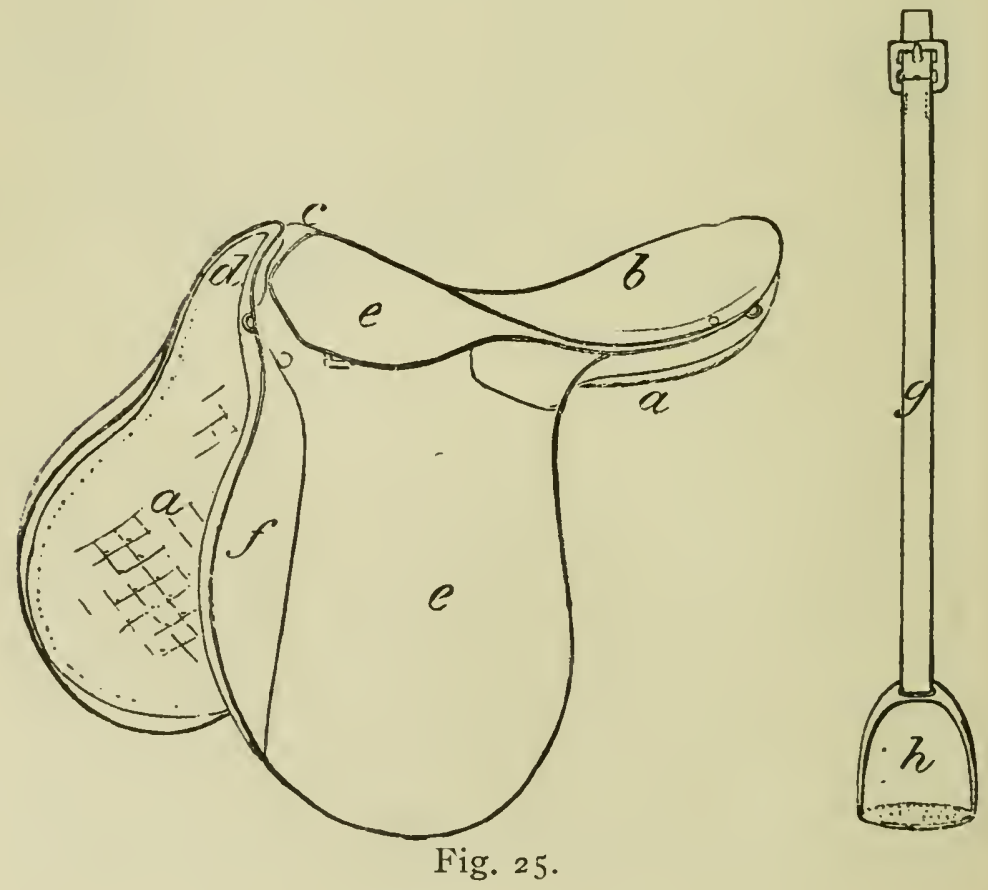

Fig. 25 . 
In the choice of a saddle, the shape of the horse and the size of the rider have to be taken into consideration. This can only be done by trying all three together.

The panel should be shaped exactly after the back of the horse, and the seat to the size of the rider. A seat which is well rounded on both sides prevents the rider from being galled, and a deep seat is more comfortable than a flat one. The under part of the pommel must lie well up from the withers. The skirts ought to have such a length as to prevent the tops of the riding-boots from interfering with their lower edge; the knee rolls must not be so far in front as to offer no support for the knees if needed. The stirrupleathers should be rounded at the edges, the stirrups light and wide, and during the winter provided with bottoms of grey, not coloured, felt.

Cord girths are considered to be the best saddle-girths.

The saddle-cloth, made of felt or very thick linen, is only used for the purpose of preventing the perspiration from the horse's back penetrating the panel.

A breast-plate is used on horses when the saddle is liable to slide backwards; the most frequently used is the Hanoverian (Fig. 26).

The bridle, which is best made of soft, yellow leather, may be two kinds: snaffle bridle and curb bridle. 


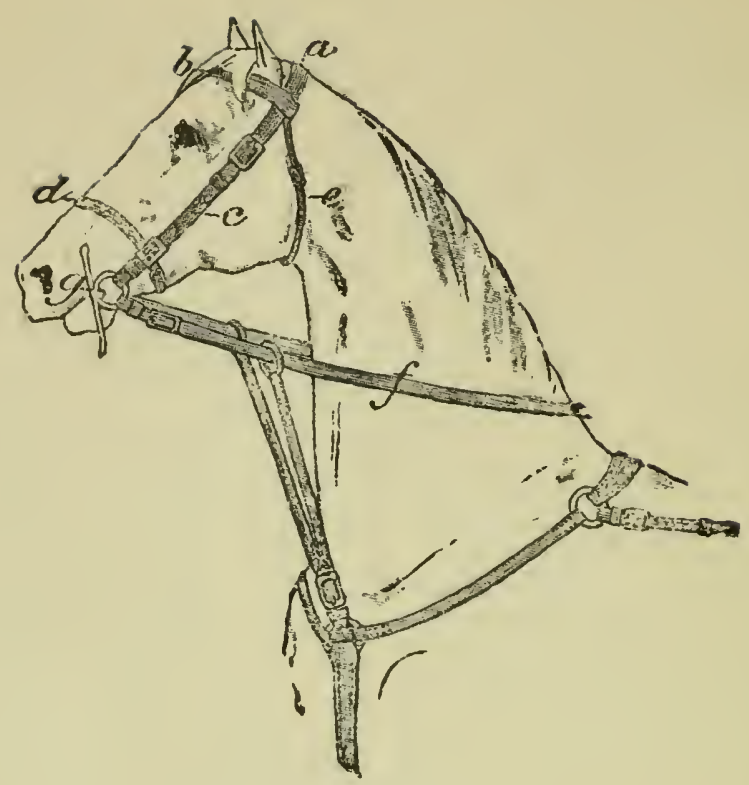

Fig. 26.

The snaffle bridle (Fig. 26) consists of:

a. Headpiece.

b. Brow band (front).

c. 2 cheek pieces.

d. Noseband.

e. Throatlatch. f. Reins, parted and with buckle.

g. Snaffle-bit jointed in the middle and with guard pieces (or large rings).

The curb bridle (Fig. 27) consists of:

Headpiece, parted in two strap-pieces on each side.

Brow band (front).

Throatlatch with loose headpiece.

4 cheek pieces.

Noseband (may be left out).

Curb-reins (sewn together). 

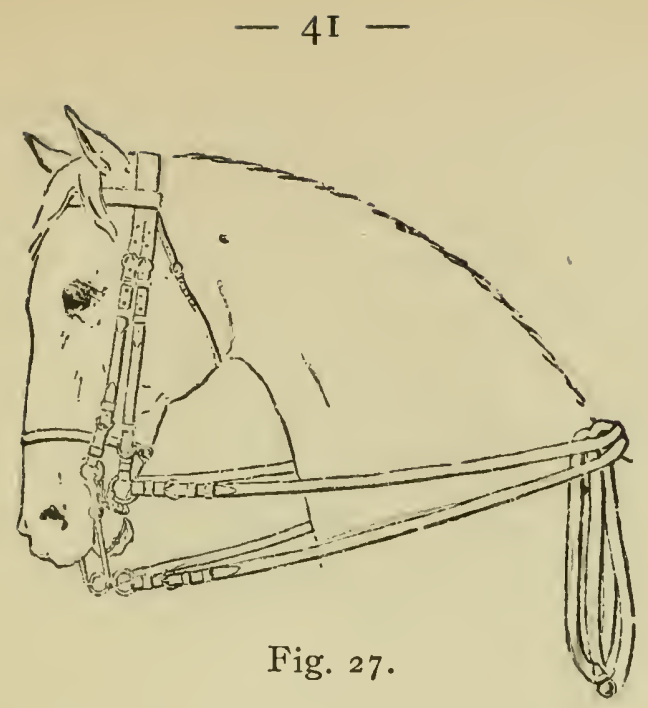

Snaffle-reins (parted with buckle). 2 bits, i.e., curb and snaffle (bridoon).
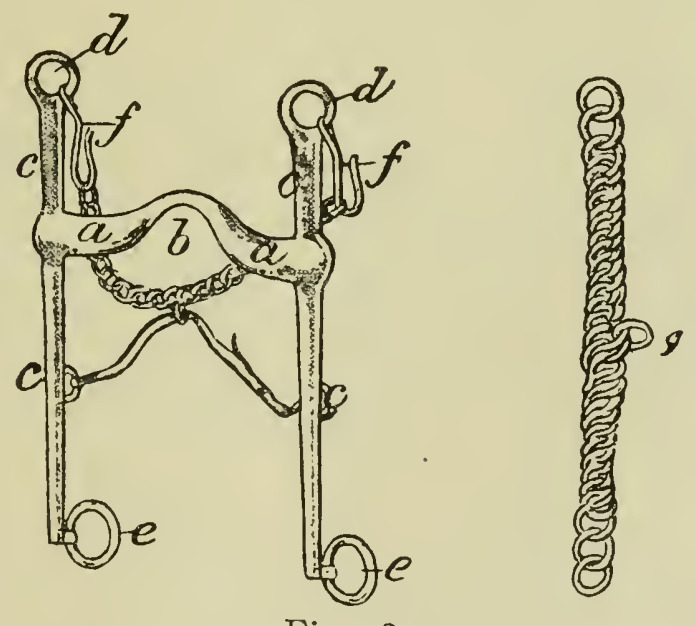

Fig. 28.

The curb-bit (Fig. 28) consists of:

Mouth piece $(a)$ without joint and with a raised middle called port (b), 2 arms (c) with fixed rings $(d)$, rein rings $(e)$ and 2 curb-chain 
hooks ( $f$ ), and the curb-chain ( $g$ ) made of thick broad rings and with an extra ring on the middle (for the lip-strap).

The snaffle-bit is without guard pieces.

The longer the lower part of the arms of the curb-bit is, in proportion to the upper part, the thinner the mouth piece, and the larger the port so much greater is the severity of the bit. The width of the mouth piece depends upon that of the horse's mouth; the curb-chain hooks should be placed so as not to hurt the corners of the mouth and not to allow the snaffle-bit to hook itself on them.

A Pelham bit (Fig. 29) is something between a snaffle and a curb. One kind, which is preferable, has the joint of the mouth piece arranged to allow

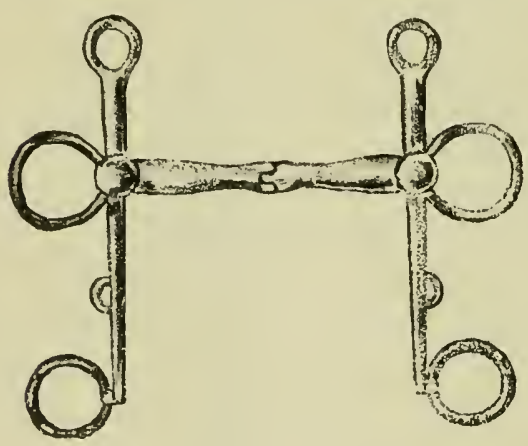

Eig. 29 . motion in a horizontal direction only. The principal advantage of the Pelham is that the snaffle and the curb are combined in one bit; but it has also the disadvantage of easily making the curbchain to slide upwards so as to gall the sharp edges of the lower jaw.

The Martingale (Fig. 30) or, as it also is called, rearing-rein, is used with horses that point their nose upwards, throw their head backwards or rear. The martingale is used only with the 
snaffle-reins. In riding with snaffle alone, it is advisable to have two pair of reins and to pass the lower ones through the rings of the martingale. The rearing-rein may also be fastened on the noseband and should then have only one ring; the advantage from this is that the rearing-rein does not work on the horse's mouth.

A combination of martingale and Hanoverian breast-plate is shown in Fig. 26.

To prevent the horse from striking himself during riding, boots are

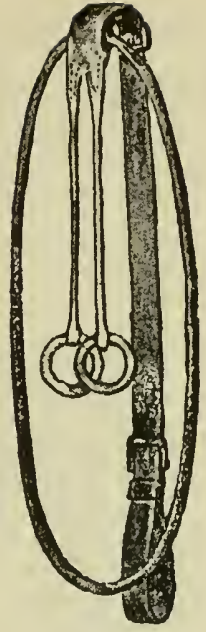

Fig. 30 . used on the fore legs and interfering boots on the hind legs.

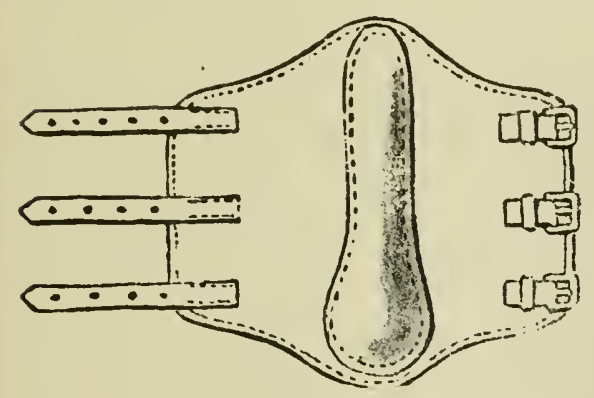

Fig. 31 .

The boots (Fig. 3I), which protect the inner side of shank and fetlock joint, are made of elastic cloth or thin felt of the same colour as that of the horse's legs; the inner side of the boots should be padded and covered with a thick but soft piece of leather. During the breaking, during very hard riding and on horses with badly placed fore legs, it is advisable to use boots.

Interfering boots (Fig. 32), used as protection for the pastern joint of the hind legs, are made of 
yellow, thick leather, which has been soaked, shaped on a form and then padded and lined with wash-leather on that part of the inside which is placed above the fetlock. On the strap is put a pad made of several layers of felt.

All kinds of boots should

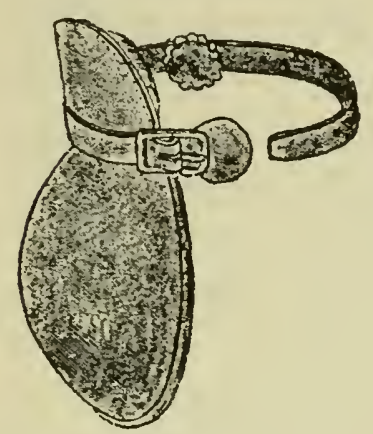

Fig. 32. be made so as to fit each leg.

Means of protection, as above described, may be equally needed on horses without as well as with shoes.

The saddlery is preserved by keeping it clean and dry and the leather soft. All things made of iron or steel should, when not used, be gone over with a greasy cloth. New, yellow leather, before being used, ought to be smeared with a little salad oil, and, when the oil is absorbed, rubbed and polished with English saddle-paste. On the pigskin cover of the saddle oil is not applied, but only saddle-paste. A similar treatment of the leather should also occasionally be given later on to protect it against moisture and to prevent it from cracking.

The saddlery ought to be cleaned as soon as possible after it has been used, that is to say, directly after the cleaning of the horse. First the mouth piece is washed, well dried, and, in damp weather, gone over with a greasy cloth, then the leather of the bridle is rubbed off with a moist piece of cloth and afterwards with a dry 
one; martingale and breast-plate are treated in the same manner. Stirrup-leathers with stirrups are taken out of the saddle; the stirrup-leathers are treated, if they are soiled, the same as the bridle; if not, they are only rubbed with a dry piece of cloth. The stirrups are rubbed off and in damp weather gone over with a greasy cloth. The saddle-girths are taken out of the saddle and brushed clean from dust and horse hair; if wet, they should first be dried; if very dirty, they should be washed, which is done by stretching them out on a piece of board in which are put nails on which the buckles are placed; they are then brushed with soap and water and washed out with clean water. The board with the girths on is then put up to dry in such a manner as not to allow the water to run on to the buckles. The saddle is placed so that the panel may dry, then the latter is beaten and brushed. The cover of the saddle is cleaned with a moist piece of cloth or sponge, and is rubbed dry with wash-leather or a piece of linen. Saddle-cloths of felt are dried, beaten and brushed. If the felt has been used for some time, and often been soaked through with sweat from the horse, it will at last become stiff and hard and then require washing in the same manner as ordinary woolen stuff is washed. Boots should not be washed; if wet, they should be dried before being brushed, and the leather should be greased.

The saddlery should be kept in a dry place, but not in the stable. 
Before saddling the horse, the saddlery should first be dusted off and brushed, mouth piece and stirrups thoroughly rinsed from oil and, if necessary, from rust, and then polished; the spring of the stirrup-leather bar is looked at and oiled.

Do not delay having necessary repairs done, for " a stitch in time saves nine."

\section{Saddling and Bridling.}

Whether obliged to saddle the horse yourself or to have it done by some one else, every rider must understand when the saddling is rightly done; because on a careful saddling depends, to a great extent, the welfare of the horse, as well as the safety of the rider.

Previous to the saddling ascertain if the saddlery is clean, in good shape and rightly put together. The saddle-cloth and the panel of the saddle are examined, and on neither should hard unevennesses be found. Stirrup-leathers with stirrups are put on the bars, the springs of which are closed. The buckle of the stirrup-leather should be on the outside and close up to the bar. The stirrups are moved up along the under part of the stirrup-leathers, which are passed through the openings of the stirrups from above. The girths should be buckled on the right side of the saddle. In the putting together of the bridle it should be observed that the bits are fixed so that they are placed rightly in the mouth of the horse, 


\section{$-47-$}

when the bridle is put on, that the reins are rightly buckled, and that the noseband is so arranged that it may be buckled on the left side just behind the cheek piece. With a curb bridle the noseband is placed in the front cheek pieces, in which the curb-bit is put. On the curb bridle it is often found that the snaffle-bit is put in a loose headpiece, which is passed underneath the principal headpiece and through the stalls of the brow band, which allows the bit to be pulled out of the horse's mouth easily; the throatlatch, however, may be very well arranged in this manner (see Fig. 27). The cheek pieces should be buckled so as to make them even in length on both sides.

Having ascertained the condition of the saddlery and the defects, if any, being adjusted, it may be placed ready for saddling in the following manner:

The saddle, with stirrups drawn up, the double folded saddle-cloth placed over the seat and the girths on the top, should be placed on a saddle-bracket, which ought to be of the same length as the saddle, and fastened on the stall post behind the horse. The bridle, with unbuckled throatlatch and noseband, is placed with its headpiece on a bracket under the saddle and with the reins over the headpiece.

The saddlery thus arranged, the saddling is done in the following manner:

The saddle with saddle-cloth is taken on the left arm, the pommel towards the man's shoulder, and, in going up to the near side of the horse, the 
saddle-cloth is taken by the right hand and placed, with the rounded corners in front, evenly on the horse's back, the foremost edge of the cloth lying close behind or somewhat over the play of the shoulder. The cloth must not be pushed against the hair of the horse, but it should be raised and moved forward if placed too far back. The saddle is then taken with the right hand at the cantle and with the left one under the pommel, and is raised above the horse's back and placed evenly on the saddle-cloth with the front edge of the saddle about a hand's breadth behind the play of the shoulders; the right hand lets the girths carefully down on the off side of the horse; passing around to the off side of the horse, the skirt and girths are adjusted so as to lie flat to the sides of the animal. The girths being divided, the back one is placed somewhat over the one in front. Then, passing again round to the near side of the horse, the saddle-cloth is raised well under the pommel with the left hand, while the right one supports the saddle. The girths are then loosely drawn on each strap, the front one first, after which the cloth is smoothed and again raised under the pommel, and the hair on the withers pulled forward. The girths are then tightened by degrees, while with the fingers in under the girths, possible folds of the skin are smoothed. The girths must not be drawn tighter than to admit the hand as far as the thumb being passed easily between them and the horse's side. 
After riding for awhile the girths may need tightening.

In passing around from one side of the horse to the other, it should be observed that the saddle does not slide off; for this reason on very nervous animals the girths should be drawn loosely before passing round to the off side in order to arrange the skirt and girths.

On most saddles there are three girth-straps. By drawing the girths on the two front ones or the two rear ones, the saddle may be raised accordingly somewhat at the back or at the front; but its sliding forwards and backwards can only be prevented by an exact fitting of the panel to the back of the horse.

Having fixed the saddle, the bridle is taken and placed with the headpiece and reins on the left arm and, in going up to the near side of the horse, the halter is taken off and fastened to the rack or the ring for the tie; the right hand takes the reins and passes them over the horse's head, letting them rest on his neck; the left hand takes hold of the horse's nose. The right hand takes the headpiece and lifts it up towards the horse's forehead, while the left hand lets go the nose of the horse and takes the mouth piece and, by raising the headpiece, inserts the bit into the mouth of the horse, which is opened by pressing on the gum with the thumb of the left hand; the headpiece is passed above the horse's ears, which are drawn gently forward with the left hand; the forelock is arranged over the brow band, the 4 - Handbook for Riders. 
throatlatch is drawn sufficiently slack to admit the breadth of four fingers between it and the throttle. The noseband, being placed two fingerbreadths below the projecting cheek bone, and with its buckle on the near side, should admit one finger between it and the nose bone. If curb bridle is used, the noseband should pass under the cheek pieces of the snaffle; the curb-chain is fastened on the off curb-chain hook and passed under the rings of the snaffle-bit, then, in twisting it until it becomes flat and with the extra ring on the middle hanging downwards, it is fastened with the lower part of that ring, which suits, on the near curb-chain hook, the curb-chain being loose enough when the arms of the curb-bit, by feeling the reins, are forming an angle of $45^{\circ}$ with the lower jaw. If the curb-chain has more rings than needed, they are to hang above and behind the hooks and with even number on both sides or with the greater number on the near side.

The horse having very sharp jaw bones, and consequently being liable to be galled in the chin groove, the curb-chain, after first being laid flat and smooth, should be placed in a curb-chain guard made of rubber (Fig. 33); leather

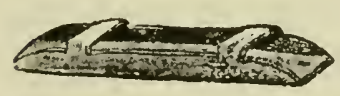
may also be used, but it will soon become hard and stiff on Fig. 33 . account of the saliva from the horse's mouth.

The cheek pieces should be adjusted so that the snaffle-bit touches the corners of the mouth, but without drawing them up; and the mouth 


\section{$-5^{I}-$}

piece of the curb should be placed directly opposite the chin groove, but without touching the nippers or tusks.

If the horse be in the bad habit of taking the arms of the curb-bit between his teeth (bite the curb) a small strap (lip-strap) may be placed between the arms and through the extra ring on the curb-chain (Fig. 28).

In using the martingale it should be put on before the saddle. On unfastening the tie from the halter, the neck-strap of the martingale is put round the horse's neck and the tie again fastened. Then the saddling goes on as above described, not forgetting to pass the girths through the loop of the martingale before the girths are drawn. The martingale should be so fixed that the reins are kept horizontal when the rider's hand is level with the withers.

Without interfering with the motions of the horse, the breast-plate should be so fitted that the saddle may be kept in its place.

The boots should be put on so that the straps come from the front and the buckles from the rear (Fig. 34), the lower strap being buckled first, while the lower edge of the boots is kept a little above the fetlock, on which the boot should rest. The boots should not be buckled tighter than to admit one finger between their

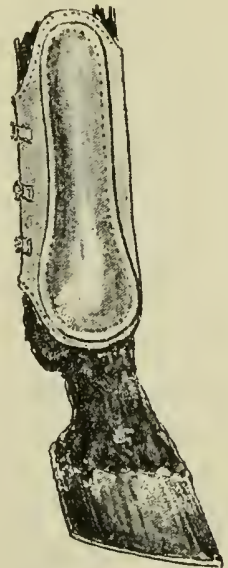

Fig. 34 . 
upper edge and the back tendons. Before the boots are put on, it should be observed that the inner side of them is without any unevenness, and that the back tendons and the pastern joint are stroked several times with the hand along the hair.

The interfering boots should be put on in a way that the strap, without pressing, rests on the fetlock with the buckle at the back of it and with the pad, which is on the strap, placed between the cannon bone and the back tendons. If the felt pad is sewn to that part of the strap, which answers the purpose, the boots will rest more steadily.

If proper attention is not paid to the fitting of the boots they may easily do more harm than good. They are always put on before saddling.

\section{Unsaddling and Unbridling.}

The "Unsaddling" is done from the near side of the horse and in the reverse order of the "Saddling":

The lip-strap-if such is used-is unfastened, the curb-chain is taken off, noseband and throatlatch are unbuckled. If martingale with two rings has been used, the bridoon-reins should be unbuckled. The bridle is then gently taken off and with its headpiece and the reins placed on the bend of the left arm, the halter is put on and the bridle is hung up. The breast-plate, if worn, is unbuckled from the saddle on the near side, the 
girths are unbuckled and drawn out of the loop of the martingale or the breast-plate. With a grasp of the left hand under the pommel, the saddle is lifted up from the horse's back, while the right hand removes the saddle-cloth over the croup and places it folded across the seat of the saddle. Taking hold of the pommel with the left hand and the cantle with the right, the saddle is lifted sufficiently to allow the saddle-skirt on the off side to pass clear of the horse's back, after which the saddle, while being held close to the horse's near side, is lowered until the girths of themselves drop across the saddle-cloth. The breast-plate should be placed over the girths, and the saddle is hung up. By then unfastening the halter-rope, the martingale can be taken off. Leaving out what has been said about the curbchain, a snaffle bridle is taken off in the same manner as the full bridle.

\section{Packing the Saddle.}

On long rides various things should be carried along, as much for the welfare of the horse as well as for that of the rider, as it may be difficult to procure them at places where rests are taken or where one intends to stay for the night. The packing consists of such things arranged in the pack equipment, which has been made for this purpose, and which should be as light as possible and so arranged on the horse's back as not to cause galls and also so that the total weight may 
be evenly divided on fore and hind part. The minimum weight of the packing is obtained by diminishing the things that are needed to the most necessary ones, and by choosing them and the equipment from as light material as is consistent with their durability. On account of the horse's fore part being more loaded by the weight of the rider than the hind part, the weight will be more evenly divided if the principal part of the packing be placed behind the rider.

For the sake of the horse the fol-

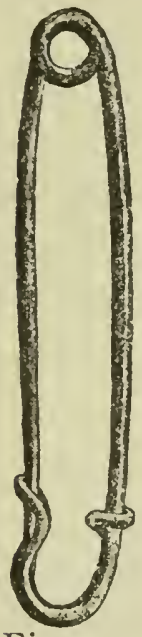

Fig. 35 . lowing things should be carried along: Halter with tie,

horsecloth with a loose breast piece and two blanket pins (Fig. 35),

surcingle (formed of the saddlepack and a divided strap-piece (Fig. 38) buckled to the saddle-girths), some horse-shoe nails and a light hammer and, if there is room for them, 4 linen bandages.

With regard to what the rider might want for his own use, it is important, as above mentioned, that this be diminished to the minimum. Rain-cloak, stockings, shoes or slippers and toilet things should not be forgotten.

A small jar with cerat or vaseline and a small wooden covered bottle containing carbolic acid should not be wanting in the rider's packing.

The most necessary articles in a pack equipment are: 
III. Two separate straps for the saddle-pack, which are put through the loops a (Fig. $37 \mathrm{~A}$ ) and rolled together when not in use (Fig. $3 S$ ).

In the case of saddling with packing, the halter is kept on the horse and the bridle is put outside it, or the halter may be so arranged that the bit with the reins can be fastened by small straps or snaps to the rings on the sides of the halter-noseband, thereby making the halter a part
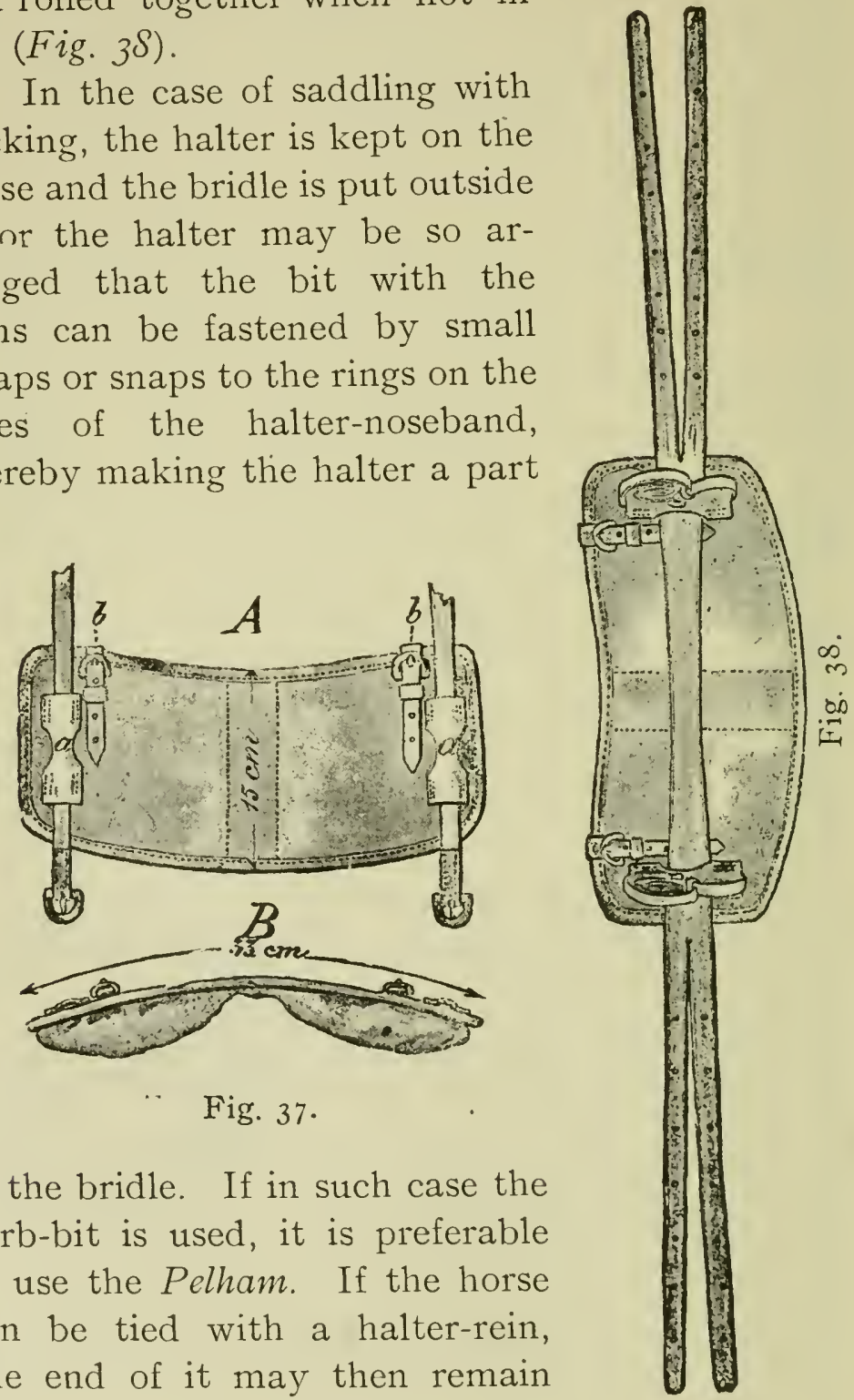

of the bridle. If in such case the curb-bit is used, it is preferable to use the Pelham. If the horse can be tied with a halter-rein, one end of it may then remain 
in the halter, and the other end may be fastened in the near pommel ring (see Fig. 25). If the horse must be tied with an iron chain, it should be placed in a leather bag and packed in one of the saddlebags. Nails and hammer are likewise placed in a leather bag. The horsecloth, 3 feet 9 inches long and 5 feet 3 inches broad, is also used as saddle-cloth by being folded into four thicknesses, and thus placing it on the horse's back, the open edges in front and on the near side of the horse, and so far back that the saddlepack may rest on the cloth. The loose breast piece, which, when used as cover, should be fastened on both sides to the cloth by the two blanket pins, is rolled together with the rider's rain-cloak, and the whole secured by the straps to the saddle-pack. When the cloth is used for covering up the horse, the pack itself should then form a part of the surcingle by passing a divided strap piece (Fig. 38) through the loops $a$ (Fig. $37 \mathrm{~A})$ and be buckled to the saddle-girths. When not used, the strap piece should be placed in one of the saddle-bags.

All other articles needed for the horse and the rider are placed in the saddlebags in a way to make them of even weight.

When the horse has been saddled, and the saddlebags and the saddle-pack have been packed, the pack equipment is put on by first fastening the pack firmly, and close to the saddle; then the saddlebags are placed with their middle piece on the seat and with the cantle partly through 
the incision; after which their straps are passed under the saddle-girths and buckled, the buckles being placed under the skirts.

The packing is taken off in the reverse order.

During long rests the packing should be taken off, but the saddle should be left on for some time, for instance, I to 2 hours after half a day's ride. If there be no guard and there is danger of the horse lying down, it is advisable to take the saddle off, but the saddle-cloth must, in any case, be kept on and be fastened by the surcingle until the horse is somewhat cooled off, when the cloth is folded out and the breast piece put on.

If, for some reason or other, the rider, when on foot, needs to bring his packing with him for a longer distance, he may for this purpose provide himself with two rug-strap handles, the ends of one being hooked by a snap hook in the loops placed at the lid of the saddlebags (Fig. 36, b), the middle piece being bent down and the straps (for fastening them to the girths) taken out. The other handle may be used as an ordinary rug-strap by passing the two loose saddle-pack straps through the loops of the handle; the things, formerly being carried on the saddle-pack, may be brought in this rug-strap.

\section{Grooming and Care of Horses.}

It is not said without reason about the horse, that the grooming is half the food, because on proper 
care depends, in a great measure, the health and welfare of the animal, consequently, its stamina.

By proper grooming is not only meant that the horse, when led before the rider, shall look clean and smooth; for it does not unfrequently happen that a shiny surface covers thick layers of dust and dirt which clog the pores of the skin, thus preventing the secretion, which otherwise occurs through them. To ascertain if the horse is properly cleaned, one need only pass the fingers through and against the hair; if this leaves grey stripes on the coat the grooming has been deficient. The head, the neck, under the mane, the legs, especially the knees, hocks and pasterns, should be examined carefully.

For the grooming of a horse the following articles are required:

Curry comb.

Horse brush.

Mane comb of horn or metal.

Hoof pick (Fig. 39) of iron (a) or bone (b).

Hoof brush (Fig. 40).

Pastern cleansers made of two thicknesses of flannel strips, about 2 inches broad and 2 feet 6 inches long, which are sewn together lengthways by several seams.

Sponge.

Towel.

A duster of horse's tail or a piassava brush.

A large flannel rag.

Straw-wads.

After being used, the grooming articles should be dried and cleaned outside the stable. The curry comb, horse brush, duster and flannel rags should not be kept in the stable. 


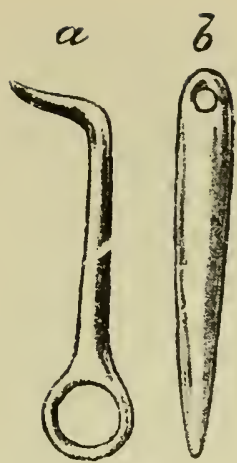

Fig. 30.

The curry comb is principally used in removing the dust from the horse brush; it may, however, also be used on horses whose skin is not too sensitive, and then only to loosen the scurf and matted hair. On the head and on the legs below the knees or hocks, the curry comb is not used, except to gently loosen dried mud from the legs.

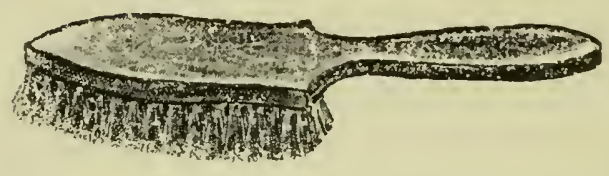

Fig. 40.

The horse brush is used on the hairy parts and principally with the natural direction of the hair, but it must never be used on parts that are wet. On the shanks, knees and hocks, and on very dirty parts, the brush may be used against, as well as with, the hair. Forelock, mane and tail are brushed carefully, the hair being first parted with the fingers and then combed.

With the hoof pick all grit and dirt are removed from the under surface of the hoof, after which the whole hoof is brushed with water.

The back of the pastern is rubbed dry and cleaned with the pastern cleanser which, with one end in each hand, is drawn slowly and not too firmly to and fro under the pastern joint.

With the wet sponge the eyelids (eye-corners), 
nose, nostrils, lips, chin, dock, and the parts between the hind legs and under the tail are cleaned, altogether the hairless parts, after which they are dried with a towel.

The duster or piassava brush is used for removing loose dust and loose hair; the coat is smoothed with a flannel rag or a towel.

For straw-wads it is best to use long straw, which is turned so as to form a rope, which again is bent double, thereby twisting itself.

To loosen the dust on horses who are very ticklish, which is especially the case during the shedding of the coat, straw-wads or loose straw are applied rather than the brush; but strawwads are principally used to rub off the horse when the coat is greasy, wet, or in a perspiration.

If some parts of the horse should need washing, it must be done cautiously and, as a rule, not in cold and damp weather; in any case, the washed parts have to be rubbed dry immediately. The yellowish-brown spots, which light-coloured horses often get by lying down, should be cleansed with lukewarm water and soap; such spots may also, some time before the washing, be rubbed with moist, powdered charcoal. For the washing of the horse, the hoof brush or wet straw-wad may be used.

On badly groomed horses the hair in the forelock, mane and tail is often found to be matted on account of greasy grey dust, which causes itching; it should be removed by lukewarm 
water and soap, with which forelock, crest, mane and the root of the tail are brushed; the tail itself is rinsed in a pail of water, the soap being washed out well with clean water, then afterwards pressed well out of the hair; the hair should not be wrung. If, nevertheless, the horse rubs the root of his tail against the sides of the stall, it should be examined to see if the evil is not caused by dust under the tail or by worms.

In the udder of the mare and in the sheath of the male animal there is sometimes found, on badly groomed horses, a black, greasy substance, which should be removed by the fingers, after which the place is washed with a sponge, dried with towels and, if necessary, greased.

When the horse is shedding the coat, the loose hair should be removed by wetting the points of the fingers and stroking them in the natural direction of the hair, but not harder than sufficient to cause the loose hair to come off.

Before a groomed and ready saddled horse is brought out for the rider, the forelock, mane and tail should be brushed, all loose hair and dust, which might appear during the saddling, as well on the horse as on the saddlery, are wiped off with the towel, and the hoofs are cleaned with wet hoof brush. For the sake of appearance, smearing a sound and healthy hoof with any kind of hoofdressing should not be allowed; a clean washed hoof is a better. and more lasting trimming, as the dressing causes dirt and dust to stick to the hoof-but what is of still more importance, the 
dressing prevents the favourable influence of the air and the moisture on the horn.

Halter, horsecloth and surcingle should be cleaned in the open air and every day; the halter, while the horse is out, the cloth and surcingle at the times when the horse is groomed. The halter and surcingle should be brushed and the cloth shaken; once or twice a week the latter should be aired and beaten. Both the summer and the winter horsecloth should be washed at least once a year, care being taken that the buckles and straps of the breast piece are first removed. The halter should, when taken off the horse, be hung up and not placed on the floor. The cloth is taken off. by first opening the straps of the breast piece, then the surcingle, and with the left hand from the front, sweeping both off at the same time and in the direction of the croup. The cloth is folded up properly and, together with the surcingle, hung up behind the horse, but not thrown over the partitions of the stall.

For horses with thin and fine coat, the headpiece of the halter and also the noseband may be lined with sheep's wool, so as not to cause gall. The surcingle should be provided with panel to be placed over the horse's back, and the cloth cut so as not to gall the withers.

After the ride, the horse must be treated with the greatest care, and for this reason the grooming, which is done after the ride, should be looked after more than that which is done previous to it. I am sorry to say that it happens too frequently 
that the horse, upon returning to the stable, is placed in the stall, tied, unsaddled, and otherwise left to itself. To feed and water directly after the horse has returned from work should not be allowed. To ascertain if the animal, after being used, is properly cared for, it is advisable to make a visit to the stable at once, and, if the time does not allow you to stay there during the whole of the grooming, you had better come back again after an hour's time. Of course, the grooming may be arranged according to how weather and roads have been, and the exertions that the horse has undergone.

When the horse has returned after the ride and has been tied up, the saddle-girths are loosened somewhat; if boots of any kind have been in use, they are taken off, and the legs of the horse are rubbed with straw-wisps with and against the direction of the hair, finally only with; the back of the pastern is well cleaned. It is considered very useful to apply massage to the back tendons and the pastern joint by repeatedly stroking with the thumb on one side and the other fingers on the other side and in the direction of the hair. If the saddle need not stay on for a longer time, it is then taken off, and the horse is rubbed with a dry straw-wad in each hand, while one wad is moved with, the other against, the hair; the back, belly and breast are rubbed first, then the other parts of the body; as soon as one wad has become wet it is changed with a new one. If the horse be disposed to fits of colic, or in order to prevent such 
accesses when, from muddy ground, and especially in cold weather, the animal's belly has become moist, this part must first be attended to and be rubbed thoroughly dry and warm. A rug should always be thrown over the back and loins, when other parts of the horse are attended to. When the horse, in this manner, has been rubbed dry, his coat is smoothed and the cloth and surcingle put on, after which the head is wiped off, the tail, if needed, is washed, the hoofs are cleaned, and the legs bandaged.

For bandages is used either the ordinary elastic cotton bandages or flannel ones which are to be 4 or 5 inches broad and about 3 yards long, and with the one end laid in a point, to which are fastened two ribbons each about 20 inches long. Cotton bandages are used especially during the hot season and may then, in order to prevent swollen legs and before being put on, be soaked in water, or still better, in water mixed with a little spirits of wine, the water to be squeezed out well. Wet bandages must not be applied before the legs have been cooled off, but dry ones may. With the ribbons inmost, the bandage is rolled together to form a firm roll, which is taken in one hand and is unwound 4 to 6 inches; the other hand places the unwound end round the shank a little below the knee or hock and keeps it firm and close into the horse's leg, while the roll is passed over the end, ano the bandage is gradually rolled round by letting it pass slantingly downwards close into and round

5 - Handbook for Riders. 
the leg in a manner that each following turn of the bandage somewhat covers over the previous one; when past the pastern joint, the roll may, without being reversed, in a like manner be moved upwards. Without any pressure, the ribbons are wound round the leg and tied together at the back of the leg. Bandages may stay on from 2 to 4 hours and should in no case be applied on wet legs. After removing the bandages, the legs should be well hand-rubbed.

Every time the horse is groomed, his whole body should be examined to see if there be any external injuries, and also his condition in other respects, about which it will be explained under "Treatment of Sick Horses."

If weather and other circumstances allow it, the grooming should be done in the open air.

The clipping of horses is a precarious question and depends entirely upon climatic conditions and the condition of the horse's coat. In cold, temperate and dry climates, clipping is rarely done nor needed if the coat is kept in good condition by proper grooming; whereas it may be needed in warm and damp climates, according to the nature of the coat and for the sake of the horse's well-being. Horses, with a heavy coat that sheds slowly and sparingly, will generally become sluggish if not clipped. If the conditions be such as to admit a natural shedding of the coat, clipping should be avoided. Careful grooming, proper feed and sufficient exercise may accelerate the shedding. The part covered by the saddle 
should never be clipped, and on hunters the lower part of the legs shouid also remain unclipped, as also on horses with rheumatic propensities.

By careful grooming and proper blanketing the horse's winter coat may, in many cases, be kept in such a state as to render clipping needless.

The coat of a clipped horse loses that glossy appearance which the natural coat may assume by proper treatment.

\section{The Riding-School.}

As probably riding may, by the majority of readers, be looked upon particularly as a pleasant mode of taking exercise, it should especially be practised in the open air; still, it should be evident to everybody that it would not be advisable to go out on the road at once; in that respect there are enough of warnings amongst the so-called Sunday riders, who have too soon left the four protecting and reticent walls of the riding-school.

An open manège, enclosed by low walls or fenced in, should thus seem to provide for all that concerns health and safety. The more lively temper of the horse when in open air, causing freer and higher actions, and also other outward influences, which may bring about unexpected movements of the animal, will make the ridinghouse a necessary evil for the beginner.

A riding-school should be well ventilated and light and have an elastic but firm ground and sufficient space. 
On account of the strong perspiration from both horse and rider, good ventilation is required in riding-houses more than in dwelling-houses; but to let in the fresh air from all sides should be avoided-many old "ring-riders" have thus, through carelessness, contracted many cases of rheumatism. A well-built riding-school, which is free from draught, must not be kept hermetically sealed during the winter from fear of letting out any of the warmth; in sacrificing five minutes between each hour, leaving the doors open, fresh air will pour in in abundance. During such an airing one should not stay in the school. In not removing the droppings from the manège, the air becomes especially unhealthy. By partly removing the droppings and by occasionally putting on a thin layer of fresh sawdust from pinewood, the air may be kept pure, and it will save the expense caused by removing the old covering and renewing it.

A firm and elastic riding-ground may be obtained by filling it with clay at the bottom and rolling it, then on the top of this a layer of fine gravel, which is sprinkled with water, rolled and left to dry; the whole is then covered with even parts of coarse sand and sawdust, or with tanbark about 3 inches in depth. A thicker covering and especially more sand would make it heavy for the horse to move on and, consequently, strain his legs too much. If coarse mould, in whole or in part, be used instead of sand, the ground would become more firm and, therefore, make it easier 
for the horse to move; but from economical reasons mould is only used in very small manèges such as circus rings.

In riding-halls that are not heated, it may occur during the winter that the ground gets frozen; this may, however, be prevented by strewing on some salt. By using sand taken from the seaside the ground would not so easily be frozen.

As it has been observed that the hoofs, when being much in contact with saline ground, will suffer from it, a careful cleansing of them is of more importance then than at other times.

The ordinary shape of a manège is the rectangular one, the length being twice or three times the breadth, with, respectively, one or two yards added to the length in order to allow riders, who are moving at the same time on different "great circles," to pass one another. The average size of a manège should be 4 I yards by 20 or 62 by 20 . If the space at one's disposal be not large enough and of quadrangular shape, there may be laid out a circular manège; its diameter should, however, not be less than 42 feet. Circular riding-houses are economical in every respect, their structure is plain, and they are more practical for the purpose of training and teaching than a square one of the same area would be.

The line staked out for riding-ground, and on which the horse moves, is called the hoofmark, the trace or the track.

In riding along the sides (walls) of the school, 
the side, which is towards the interior of the manège, is named the imner or imward; the other side is the outer or outward. In turnings, riding in circles, and, on the whole, in bending lessons (which will be entered into later on) the immer or imward side is the one to which the turning, the circle, or the bending is made. The different parts of the horse, the rider and the saddlery are named accordingly, i.e., inner leg, outward rein, etc.

The ride is to the right or on the right hand, when the right hand is towards the interior of the manège and vice-versa.

When riders meet each other on the sides of the school, the rider, who is on the left hand, should always take off from the side, and do it betimes and sufficiently to avoid collisions. When passing a rider in front, it should be done on the inner side, and the passing rider should, before resuming his place at the boards, advance sufficiently that he may not disturb the former. If a rider, being on the great circle, meets another one who is on the side of the school, the former should take off from the side. If the horse is brought to a halt, it should not be done at the sides of the school. If two or more are riding abreast, when there are other riders present in the school, and are not riding on the same hand and at the same pace as the latter, the former should keep inside the hoofmark.

If ladies be present in the school, it is customary to ride on the same hand as they do; at any rate, they should not be expected to turn aside.

In overcrowded schools, the riders being 
probably of extremely different ability, the ride should be kept on the same hand, and those walking their horses should keep not less than 6 feet inside the hoofmark.

Last, but not least: "Do not sit gazing at your hands and legs, but open your eyes and close your fingers in order to uphold the rules of the school!" 



\section{Second Part. Riding Instruction.}

Though it is impossible to learn to ride by theory only, still the written instruction is of great advantage to the pupil when judiciously combined with actual practise. That is, if the pupil ride first and read afterward he will more readily comprehend and remember what the instructor has taught, thereby avoiding unnecessary repetitions of statements during the riding hour; for every pupil, however apt, unconsciously and repeatedly makes the same mistakes, especially during the first lessons, when all his energies are concentrated on "staying with" the horse. And the constant repetition of apparently unimportant detail, often so impatiently heard by the pupil, is essential if he wishes to become a good rider.

When a pupil particularly likes a certain horse, he often wants to ride that one and no other during the entire course of instruction. This should never be allowed when it is possible to vary the mounts, for each animal presents new difficulties, which are better faced and overcome while the pupil is under supervision. 
The object of lessons in riding is to give the pupil a safe and graceful seat and proper control of the horse; to accomplish the latter, a good seat-one without dependence on the reins-is absolutely necessary. Therefore, when the opportunity offers, the first lessons ought to be given without allowing reins in the hands of the pupil, the horse being held in "longe" by the instructor; or else the pupil may be mounted on an old and steady school-horse, which keeps a regular pace and moves willingly upon the track (next to the wall) without being guided by the reins. They may begin on a saddle with stirrups, later advancing to a blanket only, and finishing, to his lasting benefit, on a saddle without stirrups.

The blanket used for riding is the one mentioned on p. 57. It is folded four times, and placed with the longest side along the horse's back, with its open sides in front and on the off side, and so far forward to allow room for the rider behind the surcingle (without panel), with which the blanket is fastened. That part of the blanket, which lies in front of the surcingle, is folded together so as to form a firm roll (Fig. 4I, page 9I). When riding on saddle without stirrups, the stirrup-leathers should always be taken out of the bars, not merely taken up in front of the saddle.

Gymnastics on horseback add greatly to attaining a safe seat. These are done while riding without the help of reins, first at the stand, later on during motion. and in the following order: 
I. Hands on hips with loose wrists and well lowered shoulders.

2. Bending trunk forward, backward and sideways at the same time keeping seat and legs in proper position.

3. Twisting the trunk in different directions, taking care to keep hips at a right angle to the length of the horse's body.

4. Moving the arms-somewhat more slowly than during gymnastics on foot.

5. Moving the legs, either alternately or both together, over the neck or the croup of the horse (here the hands may assist). These motions are a part of the real "Voltige on the living horse," since the hands principally carry the weight of the body. During this practice, the pupil learns the position used by a woman in side-saddle, both on near and far side.

6. Jumping on and off the horse without stirrups and during motion. The pupil takes position on the inner side of the horse, i.e., the side turned towards centre of ring, and, with both feet together, springs from the ground at the same instant as the horse's inner fore leg is put on the ground. In jumping on, the hands must be used to prevent the rider from coming down too heavily on the animal's back; in jumping up, taking an astride position, alighting too heavily may also be prevented by pressing the thighs slightly together at the moment of impact. In jumping off the horse 


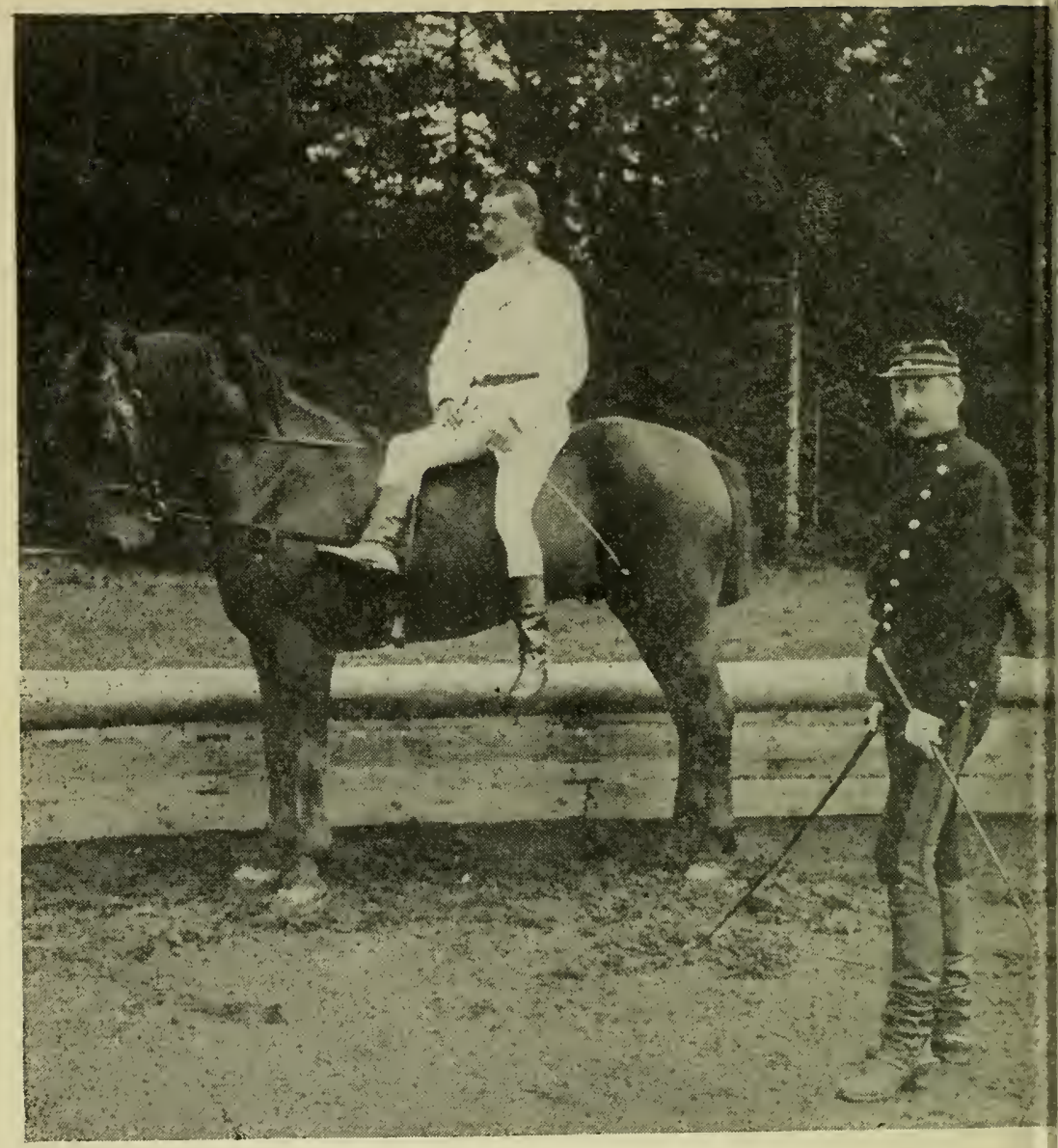

This picture illustrates how a young Norwegian cavalry office goes through the drill in "voltige on hor seback," which consists o. the different ways of placing the legs in jumping from the groun up on the !horse, and, while seated, the moving of the rider' legs (one or both at a time) over the neck or croup of the horse thus taking alternately cross and side saddle position (the latte to the inward and outward side), the rider facing to the fron or to the rear; it is executed with and without the aid of the hands using both or only one. "Scissoring" the legs to the rear an to the front; turning somersaults to either side of the horse' neck, the rider landing on his feet, are also practised, beside other features. These movements of the rider are executed at th stand as well as at the different paces. 
during motion, care must be taken that the rider lands on the ground with his feet by the side of the horse's fore foot, facing in the same direction as the horse, and with chest out and body balanced.

7. Throwing practise, in which the pupil throws up a ball, a cap, or a whip, and catches it again. Later on, pupil and teacher may throw to each other.

\section{Leading the Horse, Dismounted or Mounted.}

A horse should be led slowly out of the stall, whether he has been turned first or not, and in either case letting him get out from the stall a whole length before turning him to the side.

If the horse is to be led only a few steps straight forward or backward, place yourself in front of him, take a snaffle-rein in each hand close to the bit, and draw him with you or force him away from you, in the first case without looking him in the eyes. If, while backing, he should throw his hind quarters to one side, straighten him out by pressing with the rein on that side to which they fly out, thereby bendirg the head and neck somewhat to this same side. Lead through a door in the same manner.

If a horse is quiet and to be led only a short distance, the snaffle-reins are to be held with the right hand, the forefinger between them, close under his chin, the back of the hand held upward. Walk on the near side of the horse, keeping time 
with him and about half-way between his head and shoulder. When trotting the horse, the reins may slide and be held at a length sufficient to allow the man leading to run at the horse's shoulder.

If a horse is nervous or is to be led on foot a longer distance, the snaffle-reins are taken from his neck, the right hand holding them as before, the left hand, with the arm hanging straight down by the side, holding the end of the reins. If the horse is equipped with a curb bridle, then both snaffle- and curb-reins may be taken from his neck and held as described above. Always remove the curb-chain before leading. If a whip is carried, hold it in the left hand with the point down.

When a horse hangs back and does not lead well, press the knuckles of the right hand against his lower jaw, at the same time urging him on by "clucking" to him. If, on the other hand, he rushes forward and cannot be stopped by ordinary means, throw the left hand suddenly up in front of his eyes, or, where there is room enough, turn him round and round several times in a circle to the left, after which proceed straight forward again.

If he attempts to kick, bring his nose sharply upward by stretching out the right arm. If he attempts to shove against you, press the right elbow firmly against the animal's neck, and bend his head towards you.

If the horse rears and cuts the air with his fore legs, lengthen the reins by letting them slide through the hand, hang back a little, and punish 


\section{$-79-$}

him with a few moderate jerks in the mouth. When he "comes down," talk soothingly, shorten the reins again, and proceed as before.

If the person leading the horse is afraid of being struck, he may walk by the horse's side, holding the off rein and a whip (if desired) with the point down, in the right hand, the right arm resting across the horse's back, and the near rein in the left hand close to the horse's shoulder.

If a rider is leading a horse in hand, i.e., riding one horse and leading another, he keeps the latter close to his right side, holding him with the snaffle-reins, which have been brought over the horse's head. If a horse led in hand wears a curb bridle, the curb-chain should be taken off, and if the curb-reins are joined by a buckle, they may be unbuckled and passed under those of the snaffle (previously passed over his head) back onto the horse's neck, and buckled together again; by this arrangement, the snaffle-reins cannot interfere with the arms of the curb-bit, especially if the horse makes an attempt to rush ahead.

If the horse in hand starts to kick and plunge, attempting to break loose from the rider, the rider presses his own horse forward and up against the other, at the same time riding a circle to the right.

When a horse, which is led, is saddled, the stirrups should always be drawn up. The man leading a horse should always keep himself between the horse in hand and all passing objects.

When leading a horse out for inspection, 
the person in charge places himself in front of the animal, facing it, takes one snaffle-rein in each hand close to the bit, and holds up the horse's head, at the same time making him stand with legs straight under him. The horse is urged into this position by means of one or both reins, whereby his legs may be moved forward, or backward, into the desired position.

\section{Riding with Snaffle.}

Riding lessons are frequently commenced with the use of a curb bridle, which is not the proper thing, because the handling of four reins may easily lead to mistakes in the taking up of the reins, and a beginner has generally so much to do in trying to stick on that, even if at first he does take refuge in the reins for his support, it does not lead to any serious results for either parties, if it is done by means of the snaffle-reins. If no snaffle bridle be at hand, leave out the curb-chain.

A horse is generally more willing to "go up to the bit" when ridden with the snaffle than if the curb is used, and, since a beginner's hand is always more or less unsteady and rigid (tending to an irregular guidance), it is best for him always to continue using the snaffle until the hand has become sufficiently supple to admit of the use of a more severe bit, with which he would otherwise most likely have injured the horse's mouth, or allowed the reins to hang loosely and let the animal take its own course. 
The snaffle-bit should be adapted to the 'sensitiveness of the animal's mouth as well as to the rigidity of the rider's hand.

A bit with a thin mouth piece is more severe than one with a thick mouth piece.

Horses with lean tongues and lean and sharp interdental space have, as a rule, sensitive mouths.

\section{Mounting and Dismounting.}

If the reins have been taken over the horse's head, they are, before mounting, brought up, and left lying on his neck just in front of the withers, and hanging down equally on each side; the stirrups, if used, are let down, and the horse is made to stand in position with all four legs straight under him (see page 80). If the fore legs are placed back too far, they may be brought forward by gently touching the back of the fetlock with the point of the toe or the whip; if the hind legs are placed back too far, take position in front of the horse, as described on page 80 , and urge him on a bit by "clucking" to him, at the same time preventing a forward advance with the reins. Or, instead, while still on foot, the whip may be used on the near side of the horse's hind quarters, the haunches being prevented from flying out by the left hand of the person who is holding the horse on the off side; or the horse may be placed with his off side to the wall.

The person who holds the horse, during mounting and dismounting, should stand at the

6 - Handbook for Riders. 
off fore leg with his face turned towards the animal, and hold with his right hand the right cheek piece of the bridle close above the bit, and with his left hand the stirrup-leather close to the stirrup, which is then placed, when mounting, on the rider's foot with its front part turned outwards and, when dismounting, is drawn up. When the rider is in the saddle and has taken up the reins, the attendant lets go of the bridle. In case the attendant is needed to hold a second horse while the first is being mounted or dismounted, he may slip the snaffle-reins of the former over his right arm, taking care that the hind part of this one will not touch the other horse. If the rider should not be on hand when the horse is brought round, the attendant may walk the animal about.

As a rule, no groom or attendant should be allowed to ride, unless he has a long distance before him or more than one horse to lead, and unless he can ride fairly well. In the case of a very nervous animal, however, it is better to have it ridden, even by an inferior rider, rather than risk sustaining an injury to the horse amidst all sorts of traffic.

When the horse is brought up to be mounted, he is placed with his near side toward the approaching rider. If he is to be mounted in the school, he is placed in the middle, and parallel to the shorter sides, but not on the track alongside of the wall. If more riders are mounting or dismounting at the same time, the horses are formed in line with intervals of four steps between horses. 


\section{$-83-$}

When about to mount, never rush towards the animal, even if greatly hurried, for "haste makes waste," and even the quietest animal may become alarmed, when approached in such a manner, and probably take some time to regain its former composure.

\section{Mounting.}

\section{a. At the Stand.}

I. On Sadde with Stirrups.

With the whip in the left hand, point downward, the rider walks from ahead and obliquely towards the horse's near shoulder, meanwhile attentively looking at its head, ears, eyes, nostrils, flank, legs and coat, to ascertain if it is afflicted by any internal illness or external unsoundness (see "Treatment of Sick Horses"), or shows evidence of vice. Having seen to it that the animal has been properly groomed, bridled and saddled, the rider stands facing the horse, taking position somewhat behind the near fore leg (but not too close to it), and takes hold of the left rein, close to the bit, with the left hand, holding it between the third and fourth finger. Then, placing the right hand close behind the left, he slides both hands along the rein back to the withers, tightening the rein, until the horse's mouth is "felt"; then the right hand shortens the right rein, making it even with the left one, and places it in the open left hand, the back of which is turned 
downwards. The end of the reins hang on the near shoulder of the horse. With the right hand the rider now takes a lock of the mane and places it in his left hand, which is closed, turning the back of the hand upwards. If necessary, the mane may be twisted round the thumb.* Having steadied the stirrup with the right hand, and placed his left foot into it, he now takes hold of the cantle of the saddle with the right hand (thumb nearest the seat), and pushing off with the right foot, he raises himself, back and head erect, lightly up in the stirrup, taking care not to pull the saddle over to his side; the body should lean slightly forward, the legs be together, and the thighs and the knees, the latter slightly bent, pressed against the saddle skirt. Moving the right hand to the pommel and keeping the left knee still close to the skirt, he then passes the right leg over the horse's croup (without touching him there), knee straight and heel turned up, and down to the off side, and lets himself slowly down on the seat, taking care to keep his body erect.** The hold on the mane is then withdrawn, the right hand draws the whip out of the left and holds

* Should the hairs of the mane be scarce and fine, the rider may, after taking up the reins in the manner described above, grasp only the withers instead of the mane, keeping the four fingers on the off side and the thumb on the near side, pressing the reins firmly against the withers.

**If the rider has no one to place the off stirrup on his foot, he may do this himself (without looking down) by raising his toe, pointing it inward, and lightly touching the rear branch of the stirrup with it. The stirrup will then swing round, and the foot may be placed into it, with the ball of the foot resting on the bar. 
it with point upward, pointing in direction of horse's near ear, then, placing the right hand in front of the left, the off rein is taken between the third and fourth finger and with the thumb; the left hand then lets go its hold of the off rein. The reins should be kept equally long in both hands, and the hands held in the fundamental position (see "Handling the Reins").

If parted reins are used, i.e., reins not sewn together on the ends, they are placed crosswise over the horse's withers before mounting, so that the near rein falls to the off side and vice versa, and are held in the left hand in the same manner as if joined. When the rider is mounted and has taken one rein in each hand, he may throw the ends of the reins to their proper side with a swift outward motion of the hands.

"Parted reins" are always used in military remount schools.

\section{II. $\mathrm{On} \mathrm{B} 1 \mathrm{anket}$ :}

The rider stands somewhat nearer the horse than when mounting on saddle with stirrups, the left hand takes hold of the reins as before described, the right hand is placed on the surcingle with the thumb to the left and the other fingers to the right of the animal's backbone. First bending, and then straightening the knees, the rider makes a spring from the insteps and raises himself with straight arms, keeping the shoulders well lowered. All the rest-position of body, passing of right 
leg over croup, sitting down, and holding of reinsto be done as before described in I. While mounting, the rider must not with his toe kick the horse's near fore leg.

\section{On Saddle without Stirrups.}

To mount on a saddle without stirrups, the rider proceeds just as when mounting on a blanket, excepting that in this case the right hand takes hold of the saddle and goes through the same motions as when mounting on a saddle with stirrups.

When a rider requires assistance in mounting, he bends his left knee, and the person aiding him grips him under the left shin bone and raises him up, while at the same instant, the rider springs from the ground with the right foot. If a saddle is used, he may grasp the pommel with his right hand-but not the cantle.

\section{b. During Motion.}

Mounting during motion should be done at first without stirrups. The rider leads his horse as described when "Leading the Horse, Dismounted." With feet together, he springs up from the ground, but nearer the fore legs than when mounting at the stand. With a blanket, the hands take hold as described in II; but on saddle without stirrups the right hand grasps the pommel (never the cantle) with the thumb on the top and the four fingers laid in the gullet. 
When mounting during motion, the rider should take care, especially when horse is galloping, not to get too far over on the off side of the horse's back.

When saddle and stirrup are used in this form of mounting, the rider must be discreet and cautious, but it is a most useful exercise and should not be omitted. It is done just in the same way as mounting at the stand-hands taking hold of reins, stirrup-leather and saddle, as before described. Then the rider, keeping abreast of the horse's fore leg, turns his body obliquely towards the rear, steps up in the stirrup with his left foot, and springs from the ground with the right foot at the same instant that the horse sets down the near fore foot. The rest is as described in $\mathrm{I}$.

\section{Dismounting.}

\section{a. At the Stand.}

I. From Sadde with Stirups.

The rider takes hold of the left rein with the thumb and forefinger of the right hand, keeping it close to the left hand, which slides along the rein as far as the withers, where both reins and a lock of mane are taken and held as in mounting; the whip is held, point downward, in the left hand and on near side of horse. Next, the off stirrup is released, and with the help of the right hand on the off side of the pommel and the left foot in the stirrup, the rider raises 
himself up from the saddle and passes his right leg backwards over the horse's croup (as in mounting), at the same time moving the right hand to the cantle, keeping position of legs and body as when mounting. Then, bending the left knee, the right foot is set down, the left foot taken out of the stirrup, the reins released, and the near stirrup taken up if the ride is ended. If there is no one to assist, the rider takes up both stirrups himself, slipping the reins over the left or right arm while doing this, and then holding them as when about to lead the horse.

While the left foot is still in the stirrup, and the rider is about to place the right foot on the ground, he must be very careful not to let the left foot slip out of the stirrup, for the stirrup might swing and hit him. If the rider has legs so short that he cannot reach the ground with the right foot, while the left is in the stirrup, he must take his foot out of the stirrup and alight to the ground on both feet.

\section{From Blanket.}

Reins, whip and mane are held as described in I. The rider places his right hand close in front of his seat, just as when mounting on blanket, and with body slightly bent forward, raises himself on both hands, and swings the right leg in the usual manner over the horse's croup to the near side. Remaining for a moment in this position, arms straight and body erect, he alights 
on his toes, with knees bent. The reins are released, or held as described in I.

III. From Saddle without Stirrups.

This is done in the same way as when a blanket is used, but the right hand is used, just as when dismounting from saddle with stirrups.

\section{b. During Motion.}

Reins, whip and mane are held just as when dismounting at the stand.

If stirrups are used, they are released before dismounting.

In dismounting "from saddle," the right hand takes hold of the pommel, as in mounting during motion (see page 86), but is not to be moved to the cantle. Otherwise everything is done just as in dismounting at the stand, except that the momentary intermission on straight arms (named in II) may be dispensed with. After alighting on the ground (see page 75 , no. 6), the rider runs with the horse, holding the reins in manner described for leading him.

When the rider practises without reins, he goes through the processes of mounting and dismounting in the same manner as in riding with reins, leaving out all motions concerning the reins and the handling of them.

Mounting and dismounting should be practised likewise on off side of horse. 
When the rider mounts and dismounts at the stand, the horse must remain absolutely quiet; the reins must, accordingly, be adjusted to meet the demands of the situation, i.e., a horse inclined to move forward would require a shorter rein, and one inclined to step backward would require a longer one. If he moves sideways, that rein on the side to which the horse moves, is taken up shorter.

\section{The Rider's Position when Mounted.}

(Fig. 4I.)

"Your knees to your nag's side, Your arms to your own, Your hands and heels down, Your heart and head up."

The attitude of the rider on the horse must be easy, natural and unconstrained; if he assumes an awkward and unyielding position, the rigidity of his seat will be felt by his mount, whose movements will become correspondingly hard and uneven.

The reader has, no doubt, often heard expressions like "to feel at home on the horse's back," or "to look as if one is at home on the horse." The one is a consequence of the other. If one really feels at home on the horse, he will surely look to be so, and such security is obtained only by a correct and unconstrained position.

A good position depends principally on a quiet seat, which is attained by keeping the legs 


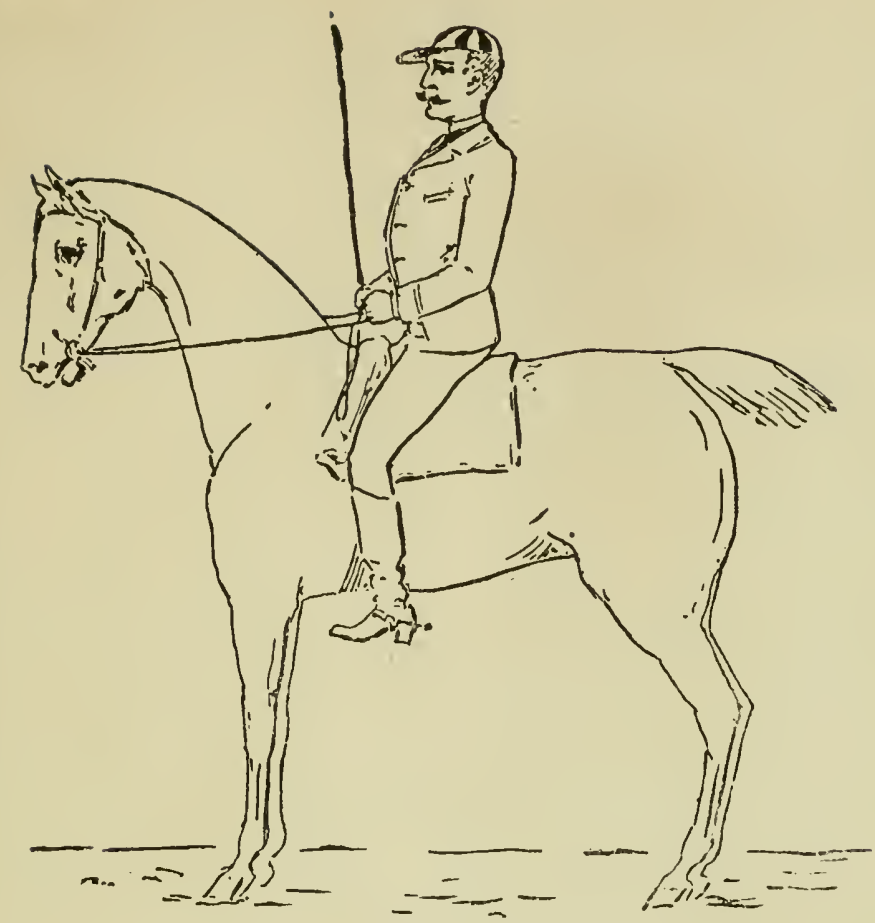

Fig. 4 I

nearly immovable from hip to knee, and keeping the legs below the knee and the upper body movable. In the proper mounted position, the seat rests on three points-both seat-bones and the crotch-on which the weight is equally divided; hips straight over seat-bones and at right angles to backbone of horse; thighs well turned from hip-joint, so as to expand the crotch; the inside flat of the thighs and the knees fitted closely (without pressing) to sides of horse, and with knee-caps pointing forward. Resting the seat on the three "seat-points," the thighs are stretched well downward. 
If the rider rests his weight only on both seatbones, his back becomes crooked, and knees and thighs creep upward and forward; such a position, to say nothing of its awkwardness, obviously prevents proper use of the legs. If, on the other hand, he rests the weight on the crotch (the forkor scissor-seat) his balance is easily lost. If he hangs to one side, the hip sinks in and the shoulder down on opposite side. This uneven position will easily cause the animal's back to be galled.

The body must be kept straight over the hips, the shoulders well back and equally lowered, the centre of chest in a straight line with crest of horse, the back straight, but not rigid, the neck and head perpendicular on shoulders; the chin drawn back, and the eyes looking straight forward between the horse's ears. The shoulder joints must be firm so that the rider's arms cannot be drawn forward, the upper part of arm hanging straight down from the shoulder, but not pressed close to the body, thus preventing the shoulders from creeping upward. The elbow should be bent to such a degree that the upper arm will form a right angle (approximately) to the lower arm, which with the inner side will then touch the waist-line. Elbow-joint and wrist are to be kept loose and limber, to avoid jerking the horse's mouth; by bending the hands a little inwards, so that back of hand and outside of lower arm form at least a straight line, the wrists will become rounded. The hands should be closed without being convulsively clinched and be held with knuckle of 
thumb straight upwards and the fourth finger downwards (i. e. hand on edge) about a hand's breadth from the waist, equally raised, and above the middle of horse's withers, with middle finger knuckles I to 2 inches from each other. The reins are held in the fundamental position (see "Handling the Reins").

The knee-joints must be loose, the calves of the legs hanging straight and easily down alongside of the horse, but without touching him; ankle joints, insteps and toes movable and limber; heels down, and feet held in position into which the turning of thighs from hips will bring them.

When using stirrups, the ball of the foot and the little toe rest on the bar of the stirrup, the leathers of which are to be equally long, and of such a length that the foot (the rider holding his leg in the position above described) will rest lightly in the stirrup*, which in ordinary circumstances serves only to carry the weight of the leg. During jumping, side-leaps, bucking, etc., however, more support may be taken from the stirrup, while, at the same time, thighs and knees take a firmer grasp on the horse. If the stirrup is held correctly,

* Ordinary measurement for the length of the stirrup-leather is considered a hand's breadth between the crotch and the saddle, when the rider, having straightened his legs without drawing up his heels, raises himself in the stirrups. Stirrups, however, are to be used shorter on narrow horses and longer on those having a wide barrel, so the most accurate measure will always be obtained by taking the horse's shape into consideration-thus, when the bar of the stirrup touches the rider's instep, his leg hanging in the above-described position, the stirrup-leather will then be at its right length. 
the sole of the foot will rest quietly on the bar, while the heel may bob up and down-thus preventing the rider from being tossed up and down in the saddle.

Riding on a blanket is especially recommended for the beginner, for in this way the pupil sooner acquires a safe, good seat, and is, moreover, not so likely to become chafed. He will, on the blanket, settle down deeper on the horse's back, which demands a greater expansion of his thighs than is the case on the saddle, which is of less breadth. Consequently, his legs will reach down farther, which will enable him to use the calf of the leg to better advantage.

The preservation of the horse's fore legs depends largely upon the position of the body of the rider, as is shown by the following table, supposing a man weighing I $50 \mathrm{lbs}$. to be mounted:

In a vertical position, he weighs down the fore part with $96 \mathrm{lbs}$.

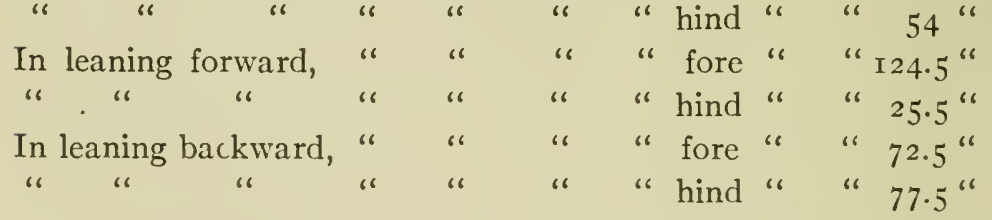

Consequently, the distribution of the rider's weight plays an important part in the endurance, movement, and staying power of the mount. However, it is not always the "light" rider who is the lightest burden to the animal, as it depends greatly upon a correct and quiet seat, and the ability to adjust oneself pliantly to the movements of the horse. 


\section{Handling the Reins.}

Without a secure and correct seat, loose elbow joint and wrist, and firm shoulder joint, a proper handling of the reins is impossible. The reins are the chief factor employed in teaching the horse to

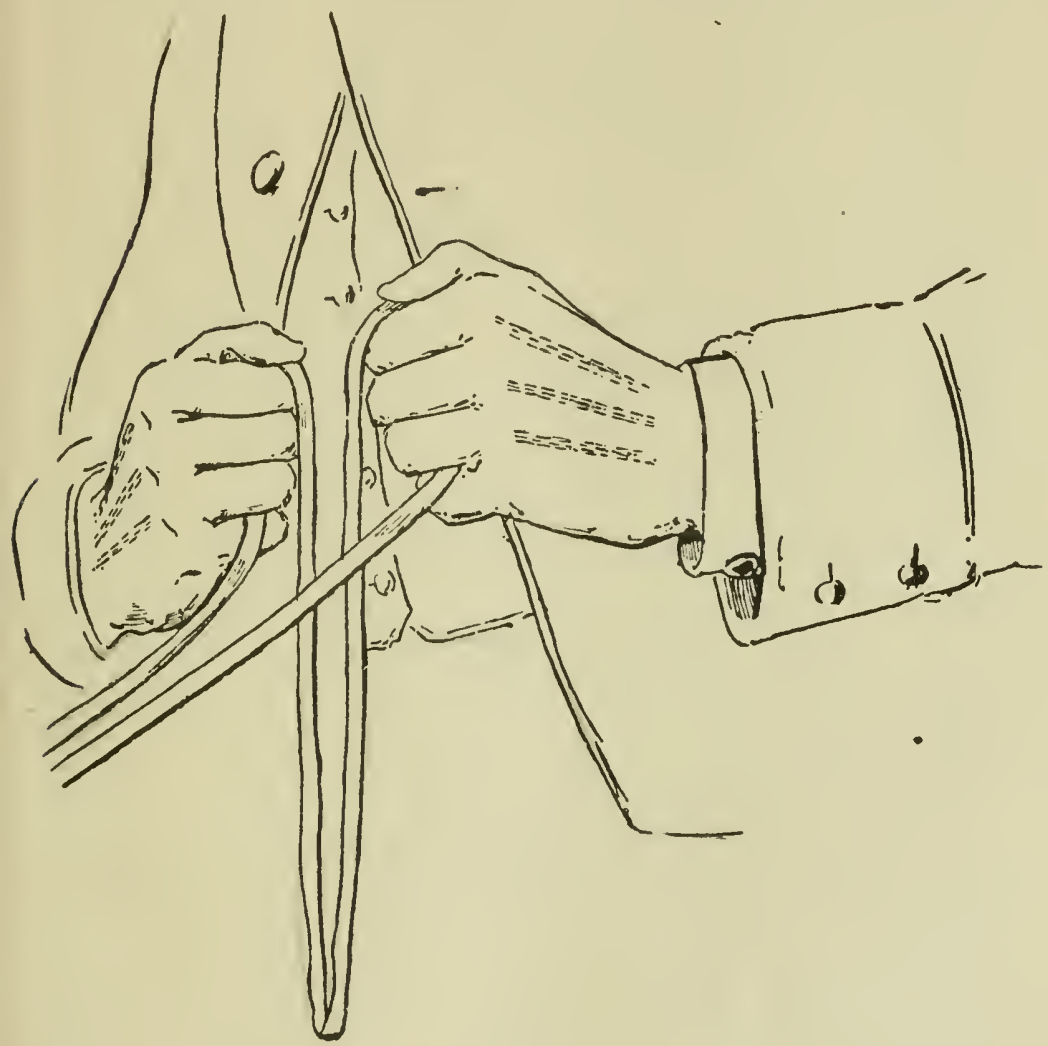

Fig. 42.

understand the rider's will, but an experienced rider on a well-trained animal should not use them more than is necessary, lest he be called a "rein-rider" - a term which is almost abusive in horseback parlance. 
The fundamental position (Fig. 42). With hands held as described in "The Rider's Position when Mounted," the reins are held, one in each hand and with hair $\$$ side of hide turned outward, between the fourth and the third finger and over the middle part of the first finger, against which the entire end (not the nail) of the thumb presses the rein; the nails of the other fingers lightly touching the palm of the hand. The end of the reins pass forward over the first fingers and hang down on the near side of the horse's shoulder, and on inside of left rein. If the reins are parted, the ends hang down, one on each side of the horse's shoulders, outside of the reins.

The height at which the hands are held above the withers varies. Thus, a horse carrying his neck and head too low will require hands held higher, whereas an animal carrying its neck and head too high or nose high ("a stargazer") will require a low hand.

The giving (slackening) and taking (tightening) of the reins is accomplished by turning the hands at the wrist, but without allowing it to stiffen, and in such a way that the little fingers are moved forward or backward. The hand is turned like a door on its hinge (the thumb being the hinge); turning the wrist must be done gradually, not all at once, and must not be jerky. When the desired effect has been obtained, the hands are brought in the same manner into their original position. Should such turning of the wrist prove 
insufficient, the hands may be moved straight forward or backward.

Giving. By turning the wrists, the little fingers are brought forward and outward; thus the back of the hand is turned more or less upward.

Taking. By turning the wrists, the little fingers are brought towards the waist and closer to each other, without dropping the thumbs downward and outward.

Turning. In taking on one rein, the other one should be slightly eased.

Bending the Horse's Head Sideways. To bend the horse's head (from the poll) to one side, one rein (the inward) is shortened by gradual taking and to such a degree that the rider, without bending his head forward and inward, can catch a glimpse of the horse's inward eyebrow and nostril, though, in most cases, he will have to be content with a slighter bend. The outward rein is used to prevent too great a bend to the side (neck-bending). As the horse bends more readily when the hand is held low, the inward hand should, as a rule, be lowered. If the horse leans his ears to one side and his nose to the other, the rein on the side to which the ears are pointing should be held higher than the other rein. If he turns his whole neck inwards from the shoulder, the outward rein is brought low and tightened, the inward rein being drawn a little outward and upward.

Shortening of the reins. This is done first with one rein and then with the other. The thumb and forefinger of the right hand take hold of the

7 - Handbook for Riders. 
left rein close above the left hand and draw it through the hand to the desired length; then the same thing is done with the right rein by the left hand. If the reins are to be considerably shortened, they should not be shortened all at once, but by degrees, i.e., first the right rein, then the left; then again the right, etc.

Up to the bit (or "on the bit"). This expression is used when the horse, with a light feeling of the bit, readily responds to the influences of the reins. These should so assist the horse in carrying his neck and head in a position that the weight of these parts does not put any more strain than is inevitable on the fore part of the animalthereby serving almost as a fifth leg to the horse. But to ride with light reins or to have a light hand does not mean to ride with long or loose reins, for, in this case, the rider is utterly unprepared to act quickly in the event of any spontaneous motion on the part of his horse. Then, too, a long rein, by depriving him of the needful support on the bit, will cause the horse to carry himself badly, and so bring more weight to bear on the fore legs.

The faster the pace the more will the horse need a firm support on the reins.

Hard Mouth. The horse is said to have a hard mouth when he does not willingly obey the influences of the reins in taking, turning, bending of the head, etc. A hard mouth may be the fault of horse or of rider, or of both. If the horse has been wrongly broken or afterwards badly ridden, or if he has a weak fore part, causing him to be 
out of the correct balance, he must be brought back into balance by alternate light feeling and easing of the reins before a proper support on the bit can be re-established. A continuous pull or tension on the reins will only result in further "deadening" of the mouth. Very often the natural sensitiveness of an animal's mouth has been spoiled by a rider with "hard hands," which causes the horse to hang with dead weight in the reins; nor can the animal be benefited in such a case except by a prompt removal of the cause. An insecure seat is often the cause of a hard mouth, because by reason of the effort necessary to maintain the requisite balance, the rider can give no thought to his arms and hands, which consequently are jerked hither and thither with each move of his body, thereby inflicting untold agony on the sensitive jaw of the horse. The animal soon finds that by bearing hard upon the reins the pain is lessened, as the pressure becomes constant, which will enable the rider to support himself more evenly and continually upon the reins; but one fine day the animal, thus ridden, may bolt.

Behind the bit. This expression is used when the horse does not take support on the reins at all or only slightly, and does not obey the influences of the rider. This fault arises generally from a hard hand on the part of the rider and from a very sensitive mouth on the animal, the sensitiveness being either natural or caused by ill-treatment. When a horse is behind the bit, he will show an inclination to draw back if his rider attempts to 
bring head and neck into correct position while at the stand, and when in motion he is likely to trip, and is reluctant to move at fast paces, especially in the trot, which pace he will of ten seek to avoid altogether by breaking into a gallop. In most cases, where the horse is behind the bit, he bends his nose too much towards his chest, and to shorten the reins until one feels the animal's mouth will prove worse than useless, and may often result in the animal becoming restive. On the contrary, the horse must be urged to seek support in the reins himself, and the only remedy lies in the rider's legs (this will be described further on). Sometimes a horse, not properly up to the bit, will carry his nose high in the air, but this happens less frequently; and a quiet, low hand, combined with energetic use of the legs, will generally prove effective.

Riding with double snaffle. When two snafflebits are used, one is placed above the other in the horse's mouth and each has its own pair of reins. The upper rein is placed between the third and the middle finger, and the lower one between the little and the third finger; otherwise each pair of reins is held as explained for single reins. When a martingale is used (see page 42 ) the double reins are held in the same manner.

\section{Saluting on Horseback.}

People on horseback attract more attention than those on foot, and so, consequently, are 
subject to severer criticism; therefore, it behooves every rider to look and act his best. An unassuming and genial manner will never fail to make a good impression, but foppish conduct, as well as an uneasy or constrained manner will never fail to bring forth ridicule. One so taken up with admiration of himself or with management of his steed as to forget to salute acquaintances, or doing it in an awkward way, is generally rewarded with a compassionate smile or shrug of the shoulders. Of course, there are cases when even the best horseman will be forced to devote all his attention to his mount, and then greetings may be shortened to suit the occasion.

The head-covering is removed with the right hand. First take the right rein in the left hand, as if to dismount, and the whip, if one is used, in the thumb-grasp with point downward and to right of horse. Under no condition should the whip be held in the same hand which removes the hat. The head covering should be taken off with ease and brought down close to the rider's right side; in the same way it is moved up again and replaced, after which first the whip and then the rein are taken by the right hand.

When, for some reason, the head-covering cannot be removed, the salutation is performed instead by a slight bowing of the head, or by touching the hat with the handle of the whip, or indeed by both. To salute with the point of the whip turned upward-as military men do with the sword-does not look well, and may easily 
alarm a nervous animal. Salutations on horseback should always be executed in such manner as not to influence the horse at all.

When the management and control of a horse call for the use of both hands, then the rider is fully justified in omitting all salutation except bowing the head, for the lives and limbs of passers-by are surely of greater importance than the observance of such general formalities.

The rider familiar with "horseback etiquette" will at all times be mindful of the comfort of both pedestrians and his own companions. To remove cigar, cigarette or pipe from mouth before saluting; when on muddy roads, so to regulate the pace and distance between riders that passers-by may not be splashed; to know when to stop talking in a company of riders; during conversation, to keep one's mount in such position that he cannot annoy the other horses, or suddenly switch his tail into a person's eyes-these are a few of the important details of riding which are so often overlooked.

As a groom should show proper respect at all times, I will not omit to mention the proper manner in which this is done.

A groom on foot, with a horse at the stand, salutes by standing in front of the animal (as when it is brought out for inspection, page 80), with heels together, and face turned towards the one to be saluted.

A groom on foot with a horse in motion, salutes by looking at the one who is to be saluted, and preserving at the same time a respectful attitude 
and sober countenance. If the groom is spoken to, he stops at once, stands in front of the horse, and holds him in such position that the horse's shoulder is straight abreast of, and about I yard from, the person speaking to the attendant.

When the master or a visitor enters the stable, the groom, if at work, stops his work, keeping hold of the tools, however, which he is using, and salutes by straightening himself up and by looking at the one who enters. If his right hand is at liberty, he takes off his cap.

Grooms should be strictly forbidden to run and rush nervously about in order to show themselves attentive; smartness and calmness, combined with self-control, are invaluable qualities in those who are about horses.

\section{The Aids in Horsemanship.}

The indications by which a rider makes known his wishes to the horse are as follows:
I. Voice.
4. Spurs.
2. Reins.
5. Weight.
3. Legs.
6. Whip.

These "aids" must be applied at the right moment, mutually assist one another, commence with the mildest, and gradually be increased in the order of severity. When the desired effect has been gained, the application of the particular "aid" which has been used must cease, lest the horse become insensible to its action. The less visible the "aids" applied, the more perfect the riding. 
The voice is principally used during the breaking-in, for the purpose of making the horse understand the holding back and urging-on effect of the reins and the legs, but after he has been properly broken, such use of the voice is dispensed with.

Lazy horses may be encouraged by "clucking" to them, while high strung and frightened ones are talked to in a soothing tone, at the same time stroked on the neck with the hand.

The use of the reins has already been mentioned under "Handling the Reins." They act principally upon the fore part of the horse and assist in regulating the pace. By means of the reins the horse is gathered, i.e., his neck is raised and the head is bent as near to the perpendicular position as his structure permits; the former is accomplished by a gentle taking upward of the reins; the latter by more or less backward tightened reins. If the horse stiffens the neck at the poll and strives against every taking of the reins, then alternately giving and taking is applied. If the rein is pulled to one side, the hind part will swerve to the opposite side; if the rein on one side is placed low and tightened against the horse's neck as if pressing over to the other side, this will cause his shoulders to be pressed to the last mentioned side, at the same time as the aforesaid influence of the rein on the hind part ceases.

Both reins are always used together, although each has its special effect.

The inward rein (bending- and turning-rein) 
bends the horse's head sideways and turns him, as well as prevents shoulders and hind part from pressing inward during turnings, circles, side-gaits, etc.

The outward rein (taking-and collecting-rein) acts principally upon the outward side of the animal, while preventing shoulders and hind quarters from pressing out; during riding with horse's head bent sideways, this rein raises the neck and works against wrong bendings of neck and head. This rein also fixes the size of circles and turnings, as well as regulates the pace.

The end of the reins must not be used to smack the horse on the shoulders in order to urge him forward, as this will cause him to become rein-shy or even hand-shy,--both bad habits in the horse.

The legs, i.e., the calves, are the main aid which the rider applies on a broken horse. They are pressed to the sides of the animal with their inner and hinder part by bending of the knee joint and by using first the upper part of the calf; the pressure is applied gradually. without kicks and, if needed, is strengthened by also using the lower part of the calf, until the desired effect is obtained. At the same time the thigh, the knee and foot retain their original position, and the body must not lean forward. If the horse is insensible to the leg pressure, this ceases, is again renewed and, if necessary, is strengthened to a pressure of the heel or the spur, until the animal has understood and obeyed the rider's will, after which the legs are 
brought into their original position. A continual pressure of the legs will make the animal insensible to them, and eventually he will notice the leg pressure no more than the girth that encircles his sides.

Both legs always work together, either by evenly strong pressure of both or by one stronger than the other. According to the different effect which the legs are to produce, they are either applied just behind the girth or further back, but never in front of the girth or back at the flanks. Both legs used equally strong and just behind the girth forces the horse forward, and used further back they force the hind legs forward. A stronger pressure of the leg on one side forces the horse or only his hind quarters over to the opposite side, or it may assist in making him yield to the rein on the same side.

As each rein has its special effect, so has each leg. The imward leg is the forward and outward forcing one, while the outward leg is the holding back, collecting and inward forcing one; it is also the latter that prevents the haunches from flying out in bending lessons, and, for this reason, is often called the guarding leg.

The spurs are used in the same cases an 1 at the same place, relative to the girth, as the legs, when the animal is lazy or does not respond to the legs.

If the spur is used, the toepoint is turned outward and a trifle downward, without the knee altering its position. The spurs are applied on the 
same principle as the legs, that is, with evenly increasing pressure, until the desired effect has been obtained, but they may also be applied with a sharp cut, in cases where a sudden or very strong effort is required of the animal, such as by violent jumps, etc. The cut of the spurs must not be accompanied by a removal of the rider's legs from the sides of the horse, as if making a jib at him, for this would frighten him and at the same time derange the seat of the rider.

The weight of the rider serves partly in keeping the balance on the horse and partly in assisting and increasing the effect of reins and legs. Placing the weight forward tends to urge the animal forward, while weight backward serves to hold him back and also for collecting; weight to the side for purposes of turning.

The bringing forward of the weight is accomplished by a nearly imperceptible pushing forward of the hips, the bringing back of the weight by a heavier sitting down in the seat, and by moving head and shoulders backwards. Weight to one side is accomplished by the rider's heavier sitting down on one side of the seat bones, without displacing the seat or otherwise disarranging the position.

During moving forward, holding back, collecting and turnings, the transfer of the rider's weight must not be noticeable, except to the animal. In gallop at full speed, a leaning forward of the whole body is then permissible.

In order that the rider may keep his balance, 
the weight of the body, when riding up hill or on a rearing animal, is brought forward; riding down hill or on a kicking horse, weight backwards, and in sudden side-leaps, weight should be to the side where he leaps.

The transfer of the weight must, necessarily, as reins and legs, be adapted according to the rider's aim and the sensitiveness of the horse.

In the art of riding, the correct co-operation of reins, legs and weight, and the proper actions employed at the right moment are the true means used by the subtle and clever rider, who always keeps his mount, as it is often expressed, between legs and reins, i.e., the legs are on guard, while the hand with the reins allows the horse, with light support on the bit, both in motion and at the stand, to take such a bearing that he will be unable to do anything without the rider's will, or if he attempts to do so, the able rider immediately prevents.

When legs, reins and weight act in such harmony that the horse, without too great an effort, can carry the rider and always be in readiness to obey his will, the horse is said to be in balance, i.e., the weight of the horse and rider and the work, which is required of the former, should be divided on fore and hind part as equally as possible.

The whip serves principally during the breaking-in, to teach the horse to understand the legs, but later on it also assists the legs with lazy horses, especially mares in heat, on which legs and spurs often have the opposite from usual effect. In 
such cases, the whip is held, as a rule, on the inner side with point downward, just behind the horse's shoulder, where it will prevent this part from pressing in; applied on the hind part, it will naturally press this part over to the opposite side or bring the horse forward. If the whip has to be moved from one hand to the other, for instance from the left to the right, this is done in the following way: The right rein is placed in the left hand, as in dismounting; the left wrist is turned in a way that the little finger passes a little backward and then decidedly upward, thus also moving the point of the whip backward and upward; the right hand with its little finger turned upward, seizes the whip close above the left hand, pulls it out of the latter, and moves it, with point turned backward, down to the right side, after which the right rein is taken by the right hand, as in mounting. In so moving the whip, it passes unnoticed by the horse.

\section{How, When and Where to Punish Horses.}

He that loveth him,

Chasteneth him betimes

Punishment is an augmented use of the aids. It is applied to very lazy or vicious animals, and to such others that are obstinate or resist the rightly applied aids-providing these aids are understood by the animal. The punishment must always immediately follow the fault, for, if delayed, the horse will certainly not understand why he is 
punished. Moreover, the punishment must be applied in the right place, by the right means, and cease as soon as obedience is obtained. Every punishment must necessarily be carried out with firmness and forced through until the rider's will has conquered; further, it must be adapted to the temperament and sensitiveness of the horse. 'Untimely punishment, for instance, to horses that misbehave from fright or ignorance, must not be given. Unskilled riders should, therefore, try to escape getting into situations that might tempt or cause the horse to disobey or become unmanageable, rather than encounter such difficulties and then try to punish the animal, since the fault, in many such instances, is the rider's, and surely it is one of the greatest blunders to punish the horse for the fault of the rider. Eventually the poor animal becomes so muddled that he does not know "head from tail," nor what is right from what is wrong, and after such an experience even a skilful trainer finds it difficult to restore the animal to normal condition.

The means by which the rider punishes the horse are:

The voice, the spurs and the whip.

As the horse is susceptible to the influence of the human voice, rewarding and encouraging. as well as punishing, every rider should acquire the knack of giving his voice the proper emphasis, force and tone to attain the desired effects. I know from experience that cases occur when spurs and whip are not able to produce the same effect 
as a harsh tone. When the rider is on foot with his horse, a sudden and emphatic shout at the right moment may often save him from an intended kick of the animal, especially if the shout is accompanied by a penetrating and defiant look into the horse's eyes.

In the treatment of animals, one should be as humane and lenient as consistent. In order to obtain obedience, first try the gentlest means. I must beg the reader not to forget that the voice is frequently effective, and, at any rate, try this mode first, always remembering "If at first you don't succeed, try, try again."

If spurs are to be applied as a punishment, they are applied by sharp digs or they are pressed firmly into the animal's sides, keeping them there for some time, as a last resort, to bring the animal to reason, when quite out of the rider's control; for instance, when running away. As a proof of this I can state that I, when a pupil in the cavalry training school, had once a runaway horse to break in, and, one fine day, he got the better of me and bolted straight across the training-ground for the open stable door, in front of which the ground was paved with rather slippery stones. After vainly trying all the less severe methods I knew of, then, on nearing the door, I suddenly gave him his head completely, thus depriving the horse of all support on the bit, which, for a moment, startled him and caused a sudden, though trifling, slackening of speed. Taking time by the forelock, I thrust my spurs with all my strength into the horse's sides, 
at the same time leaning back almost touching his croup, and tightening the reins with all my might, I brought him to a standstill, with the result that his hind legs were brought so far forward that he sat down on his tail, still keeping his fore legs erect. I can assure the reader, I was quick in jumping off and in getting out the longeing tackle. My action probably saved my life and the horse never attempted to bolt with me again. This may also serve to show the necessity of teaching the horse to obey the collecting influences, of which we shall speak later. Punishment by only one spur is applied to a horse that will not respond or yield to the touching of the one leg or spur, or presses himself against it.

Spurs, to act as punishment, must be sharp; if not, they only tend to irritate, and the effect will be the reverse of the rider's wish.

The whip is the most powerful means of punishment at the rider's command. Even when spurs are ineffective, for instance, on spur-restive horses, the whip will have good effect. The whip, when used for punishing, is held with the point upward, in the right hand, and the lash falls quickly from above and slantingly downward, but whip and arm must not be brought so far out from the body, previous to the lashing, that the attention of the horse may be called to it, because it would then cause him no surprise. When the whip is used for such a purpose, the reins are held in the left hand.

Cuts of the whip must not be applied further 
in front than the shoulders, where they generally take good effect, esfecially if the horse throws himself to the side.

On the hind quarters the whip must hit the flank and bend itself around the belly, and meet the other flank. On lazy horses and on those that rear, run backward, or become restive from other causes than fright, such a well directed lash will most frequently take effect.

After applying a cut of the whip, it may often be well, in order to make the horse fearless of the whip when it is not intended as punishment, to flourish it above and on both sides of his head, at first slowly, then gradually faster, taking care not to touch him with the whip, and at the same time assuring him with the voice and stroking him on the neck. If he takes kindly to this use of the whip, he will not be in fear of it later on, but this is only the case when the whip is not used in punishment with movements which are sweeping and visible to the horse.

To accompany the foregoing means of punishment with jerks of the reins or altogether to punish the horse with the reins, either by jerks of the bit on the interdental space, or by slaps with the reins on the fore part, is improper and objectionable.

Finally, I suggest to every rider, before punishing his horse, to reflect and ascertain whether possibly the fault or part of it may not be his own, as one is often tempted to shift the blame to others. 


\section{The Various Paces.}

The paces of the horse are either natural or artificial; the latter, being only an improvement and development of the former, are produced through schooling. This is necessary, as the extra weight of the rider must be provided for, so that the animal may keep its proper balance, to prevent its becoming unsafe and soon worn out. Schooling adds the necessary support to repair and improve the balance.

The natural paces of the horse are the natural walk, trot and gallop-also the gallop at full speed (carrière) which may be considered as a special pace.

At the walk, four beats of the hoofs are heard. Two feet are always up, while the other two are planted, the latter being alternately on the same side and diagonal. In counting the four beats of the hoofs, beginning with a fore leg, the second beat falls on this one's diagonal hind leg, third on the other fore leg, and fourth on the other hind leg. Beginning with a hind leg, the second beat falls on the fore leg on the same side, third on the other hind leg, and fourth on the other fore leg.

The walk of the unbroken horse (natural walk) is slow and dragging, because the easy motions of the fore part are prevented by the lowered and stretched out position of the neck and head; the hind hoofs will, for this reason, be placed down in front of the print of the fore hoofs and frequently cause a clicking of the shoes, i.e., the hind hoofs strike the fore hoofs before the 
latter are moved sufficiently forward, often injuring the bulbs of the heel of the fore foot, and causing the horse to stumble or even fall.

At the trot, only two beats of the four hoofs are heard, as the diagonal legs are planted at the same time. Before the pair of diagonal legs first lifted have reached the ground, the other pair have already pushed off, consequently there is a moment when all four legs are up.

The natural trot is, like the natural walk, slow and dragging. If an unbroken horse is at liberty and wishes to quicken his speed beyond the natural trot, he will rarely do so by increasing the trot, but by a series of plunges, which are the gallop.

If the horse gallop correctly, three beats of his four hoofs are heard in each stride: one from the right (or left) hind leg, one from the left (or right) hind leg and the right (or left) fore leg, and one from the left (or right) fore leg. The time which elapses between the different beats of the hoofs of which one gallop-stride consists, is about the same, but between the last beat of the hoofs of one gallop-stride and the first beat of the hoofs of the next one, there is a longer interval.

The natural gallop is heavy, i.e., the weight during strides is thrown over on the fore part; moreover it is unsteady, i.e., during the strides the legs do not always move in the same or right order.

The carrière is, like the gallop, a series of plunges which, when it is forced to the utmost speed, sounds only as two beats of the hoofs in each 
stride, i.e., one from both hind legs and one from both fore legs, but this is considered doubtful by many. In the strides of the carrière, the horse stretches out the bent and far advanced hind legs and throws himself forward on the extremely extended fore legs-thus he becomes as long as possible, his belly draws low to the ground, while neck and head are stretched forward. From the horse's position in the carrière, it is often remarked that he lies flat towards the ground (ventre à terre).

The unbroken horse in the carrière is unable to attain the speed of a broken one, because his fore legs do not reach so far forward, also because the joints of the hind legs are not yet made flexible by schooling.

The improvement and development which the natural paces undergo through schooling consist in producing an even and correct tempo, i.e., the strides are to follow each other in the same order, be equally long, equally high, and equally rapid, and also in making easy the movements of the fore limbs by dividing work and weight, according to the purpose or object, equally between fore and hind part, or mostly on the latter.

The artificial paces are designated in the same way as the natural.

Through the breaking, three kinds of walk are obtained-ordinary walk, road-or campaignwalk, and collected walk.

In the ordinary walk, which is used during 
school riding on one path (i.e., the hind feet should step in the track of the fore feet), through city streets or on difficult, slippery, pebbly or cespitose land, etc., the horse should do about II5 yards per minute. In the ordinary walk, the horse's neck should be raised and the profile of his head should be as near perpendicular as his build permits, the fore legs lifted easily and the hind hoofs should not be planted in front of the print from the fore hoofs.

The road-walk, which is used on even ground during outdoor riding, long distance rides, training for hard riding and in exercising a horse, is long, flat and fast. The movements of the fore part should be free and easy and the fore legs should reach far forward. The campaign-walk gives the animal good exercise without much fatigue, while it also develops chest and lungs. The speed of this particular walk may vary considerably with different horses and types. With the ordinarily good and middle sized half-bred animals, it is about 142 yards per minute, but, naturally, such speed cannot be continued hour after hour, and should be broken off, according to the distance to be covered, by shorter or longer intervals of rest in slower walk.

The collected walk, which is used during collection and in side-gaits, is shorter and higher than the ordinary walk. In the collected walk the fore part of the horse is raised by bringing the weight more over to the hind part, the hind legs being brought under the horse's body. The 
tempo is about the same as in the ordinary walk, because the collected walk loses in time by taking higher steps just about as much as it gains by the steps being shorter.

Pacing is an incorrect motion of walk, wherein the horse moves fore and hind legs on the same side forward at the same time, and in.which movement only two beats are heard from his four hoofs.

At times there may occur a deranged mixing of pacing and trot-for instance with frightened or irritated horses that are made nervous or in high spirits by riders with like qualities and temperaments.

The different kinds of trot, which the horse is taught through the breaking, are: short (slow), medium and extended trot, also collected trot.

The short trot, used especially during the first riding lessons, has a speed of about 230 yards per minute. It is developed from the natural trot by raising the neck and bending the head, with its profile as near to the perpendicular line as possible and thereby bringing the horse into balance, thus allowing an easier movement of his legs. In the short trot the hind hoofs are put down behind the print from the fore hoofs.

The medium trot (about 257 yards per minute), also called balance-or road-trot, is a little faster than short trot, still retaining the gathering of the horse. The hind hoofs are put down nearly in the print from the fore hoofs.

The extended trot is developed from the medium trot and is the fastest of all trotting. In this kind 
of trotting, the horse is allowed to stretch neck and head more forward, but without going on his shoulders, which generally causes clicking. The fore legs should be well extended and the hind legs reach far forward. In the extended trot, the hind hoofs are put down in front of the print from the fore hoofs. This trot, being very fatiguing to the horse, should, therefore, not be used on hard roads nor for long periods; still it can be beneficially practiced during riding lessons, for it is a good test of the rider's firmness in the saddle.

The collected trot, which requires a correct balance of the horse, is a trifle slower than the short trot, but with higher steps of the fore legs, the joints of the hind legs well bent, the back well lowered, and the weight on the hind part. This trot develops easiness in the shoulders, strength and elasticity in the hind legs, by the great bending of the joints of the hind part, and in the same manner that the human body is made muscular and supple by gymnastics. The collected trot lightens the fore part of the animal and brings the greater part of the work over on the hind part. It is used during collection and in side-gaits.

Horses are said to be either easy or hardtrotting. Horses that carry high, or, at any rate, fairly high, have better action in the limbs and, therefore, are the more desirable for riding, having better and more genuine paces.

The short (collected) and the extended gallop are developed from the natural gallop through schooling. 
In the short gallop, which is ridden at about the same speed as the short trot, the horse should in correct bearing, with the weight on the hind part, and his haunches well under him move in short, regular gallop-strides, which, when extremely shortened by bringing the weight still more over on the hind part, give the sound of four, instead of three, hoof beats. The short gallop, which especially exerts the hind part of the horse, must not be ridden long periods at a time nor on hard roads.

The extended gallop (hunting-or road-gallop), which has a speed of about 383 yards per minute, is ridden in long, flat, easy strides and with less bearing than the short gallop, though without letting the horse get out of balance.

There is a gallop right and gallop left in the short as in the extended gallop, according to whether the horse "leads" with the right or the left legs (the advanced legs in each stride). In the right (or left) gallop the horse pushes off from the ground with both fore legs, starting with the right (or left), by which the weight is brought over on the left (or right) hind leg, the stretching of which throws him forward into the gallop-stride, after which the bent and far advanced right (or left) hind leg admits the weight at the same time as the fore part is sustained for a moment by the left (or right) fore leg, and finally the high lifted and far advanced right (or left) fore leg receives the concussion from the forward thrown fore part. The forward pushing hind leg and the fore leg, 
that receives the concussion of the forward thrown fore part are exerted most. Accordingly, a horse with weak right fore leg ought to be ridden for the most part in gallop left, while one with weak right hind leg in gallop right.

Cross (disunited) gallop, which is wrong, injurious to the animal, and unsafe for the rider, is a mixture of gallop right and gallop left in each gallop-stride, while the fore legs move in one gallop and the hind legs in another. In crossgallop the horse may take false with either fore or with hind legs.

Half-gallop is a mixture of gallop and trot, in that the fore legs move in the gallop and the hind legs in the trot. This wrong gait is found sometimes in sluggish and long backed horses with shuffling movements in the hind legs.

The gallop at full speed (carrière) cannot be performed to perfection until the horse, through schooling, has attained easy motions in the fore part and flexibility in the hind part, when the strides may extend to a very considerable length. The carrière, which cannot be practised in the school and ought not be ridden on roads, but on large, open and flat country, is the pace requiring most exertion. For practice it should be ridden only quite short distances ( 220 to 330 yards) at a time. With middle-size (about I $^{-2}$ hands) halfbred horses, the carrière speed varies from 765 to 985 yards per minute.

The above-mentioned paces are, with the exception of the extended trot and the carrière, 
somewhat slower than those decided upon by military instruction, which establish:

The ordinary walk to 150 steps (of $291 / 2$ inches length) per minute. The short trot " 300 The extended trot " 350 The short gallop " 300 " The extended " "500" The carrière from 700 to 1000 "

$\begin{array}{lllll}\text { i6 } & 66 & 66 & 66 \\ 66 & 66 & 66 & 66 & 66 \\ 66 & 66 & 66 & 66 & 66 \\ 66 & 66 & 66 & 66 & 66\end{array}$

The so-called canter or lope, being similar to a cow's gallop, is often mistaken for the short gallop. It gives a very easy ride and is peculiar to certain varieties of horses. In this pace the horse is seldom gathered and goes, consequently, without bearing of the forehand, and therefore weighs heavily forward on account of the hanging neck and head. In this kind of gallop the hoofs give the sound of four beats.

\section{Carriage of the Horse when Mounted.}

The bearing of the unbroken horse (habitual bearing) is different, and may or may not be less favourable for his use as a mount, from the broken one; but only in the broken horse will satisfaction be found. With the unbroken animal, the greatest part of the weight of the body is carried on the fore part; besides, the rider in perpendicular position on horseback loads the fore part considerably more than the hind part (see page 94 ); if this disproportion in the distribution of weights could not be adjusted, riding would be unsafe and more or less injurious to the horse, according to his 
build. By giving his body the correct bearing in proportion to its frame, this disproportion can be greatly, if not entirely, remedied.

In deciding the bearing of the horse, it must also be borne in mind that the aids, which are at the rider's disposal, ought to be allowed to act under the most favourable circumstances, both for horse and rider: for instance, the position of the horse's head should be so that the reins may act at a right angle to the lower jaw, and the position of the horse's legs and the distribution of weight so that the legs of the rider may have the intended effect.

All horses cannot be modeled to the same bearing any more than the very same horse can retain the same bearing under different circumstances. It may appear that the bearing which produces balance is the most favourable, and it is certainly true in most cases; still, there are exceptions-cases where a greater placing of weight on the hind part is necessary. To be able to choose between these, at the proper time and in the right place, is one of the chief tasks of the art of riding; and also what the riding instruction, by teaching the application of the different aids, makes clear to the rider.

By raising the neck and the head, the fore part is lightened, by directing the nose inward towards the lower edge of the neck the reins are brought to act in the most favourable angular position with the lower jaws, which is the rightangled one (Fig. 43). In most cases one must be satisfied with getting the tip of the nose level with 
the deepest part of the back, or even level with the hip, ${ }^{*}$ and the profile line of the head somewhere between the perpendicular position and $45^{\circ}$ forward (Fig. 4I, page 9I). Even horses with correct position of the head are allowed, when in more rapid paces, to hold the tip of the nose level with the hip and the profile line of the head $45^{\circ}$ forward.

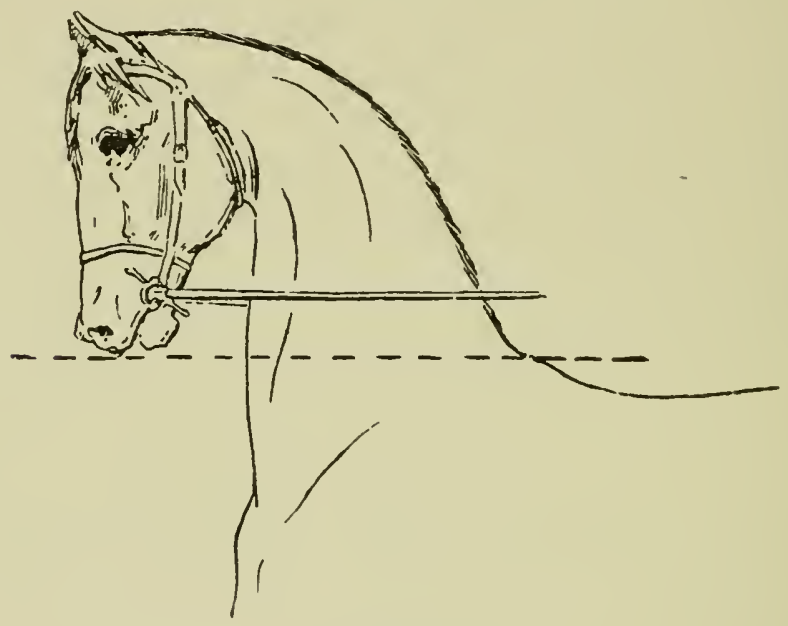

Fig. 43 .

The raising of the neck depends upon the position of the shoulder blade. The more aslant it is, the higher the carriage, provided weak back and hind quarters do not prevent it.

The more or less perpendicular position of the head depends on the jointing with the neck (the poll) and also on the shape of the jaws and of the parotid glands (see pages 8 and 9); if the conditions for bending the head at the poll are not at

* On horses with badly shaped fore part still lower. 
hand, the extreme vertebræ of the neck are allowed to bend with the head, but the neck must not assume the shape of a wheel (Fig. 44).

The bearing of the fore part is taken care of by the reins (see "The Aids in Horsemanship"), with assistance of the rider's legs, which prevent the horse from drawing backward or going behind the reins.

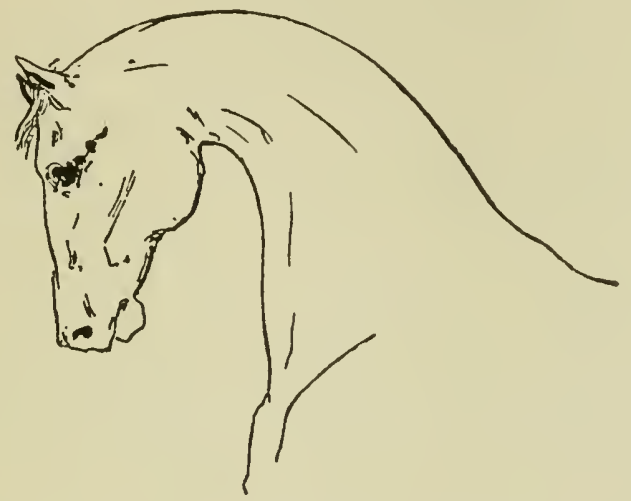

Fig. 44 .

Thus, the carriage which the fore part can assume is qualified by the frame of the whole animal, and if proper allowance be not made for this, the horse may easily be spoiled and rendered unable to do the work which he might readily have done, if given a bearing more favourable to his build.

At the stand, the horse should stand straight up and down on all four legs (Fig.4I, page 9I).

If both fore legs are under-placed, this is adjusted by the rider's weight being brought a little backward; the reins are raised and the legs 
of the rider are applied a little more in front than usual.

Should one fore leg stand too far back, then the rider's weight is brought over on its diagonal hind leg, the rein on the first mentioned leg's side is raised, and the rider's legs are applied, the one on the mentioned fore leg's side further in front, stronger and quite abruptly.

If both fore legs be placed too far forward, the reins are placed low and yielding, while the rider's legs press forward the hind legs, until the fore legs stand straight up and down.

If one fore leg stands too far in front, the rider's weight is brought over on the opposite side and the rein to the mentioned fore leg's side is given a slight tension, the rider's legs on guard in order to prevent any further backing.

If one or both hind legs be too much underplaced, the rider by pressure of his legs makes the horse step forward with the fore legs, until the hind legs are straight up and down.

If one or both hind legs are backward-placed, the rider's legs are applied, while the reins prevent the horse's fore legs from advancing.

Generally the wrong positions of the horse's legs should be adjusted by advancing.

The rider may avoid bending and moving about to see whether the horse's legs are correctly placed, by noting the difference in the seat caused by the various wrong positions of the horse's legs, 
though the rider can discover whether the fore legs are evenly placed or not by glancing at the horse's shoulder points; if they stand evenly, then the position of the fore legs also will be even; if not, the fore leg is always more advanced on the side where the shoulder point is more advanced.

If the fore legs are under-placed, the rider has the sensation of the horse's fore part slanting forward and of sliding forward in the seat.

If the fore legs are stretched forward, the horse gets low in front and one feels as if he is leaning backward.

If the horse does not stand evenly on both hind legs, the rider will feel this under his seat bones, which sink on the one or the other side.

With backward stretched hind legs, the horse becomes lower behind and its back weak, which is made known to the rider by a considerable sinking of the animal's back.

If the hind legs are under-placed, the horse's back will slope slightly to the rear and the rider will have the sensation of the animal's back being strong.

In horses of abnormal structure, small deviations from the above distinguishing marks on the leg positions may, nevertheless, occur, but to discuss all such cases would be too expansive, and aside from the purpose of this book. 
The position of the horse's legs during motion will be mentioned later on under the different paces and lessons.

\section{Riding in Classes.}

This means that two or more riders take lessons in company. The instruction will be most profitable to the pupils and of least trouble to the teacher when all in the same class are equally far advanced.

When the lesson begins, each rider places his horse in the right bearing and in such manner that the shoulders of the riders are abreast on a line, which is supposed to be drawn between the middle points of the two short sides of the school (the middle line), and by which the mounts are thus placed at right angles to the long side, and with an interval of 4 steps between them. The rider on the right flank having placed his horse in the proper manner, the others, one by one, arrange themselves after him (Right Dress). If the distance between one rider and his neighbour to the side of dressing is not correct, this is altered by closing travers (see page I83). If the horse should not stand at a right angle to the long side of the school, the fore part is adjusted after the rules for "Turning on Haunches" (see page I 84), and the hind part after the rules for "Turning on Forehand" (see pages 140 and 162 ).

When a class starts riding, it commences either 
with the command*-"Forward March!" performed by all at the same time; or by one at a time, riding forward on the command- "By files from right (or left ) Forward March!" In the latter case the right (or left) flank man rides forward first, the others follow, one by one, as soon as the tail of his neighbour's horse is abreast of their right (or left) leg. In either case, all ride straight forward and at the same pace, while each one takes an eye-mark on the long side of the school, straight ahead of him; when arrived at a horse's length distance from the wall (the track) all turn to the same side, which in simultaneous advancing should be directed by the teacher, giving the word, "Right (or Left)!" but which in successive advancing is the side from which the riders file. When on the track, in simultaneous advancing, the distance between each following rider and the one ahead of him is one step, but in successive advancing four steps, calculated from the tail of the horse in front and to the head of the next one following; these distances will be retained if the riders keep the same pace and the same track. If, during the riding, wrong distances occur, this

* Most of the words of command are divided into two parts : the cautionary and the executive word; the first indicates what is to be done, the second the moment for the carrying out. Some of the words of command consist of but one word, which is often divided, nevertheless, into two parts, the latter one indicating the moment of execution, for instance, "Slow-er!"or which only indicates what is to be performed, after which the execution comes as soon as possible, or on that place and at that moment of which the rider has been previously instructed. The two different parts of the words of command, the reader will find in this book divided by a dash, thus-.

9 - Handbook for Riders. 
is, if possible, corrected by deviating on the way, and not by a change of pace.

The original distance between the riders in advancing on the hoof-mark may, according to circumstances, be changed later on in one of the following ways:

The distance of four steps is changed into one, either by the leading rider retaining the pace or speed and the following riders increasing it; or by the leading rider decreasing the same (riding at a slower speed) or halting, while those following continue at the same pace. As each rider in one of these ways comes within a distance of one step from the rider ahead of him, the same "pace" as the leader is taken or "halt" is made. If the leader is to continue at an unchanged pace, the command is: "Close your files (and a faster pace)March!" If not: "Close your files, leading file Halt (or a slower pace than before)!"

The distance of one step is increased into four by the leader, who either moves forward from the stand or increases the pace. The following riders assume the same pace as the leading rider, after they have attained the distance of 4 steps from the rider ahead of them. The command being: "4 steps distance forward (or a faster pace than before)-March!"

The distance of 4 steps should be kept in any pace faster than the medium trot.

If the riders again be placed on the middle line of the school, this may, like the advancing, be done by all at the same time or by successive 
entering into the school (deployment). In the former case, the command is: "Right (or Left) turn-March!" (See page I67); and when the riders are on the middle line: "Halt!" In deployment the command is: "Left (or Right) form line, leading rider right (or left) turn-March!" The leading rider turns in to the right (or left) and goes, when the turning is completed, into a walk, if the pace has been faster, riding then at a right angle to the long side, he stops when the command, "Halt!" is given. The nearest following rider continues along the hoof-mark until he is straight behind the leader, then turns in and rides at a right angle to the long side; when the head of his mount has reached abreast of the tail of the horse in advance of him, he slows down into a walk, if the pace has been faster, and he stops when he is abreast of the rider who has been riding in advance of him. Each rider does just the same as the one ahead of him.

If the word be given: "At ease!" either at the stand or during motion, the horse, as well as the rider, may assume an easier position, though during motion the distances must be kept. When after "At ease," the lesson is to be resumed, the word will then be given: "Take up the reins (or Attention)!" Reins and legs bring the horse, little by little, again into correct bearing, and at the same time the rider's legs prevent the horse from stopping, and at the stand from backing or side stepping, i.e., the horse is gathered. 


\section{To Put the Horse into a Walk.}

When the horse stands with correct bearing and light support on the bit, the command is given: "Forward--March!" The rider's legs are applied, at the same time easing the reins, though without losing all feeling of the bit, and the rider's weight goes with in the advancing motion of the horse. When the horse has got into a regular walk, the rider's hands, then the legs, resume their original position, thus adjusting the reins and relaxing the legs. Even pace (ordinary walk) is then kept up by the rider's legs, reins and weight.

The motion of a horse in correct bearing should begin with a fore leg and the first step be taken to its full length.

The ordinary walk is increased to a road-walk by giving the horse his head a little more, thereby giving neck and head a somewhat lowered position; while retaining the support on the bit, the legs then press the animal forward. The rider must not prevent him from an easier gait by sitting down too heavily. The walk will reach its greatest speed if the rider, instead of pressing with toth legs at the same time, will alternate the leg pressure in such a manner that each leg follows the advancing fore leg on the same side. Before the rider has learned to feel the motions of the horse's legs in his seat, he may glance at one of the horse's shoulder points, and at the moment when it stands furthest back, a short pressure is given by the leg on the same side, after which the other leg in like manner follows the forward motion of the other 
fore leg. The more rapid the pressures from the rider's legs are changed, the more rapid, also, will the movements of the mount's legs become. If, at such a time, the horse starts to mince, usually accompanied by going behind the reins, ${ }^{*}$ he is pressed forward into a regular trot and put into a walk after support on the bit is established, after which the rider's legs again try to increase the speed of the walk. By demanding too much from the horse at this kind of walk, he easily breaks into pacing. Curing this fault requires restraint and unlimited patience.

A horse coming direct from the stable should be ridden at a walk for the first ten minutes.

\section{To Pass from the Walk to the Trot.}

When the rider is able to maintain a fairly correct position and regular pace at a walk, the horse is put into the trot at the command: "Short trot-March!" which is done in the same manner as he is put into a walk from the stand, but with somewhat stronger pressure from the rider's legs.** During the first trot, which should be ridden at a very slow pace, the rider must pay more attention to his own position and balance than to the management of the horse; therefore, he should keep

*A horse that goes behind the reins is said to "balk" or to "gib." ** In the manner that riding lessons are given in this countrywithout previous practice in balance-riding, without reins and with the horse held in a longe-the teaching of how to trot should certainly be practised with reins laid down on the horse's neck. 
his hands as passive as possible, which may not be easy at first on account of the jogs caused by the motion of the horse. A pliable elbow joint and wrist, steady and well lowered shoulders, a limber ankle joint and instep, together with a lithe and straight downfall on the animal's back during the trot, are the essential conditions for a steady hand and sure seat.

When the rider assumes a correct position in trotting, he will be thrown straight up and down, and not forward and backward.

If, as frequently occurs during the first lessons in trotting, the rider get fatigued, causing a deranged position, the balance may be easily lost, and then the horse should be put into a walk and "at ease" (see page I3 I).

When the rider can maintain his balance without supporting himself with the reins, then he will be able to turn his attention to the management of the. horse and to a more energetic action or influence of his legs, thus producing a regulated short trot with the horse gathered and in balance.

Should the horse slacken the trot or be inclined to go behind the reins, do not relax the reins, but urge him on with the legs up to the bit and against a steady and pliable hand. If he try to avoid the reins by falling into a gallop, he must be forced forward by the leg pressure, until he has taken proper support on the bit, after which soothing address and repeatedly slight and short tensions upon the reins are applied. 
If it is difficult to re-establish the trot, then the horse's head should be bent very much to the side that "leads" in the gallop. Should he still persist in the gallop, then halt is made and the horse is put into a walk and a trot again.

\section{To Pass from the Trot to the Walk.}

Passing from the trot to a walk, the command is: "Walk-March!" which is carried out by a gradual tension upon the reins, at the same time the weight is carried backward and the rider's legs are quietly closed to the horse's sides in order to bring the hind legs under and prevent the horse from leaning forward. As soon as he gets into a walk, the hands resume their original position by degrees; the legs prevent the animal from halting, and when the walk has become regular, they are relaxed.

\section{To Halt from the Walk.}

The command is "Halt!" Apply the same aids as "From the Trot to the Walk." When the horse has stopped, the reins are immediately relaxed, so that the horse can assume the proper balance and position by moving his fore legs a little forward, while the rider's legs prevent the hind legs from drawing back or aside, and when the horse stands still in correct bearing, the rider relaxes his legs. 
Every increase and decrease of the pace, as well as the halt, is at first performed by gradual, not abrupt, changes, and with the horse on a straight line.

\section{Turning Corners.}

As the corners of the riding-school, even from the first lesson, must be passed, it is necessary that the rider immediately learns the right way of doing it, although it can only be done correctly after practising "Bending the Horse" and "SideGaits." The corners are turned as a part of a circle, the radius of which, according to the speed, varies from one horse's length to half the breadth of the school.

When the horse is approaching the corner, he is inclined to press the fore part out from the track (i.e., press up against the wall), and the hind part somewhat in; this is prevented by forcing the horse (using both legs, mostly the outward one) well forward on the reins, which are moved somewhat inward, but without bending neck and head outward. When in the corner, the horse is inclined to bring neck and head outward, slacken the pace, throw the shoulder in and cut the corner off in a flat curve; tension on the inward rein prevents the neck and head from bending outward, while the rider's inward leg and a moving outward of both hands forces the animal forward and out in the corner. 
The more the corners are rounded off, the easier the rider will find it to maintain his balance when turning corners, therefore, in the beginningespecially as the more rapid paces are practisedthey should be ridden in such a manner that the short sides are passed in an even semi-circle, the middle of which reaches entirely out on the track of the square. Arrived at the point where the semi-circle is to begin, the rider conveys the weight slightly inward, eases the outward rein somewhat and keeps the horse well forward by using his legs, especially the inward one, which also prevents the horse from pressing in.

As the rider's seat becomes surer, and, consequently, the use of the aids more effective, the corners are ridden out better by means of legs and reins, keeping the mount more straight forward towards the corner and preventing a pressing out before and in at the corner. As soon as the corner is turned, the rider's weight is carried straight on the horse and hands and legs back to their original position; if this be not done at the right time, the horse will naturally continue the turn and move into the centre of the school-no uncommon fault with beginners.

The correct turning of a corner when at a walk, short trot or collected gallop should be done on an arc with a radius of not less than a horse's length, in medium and extended trot, with proportionately greater radius, and in extended gallop always with a radius equal to half the breadth of the school. 


\section{Turning Diagonally Across the School.}

As all riding lessons must be performed to both hands, for the sake of the horse as well as the rider, the passing from one hand to the other is one of the most frequently occurring practices during the lessons. The easiest way to accomplish this is by turning diagonally across the school at the command, "Turn across the schoolMarch!" when the rider-after passing the corner from the short side, and reaching out on the long side-turns in and rides aslant across the school towards the diagonal corner and on a straight

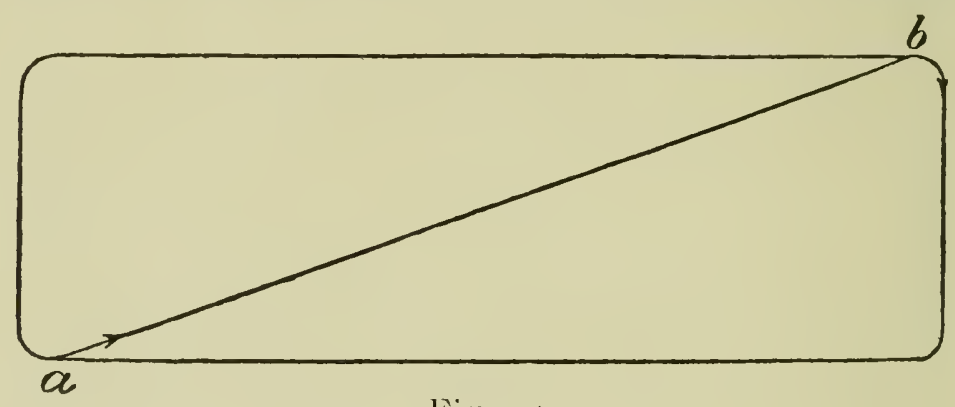

Fig. 45

line, $a b$ (Fig. 45), which divides the school in two equal parts.

Turning across the school is executed by the rider, after passing the corner, continuing with the same aids as during the turning of the corner, until the horse arrives on a slant line, the direction of which is fixed by the more of less rounding of the corner, because the horse must not be turned in, before the long side has been reached, which during the sharpest turning is done a horse's length from the corner. 
Approaching the opposite long side, the horse is liable to press out (referring to the other hand) before reaching the track of the square; the same rules are observed as before turning the corner.

In order that the line across the school may be straight and the turning in from the track not be continued too long, the rider, while turning, ought to fix his eyes on the diagonal corner, and during the turning, little by little, move the eyemark towards the spot at the opposite long side where the turning out on the track is to be made; when the horse points straight against this spot, the turning-aid ceases.

Riding in class, the leading rider turns as above described, the others following precisely in his track and keeping pace and distance.

\section{The Medium Trot.}

When the rider, without depending upon the reins for support, has obtained a sure seat at the short trot, a tolerably good management of the horse, and is able to apply the aids correctly for putting him into a trot and from a trot to walk, then the horse is passed over from the short trot to the medium trot at the command, "Faster!" The same aids as "From the Walk to the Trot." When the rider's seat has become sure and steady in the medium trot, he tries, with his legs, to bring the hind legs more forward, and by well supporting reins the forehand is raised, thus 
freeing the motions of the fore legs, i.e., the horse is moved into a correct pace.

When again passing into a short trot, the command is, "Short trot-March!" which is done as "From the Trot to the Walk."

\section{Turning on Forehand with Horse's Head to the Front.}

Turning on the forehand is accomplished at the stand, as the horse, with one fore foot as centre of rotation, moves the other three. legs on arcs around the first one. In these turnings the legs always move at a slow walk and, in the beginning, only one step at a time, with halt between each step. The horse must never be allowed to draw back during the turning, but rather step slightly forward. The intention of the turning decides its circumference. Turnings on the forehand should not be practised too much, as it might cause injury to the forepart, owing to its loaded condition during such turning.

For practice, a tuming around (half circle) is accomplished in 6 steps and at the command, "On forehand, right (or left) about (one step at a time)-March!" with decided halt between each step. When the horse stands in proper bearing with slight support on the bit, the hands are held still and low, while the right (or left) leg presses the hind part one step over to the left (or right) and by a pressure of the left (or right) leg 
just behind the girth, the left (or right) fore leg is brought a short step forward around the right (or left) one. The rider's weight is slightly to the side, where the hind part is moving. As soon as the hind legs are put in motion, pressure of the leg ceases, so that the horse may take but one step at a time; should he, nevertheless, continue to move, it is counteracted by the other leg of the rider and by a slight feeling of the rein on the same side; the rider uses the same aids, but with somewhat stronger action, should the horse also move the shoulders over to the side where he. moves his croup. Step by step it is continued in this manner until the turning is completed. Later on, the steps are taken after each other without interruption but still measured and never more rapid than at ordinary walking-pace.

\section{Bending the Horse's Neck at the Stand and while in Motion.}

As the structure of many horses will not allow bending only from the poll of the neck, one or more of the vertebræ of the neck-according to its shape-must participate in the bending of the head. Although bendings of the neck, strictly speaking, belong more particularly to breaking, being a preparation for bending the head, still every rider should, nevertheless, have some knowledge of it.

a. At the Stand. With low hands and light takings of the reins, the neck is bent until the 
position of the head becomes perpendicular; the rider's legs prevent the horse from backing. When the horse, with head straight, readily bends the neck, which he signifies, as a rule, by champing the bit, then bendings to the sides are practised; these bendings must not be made greater than to let the horse's nose reach his shoulder joint and not all the way to the rider's leg. The command is, "Bending of neck to the right (or left)!" With low hand, the right (or left) rein is gradually drawn (shortened); the left (or right) rein gives way entirely at the beginning, while the hand, without letting go the rein, is moved forward and rubs the horse, in a caressing manner, from in front backwards and down the left (or right) side of the neck, which then again slowly (i.e., the hands are by degrees brought into their original position) is straightened and the same movements performed to the other side. If the horse accommodates himself quietly to this, the outward rein should not give way, then, entirely, but only as much as the inward rein is drawn. Repeatedly slight pressures from the inward leg, without turning the horse, assist in the bending. If the animal avoid bendings of the neck to the side by turning on the forehand, or if they are accompanied by such turning, and if this cannot be prevented by careful use of the outward leg and rein, together with moving the weight inward, then let the horse walk quietly around until he stops this, which, as a rule, soon will occur. In the riding-school such a turning on the forehand 
may be partly prevented by placing the horse with outward side up against the wall.

By raising the hands little by little and by less giving of the outward rein, the bendings of the neck are taken only in the uppermost vertebræ of the neck, i.e., gradual passing over to bendings of the head (from the poll).

b. In motion. When the horse takes the bendings of the neck correctly at the stand, these are also practised while in motion and on both hands. Bendings to the side are not made so great as they are when at the stand, and at first only to the inward side. Apply the same aids as "At the Stand," with, however, an increased use of the inward leg and the weight slightly outward, which will prevent the horse from turning in; the outward leg prevents the haunches from swerving more than to allow the inward hind hoof to step in the mark of the outward fore hoof. Later on, bendings of the neck outward on the long side and inward on the short side are practised, during which it is observed that the bending is changed before the rider, coming from the long side, turns the corner. In this way, bendings of the neck are at first practised at a walk, later at a short trot.

\section{Bending the Horse's Head at the Stand and while in Motion.}

Every rider will soon experience the advantage and comfort of having a horse with well 
shaped and correctly placed neck and head, because upon the correct carriage of the fore part depends the bearing of the whole horse, i.e., the balance of the body, by which perfection in movement is attained. As before mentioned (see "Carriage of the Horse when Mounted") it is the "habitual bearing" of the horse, i.e., the carriage that he possesses, when no additional influences

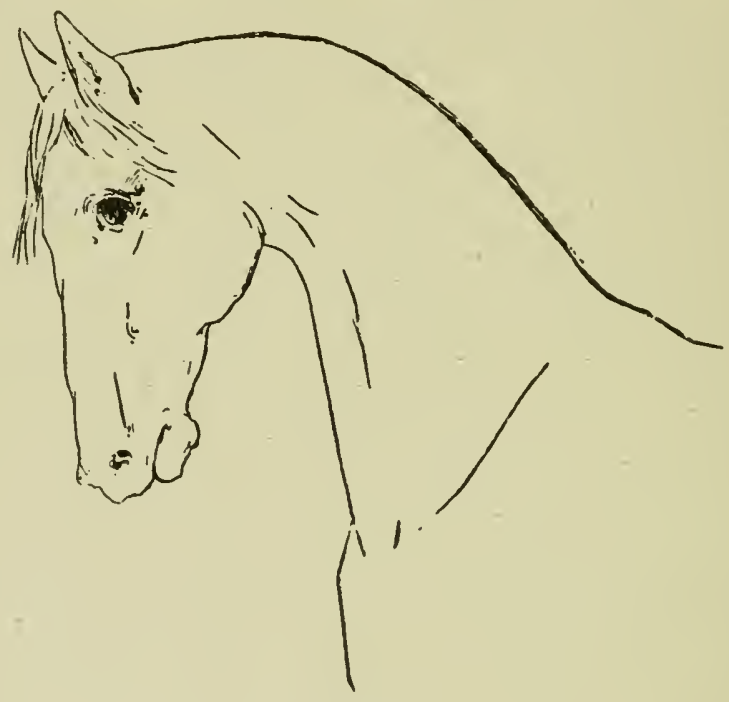

Fig. 46.

are forthcoming, which decides the position that may be given to neck and head, and the rider must bear in mind that all horses cannot be schooled to assume the same bearing. Judging from the rider's point of view, on a well shaped neck, the bending should take place at the very poll (see Fig. 43 and page I23), without the other portion of the neck taking any part; but as such a neck and union between neck and head (see page 9) are 
exceptional, it must generally be allowed that the vertebræ of the neck nearest to the poll partake somewhat in the bending, when only the poll remains the highest point and the neck does not assume the wheel shape (Fig. 44, page I25) or becomes snapped (Fig. 46), i.e., the front half of the crest forms a horizontal line or even slants downward.

a. Bending of the head placed straight. When the rider's seat is sure at a medium trot and he understands how to apply the aids rightly, then bending of the horse's head placed straight is practised, first at a short trot, later on at a walk and finally at the stand. During such bending, the neck should point straight forward from the withers, therefore, the rider's hands are kept close together and just above the withers; by which the neck is kept pressed in between the reins, thus avoiding false bendings; by this means throwing of the head may also be prevented. The bending is performed by a light feeling of the reins; at the same time, the rider's legs must prevent any reduction of pace. In most horses, a raising of the neck is necessary, in order to produce bending at the very poll. If this is found necessary, then the hands are raised just enough to let the reins come close under the edge of the horse's jaws. On the contrary, if his head (nose) is to be lowered, the hands are placed lower; if necessary, quite down upon the withers. Before the hands are raised, in order to produce a higher bearing of the neck, the bending of the head into the perpenro - Handbook for Riders. 


\section{- $146-$}

dicular position must always be awaited before further raising of the neck. When in this manner the horse, by degrees, is brought to the correct carriage of neck and head, which should be suited to his structure and to the object in view, the hands remain quiet and pliable until the horse yields to the bit; the rider's legs keep him from going behind the reins.

If the horse readily goes into correct bearing with neck and head during motion, halt is made and the rider tries if the horse, with low position of the neck and with nose dropped, may be brought to stand for the reins, i.e., if the horse, without drawing back or leaning backwards, and without pulling on the reins, will allow the reins to rest slightly tightened. If this is done, the neck is raised and the head bent, while the hands accordingly are raised or lowered; the rider well down in the seat, his legs only acting to keep the horse at the stand. Should he, nevertheless, draw backwards, too severe aid of the legs must not be applied, but he must be left alone until he stops, which generally occurs very soon. When the horse has yielded to and champs the bit, the hands remain quiet, in order that the horse may feel that he secures light and relieving reins by yielding.

When the rider's attention is called by the instructor to the horse's neck and head having taken correct bearing, there are two measures by the eye which the rider should bear in mind. The one is the perpendicular distance between his horizontal line of vision and the poll of the neck, 
i.e., the raising of the neck; the other is the distance from the hands of the rider to the mouth of the animal (the length of the reins), i.e., the bending of the head.

$b$. Bending of the head sideways (Fig. 47) completes the bending of the head placed straight and is a preparation for "Bending the Horse," and is also the means of making the horse easily turned. With ordinary riaing horses, bending of the head to the sides is taken very slightly (see page 97). Correctly accomplished

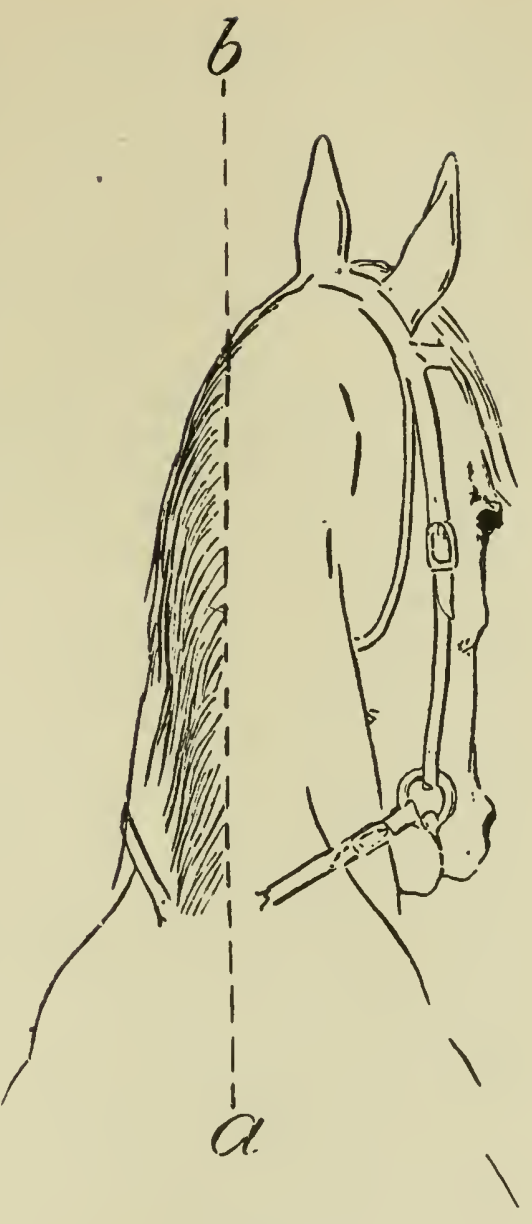

Fig. 47 .

bending of the

head to the sides requires that the neck does not lean or twist to the sides and that at least the four vertebræ nearest to the shoulder remain in the middle line $a b$ (see Fig. 47), and also that the head retain its perpendicular position, i.e., the poll must not point to one side and the nose to the other. 


\section{$-\mathrm{I} 48-$}

When the rider has learned to bring the horse's neck and head into fairly correct bearing when placed straight, bending of the head to the sides is then practised, at first at the stand, later on at a walk and at a short trot and at the command: "Bend horse's head to the right (or left)!"

I. At the stand. By repeated and light play with the inward rein-while the inward hand is moved straight above the middle of the horse -and by corresponding giving of the outward rein, the edge of the inward jaw is drawn nearer the inward muscles of the neck and the outward one withdrawn from the outward ones. The rider's inward leg assists in the bending, while the outward one, together with the outward rein, prevent shoulder and haunches from flying out. The outward rein prevents wrong bendings of the neck by being placed tightly over the strongest false bending (also see pages 97 and 105). The rider's weight should be even.

In order to avoid bendings of the head to the side, the horse will commonly place himself unevenly on his legs, stand lightly on or lift the inward fore leg and lean the outward shoulder outwards; his legs are then directly brought back into proper position (see page I 25), principally by means of the rider's outward leg and rein.

II. In motion. This practice is commenced when the rider understands how to place the horse in balance, by which he carries himself lightly on the reins, i.e., self sustaining on the fore 
part. The aid of rein and of leg same as under I; weight slightly outward. Both legs of the rider maintain the pace. At first the haunches may be permitted to swerve a trifle outward, not more, however, than to allow the outward fore leg and inward hind leg to step in the same prints. As the rider, during this practice, grows more proficient in the use of the aids, an increased use of the outward leg and rein must produce such an effect that the hind legs follow exactly in the prints of the fore legs, by which is produced, to some extent, a gradual going over to "Bending the Horse." Bendings of the head to the sides should, at first, be taken only to the inward side, but later on to the outward side at the long side, and to the inward side at the short side of the school; and when the horse, during such bending, follows correctly the track, the bending outward is also attempted at the short side of the school. Add I and II. If the horse does not bend equally well to both sides, bending to the side, which is more rigid, is especially practised.

When the bending of the head sideways is to cease, the command is: "Place horse's head straight!" While easing the inward rein, the outward one places the head straight.

Add $a$ and $b$. As bending of the head is often very fatiguing to the horse, especially when the joining of neck and head is unfavourable, discretion must be used that he is not provoked to obstinacy, for it is more by stratagem than strength that the rider overcomes the horse's 


\section{- I5O -}

power of resistance. Short repetitions, reasonable demands and, when the horse has yielded, the word "Easy!" accompanied by caresses, are the quickest means of achieving the desired suppleness of the neck.

During bendings of the head, make it a fixed rule that a passive (non-yielding) mouth requires an active (alternate feeling and easing) hand by the rider, while an active (yielding) mouth requires a passive, but pliable (stationary) hand.

\section{Backing.}

Although most horses naturally object to back, still every well broken horse should be equally willing to step backward as forward, when only the right aids are used.

Besides being a manner of moving the horse, when no other movement would answer the purpose, backing is also a means of disciplining him, i.e., awakening the blunt, punishing the disobedient, and calming down quick-tempered animals. As a means of breaking, backing improves the carriage of the fore part and the bending of the joints of the haunches, or, in other words, it is an introduction to "collection at the stand."

Contrary to advancing, the fore part is, during backing, the shoving off, and the hind part the supporting one, for this reason more weight on the hind part is necessary to bring the hind legs nearer under the centre of gravity, by which the fore legs are lifted freely and not dragged. 
Backing should be performed on a straight line in short, regular steps and begin with a hind leg, which is then followed by this one's diagonal fore leg, etc. If the hind legs be placed backward, the movement will commence with a dragging step backward of a fore leg, generally followed by the hind leg on the same side.

When the rider has learned to convey his horse into correct bearing at the stand and to stand with easy support on the bit, then backing may be practised-at first only one step at a time, later on even up to 6 or 8 steps in succession, and at the command, " $(I, 2,3$, etc. step) BackwardMarch!" Having brought the horse into the best possible carriage at the stand, he will, during further attempts at gathering, show inclination to back, which is allowed one step, when a slight easing of the reins and increased pressure of the rider's legs stops the backing. If more steps are to be taken in succession, the reins take and give at each step, while the legs keep the horse constantly on the reins, so that he will not draw behind the bit, i.e., the rider feels as if the horse is equally willing to stop, to advance, or to back further, by the proper application of the aids at any step. While backing, the rider's seat is firm, his weight and legs backward, and hands generally low.

Still, backing can only be done correctly when the rider has learned to collect his horse, while, during this, he acts as if advancing, but at the moment the animal is about to advance, as it 
were, the rider hesitates and increases the feeling of the reins in proportion to the pressure of his legs.

Should the horse back too rapidly, strong aid of the legs is applied, and, if needed, the horse is pressed a few steps forward, after which backing is resumed.

If the horse try to step aside with the haunches, this is prevented by a strengthened use of leg and rein on the side to which he steps.

As punishment, backing is applied to horses that rest too hard on the rein and are constantly trying to increase the pace. In this case the horse is made to back quickly and several steps at a time, whereupon he is ridden forward again at the same pace as before. In order to calm down quicktempered horses, they are made to stand still a few moments after backing, then ridden forward a few steps, then backward the same number of steps and continued thus with soothing words, until quieted.

Backing must be practised with caution and not too frequently, especially with horses that have weak back or hind quarters.

\section{The Extended Trot.}

When the rider's seat is sure in the medium trot, he goes from this over to the extended trot (see page II 8) at the command, "Extended trot-March!" Without losing the support on the 
bit, the reins are eased just enough to allow the horse to step out. The legs of the rider press the horse cautiously into the faster pace, the leg pressure being repeated as often as he tries to slacken the speed or go behind the reins. The rider's body should be erect, not inclined forward.

Perfection in the extended trot cannot be attained without an even and good support on the bit, which depends upon a sure and quiet seat and a lithe, steady hand, and without stretching the trot to the extent that the horse may break into a gallop. If he goes into gallop, a slackening of the speed must not be allowed-on the contrary, the rider's legs must keep him well forward and up to the bit (also see page I34).

If the horse be inclined to hang on the reins and to click, the hands are raised, at the same time as repeated pressure of the rider's legs try to produce a more active movement of the fore legs.

While turning the corners and short side of the school at the extended trot, the rider must watch closely that the horse does not press inward and thus shorten the way. Even if the corners are rounded ever so much, the horse must, at the middle of the short side, be quite out on the track (otherwise see "Turning Corners"). If this be neglected, the animal may easily slip or even fall, causing injury to itself and rider.

If riding in class a following horse goes into a gallop, he is forced forward until at a distance of one step from the rider in front, and then again put into a trot; failing this, the horse is then 
ridden closely up on the inner side of the rider in front and kept there until he has been made to trot, after which the former place in the file is resumed.

If the extended trot is to be changed to medium or short trot, the command is: "Slower!" or "Short trot-March!" when the rules for passing "from the trot to the walk" are applied.

\section{Collecting the Horse.}

To collect the horse is to transfer a greater or smaller part of weight and work on the hind quarters, and in order that this may be done, he must be pressed together lengthwise, as if he were made shorter, i.e., neck and head are brought into bearing (gathered), the back is lowered slightly, and the joints of the hind legs are bent, thus bringing the hind hoofs further under him and nearer the centre of gravity. It is only through the work of collection that we can impart to the animal the balanced carriage, which is necessary to the ordinary riding horse in most cases, and which is the condition of proportionate distribution of weight and work on the fore and hind parts. Collection, by transferring a greater weight to the hind quarters, is performed occasionally, but generally only when a great and sudden exertion of strength is required of the animal.

When the rider has attained sufficient skill in bringing the horse's neck and head into correct bearing at the stand and in motion, collection is 
practised, and, as experience has shown that greater skill is necessary to accomplish this at the stand, it ought, therefore, to be practised during motion first, rather than at the stand. Irregularities arising more readily and being harder to remedy, when collecting the horse at a walk than it is at a trot, the first lessons should take place at the trot, later on at the walk and the short gallop. In extended trot, extended gallop and carrière, the horse is only collected when being taken in.

I. In motion. From the short trot one passes over into the collected trot (see page I I9) at the command, "Short collected trot-March!" While reducing the pace somewhat and bringing the rider's weight more over on the hind quarters, the rider's legs, carried well backward, act as if the horse were to be put into a faster pace, while, at the same time, this is prevented by an easy taking upon the reins; these aids, acting against each other, make the animal lower its back and move the hind legs more forward; promoting higher and freer action of the fore legs. The aids are repeated as often as required and so adapted that the pace shall not be altered. In the collected trot, the rider will feel the jogs more plainly, and be apt to slide backward in the seat.

From a walk and from a stand-still, the collected trot is accomplished by strengthened use of the legs and easier reins.

If the horse is to be collected at a walk (see page II 7), the same aids are applied as at a trot, 


\section{$-\mathrm{I} 56-$}

but with greater caution, the steps a trifle shorter than at the ordinary walk.

Should the horse, in collected motion, move with light support on the bit, the hands are kept quiet and lithe; the rider's legs keep up the pace and prevent the horse from going behind the reins.

Collection during motion is principally used in passing over from a faster to a slower pace and in order to prepare for the halt, but also in passing over into faster pace, such as from walk or trot to gallop.

II. At the stand. When the rider in good position, and without disturbing the pace, is able to collect his horse at a trot and at a walk, collection at the stand is practised. The same aids are applied as during motion, in that the rider, with his legs well backward, acts as if putting the horse into motion, which, however, is prevented by the reins and the rider's weight. In this manner the reins keep the forehand at a stand-still, while the rider's legs bring both hind legs equally toward the fore legs and prevent the former from stepping aside, and the backward placed weight of the rider makes the animal lower its back. Usually the collection at the stand is forced no further than to make the hind hoofs stand straight under the hips of the horse; by closer collection, for instance, by going into collected gallop from the stand, one or both hind hoofs may be brought quite in under the centre of gravity, i.e., in the prolongation of the rider's spine, by which the 
horse's forehand may be raised and the fore legs be bent in a manner to make the under surface of the fore hoofs draw near to the elbow (Fig. 48); this degree of collection (pesade) ought only to be practised by very clever riders and on horses with strong backs and hind quarters, and it must be done with great caution and not degenerate into rearing.

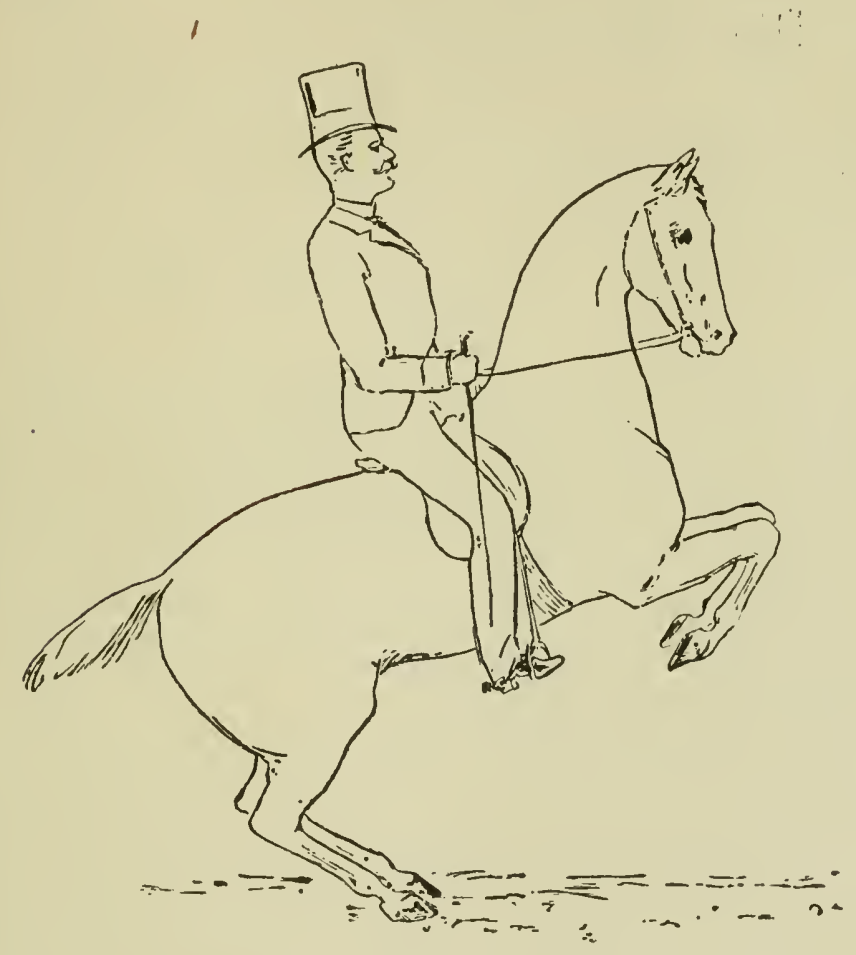

Fig. 48 .

Horses that are apt to draw behind the reins during collection at the stand are pressed a few short steps forward in order to attain a better support on the bit. Horses that, on the contrary, 
rest heavily on the reins are collected by backing a few steps.

Collection at the stand should precede all advancing and backing, as through this the horse obeys the rider's influençes more readily.

All collection is in vain as long as the fore part is not brought into correct bearing.

If the collection is to cease and the horse be restored to his position with all legs straight up and down, it is accomplished by advancing the fore legs, while the rider's legs, during easing the reins, keep the hind legs still.

\section{Halts.}

By halts are meant reining in the horse in motion, with or without the aid of the rider's legs. One distinguishes between the half-halt and the halt thus: the former consists in a taking on the reins, without altering the pace, or in going over from a faster to a slower pace; the latter in a complete halt from any pace.

I. The half-halt consists in a short and evenly increasing tension upon the reins, which is repeated until the object is achieved, but which must never degenerate into jerks on the reins. Half-halts are applied when the horse is avoiding collection, hanging upon the reins, increasing the pace and when his attention to the aids has to be aroused. If the horse avoids collection, then reins, weight and legs are applied and adjusted proportionately to each other and to the temperament 
and structure of the animal. With horses that hang upon the reins, raising tensions on the reins, together with the rider's weight brought backward, are applied, until the fore part goes into correct bearing, when the legs also are applied in order to bring the haunches under. With spirited horses that are inclined to increase the pace and "collect themselves," so to speak, reins and weight are applied, but not legs, for the last mentioned would only make such animals rush still more.

In the above mentioned ways, half-halts may be applied in order to arouse the attention of the horse, when the cautionary words of command for the prescribed practices during lessons are pronounced.

With lazy and restive horses and with those inclined to go behind the bit, half-halts must be used cautiously and with a predominant aid of legs.

The rider must try to acquire the sensation of knowing when the half-halts have availed, for if continued after the attainment of the object, schooling that has been with great difficulty imparted to the animal, may easily be upset.

The following practice may serve as illustration to half-halts, when the rider, at the words, "Halt! Back! Forward!" lets these movements pass almost imperceptibly one into the other.

II. The complete halt cannot be performed with certainty until the rider, by means of halfhalts has learned to bring the haunches under the horse. Complete halts should be performed with 
predominant aid of legs anf weight, in order to enable the horse to stop the speed with his hind quarters and not come to a stand-still on the forehand, which is injurious to the animal and very disagreeable to the rider. At first the halt is performed by degrees and with evenly decreasing speed, while during this the rider keeps the horse gathered and collected, but as the rider gains in skill, the halt is accomplished more speedily, although adjusted always to the rider's ability and to the schooling and strength of the animal. After the halt, the horse must not be kept in the collected position (see "To Halt from the Walk").

Halts may be used with spirited horses when half-halts do not avail (otherwise see "Backing").

Passing over from faster to slower paces and to halt can, by means of preparatory half-halts, be accomplished more abruptly, although they must never be executed with violence, especially when the difference is considerable.

\section{Bending the Horse.}

This means curving the whole body of the horse by which one side of the animal, as it were, is shortened and the other one correspondingly lengthened, i.e., the muscles on the one side are contracted, while those on the opposite side are expanded; the concave side is always called the inward side, the convex one the outward.

During riding with horse bent, his legs act much the same as at the gallop, i.e., the outward 
hind leg shoves off strongly, the inward hind leg is bent considerably and placed far under him, the outward fore leg is advanced and, with the inward hind leg, supports the weight of the body, and the inward fore leg is raised.

When the rider has learned to balance the horse, to place his neck in correct bearing, to bend his head and to collect him, bending the horse is practised preparatory to side-gaits, riding on curved lines, and the gallop.

When on the sides of the school bending the horse is practised, the word is given: "Bend the horse to the right (or left)!" The rider bends the horse's head to the right (or left), while both hands are brought so much outward that the inward hand is placed above the middle line of the horse; the inward leg, just behind the girth, presses the middle part of the horse outward, at the same time as the outward leg, placed further back, supports the hind quarters and prevents them from flying out; fore and hind feet should follow in the same track; the rider's weight equally on the horse's back or rather somewhat to the inward side. The use of the different reins and the rider's legs has already been mentioned under "Handling the Reins" and "The Aids in Horsemanship."

On curved lines, during side-gaits and gallop, the horse is bent to the inward side and without any special command or at the cautionary word of command, provided the word, contra-bending, i.e., bending to the opposite side of the hand to which 
the horse is moving, has/ not previously been given.

Changing the bend of the horse is also performed without any special command when passing over from one hand to the other; the change is done gradually and without any disturbance of the pace.

In riding on curved lines, the bend of the horse should always be adjusted to the curve, and the rider must bear in mind not to make the bend too strong.

When on straight lines, bending the horse should be discontinued, the word is given- " $U n$ bend the horse!" The unbending should be gradual, while the hands, legs and weight of the rider resume their original position by degrees.

\section{Turning on Forehand with Horse's Head Bent Sideways.}

This turning is accomplished by the same rules, the same command and the same aids as "Turning on Forehand with Horse's Head to the Front" (see page I40); but at the cautionary word of command, the horse's head is bent to the side, to which the turn is made (the inward). In turning the horse on his forehand with his head bent sideways - and especially if the head be bent much sideways - the forehand is more apt to move outward than it is when the turn is performed with head to the front; increased use of 
the outward leg and rein is then required. If the horse should, notwithstanding this, press the forehand outward, his head may (at the command, "With contra-bend on forehand right (or left) aboutMarch!") be bent to the opposite side of the one to which the turn is made.

; During turns on the forehand, the rider's hands should be kept as passive as possible, for the reins have only to keep the inner fore leg in place and not to prevent the outer one from advancing.

When the turn is completed, the horse's head is placed to the front, and, if he be apt to draw backward, he is made to advance a few short steps.

\section{The Great Circle.}

The circumference of the great circle should be so described as to reach out on the track at the middle of one short side of the school and at the two long sides or only at the (two) latter onesthe diameter being always the breadth of the school. By placing the great circle at one of the ends of the school, the rider will have three marks (points of contact) to go by, and, in keeping his attention directed to them, he may be able to describe a regular circle with his horse. The half of the circle that touches the short side at the middle and also the two long sides is named the closed part, the other half the open one.

At an early stage of the riding lessons, and 
before "Bending the Horse" has been taught, riding on the great circle should be practised in - order to develop the rider's balance; the same aids are then applied as in "Turning Corners" at first. However, the great circle can only be ridden correctly when the rider has been taught to bend the horse, the knowledge of which is easiest acquired by riding on the great circle, because the horse's body should then constantly and evenly remain curved to the inward side. With fiery and nervous horses, riding on the great circle sets them at ease.

The horse, going round by the side of the school, is put on the great circle at the command, "Great circle-March!" At the cautionary word of command, the horse is bent to the inward side, and at the word "March," the rider describes a circle according to the breadth of the manège, by bringing his weight inward, by increased pressure of the outward leg and feeling the inward rein. In order to form a perfect circle, too frequent influences must be avoided, as these easily disturb the pace and cause riding in a zigzag line instead of a circle. If the rider keep a steady seat, reins and legs in their proper position and his weight slightly inward and backward (the rider should, according to the speed, assume the same inward angle as the horse), a trained horse will most frequently keep on the circle of his own accord. The commonest faults, while riding on the great circle, are that the horse does not get sufficiently out on the track at the "marks," or the "marks" 
may be displaced in the manner shown by the dotted line on Fig. 49 (page I66), representing a great circle ridden to the right hand. How to prevent and correct these faults is explained under "The Aids in Horsemanship."

When the horse is to follow the side of the school from the great circle, it should be done from one of the "marks" and at the command "Straight on-March!" -In placing his weight evenly on the horse and unbending him, the rider guides his horse on to the track by the inward leg and the outward rein.

When riding in class on the great circle, the leading rider acts as here described; the others follow in his track, keeping their distances and the same rules.

\section{Turning while in Motion.}

This is always performed on circular lines, which are at first made wide, but, as the rider makes progress, the turns should gradually be made shorter, still always with proper consideration for the pace, the strength of the horse, and the education of horse and rider. At the walk, the short trot and the short gallop, the turns are correctly executed when they form a part of a circle with the diameter of 2 horses' length (i.e., a small circle); at the extended trot and the extended gallop, the turns should be made as if riding on great circles. In riding with horse's head to the front, at the cautionary word of com- 
mand, all turns are prepared for by gathering the horse and bending him to the inner side; otherwise the same rules are observed as in turning in on the great circle, though the different aids should be adjusted according to the arc to be described and without disturbance of the pace. In practising the turns, they are made in the easiest way from one side of the school over to the opposite one and in such a manner that the horse, after having completed the turn, forms an angle of $45^{\circ}$ (Fig. 49, $a b)$ or $90^{\circ}$ (Fig. $49, c d$ ) to his original direction. By the former turn $\left(\frac{1}{8}\right)$, the rider will, after crossing the manège, be moving to the other hand, like in "Turning Diagonally Across the School," whereas the latter $\left(\frac{1}{4}\right)$ is executed the same as "Turning Corners."

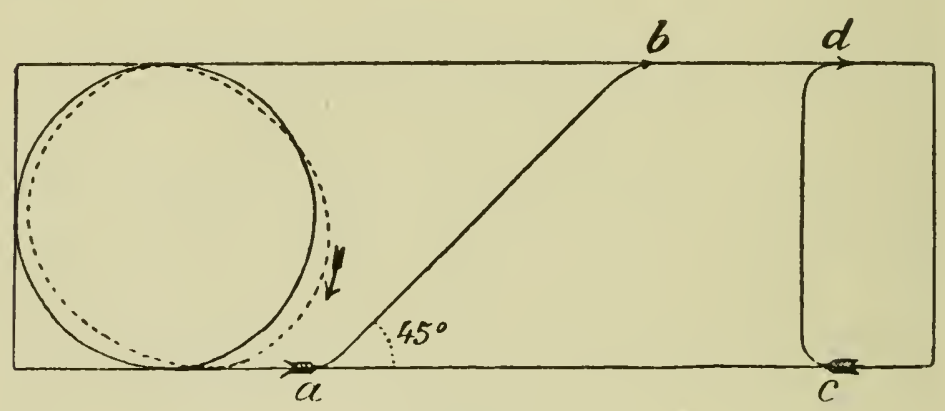

Fig. 49 .

The rider being upon one of the long sides, the $\frac{1}{8}$ turn is made at the command, "Right (or Left) half turn-March!" When the turn is completed, the rider moves obliquely to the opposite side and, before turning out on the track, changes the bend of the horse, 
The $\frac{1}{4}$ turn is made at the command, "Right (or Left) turn-March!" When the turn is completed; the rider moves at a right angle to the opposite side, where the horse is turned to the same hand as before and without any special command. If, on the contrary, at the $\frac{1}{4}$ turn, the hand should be changed, the word "Change!" will then be given when half way across the manège, in order to give the rider sufficient time to change the bend of the horse before arriving at the other side of the school.

When riding in class, these turns are made by all at the same time.

If, when riding in class, the turns should be made successively, the command is: "Leading rider right (or left) half turn (or right [or left] turn)March!" The leading rider executes $\frac{1}{8}$ or $\frac{1}{4}$ turn; the others follow his movements and turn successively on the same place as the leading rider; on arriving at the opposite side of the school, the same rules are observed by each rider in succession, as previously explained for simultaneous turns.

The commonest faults that arise during a turn are that the horse, when turned in from the side, turns too sharply, and, before turning out on the opposite side, presses out; the former of these faults is remedied by the inward leg and the outward rein, and the hands brought slightly outward, the latter by the outward leg and rein and the hands somewhat inward, but without drawing the horse's head outward.

If the turn is to be made with "contra-bend," 
it should be announced before commencing it; the position of legs and reins is then changed; thus what has been explained previously about the use of the inward (or outward) aids refers in that case to the outward (or inward).

\section{Change in Crossing the Great Circle.}

To change hands while moving on the great circle, the command is, "Change across the circleMarch!" The rider turns his horse towards the centre of the circle and moves on a line which should divide the circle into two equal parts. At first, and always at more rapid paces, this line should be given the shape of the letter $\mathrm{S}$, the two semi-circles should be equal and meet in the centre. In slower paces and as the rider makes progress, the middle part of the S-shaped line is straightened out by degrees until it becomes a straight line, only leaving an arc at each end. On the centre the bend of the horse is changed. The turn is easiest made from the "mark" by the long side after passing the closed part of the great circle.

When riding in class, the leading rider turns as prescribed; the others follow exactly in his track and do the same.

The most common faults are that the turning in from the track of the circle is made too wide, by which the centre is frequently not passed through; and that the turning out on the track is made too short. The former fault may be prevented by the outward leg and rein, and by bringing the hands 
slightly inward, and the latter one should be corrected by the inward leg and the outward rein and by moving the hands slightly outward.

\section{Yielding Sideways to the Rider's Leg.}

In this exercise the rider is taught how to make the hind quarters of the horse, while advancing, yield to the pressure of one leg. The rider will already have learned from "turning corners" and from "turning on forehand" how the horse or only his hind quarters can be made to yield to a predominant pressure of the inner leg. As an introduction to the regular stepping sideways the horse may, on the long side of the school, be brought, by degrees, a few steps sideways in from the track,-continuing forward at the same time, -by a stronger pressure of the outward leg and the rider's weight brought inward; by reversing the aids, the horse should, in a similar manner, be moved back to the track. In these movements the horse should all the time remain unbent and his haunches must not precede the shoulders, but rather the reverse. In the regular stepping sideways (upon two tracks), used as a preliminary practice to side-gaits, the horse should, while advancing on the great circle, move his fore and hind feet in two different paths, the inner (or outer) hind foot to step in the print from the outer (or inner) fore foot, and the fore feet remaining on the track of the great circle. It is at first 


\section{1}

practised at the walk and later on at the short trot.

The rider, being on the great circle and having passed its closed part and its "mark" at the long side, the word is given, "Hind quarters out!" By a stronger pressure of the inward leg, the horse's haunches are brought outside the track of the circle, on which the fore feet should remain; the pressure of the leg ceases and is repeated when required; the rider's weight being slightly outward. If needed, an increased use of the inner rein is applied, but without noticeable bending of the horse's neck. The pace should remain unchanged all the time. Having, in this manner, passed the open part of the great circle, on arriving near the other long side, the rider brings his weight inward, while his outward leg, assisted by the outward rein, moves the hind quarters in on the track of the circle; the word is then given "Hind quarters in!" By a stronger use of the outward leg and rein-without bending the horse's head outward-the horse's haunches are moved within the track of the circle, on which the forehand should remain. Thus, the yielding to the rider's inward or outward leg may be continued until ease and correctness in the movements are attained. To change hands during this practice, the turning on forehand to the side, where the horse's hind feet are stepping sideways, is most suitable to the purpose.

When riding in class, the yielding sideways to the rider's leg is commenced by the leading 
rider, followed by each rider in succession and executed at the same points and in the same manner as above explained.

\section{Side-Gaits.}

- Side-gaits, also called the lateral gaits, are the motions of the borse in which he should be bent (see pages I60 and I6I) and collected, and his fore and hind feet move on two separate paths, advancing sideways, with one shoulder preceding the other, and in such a manner that the horse's legs, to the side where the rider's "sideways-moving" leg is, step in front of and in a line with the two other legs.* The tracks of the fore and hind feet must be parallel or concentric, according to whether the side-gaits are executed upon straight or circular lines.

Side-gaits for the horse are the same as gymnastics for human beings, being the means of rendering the body and the limbs supple, by which the horse is made more fit to obey the rider's influences rapidly and accurately. They also fit the animal for the more vigorous efforts which are frequently required of the riding horse; by the practice of side-gaits he also acquires the knack of moving his legs with safety and correctness in all paces.

When the rider has learned to collect his horse while in motion, to bend his horse, and to

* The so-called closing travers, being an exception to this rule, will be separately explained later on. 
make him yield sideways to the rider's leg correctly, the side-gaits may be practised first at the walk, later on at the short trot, and partly at the short gallop; they may be executed on the track of the square or on that of the great circle and, when proper skill has been attained, also in turnings and upon small circles; they should always be performed at the collected paces. In the streets and on roads, side-gaits should not be practised. As a preliminary practice in order to facilitate the work of the horse, the side-gaits should commence without any bending of the horse's head sideways, thereby preventing such bending from being made too great, i.e., the bend not being in the very poll of the neck, but partly in some lower parts of the neck, ${ }^{*}$ in which case the horse would avoid the exercise, because the wrong bend of the neck would cause his shoulders to swerve outward and not to lead off, which they should do. However, as the carrying out of the side-gaits with horse's head to the front can be understood from what will be explained about those with horse's head bent sideways, the latter only will be fully treated in this chapter.

In side-gaits with horse's head bent sideways, he should be well gathered, bent and collected, and the rider must always bear in mind that the horse should be thus prepared before being led off on two paths, i.e., into the oblique position.

There exists two distinct kinds of side-gaits,the versings and the traversings.

* A very common occurrence with unaccomplished riders. 
In versing, the horse should move by the pressure of the rider's inward leg towards the opposite side to which he is bent, and in such a manner, that the inward legs step in advance of the outward. According to whether the horse is bent to the same hand or to the opposite of the one to which the

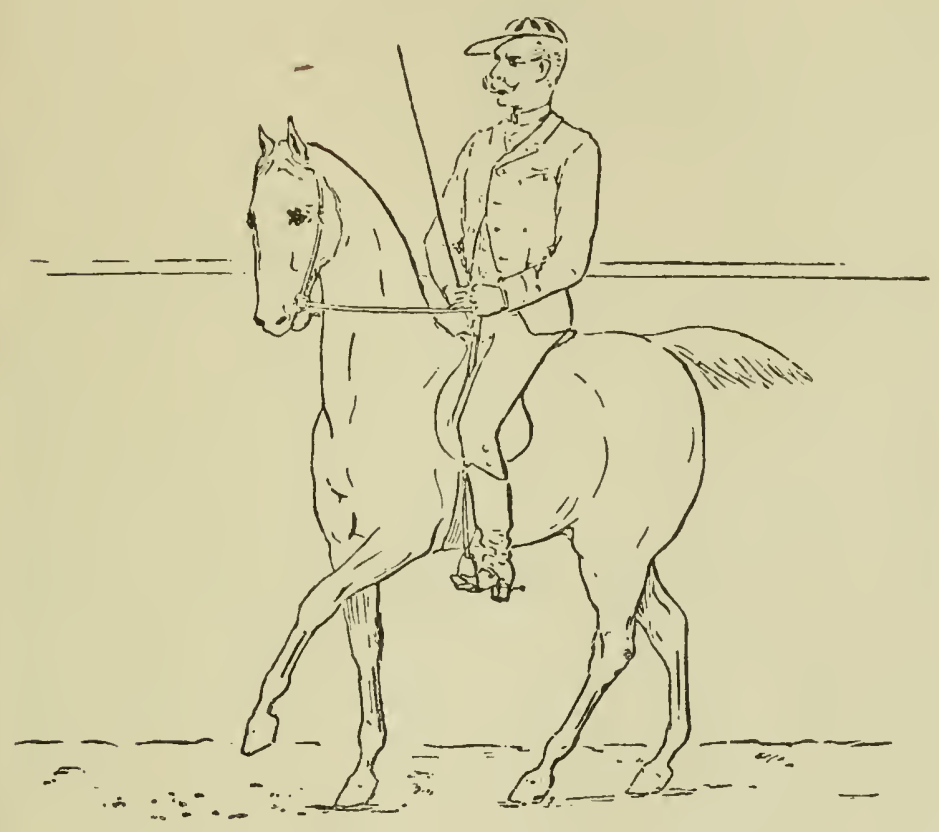

Fig. 50.

rider is moving, two kinds of versing may be produced: the versing and the contra-versing.

Versings are practised at the walk and at the short trot.

The command being: "Versez-March!" At the word Versez, collect the horse and bend him to the inner side; at the word March, bring the horse's forehand gradually in towards the interior 
of the school and not more than the distance of a short step from the track, on which the hind feet should remain. When the horse has got into correct oblique position, i.e., the inner hind foot in a line with the outer hind foot and the inner fore foot, then the rider brings his weight outward, and by the aid of the inward leg and outward rein the horse is led off in the side-gait (Fig. 50); the rider should, without turning his head, look in the direction the horse advances. The outward leg prevents the hind legs from stepping too much to the side, while the inward presses the inner hind leg well forward; both legs keep the horse up to the hand. If the horse should come to a standstill when the forehand is brought in from the track, this may be because the movement has been executed too abruptly, or the horse may have been rigid on the inner rein. In the former case, it should be remedied by the inward leg and the outward rein, while in the latter the inward leg and rein should be applied. If, in versing, the horse steps too far in from the track, i.e., the hind feet be moving within the track, it should be corrected gradually by increased use of the inward leg and the outward rein until the hind feet are replaced on the track, all the time securing the oblique position of the horse.

In versing on curved lines, the effect of the outward leg and rein should be increased. At the corners, the oblique position of the horse and the pace should be retained; but as the croup is then following the wider arc, the outward rein is 
applied in order to shorten the steps of the fore legs, while at the same time the rider's inward leg keeps the hind legs moving at the same length of step as before; by acting thus, the fore and hind legs will take an equal number of steps; when the corner is turned so far that the horse is in oblique position to the adjacent side of the school, a stronger pressure of the outward leg will bring him forward and inward, thereby preventing the haunches from coming in contact with the wall or from flying outside the track.

In versing it may be useful now and thenespecially with horses inclined to cross their legs over too much (swerve sideways) - to make the horse advance a few steps on one trace straight ahead in the direction indicated by his oblique position, this being effected by equally strong pressure of both legs, slight easing of the reins and the rider's weight evenly placed; then again, by applying the versing aids, the horse is gradually moved out until his hind feet are on the track, and the versing is continued as before.

The versing influences are applied with horses that are inclined to press their shoulders outward just before a turning, as, for instance, in "turning corners"; versing is also the means of preparing the horse for the gallop.

When the versing is to cease and the horse resume his pace on one path, the word is given, "Forward-March!" The outward rein, assisted by the rider's inward leg, leads the horse's firehand gradually outward until fore and hind feet 
are on the same track, observing that the horse's head is not drawn outward and that the inward leg of the rider keeps the horse's hind feet on the original track; the horse should then be unbent and, by the pressure of both legs, he should be made to advance at the same pace as previous to the versing.

At the command, "Contraversez-March!" the horse is prepared in the same manner as in versing, only he is contra-bent* and his forehand is kept on the original track by the reins, while the rider's inward leg presses the hind quarters a short step in from the track, the rider's weight being outward. At the corners, in turns and on circles, the steps of the hind legs are slightly shortened, while those of the fore legs should be kept at their original length.

When the horse is to resume his pace on one path, the word is given, "Forward-March!" The outward leg presses the hind quarters gradually into the trace of the fore feet, otherwise the same as "Forward-March" in versing.

In traversing, the horse moves towards the same side to which he is bent by the pressure of the rider's outward leg, and in such a manner that the outward legs step in advance of the inward and the outward hind foot steps on a line with the outward fore and inward hind foot (Fig. 5I). According to whether the horse is bent to the same hand or to the opposite of the one to which

* The reader must bear in mind that the concave side of the horse is always named the inward or inner and the convex the outward or outer. 
the rider is moving, two kinds of traversing may be produced: traversing and renversing (i.e., contra-traversing).

Traversings are at first practised at the walk, later on at the short trot and the short gallop.

As a preliminary practice in traversing, the rider should guide his horse on to the great circle and collect him; by an increased feeling of the outward rein and a stronger pressure of the outward leg, the hind feet are brought a trifle in from the track of the circle, .on which the fore feet should remain. It should be practised only a few steps at a time.

On a straight line the traversing should at first be practised in turning diagonally across the school and at the command, "In travers, turn across the school-March!" The rider turns his horse in from the side as explained for "Turning diagonally across the school," but the bend of the horse should be retained after the turn is completed; by an increased use of the outward leg and rein, the hind quarters are then brought into a slight travers position (the horse being at most parallel to the long side) and, at the same time, by collecting the horse the pace is reduced. The inward leg keeps the horse up to the hand and, together with the outward rein, prevents him from stepping sideways too much. The inward rein secures the bend of the head and leads the horse in the oblique direction. The rider's weight should be carried inward, and his eye directed at the point on the opposite long side, to which 
the horse is guided; in approaching this point at a distance of one horse's length, the rider's inward leg presses the hind quarters out on the track of the fore feet, the bend of the horse is then changed and he is led off-in the same manner as described in "Turning diagonally across the school"-

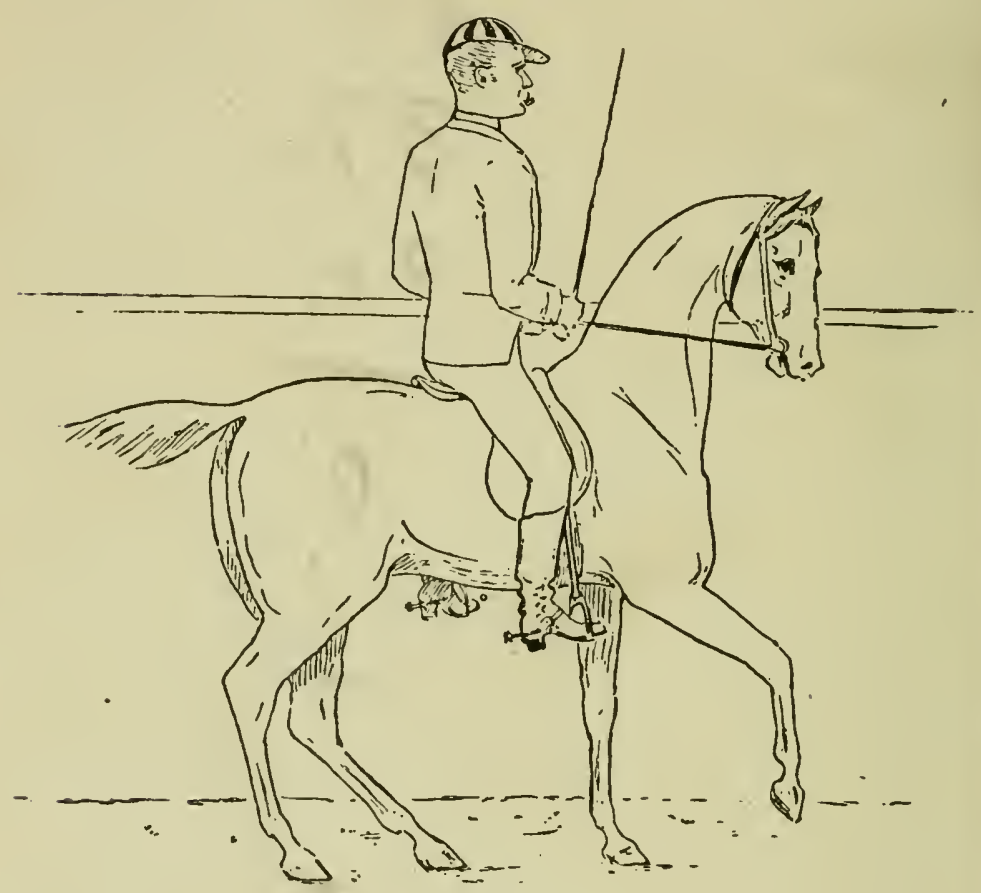

Fig. 5I

on one path out on the track by the wall, where the original pace is resumed.

Riding in class, each separate rider acts as above explained, but at the word, March! every horse should be collected, consequently the pace is reduced and thus retained until all the riders have entered on the track to the other hand and are 
moving at the side of the school, when the word is given, "Full pace!" All riders resume the original pace.

Traversing at the sides of the school or on the great circle is performed at the command, "Traversez-March!" At the word Traversez, the rider acts as directed for versing at the word Versez; at the word March, the outward rein is tightened, at the same time as the outward leg carefully presses the hind quarters a short step in from the track (Fig. 5I), otherwise the same as "In travers turn across the school."

During traversing at the sides of the school, the corners should first be turned like the arcs of a great circle, but as the rider makes progress, the horse should gradually be taken more into the corners until at last the horse's fore feet should be moving on the circumference of a small circle (see "Small Circles"), this being executed by shortening the steps of the hind legs by a stronger pressure of the inward leg, while the reins keep the fore legs moving at the same length of step as before and with the same number of steps as the hind legs, i.e., slight influence as if "turning on haunches." When the corner is turned, both legs press the horse's fore feet well out on the track, the outward leg keeping his haunches within.

When the traversing is to cease, the word is given, "Forward-March!" The outward rein keeps the forehand on the track, the inward leg presses the hind quarters gradually out on the 
track; the horse is umbent and the same pace is resumed as before traversing.

The so-called long-passade may be mentioned as a very useful practise in traversing. The rider being on one of the long sides of the school and approaching the corner, the word is given, "Longpassade!" When the corner is turned, the horse is moved over a quarter of a small circle towards the interior of the manège and is then put in traversposition to the same hand and parallel to the long side; thus he is led off to the middle point of the long side which was last passed; on arriving at this point of the track, the horse is unbent and moved on to the other hand where the same movements should be executed on approaching the next corner.

At the command, "Renversez-March!" the horse is contra-bent* and his forehand is brought in from the track by the reins, at the same time keeping the hind quarters on the track by applying the outward leg. When the forehand has been moved a short step in from the track, the rider brings his weight inward, and by the outward leg and the inward rein the horse is led off in the side-gait; the outward rein keeps the forehand inside the track; the inward leg keeps the horse up to the hand, and, supported by the outward rein, prevents the horse's outward legs from stepping sideways too much (i.e., from crossing over the inward).

* The reader must bear in mind that the concave side of the horse is always named the inward or inner and the convex the outward or outer. 
When the renvers is to cease and the horse to resume his pace on one path, the word is given, "Forward-March!" The horse's forehand is brought by the reins out on the same track as that on which the hind feet are moving, the outward leg keeping the hind quarters on the original track, otherwise like "Forward-March" from traversing.

The following should be observed as fundamental rules for the above described side-gaits:

I. Well-marked curving of the horse's body and close collection.

2. Slight but correct bending of the head, i.e., the bend principally from the poll of the neck.

3. Correct oblique position of the horse, i.e., as a rule not more than to make the inner (or outer) hind foot step in the print of the outer (or inner) fore foot, the fore or the hind feet remaining on the original track.

4. The rider's weight carried to the same side as that on which one of the horse's shoulders is in advance.

In order to illustrate the above mentioned side-gaits, the following form may prove useful:

\section{Versings.}

The horse is bent to the opposite side to the shoulder which is carried in advance.

Versing (Shoulder in).

Horse bent and shoulders in.*
Contra-versing.

Horse contra-bent and hind quarters in.*

* From the original track. 


\section{$-\mathrm{I} 82-$}

\section{Traversings.}

The horse is bent to the same side as that on which the shoulder is carried in advance.

\section{Traversing}

(Shoulder out).
Renversing.

Horse contra-bent and shoulders in.* quarters in *

In passing from one side-gait to another, the collected pace should be retained and the change may be executed, either by forehand and hind quarters changing track, or by only changing the bend of the horse, or even by both ways together, as for instance:

From versing to traversing. The horse's forehand is first brought out on the track by the outward rein and the inward leg, then the hind quarters are brought into travers-position.

From traversing to versing. The horse is pressed forward, and inward, by the inward leg on a wide arc until his hind feet are on the original track, when the forehand is brought into versingposition.

From versing to renversing. The bend of the horse is changed.

From traversing to renversing. The hind feet are first brought out on the same track on which the fore feet are moving, the bend of the horse is then changed, and the forehand is brought into renvers-position.

*From the original track. 
Similar combinations might be mentioned, but they may be all easily understood from what has been previously explained.

The greatest advantages are attained from "the side-gaits at the trot," and the rider who can execute them correctly is, with regard to the management of his horse, all right.

1. Closing travers, sometimes miscalled the passage, is a side-gait, in which the horse, without being collected, but bent as to travers, moves sideways parallel to his original position and in a manner that his outward legs step across and past his inward. Closing travers should only be practised at the walk* and a few steps at a time. This side-gait is used when the rider wants to move his horse from the stand a few steps to one side (see page I 28). Closing travers is practised in such a way that the rider, during traversing, by stronger outward rein and leg makes the horse move his haunches more sideways, i.e., he is brought into an accentuated travers-position; at first the shoulders should slightly precede the haunches; the rider's inward leg should be kept close to the horse's side, in order to prevent him from stepping too quickly to the side and thereby also preventing the haunches from preceding the shoulders. The rider must not move his seat too much inward, as that easily causes his body to lean outward.

When the closing travers is to cease, the outward rein and the inward leg are used, while the rider's weight is brought even on the horse's back.

* In High-School, also at the gallop. 


\section{Turning on Haunches.}

Turning the horse on his haunches may be executed at the stand as well as in motion, the horse, with one hind leg as centre of rotation, circling the three other legs around. These turns are first practised at the stand and, as turnings on the forehand, only one step at a time with halt between each step. Turning on haunches must never commence with backing, but rather with an inclination to advance. While in motion, the turns should at first be made at the same pace in which the horse is moving; later on more quickly; when finally the horse-as it is called-is whirled about. The object of the turn decides its circumference. Turning on haunches should be practised about the same time as "Turning on Forehand with Horse's Head Bent Sideways" is commenced, although it can not be accomplished satisfactorily until after the practising of travers has been carried out.

During practical riding* and as means of making narrow turnings, the turns on haunches should be mostly used, because they are as easily performed at the stand as in motion; they may be done slowly or quickly, and-what is of no less importance-they transfer the work of the horse and the weight of horse and rider to the hind quarters of the horse by the extreme collection which they require. Only with horses that have very weak

*We may say that riding consists of school-riding and practical riding; the latter being the application of the experience acquired in school. 
hind quarters, and where the circumstances do not justify turning on haunches-for instance when there is an obstacle just in the rear of the horsethen turning on forehand should be used.

At the stand.* As useful practice in turning on haunches a turn about ( $\frac{1}{2}$ circle) should be made in 6 steps on the command, "On haunches, right (or left) about-March!" At the words On haunches right (or left) about, the horse is collected and bent to the right (or left). At the word March, the horse is pressed as if to advance, then the forehand is circled round by the inward rein and by the rider's weight carried well inward and backward; the outward leg and rein preventing the haunches from flying out. The outward leg and rein should be applied chiefly at the last part of the turn, as the haunches are then most liable to fly out; the inward leg prevents the haunches from pressing inward and the horse from backing; the outward rein regulates the quickness of the turn and halts it.

It is advisable, at first, to let the hind quarters participate slightly in the turn, i.e., the hind feet should be moving on a narrower circle than that on which the fore feet are moving, and this is what is called a travers-circle.

In motion. When the horse is well collected and bent to the side to which he should turn, a momentary halt is made on his inner hind leg by a short taking on the outward rein; while keeping the inner hind leg in place, the other three legs

* Should at first be practised on the track (by the wall). 
are circling round at the original pace (or at an increased pace); the same aids and rules are used as "at the stand." When the turn is completed, the pace should be continued in the new direction and without interruption.

Turning on haunches while in motion may be practised at the walk, the collected trot, and the collected gallop.

\section{Diminishing and Resuming the Great Circle.}

In diminishing the great circle, the horse is caused to leave the circumference and move inward on a spiral towards the centre. In resuming the great circle, the horse is caused to move in a similar manner outward from the centre until resuming the track of the great circle. As a rule, the great circle should not be diminished further than to bring the horse in on a circle, concentrical with the great circle and of the diameter of two horse's length; the paces to be ridden on such a small circle being only the walk, the short trot and the short gallop. These practices, which can only be executed correctly after the teaching of side-gaits, will make clear to the rider how he should act in preventing his horse from pressing outward or inward during turnings. At the command, "Diminish the circle-March!" the horse is gradually brought in on the smaller circle by increased use of the outward leg and inward rein and by the rider's weight carried more inward. The inward leg keeps up the pace and prevents the hind 
quarters from getting in travers-position, the same leg keeps the horse's body curved to the inner side and makes him light on the inner rein; the outward rein prevents the shoulders from preceding the haunches or in other wordsprevents the horse from taking versing-position.

When riding in class with 4 steps' distance between the riders, the great circle should be diminished by all riders at the same time and until each following rider is I step's distance from the one in front. When the class is riding with I step's distance between the riders, the same distance should be retained in such a way that each following rider commences to diminish the circle at the same place as did the leading rider, who commences at the word March.

When the horse is to resume his place on the track of the great circle, the word is given, "Enlarge the circle-March!" Continually keeping the horse bent to the inner side, he is gradually brought outward until he resumes the track of the great circle, this being effected by a stronger use of the inward leg and outward rein, the rider's weight carried outward.

When riding in class, and the great circle having been diminished while riding at a distance of 4 steps, the same distance should gradually be resumed by all the riders moving their horses outward at the same time; but if the great circle has been diminished while riding at a distance of I step, this distance should be retained during the enlargement of the circle, by the leading rider 
commencing the movement, and the others following precisely in his track.

In order to teach the horse and the rider to observe the influences of legs, reins and weight more accurately, diminishing and enlarging the circle may be executed with the horse at one or another of the side-gaits; for instance, the great circle may be diminished at the travers until the hind feet have reached the centre, where a turn about on haunches maybe executed, the bend of the horse changed and, without interruption, he may be moved outward in travers-position to the other hand. In versingposition the great circle may be diminished until the horse's fore feet are on the centre, where a turn about on forehand may be executed, the bend changed and the horse moved outward in versing-position to the other hand.

\section{Small Circles.}

A small circle of the diameter of 2 horse's length is made from the side of the school at the command, "Circle-March!" and is ridden towards the interior of the manège; the circle is discontinued, when the horse has reached the place where the circling began. When the side-gaits and diminishing and resuming of the great circle have been taught, the small circles are practised; they are executed by the same means as the great circle, but, naturally, with more marked bending of the horse and increased aids in circling; when the circle is completed, i.e., when the horse 
returns to the spot at which the movement began, he should then be unbent and led off at an unchanged pace and in the same direction as before the circling began. Small circles may also be made from the track of the great circle and from the middle line of the school; they should only be ridden at the walk, the short trot and the short gallop.

When riding in class, it should be strictly observed that all riders make circles of equal size, which may be ensured by each individual rider observing the dressing, which should be taken up to the side to which the rider can see without turning his head, i.e., when moving on the first quarter of the circle to the leading rider, when on the next two quarters to the rear rider, and finally again to the leading rider when on the last quarter.

On the first quarter of the circle the horse is inclined to turn too abruptly, which should be prevented by the outward rein and inward leg. At the next two quarters he will generally not turn sufficiently, which may be remedied by the inward rein and outward leg. At the last quarter of the circle, the horse is inclined to press inward and take the shortest cut towards the point where the circling began, and even go past it; this should be prevented by a stronger use of the inward leg, which also keeps up the pace, which then generally becomes sluggish.

When, in riding on a small circle, the horse is to be changed to the other hand, the word, "Change!" is given. After completing a semi- 
circle and arriving at an oblique position (see page I66, Fig. 49) to the original track, the horse is led off on a straight line by the outward rein, the inward leg, and the rider's weight carried evenly; the bend of the horse is then changed, and he is turned to the other hand out on the original track, unbent and moved on at an unchanged pace in the other direction.

While small circles are of little or no use in practical riding, the semi-circle may frequently be made use of. In the school, the semi-circle is practised at the command, "Semi-circleMarch!" and is performed by the rules for small circles, but when the semi-circle is completed, the horse should be led off on a straight line, parallel to the side of the school from where the semicircle began and, when arriving at the side in front of him, the rider turns his horse to the same hand to which the semi-circle had been made and continues along the track by the wall.

If a semi-circle be made on the track of the great circle, the horse should, after finishing the semi-circle, be changed and led off to the other hand on a circle concentrical with the great circle and at a distance of two horses' length from its circumference, i.e., on a diminished great circle to the other hand, from where he may again be brought out on the track of the great circle to the original hand at the command, "Right (or Left) semi-circle-March!" the same command being used when a semi-circle is made from the middleline of the school (see page I 28 ). 


\section{The Gallop.}

The practical use of the gallop (see pages I I 5 , I 20 and $\mathrm{I} 2 \mathrm{I}$ ) is to improve the rider's seat, to collect the horse, to make him advance more rapidly, and to prepare him for obstacle-riding.

When the rider can work his horse fairly well in the side-gaits at a trot, the gallop may be commenced.

In galloping, the rider must not allow himself to be thrown up and down, but his seat should be gliding imperceptibly with the motions of the animal, without causing his body to sway to and fro. In order to preserve a steady seat at the gallop, a straight but unrestrained position of the body and a correct position of hips and thighs (see pages $9 \mathrm{I}$ and 92 ) are essential.

In order that the rider may know, without looking down at the horse's fore legs, whether his horse is galloping on the right foot or on the left, he should pay special attention to the different motions he feels, and which are caused by the two kinds of gallop. When the horse strikes off correctly, i.e., in the gallop, for which he has been prepared, the rider's outward seatbone chiefly is rubbed against the saddle, his seat is apt to slide outward and his inner leg to move upward and forward at each new gallop-stride. In order to prevent any such faults in the rider's position, he should bring his weight well inward and backward, while pressing his inwärd shoulder, hip, knee and heel downward and backward. 
Cross-gallop (see page I 2 I) causes a singular wriggling sensation in the rider's seat, which, when once experienced, is not easily mistaken.

At first the gallop should be executed on the great circle and from a short and collected trot, when a firm feeling of both reins, especially the outward (without drawing the horse's head outward), in the direction of the rider's outward hip, will cause the horse's outward shoulder to be somewhat kept back, while at the same time a collecting influence of both legs, especially the outward, will make the horse bring his weight over on his haunches (outward hind leg); then a stronger and short pressure of the inward leg will seldom fail to make the horse lead with his inward leg; the rider's weight being then mostly on the inward hind leg. In this manner, the horse being collected by degrees until he can no longer trot, he is forced to raise his forehand as if to a leap, i.e., to strike off in a gallop; the reins are then eased sufficiently to enable the horse to complete the leap by the spring of his haunches, when a continued light feeling of the reins and pressure of the legs should keep up an even succession of leaps, which means a cadenced pace. The outward leg and rein prevent the horse's haunches from being thrown out, as otherwise his outward shoulder might get in advance, and he would strike off in a wrong gallop; the inward leg prevents the haunches from being thrown more in than to allow the outward hind foot to follow the prints of the inward fore foot. When the horse is confirmed 
in the short collected gallop, the hind feet should follow the track of the fore, thereby causing the animal least strain. If a horse strikes off in a wrong gallop, he should be pulled up and again brought to the trot (see pages I 34 and I35), when the aids for the correct gallop should be repeated. If the horse goes into a cross-gallop, he should be brought to the trot, if he gallop false on the hind feet; but if he gallop false on the fore feet, he may be pressed well forward at the gallop (by pressures of the inward leg), when, as a rule, the fore legs will change.

If a horse, in galloping, breaks into a trot, the rider must not be in too great a hurry to try and resume the gallop, as it will generally result in the animal being chased into a hurried and, most frequently, wrong gallop. By keeping up a quiet trot and gradually collecting the horse, as if it did not concern the rider whether the animal trotted or galloped, the fault will be soon remedied, and replaced by a quiet and correct gallop.

If a horse, in galloping, dashes along too fiercely, avoids being collected, stretches his neck and head forward, leans on the rider's hand and is inclined to rush into a hurried trot, then halfhalts with raising tensions upon the reins and a moderate pressure of the legs are applied; this being of no use, a complete halt is made and, if needed, the horse should be backed until he yields to the hand, when his balance is re-established by bending and collecting at the stand.

13 - Handbook for Riders. 
This being completed, he is made to advance and once more prepared for the gallop.

Horses that are apt to move at the "halfgallop" (see page I2I) are put into a trot, and by strong aid of the legs the haunches are brought more under, while slight takings on the reins are applied in order to prevent the fore legs from galloping before the balance of the horse is reestablished.

The gallop should not be practised at too slow a pace in the early lessons. An easy gallop without any tendency to rushing will prove to be of greatest advantage to the beginner in riding, and also in the breaking of horses.

To pass from the gallop to the trot, apply a short feeling of the outward rein, while, at the same time, discontinuing the aid of the legs for galloping. As soon as the horse trots, he is forced to the bit by the pressure of both legs, especially the inward. Having gone through the above described lessons, frequent varying of trot and gallop should be practised on the great circle and to both hands and, when sufficient skill has been attained, the horse should be led off at the gallop from the great circle on to a straight line at the command, "Straight on-March!" In order that the gallop may not be deranged or come to a trot, care should be taken in using the reins at the moment the horse is led off on the track by the side of the school, the rider's weight and inward leg being the principal aids. In turning diagonally across the school at the gallop, when within 3 or 
4 horse's length of the opposite side of the school, the horse should be brought to the trot, the bend changed, and, when his fore feet arrive on the track by the long side, the gallop should be resumed to the other hand.

The gallop is then gradually collected and shortened, this practice being at first executed on the great circle and by simultaneous use of reins and legs at the moment the inner fore foot is planted; as soon as the horse's forehand is raised to the next gallop-stride, the reins are eased a little, when a repeated use of reins and legs will bring the haunches under and raise the forehand to the succeeding shortened gallop-stride, and so forth.

When, through the previous lessons on the great circle, the rider has been taught with ease and certainty to pass from the short collected trot to the short collected gallop, the same is practised on straight lines by bending the horse according to the gallop that should be performed; for instance, the horse being on the long side of the school and moving to the right hand at the trot, he should be made to gallop on the right foot, but, before arriving at the next corner, he is brought to the trot (which should be short and collected); when arrived on the other long side, the bend of the horse is changed and he is made to gallop on the left foot, and so forth, always bringing the horse to the trot upon approaching the corners. When the rider has been sufficiently prepared by this practice, the gallop may be changed more 
frequently by shorter intervals of trot, but still always on the long sides.

To pass from the collected gallop to the walk, the word is given: "Walk-March!" By applying half-halts, the horse is brought to a closer form of collection, and, the moment his weight is carried mostly on his hind quarters, i.e., when the forehand is raised, the rider may bring him to a momentary halt by leaning back and by using a light and short tension upon the reins, but at the very moment the horse's fore feet are brought to the ground, he must be made to advance at the walk by the pressure of both legs.

To pass from the walk to the collected gallop, the word is given, "Short gallop-March!" This practice should be executed first on the great circle, when at the command Short gallop, the horse is collected. At the command March, he should be pressed into the gallop by a somewhat stronger aid of the legs than in passing from the trot to the gallop. Being on the side of the school and receiving the word Short gallop, the horse should, besides being collected, be bent to the inward side.

To take the collected gallop at the stand, the horse is bent for the gallop that he is intended to take, and is so closely collected that the forehand is raised a trifle from the ground, when a slight easing of the reins and increased pressure of the legs will make him throw his forehand forward into the gallop-stride. As a rule, the horse should 
first be led off one step at the walk, before striking off into the gallop.

To halt from the collected gallop is executed in a similar manner to passing from the collected gallop to the walk; but at the moment the horse's fore feet are brought to the ground, instead of making him advance, the rider's legs should only be applied sufficiently to prevent the hind legs from stepping back, while the tension upon the reins should not be released more than to make the horse take the position of balance at the stand.

To pass from one gallop to another, i.e., changing the lead should, as previously described, first be executed by an interval of trotting steps* during which the horse should be kept closely collected and his bend changed for the new gallop. As the rider makes progress, these trotting steps are gradually reduced until one such step proves sufficient-thus preparing the horse for the immediate change, i.e., changing $\grave{a}$ tempo, when the change is completed in a gallop-stride without breaking the cadence. In the last gallop-strides, before changing a tempo, the horse must be closely collected, but gradually; the bend of the horse should be diminished by degrees in order to facilitate the changing of the bend, and as the horse raises the forehand to the last stride before the change (brings his inner hind leg under him) the rider applies a light half-halt, and, when the horse's inner fore foot is planted, his bend is changed and

* May also be done at the walk. 
the rider's weight brought quickly over on the new inner hind leg, the aids for the new gallop being then applied and the gallop-change will ensue as the next stride begins. While changing the bend of the horse, the outward rein (which will be the new inward) works with a short tension, the inward rein (which will be the new outward) works with a more passive tension; the new inward leg works with a short, easy pressure, the new outward should not be thrust into the side of the animal but slide' with even pressure to its new place.

To pass from the collected to the extended gallop, the pace is gradually increased by stronger pressure of the legs, especially the inward, and by releasing the tension upon the reins, thereby giving more freedom to neck and head but still keeping the horse up to the bit. The bend of the horse should be diminished, and he should not be so closely collected as in the short gallop.

Unless the ground be in very good condition, the extended gallop cannot be practised safely with extreme rapidity in the riding-school.

To pass from the extended gallop to the walk should not be done abruptly, as it would cause too much strain on the legs of the horse, and for this reason the gallop should be shortened by degrees, then changed into the trot before passing into the walk.

When the previously described practices in the gallop can be accomplished with certainty, the rider may be exercised at the gallop in dimin- 
ishing and resuming the great circle, change in crossing the great circle, turnings across the school and in riding on small circles; finally precision in turning the corners should be demanded.* An increased use of the outward rein and the inward leg, at the same time securing the bend, are the means of taking the horse into the corners.

Supposing a horse, in moving to the right (or left) around the school, be ridden in the gallop left (or right), it is called contra-gallop. As, in galloping on straight lines, it is immaterial whether the horse be in gallop right or in gallop left, the term, contra-gallop, can, in practical riding, only be used when galloping on curved lines. In practising the contra-gallop, the balance of the horse will be improved and it will teach him to turn to the right (or left) when in gallop left (or right), and to do it with ease and safety, i.e., without losing his bearing and without any disturbance of his pace; it teaches the rider, furthermore, to accommodate himself to the motions of the horse, and to apply the aids in harmony with the actions of the horse.

Contra-gallop demands a closer form of collection than the ordinary gallop, and it requires also a great deal of suppleness on the part of the horse, especially in short turns, as he is turned to the opposite side to that to which he is bent. In the turns, the inward leg and the outward rein should be active and well timed; the horse should

* In the earlier lessons, while practising the gallop, the corners should be well rounded, otherwise the pace is apt to become hurried. 
be prevented from throwing his haunches to the gallop-side by applying the aids as if bringing the horse forward and outward on the curve.

At first the contra-gallop should be taught in the following manner: the horse being in gallop right, and moving to the right on the long side of the school, a half turn is made from the side; on arriving at the opposite long side the same gallop should be continued in moving to the left, the forehand being kept slightly within the track by the inward leg and outward rein.* Before turning the corner, the horse should be brought to the trot or the gallop may be changed; but with some practice in preserving the gallop unchanged in passing over to the other hand, the horse should also be ridden in the contra-gallop at the corners.

Turning on haunches at the gallop is practised in the easiest manner by executing the previously explained long-passade (see page I80), the horse being then kept in a marked travers-position during the turning in from the corner. By gradually diminishing the circle, the horse may finally, with his inner hind leg remaining on the spot, be wheeled round in the gallop at the moment his forehand is raised from the ground; but it is necessary that the gallop be ridden very short, and that the horse be closely collected. When the turn is completed, the lead of the gallop may either be changed or the horse may be made to advance in the same gallop as before the turn (i.e., in renversgallop), in the latter case the turn should cease as

*The concave side of the horse being the inward. 
the horse comes into renvers-position to the other hand; but in either case the gallop should be continued without any interruption.

The passade is a half turn on haunches at the gallop (so-called half pirouette) and with an immediate change of lead ('a tempo) when the turn is completed. This practice should be prepared for by first riding a small circle with the horse in travers-position at the gallop, and Change!

\section{Obstacle Riding.}

The means and the manner in which to pass any obstacle presenting itself to the rider, when practising outdoor riding, should in some measure be known to every rider and be taught to all kinds of riding horses, thereby preventing a pleasant ride from coming to an abrupt ending; it is not necessary, however, to be able to jump an obstacle 7 feet high.

Besides teaching the rider how to keep going with his horse wherever there is a chance, obstacle riding is also the means of still further securing the rider's seat and balance at unexpected plunges and movements of the horse, as for instance, bucking, uncontrollable lançades, rearing, kicking, etc.

Obstacle riding should commence at an early stage of the riding lessons, but not until the rider has got a safe and fairly correct seat at the trot. In the riding-school it must be restricted to high and broad jumps, but later, during outdoor riding, it should be made to include obstacles of every kind. 
The first condition, necessary for passing an obstacle, is that the rider will get over, i.e., he must not in the least doubt that he will succeed, as his doubt will invariably be transmitted to the animal, and the outcome may then be easily guessed. Naturally, the horse must not be put to anything that neither he nor his rider can manage; rashness is in most cases as objectionable as want of pluck.

Obstacle riding may be practised at every pace, which, however, should be adapted to the nature of the obstacle; at the gallop at full speed, the horse should be taken in and collected before he is made to jump.

To leap at the stand (the standing jump) should not be made unless existing circumstances demand it, as it is disagreeable to the rider and injurious to the horse, that is, if the obstacle be of any considerable size.

If the obstacle is taken at a leap, the horse moves his legs much the same as at the carrière, the leap being commenced by a simultaneous raising of both fore legs and jointly taking off with both hind legs; as the horse is grounding, he throws himself forward on the far extended fore legs and brings the well-bent hind legs far forward, by which all four legs may be planted almost at the same time, which is most agreeable to the rider and causes the least strain to the animal's legs.

The rider should, as a rule, not influence the horse too much when just in front of an obstacle, leaving the choice of manner in which to take it 
almost entirely to the animal; but in most cases the horse should be somewhat collected when at a few horse's lengths from the obstacle. In passing the obstacle, the rider should be as passive as possible, keeping the upper part of his body, his shoulders and head well back, his arms to his sides and his legs close to the sides of the horse. Tugging on the reins, standing in the stirrups and raising the seat

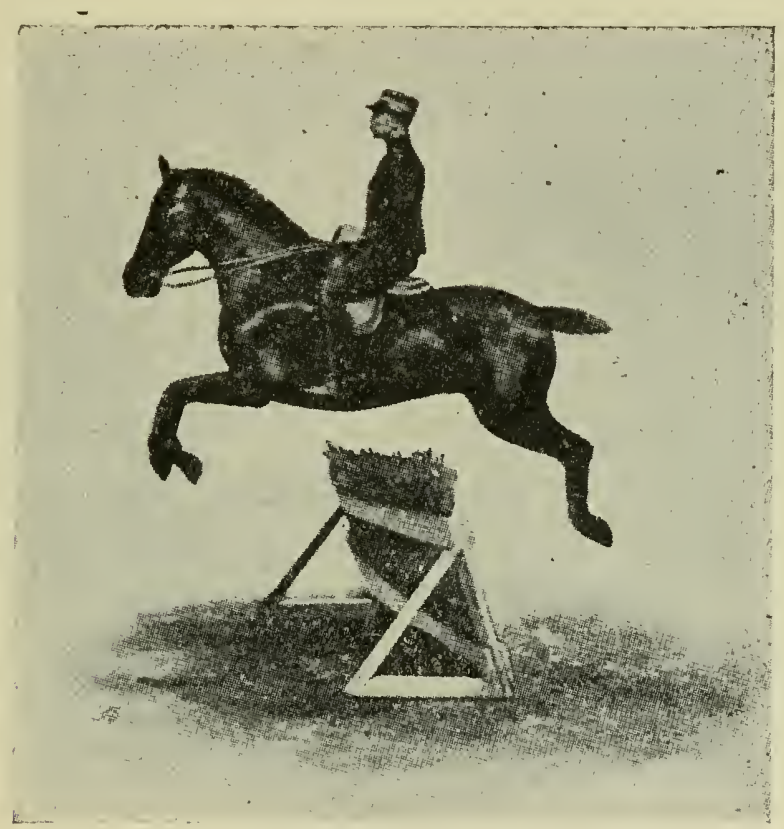

Fig. 52. THE VERTICAL SEAT.

may prove fatal to the horse as well as to the rider, as in acting thus the horse is easily prevented from clearing the obstacle, or his forehand is too much loaded and the rider unable to sustain the horse with reins and legs as he grounds; the consequence being that the horse either falls with the rider or 
that the latter gets injured in some other way. In grounding the rider must, therefore, keep his body erect and support the horse with legs and reins without checking him violently.

As a matter of fact, there are permissible variations of the jumping seat, according to the nature of the obstacle and the ground, the rider's

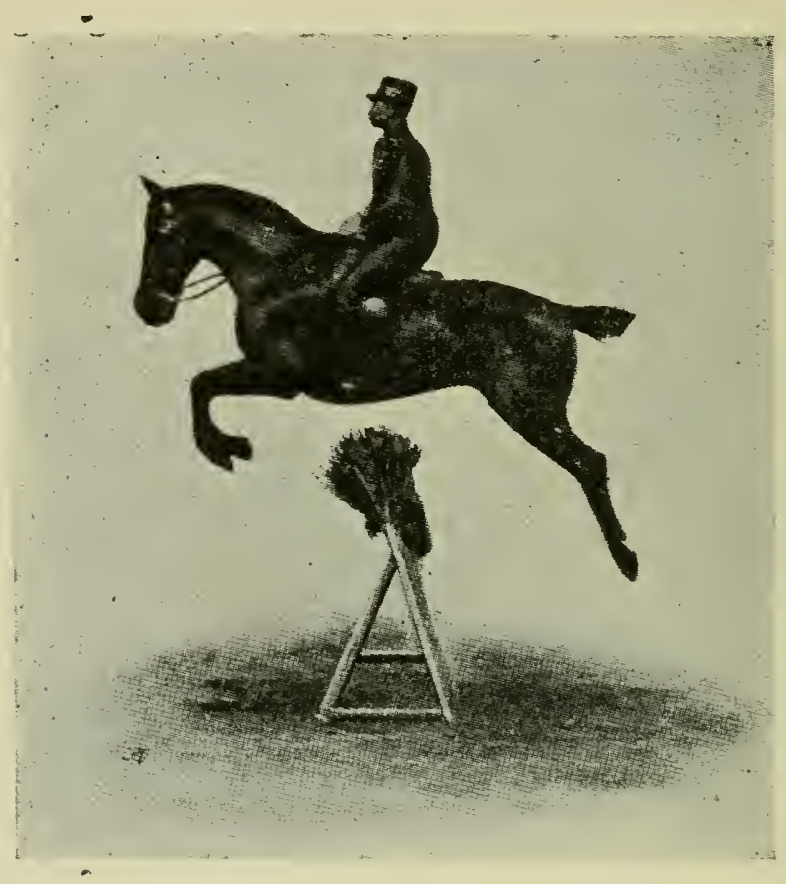

Fig. 53. THE LIGHT SEAT.

Also Illustrating One of the Three Phases of the Vertical Seat.

skill, or the structure of the horse and also the speed. Any devil-may-care sort of a rider can dash at an obstacle, regardless of his own and the animal's balance, leaving the outcome to good luck; but this is not correct horsemanship, for, if 
the horse should happen to make a mistake in the jump, the rider must be prepared and know how to correct it in the best possible way, and keep a cool head.

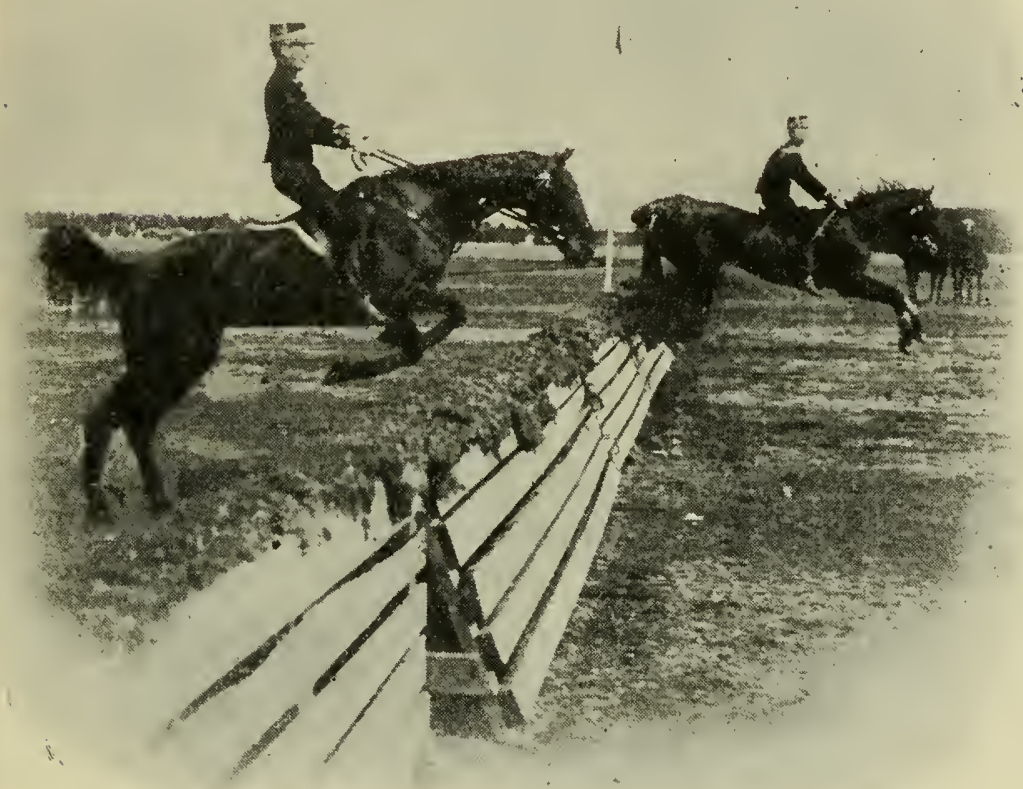

Fig. 54. AN EXTREMELY LIGHT SEAT.

The Obstacle Being Very High (the Boards, Five Feet, with Brush), and the Horse Taking Off Far from the Fence.

During the leap the vertical, the light or the deep seat may be used.

The vertical seat is mostly used and it is the safest on unknown ground (Fig. 52).

The light seat (Fig. 53) differs from the vertical 
one by being raised just sufficiently to clear the saddle; the seat should be moved well forward under the rider, the body slightly forward; the weight of the rider distributed on thighs, knees and stirrups. This seat is used with horses that have weak back and hind quarters, with horses during

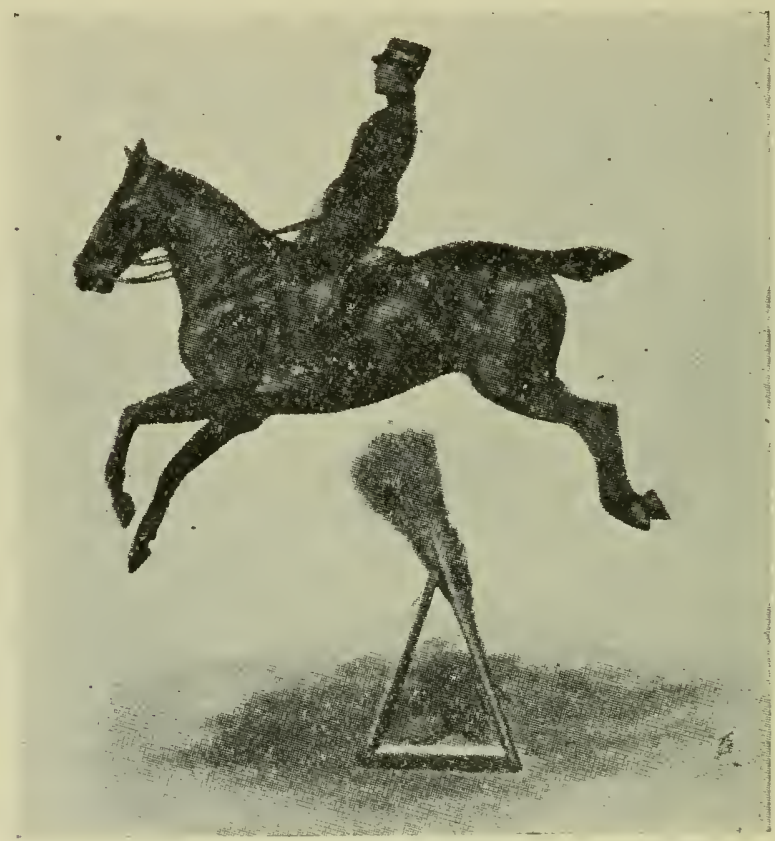

Fig. 55. THE DEEP SEAT.

Also Illustrating One of the Three Phases of the Vertical Seat.

the first breaking and in very high jumping in order that the hind legs in the downward leap may not be caught, but be set free to place themselves forward and under the horse. When the horse takes off too far from the obstacle (Fig. 54), jumps from the spot or leaps upward, this seat is also practicable. 
The deep seat (Fig. 55) is used with horses that need to be urged towards the obstacle, or that, in the downward leap, hold their hind quarters very high or that are apt to stumble. For leaping in the depth this seat should also be used, besides that, it should, as a rule, be applied by ladies when riding in side saddle (Fig. 6I, page 294).

The vertical seat must by thorough-going practice be confirmed before the rider is taught to adopt the light seat.

When passing obstacles, the reins should, as a rule, he beld in both hands.

The rider should not look down on the obstacle, but straight ahead past it.

If a fall be unavoidable and the rider has done all he can (in a correct way) to avoid it, and there comes a moment (but mind, there is only this one moment at his disposal) when he feels that all further attempts are unavailing and that he has to look out for his own safety-then he must be quick in making every joint in his body pliant, in releasing his feet from the stirrups and his legs from the sides of the animal; furthermore, he should lower his head, curve his back and draw his knees up towards his chin, not warding off the fall with outstretched arms-a somersault or two may then be the only consequence. The rider should try to keep the reins.

I have experienced this myself, as once in an Officers' steeplechase my horse, after passing over a fence, slid in a pool of water (it had been raining) 
and-all my efforts to keep him on his legs being in vain-finally fell, sending me in a somersault over his neck, landing on my feet just in front of the fallen horse and facing the same way I had been riding. I was none the worse but for a broken spur. The horse got a yawning wound in the fleshy part of his chest from the immense pressure of this part scraping against the ground, as I was trying to raise the drooping forehand or to prevent the animal from turning a somersault.

On the other hand, in "losing the right moment" or "not feeling the approach of it" (for there is very little time for thought) and thus trying to mend what an able rider should feel to be irreparable, the consequence is more likely to become fatal, as the rider, in his efforts to restore the lost balance to the animal, keeps his body and limbs too long in their supporting position and in applying the aids. When thus the erect rider receives the sudden concussion from the animal's fall on the ground, he will generally be sent forward, landing with his face downwards; then, if the speed of the animal has been considerable, the rider's body may continue the somersault-like movement and, if unlucky, he may injure his spine or even break his neck "in the reverse way."

If the horse rushes heedlessly at the obstacle, without the rider being able to prevent it, he should be given the reins in order that he may look before him and his attention to the obstacle not be diverted by the rider's influences, otherwise a wrong leap may easily ensue. 
When the horse jumps in proper style with elastic action of the back, he strains himself and the rider least; on the contrary, if the horse jumps with sunken back, high neck and the nose upward, the jump will become uncertain, his legs and back will be strained and an unpleasant and hard thump will be inflicted upon the rider at the grounding.

In a correctly executed leap, the horse "floats" over the obstacle, the back of the horse is perceptibly arched up into the rider's crotch, and after the downward leap the horse will continue the gallop without delay.

A properly ridden horse, trying to turn aside in front of the obstacle or refusing "to take it," should always be turned back towards the obstacle from that side to which he tries to turn; if merely refusing, he should be placed at a right angle to the obstacle and backed, then again urged forward.

A well broken and well ridden horse should invariably clear the obstacle without any mistake in front.

The horse will soon learn to estimate the size of the obstacle and not to take a longer run than needed before leaping, and when he has attained these abilities he may be considered safe and certain in clearing obstacles; but, in order that he may acquire such accomplishments, he should at first be led and ridaen at the various paces over a bar lying on the ground, till he goes willingly. By degrees the bar should be raised and the same method repeated, until the horse can no longer walk and trot over it, but must take

I4 - Handbook for Riders. 
it with a leap, after which he is only ridden to obstacles.

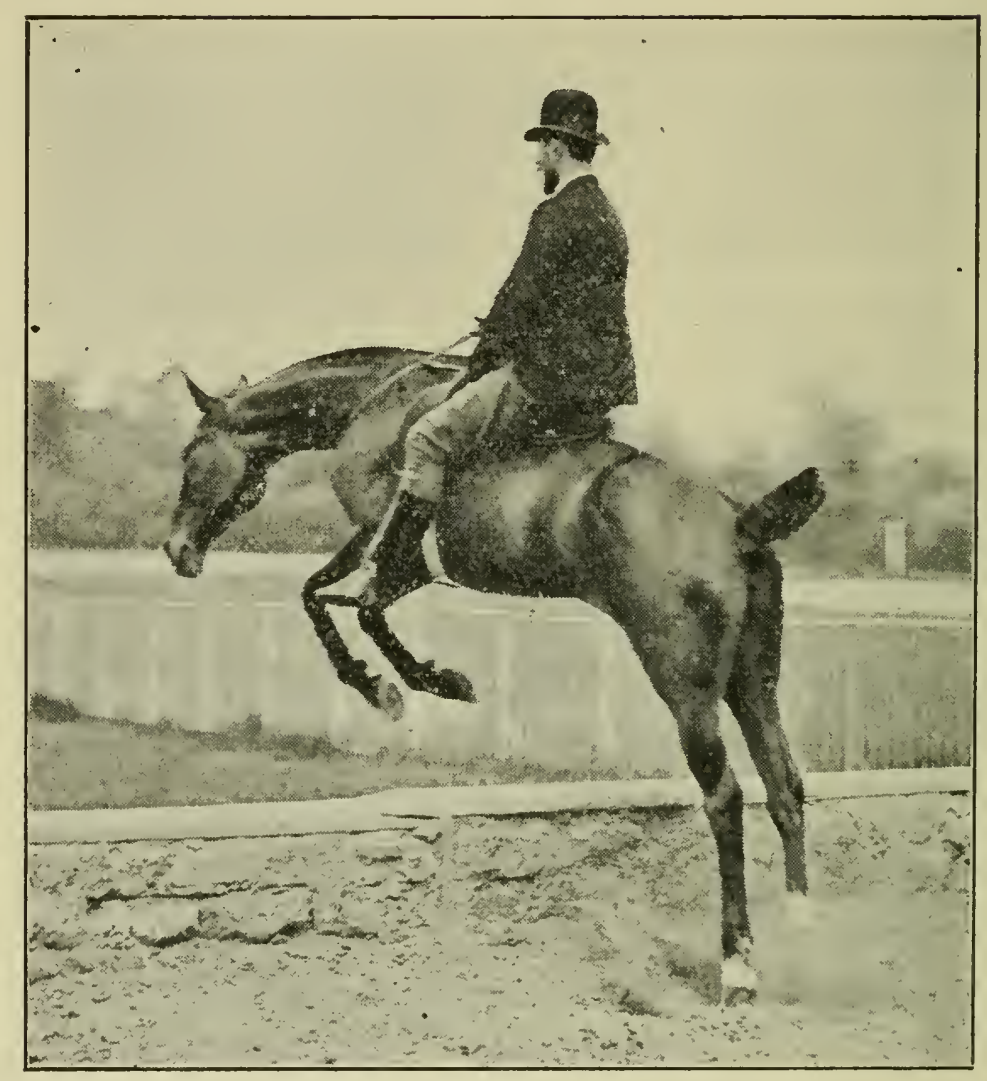

Fig. 56.

It is advisable to give the early lessons on the longe.

The best results are attained by going slowly to work, until the rider has gained confidence. Beginners, being apt to sustain themselves by the reins, should be allowed to take hold by the mane or, where no mane is, by the head of the 
saddle without leaning forward (Fig. 56), the reins to be placed on the horse's neck; gradually the rider loosens his grip and, finally, he lets his arms hang straight down, or places his hands on his hips. This mode of proceeding will prove the surest way to impart a safe seat and a correct position, and also in preventing the horse from making any misstep. For this purpose, a steady and quiet school-horse is required, and at first he should be led up to the obstacle or held on the longe.

The commonest faults during obstacle riding are:

I. In facing the obstacle, the horse does not go straight at it,

2. taking the obstacle too violently or insufficiently,

3. the grounding does not occur with fore and hind feet about at the same time, and

4. after the grounding the pace and the direction are not kept the same as they were in facing the obstacle;

for these reasons:

I. The horse should be kept at an unchanged pace (adapted to the size of the obstacle) and straight for the obstacle,

2. be collected in front of it,

3. be given his head sufficiently to enable him to estimate the size of the obstacle, and in order not to prevent him from raising the forehand, 
4. be sustained by the leaning back of the rider's body and by reins and legs in securing a correct landing, and finally,

5. be given the reins and aided by the legs sufficiently to continue at the same pace and in the same direction as before leaping.

In order that the rider may learn to take such measures, the placing of the obstacle should at first be chosen in a way that the practice may be executed on a straight and not too short line.

To leap the bar, some round poles, about 5 yards long, are used, and one or two of them should be wound around with a straw-rope or covered with canvas stuffed with some soft material in order to prevent injuries to the horse's legs, should he knock against them. At first a bar is placed on the ground, across the track at the middle of one of the long sides of the school, and passed over, as previously explained. The most practical method of raising the bars is to provide them with an iron peg at one end, having iron-clad holes at certain intervals in the wall for putting in the pegs; the other end of the bar should then be placed on removable slots that are put into the holes of a removable upright, placed on the ground at a distance answering to the length of. the bars, the covered bars always being placed at the top and level. For high jumps, a contrivance, made of two boards nailed together so as to leave a narrow space between them for the placing of twigs, may also be used, the ends of the boards 
being put on two uprights like the one previously described.

In the riding-school, broad jumps are not easily arranged, ditches being most suitable for the purpose. A broad piece of canvas, painted the colour of water, and at each end fastened to a tick roller, may, in some way, replace the want of ditches; so may also a hurdle laid flat on the ground.

At broad jumps, the horse is generally allowed to take a freer run than in high jump, and for that reason he is not collected so closely as in the latter.

A double obstacle means two obstacles placed so close to each other that there is no more space between them than for the first downward leap and for taking off to the next leap.

Compound obstacles are broad and high obstacles combined, where the latter may either be placed in front of or behind the former.

In England, where such obstacles in the shape of a bank with a ditch on either side are frequently met with, the horses show wonderful cleverness in jumping upward over the first ditch and by "topping" the bank with their hind feet, in order to bring themselves forward over the next ditch.

Obstacles of obedience are those that yield absolute obedience to the rider; they are made short, of no considerable height and of an appearance that makes the horse suspicious; for instance, benches, wooden boxes, tables, chairs, etc., which, in addi- 
tion, may be made more obvious by covering them with rugs of conspicuous colours, newspapers, or anything of the kind that might arouse the animal's suspicion.

To such obstacles the horse should be ridden at the collected walk, trot or gallop, and he should not be let out before at the last moment when he tends to take off.

Naturally the gallop, being the most advantageous gait for jumping, should always be used at obstacles of any considerable size.

In the riding-school jumping should invariably be practised to both hands and in gallop right and left; thus, for example, it may be executed on straight lines by the leaps being taken alternately in gallop right and left, or, having finished once around to one hand, the same being executed to the other hand, the gallop to be changed from what it was at the first round.

It has been said elsewhere in this chapter that the pace should be the same before as after the leap has been accomplished; if, for example, the horse takes off from gallop right he should normally land first with his left fore foot, quickly followed by the right fore, the latter generally being placed somewhat in advance of the former, the rider thus securing the gallop right to be continued (Fig. 55).

\section{Rising to the Trot.}

This manner of trotting tends to spare both the horse and the rider, as the latter only alights on the 
saddle at every other step. This method of trotting should be used in outdoor riding, but in the ridingschool only during the practising of it; and with horses that have a weak back. Even persons in delicate health may benefit by riding when using this mode of trotting.

In rising to the trot the rider remains, as it were, floating over the horse's back, as at every other step he rises and during the intermediate step keeps himself aloft, and, at the planting of the same pair of diagonal legs on which he first rose, he alights pliantly in the saddle, just touching it and immediately again rising from it.

When the practises previously explained are gone through, and the pupil has acquired the accomplishment of lithely and pliantly yielding to the motions of the horse at the trot and the gallop, rising to the trot may be practised. It is advisable first to execute the raising movement at the walk, as the rider at the planting of one fore leg* rises slowly by slightly closing his thighs and knees and by a trifling support of the stirrups; by a springy resistance of knees and ankles the rider remains aloft during the following step and then descends lithely upon the saddle and rising again at the next planting of the mentioned fore leg. At the trot the raising movement of the rider commences simultaneously with the stepping forward of two diagonal legs and always on the same pair of legs. The rising itself is executed by moving the hips upward and forward, thereby causing the seat-bones to be

* i.e., at the moment when its diagonal hind leg shoves off. 
mostly raised, though not more than needed. The rider should, as much as possible, refrain from leaning forward and curving his back, moving his seat upward and backward, raising his shoulders or flapping his arms; neither should he with rigid knees and ankles exert himself to rise from the saddle. During the early lessons, and if the teacher be mounted, he may, with the palm of his hand placed at the back of the pupil's waist, assist as well in the raising as in the alighting movement, or the pupil may sustain himself by taking hold of the mane. The hands are held low and steady, the horse well up to the bit; the reins must not be used as a lifting-gear.

When the rider applies his legs, it should be done with a short pressure and at the moment his seat touches the saddle.

When the manner of rising has been sufficiently practised at the walk, both to the right hand and to the left, one proceeds to the trot, which should be somewhat easy (the natural trot).

In order not to strain one pair of diagonal legs more than the other "the diagonal should be changed;" if a certain leg needs to be spared, the rider alights on the diagonal to which this leg does not belong.

If rising and alighting when the left fore and the right hind are brought forward and planted, the rider rides "on the left diagonal" and vice versa. As he rides on the left (or right) diagonal, he will descend into the saddle simultaneously with the left (or right) shoulder's retrograde motion and 
rise simultaneously with the left (or right) shoulder's advancing motion. As it is difficult for the beginner to know when a hind leg shoves off, he can easily determine this by glancing at the shoulder-point, thus watching the moment when a diagonal is planted. Rising to the trot on one or another foot should, for this reason, be referred to a fore foot.

At first the teacher calls out "Up!" or "One!" every time the pupil should rise; later on the pupil does so himself, and finally he receives the word"Trot on the right (or left) foot!" In the ridingschool and in turnings one should ride on the outward diagonal.

The changing of diagonal is executed at the word, "Change diagonal!" By stronger closing of thighs and knees and increased support in the stirrups, the rider either keeps himself aloft or sits down in the saddle during two consecutive steps. After alighting in the saddle, the beginner is generally inclined to remain sitting down too long, thereby often rising on the same diagonal on which he rode previously.

When resuming the sitting-down trot, the word is given: "Sit down!" Consequent to the movements of the horse at the trot, the rider is raised up from the saddle and drops again into it at each step. In order not to be raised too much and not to pound the horse too hard at the downfall, the rider should keep his whole body limber and elastic, slightly close his thighs and knees against the saddle without any pressure, and keep his 
ankle and instep limber. The "sitting-down trot is mostly used in the schooling of the horse and in giving lessons.

During long rides, it should be observed that rising to the trot is executed almost equally on each foot or that a possibly weak leg may be spared. As the speed of the trot increases, the rising of the rider diminishes; with so-called "Trotters," rising to the trot is almost impossible. Horses that cover the ground well and have naturally high action are the most pleasing ones when rising to the trot.

The principal faults, to be avoided in rising to the trot, are:

Rising entirely by means of the stirrups, rising too much and too suddenly, falling down rigidly and suddenly in alighting, rising by means of the reins,

curving the back, leaning the body too much forward, raising the shoulders, letting the head drop down on the chest, and flapping with the arms,

letting the legs move to and fro incessantly and drawing up the heels, and

moving one hip more upward and forward than the other.*

There is no doubt that rising to the trot strains the horse's forehand more than the sitting-down trot does, therefore many enthusiastic riders object to the former, saying, it is not riding but merely "conveyance on horseback." One thing * Frequently seen when riding in side-saddle. 
is certain, it does not convey to the rider's whole body that healthy all-pervading exercise, for which riding, as a sport, is one of the best adapted.

\section{Riding with Curb.}

The curb (Figs. 27 and 28 , page 4r) works in the same manner as two one-armed levers, their fulcrums being the eyes ( $d$, Fig. 28, page 4I) of the curb-bit, which are secured by the curbchain; the power (the rider) works through the reins, fixed in the rings (e), upon the weight (the horse) through the animal's mouth (the interdental space). If the effect of the curb-chain be greater than that of the mouth piece, i.e., if the former causes the horse to suffer any pain, it is evident that the curb will produce the reverse effect to that which is intended, because the pain, naturally, makes the horse throw his nose upward and forward and does not make him yield to the less severe effect of the mouth piece. In such case, the curb would prove of less use to the rider than the snaffle. When the reins work at a right angle to the arms of the curb-bit, the effect is then most favourable; if the curb-chain is made too short or, if it presses* the horse's nose forward and upward, this angle becomes acute; if the curb-chain is made too loose, it causes the reins to work at an obtuse angle to the arms of the curb-

* Narrow curb-chains with thin links cause the horse's chin to become sore easily, and especially so if the edge of the jawbones be very sharp (otherwise see page 50.) 
bit. Using no curb-chain at all, the arms of the curb-bit would almost come in the prolongation of the reins, i.e., the curb would then work almost the same as a snaffle-bit without joint.

The curb-bit should be adjusted to the sensitiveness of the horse's mouth (see pages 42 and $8 \mathrm{I}$ ) and the rider's hand, just the same as the snaffle-bit.

\section{Mounting and Dismounting,}

In riding with curb the stirrups should generally be used.

Before mounting, the curb-reins should be placed over the horse's neck just in front of the withers and hanging down equally on either side, the snaffle (bridoon)-reins in the same manner, and a handbreadth in front of the former (otherwise, see pages $8 I-83$ ); the reins should not be twisted or mingled together.

After dismounting, the reins should be placed in the same manner as described before mounting or, in leading the horse away, the curb-reins may be taken over the horse's head and held in the left hand (otherwise see page 78 ).

\section{Mounting.}

In riding with curb the mounting is executed in the same manner as when using the snaffle alone (see page $8_{3}, \mathrm{a}, \mathrm{I}$.), though with the following modifications: 
With the back of the hand turned downward the rider slides his left hand, with the four fingers gathered, along the crest of the horse's neck in front of and under the middle of the snaffle-reins, thereby placing them in the thumb-grasp; at the same time the thumb and the first finger of the right hand seize the end of the curb-reins from above and lift them up sufficiently to let the third finger of the left hand pass in between them, slightly closing this hand with its thumb resting on the reins, which, being passed over the first finger, are shortened so as to feel the horse's mouth lightly,* and then the end of the reins is thrown over on the off side of the horse's neck; the right hand grasps a lock of the mane and places it in the left hand-the other movements of hands, body and legs being the same as previously explained in mounting "with snaffle" alone. In taking the reins, the hands should not be brought higher above the crest of the horse's neck than necessary, in order to avoid the hairs of the mane getting in between fingers and reins. When mounted and after releasing the lock of the mane, the riding-whip having been taken in the right hand, the rider passes the thumb of his right hand from behind and at the end of the curbreins in between them and, in raising his closed right hand with the little finger turned upward and straight in front of his face, the reins are shortened to a suitable length, with proper allowance for the right rein being made a trifle (about

* The curb-reins must not be made too short. 
$1 / 2$ inch) shorter than the left, $*$ which may easily be arranged by a twist of the thumb and the first finger of the right hand when adjusting the length of the reins as above described. It should be

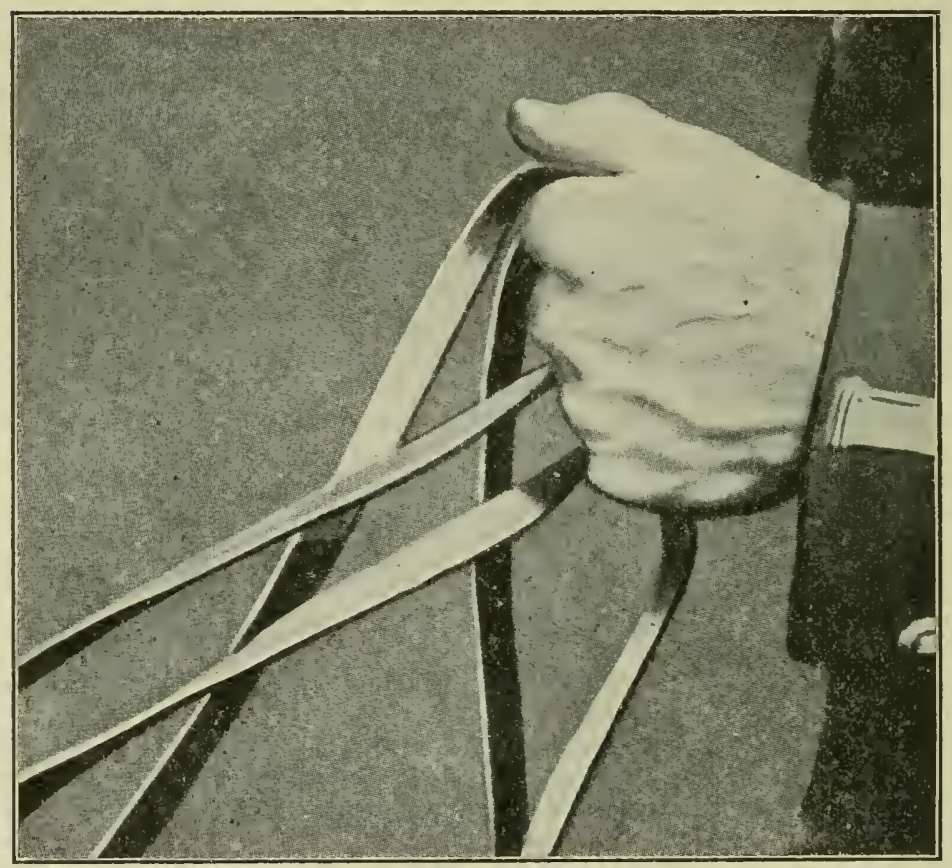

Fig. 57 .

observed that, in adjusting the length of the curbreins with the thumb of the right hand, the left

* The cause of the right rein being made comparatively shorter than the left is that the former, in passing through the left hand and being placed upppermost on the third finger and undermost on the first finger, has got the shorter distance (of the two) to pass through the whole hand. In having an extra buckle-hole punched in the strap of the right rein, where it is buckled to the rein-ring of the curb-bit, the conditions may be adjusted. 
hand, with its thumb pointing straight upward, should remain a handbreadth from the rider's waist. The curb-reins being thus adjusted, the end of the reins is then dropped to the off side, and the snaffle-reins arranged so as to hang down evenly on the outside of the curb-reins (Fig. 57). In riding with the curb-reins held in one hand, the right hand should either hold the whip with point downward and arm and whip straight down by the right side, or the whip may be held in the thumbgrasp of the left hand (within the reins) and with point downward to the right side, the right arm hanging straight down as shown in Fig. 70, page $32 \mathrm{I}$.

\section{Dismounting.}

In dismounting, when riding with curb, the same rules should be observed as in riding with snaffle alone (see page 87 a, I.), but with the following modifications:

The right hand grasps the curb-reins near and above the left, which slides forward upon the reins towards the withers, feeling the horse's mouth lightly; then the right hand lets go the reins to the off side, takes a lock of the mane and places it into the left hand; otherwise the same as in dismounting "with snaffle" alone.

If riding with all four reins held in both hands (see pages 225-226, "Handling the Reins"), the snaffle-reins may, in dismounting, be lengthened to their full length and held with their middle part in the full of the left hand and apart from 
the curb-reins, the same as in mounting (Fig. 57), or the right snaffle-rein, held in the right hand, may be brought between the thumb and forefinger of the left hand, all four reins equally shortened. If all four reins are held in the left hand (see pages 226-227), the easiest way of holding the reins, when dismounting, is to shorten all four reins at the same time and in the same manner as in dismounting with the curb-reins only (see above).

When riding with curb and practising mounting and dismounting "during motion," only the snaffle-reins should be used (otherwise see pages $86, b$ and $89, b)$.

\section{Handling the Reins.}

Owing to the considerably severer effect that the curb has, compared with the snaffle, a steady and pliable hand is absolutely necessary for a proper management of the reins when riding with curb; for the same reason, less movement is also required of the hand in riding with curb than when using only snaffle.

With the curb, the management of the reins is accomplished principally or entirely by the left hand, as the right hand, when holding the right snaffle-rein, is only used to assist in the movements of the left, which, for this reason, is called the bridle-hand. When the movements of the hand are mentioned in this chapter, it is only those of the left hand that will be explained, as the right hand, holding the right snaffle-rein, 
handles it according to what has been previously said about "Riding with Snaffle."

The fundamental position. Holding the reins the same as in mounting described, the position of the hand is the same as that with snaffle (see page 96), only that the left hand is brought so much over to the right as to stand straight above the middle line of the horse (ab, Fig. 47, page I 47).

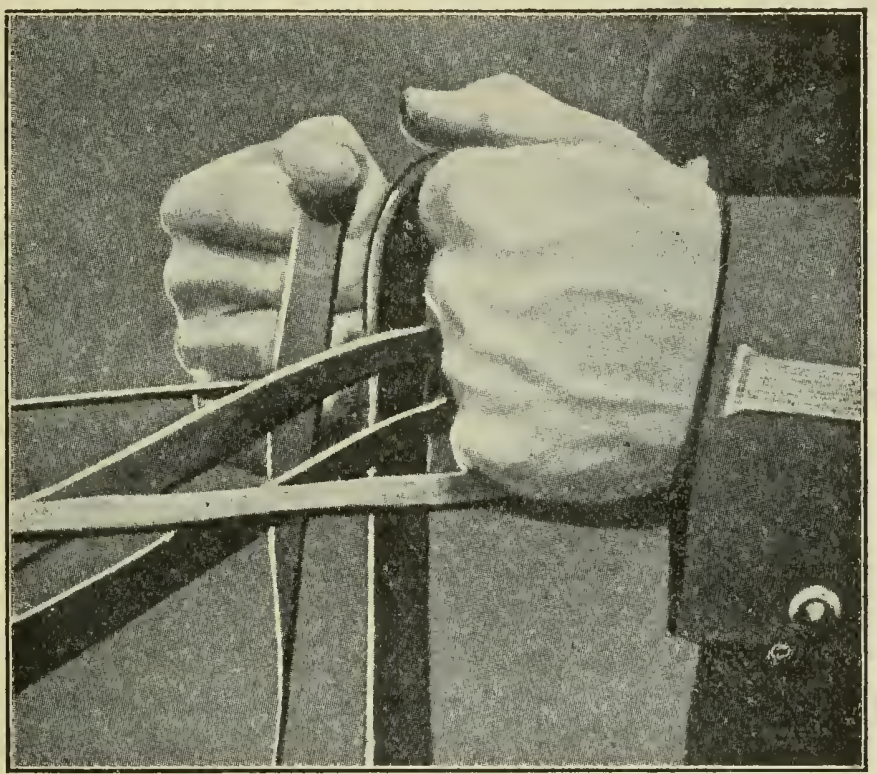

Fig. 58 .

The four reins are generally used; they act then in concert and may be held in both hands or in one only:

If the four reins are held in both hands, it should be done in the following manner: When

15 - Handbook for Riders. 
holding the reins as in mounting (Fig. 57), the right hand takes hold of the snaffle-rein close to the right side of the left hand and draws the left snaffle-rein through the left hand, shortening it to the same length as the left curb-rein and placing it over the latter with the left thumb closed upon the three reins; then the right hand shortens the right snaffle-rein so as to feel the horse's mouth lightly, and in so doing, assisted by the forefinger of the left hand;* the end of the snaffle-reins hanging down between the right curb-and

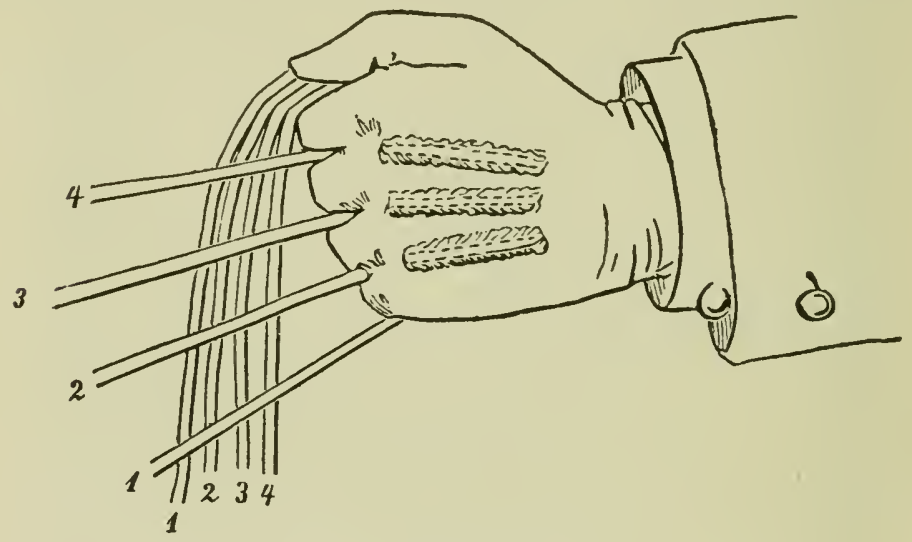

Fig. 59

snaffle-rein and the right hand holding the right snaffle-rein in the same manner as in riding with snaffle alone (Fig. 58).

If the four reins are held in one hand, it should be done in the following manner: When holding the reins in both hands, as above described, the right snaffle-rein is placed under the

* The left thumb should remain on the three reins. 
forefinger of the left hand and drawn forward over the same finger, thus placing it underneath the three other reins, then the left thumb closed upon the four reins; thus the four reins are placed over the middle part of the left forefinger and in the following order (Fig. 59): uppermost the left snaffle-rein (I), then the left curb-rein (2) next the right curb-rein (3) and undermost the 1 ight snaffle-rein (4).

When riding with the four reins in both hands, the rider may need his right hand for something or other and only for a short time, the right snaffle-rein should be placed into the left thumbgrasp above the three other reins.

The four reins being held in the bridle-hand, the whip may be placed in the left thumb-grasp (within the reins) and with its point downwards on the right side. When the four reins and the whip are held in the bridle-hand and the reins are to be taken in both hands, the whip should first be taken in the right hand.

What has been said on page 96 about giving and taking of the reins, when using the snaffle alone, may, in all essentials, also be applied to the curb; though it should be still more particularly observed that the alternate taking and giving, by which the horse is made light and agreeable on the rein, is of still more importance in riding with curb than in using the snaffle alone.

Giving. By turning the hand at the wrist, the little finger is brought forward, the thumb pointing more or less towards the waist. 
Taking. By turning the hand at the wrist, the little finger is brought straight back towards the breast, the thumb pointing more or less forward.

In bending the horse's head sideways, the same rules should be observed as explained for the snaffle, on pages $147^{-1} 5^{\circ}$.

a. To the left. The hand is turned in such a way that the little finger points towards the rider's right hip, and the knuckle of the forefinger is straight above the middle line ( $a b$, Fig. 47) of the horse. This motion of the hand not only causes the left rein to be shortened but gives a pressure of the right rein against the horse's neck, thus preventing it from false bending sideways. The right hand, when holding the right snaffle-rein, should be carried to the right sufficiently to give place for the motion of the bridle hand.

$b$. To the right. By more outward rounding of the wrist (see page 92) and by turning the knuckle of the forefinger over to the left, the little finger still remaining above the middle line of the horse, the right rein will be shortened, and the left pressed against the horse's neck.

Turning. With the hand in one of the above described positions, the horse should, when the rider's legs and weight are added, as a rule, turn; but, should it not prove sufficient, the hand, while still remaining in one of the described positions (to the left or to the right), may be turned so as to raise the little finger towards the rider's inward shoulder, thus causing a stronger 
pressure of the outward rein against the horse's neck without any easing of the inward.

When riding with horse's head bent sideways and either in order to prevent any turning or to make the horse turn with contra-bending (see pages I6I and I62) the little finger, while remaining in its turned position, should be moved towards the rider's outward hip, thus causing a tension upon the outward rein and a stronger pressure of the inward rein against the horse's neck, though without influencing the bending effect of the latter.

In the turning of the little finger of the bridle hand towards the rider's left shoulder or hip, his lower arm may also, if necessary, be moved a little backward along his waist.

In practical riding with curb, the effect of the rider's legs and weight should be first tried, before resorting to the use of the reins.

In the shortening and lengthening of the reins, the thumb and forefinger of the right hand take hold of the rein in question either behind or in front of the bridle hand and draw it through the hand to the desired length.

On account of the management of the reins being accomplished principally or entirely with the bridle hand, the rider's left shoulder is apt to be drawn forward and downward; for this reason, the reins should occasionally be changed to the right hand. Whether riding only with the curbreins or with the four reins in one hand, the transfer of the reins is done by the forefinger of the right 
hand being placed between both curb-reins just in front of the bridle hand and the other fingers closed around the reins, the back of the right hand turned upward, and the reins released from the bridle hand. In turning the horse with the right hand held in this position, the hand may, if necessary, by bending of the wrist and slight motions of the hand, cause the animal to turn to one side or another.

\section{The Lessons.}

The increased effect of the curb, compared with that of the snaffle, and also the rider's want of practice in handling four reins, makes it advisable at first to ride with the curb-reins a trifle more eased than the snaffle-reins. In order to attain proper skill in holding the reins, a halt is often made, and the reins thrown over the horse's neck and retaken; dismounting and mounting should frequently be practised; also shortening and lengthening of the reins, their handling in other respects and that of the whip, as well as saluting on horseback.

The reins should then be made the same length, and the proper giving and taking be practised. When the rider has acquired a fairly correct feeling of the effect produced by the curb, "bending the horse" should be exercised on the great circle as being most advantageous for such purpose. At this period wide $1 / 4$ turns (see pages $\mathrm{x} 66$ and 167 ) across the school are also 
made in order to establish the fact that the use of the reins will gradually be eclipsed by that of the rider's legs and weight.

Otherwise the same lessons should be practised when riding with curb as with snaffle alone; they should be executed in the same order and by the same aids as in riding with snaffle, though proper allowance must be made for the increased effect of the reins; the gallop may, nevertheless, be commenced at an earlier time than has been set for lessons "with snaffle"; besides this, the bendings of the horse's neck and yielding sideways to the rider's leg should be unnecessary practices in riding with curb, as the correctly broken horse should readily submit to bending of the head and to the influences for side-gaits, without the preliminary practices being introduced.

The lessons should at first be practised with the four reins held in two hands, later on in one hand and, finally, the easier lessons may be exercised with the curb-reins alone, though, in practising the side-gaits and in jumping, the four reins should, as a rule, be used in two hands.

\section{Measures Adapted to Special Cases.}

To discuss all the various critical incidents that may arise when on horseback would be interminable; and for this reason I shall only treat those of the most ordinary occurrence and at the same time advise the rider-should the horse become his master-to turn the animal over to an able trainer, and the sooner the better. 
Any bad habit of the horse should be stopped at its outset, if possible, or, if not, be limited so far that the animal does not get beyond one's control; in such cases the equanimity of the rider is as much required.as is the balance of his body, for the one depends on the other.

When a horse stumbles, which may occur from sluggishness, fatigue or some physical defects, he must not be punished; because the sluggishness and fatigue may either have their origin from the rider's want of skill in sustaining the animal when most needed, or from the horse's ignorance and want of practice with regard to the immediate circumstances, and to punish the animal in such cases, or for its physical defects, would not only be cruel and unjust, but it would lay bare the rider's unfitness and want of self-control. Moreover, the punishment at stumbling would generally cause the already unbalanced animal to rush forward, adding more strain to the drooping forehand, and a fall may ensue, i.e., what might have been prevented has happened. A horse treated in this manner will inevitably expect punishment when even making but a misstep, and consequently, trying to escape it in a horse-like manner, he rushes forward and, maybe, stumbles or even falls, i.e., he is being trained to stumble. To prevent or remedy stumbling the rider's influences should be instructive and sustaining to the horse, i.e., he should be kept between legs and reins (see page Io8), and when he does stumble, the rider should throw his upper body back and with a steady hand sup- 


\section{$-233$}

port the horse with the reins, but not punish him with spurs and whip.

When the horse falls in spite of the rider's efforts to keep the animal on its legs, he should not directly give up, especially so if it only goes down on its knees, when but the hind legs remain standing; for an immediate and resolute throwing back of the rider's upper body, together with an energetic raising tension upon the snaffle-reins and proper aid of his legs, will generally make the animal recover its legs. Even if the horse should fall with all four legs under him, but without falling over to the side, an active and strong horse and able rider should "stand and fall together," as even in such case a light and lithe seat in the saddle, and so balanced that the least weight is imparted to the rising legs, may enable the horse to recover his legs; the forehand should be raised first, if the horse does not by his own efforts try to raise himself by all four legs at the same time. The raising of the forehand is done with the reins, the hind quarters by the rider's legs. Meanwhile, if in such case the horse does not directly recover his legs, he will most frequently fall over to the side; it is then of importance to the rider, as soon as possible, to set himself free from the horse and rid himself of the stirrups, but an able rider should never let go the reins unless his life is at stake and might be saved by so doing.

If the horse runs away-which is most frequently caused by fright or pain, for instance, a too hard hand and a too severe bit, or by some dis- 
ease of the brain-the rider, by acting judiciously, should, in the case of fright, be able to check the animal when the cause of its fright is out of hearing or sight. If the occurrence is caused by pain, the cause must, if possible, be removed. In any case it is of the greatest importance for the rider not to lose his head, nor by shouting for help and an unsteady seat provoke the already excited animal still more. The lost respect for the bit is easiest restored by quiet words, while alternately taking and giving forcibly with the reins; a constant pulling on the reins only deadens the horse's mouth. As for the use of the spurs see page III. According to whether the horse carries his nose high or his chin against his breast, the hands are kept low or high. In riding with curb the curbreins and snaffle-reins should be taken two in each hand, the same as in riding with double snaffle (see page roo).

In order to slacken the speed of a runawayhorse, the reins on one side should be drawn very short and the leg or the spur applied to the same side; if the horse is made to turn even slightly, the pace will generally slacken a little; then, if possible, the horse should be guided towards some substantial obstacle as, for instance, the wall of a house; otherwise such objects should be avoided. If luckily there should be any large open space, to which the rider could direct his horse and there let him run in wide circles until he is tired out, gradually diminishing the circles according to the speed, the rider's control of the animal would soon be 
re-established. Meanwhile, he must not be contented with this, but he should then force the horse to run a little more than he wants; which will often discourage the animal from further attempts in the way of bolting, at all events for the time being.

If no remedy seems to avail and all control over the animal is gone, and it aims straight at some dangerous obstacle, where certain death seems to face the rider, he should look out for the safest place to get off his horse and then grasp the mane with his right hand, release the stirrups and the reins, push off from the saddle with his left hand and, in flying off to the left and forward, should try to land on his feet and on soft ground, if such be found. Should the horse be moving on a curved line, the rider must so arrange the use of his hands that he may land on the inner side. It is a risky experiment, but I have tried it myself once, when the joint of the snaffle-bit, with which I was riding, broke in the horse's mouth, and, after a few somersaults, I found myself none the worse but for the loss of the heel of a boot.

When riding a horse that is inclined to rush on his way home, strict care should be taken that the stable doors or the gate be kept closed while the animal is out.

Horses that shy must be handled cautiously and, at the same time, with firmness; cautiously, because the fault is generally caused by the animal's ignorance of the dreaded object or sound, and with firmness, because the rider's determined course of action will make the animal 


\section{$-236-$}

pay more attention to his influences than to the cause of its fear; any uncertainty on the part of the rider will only confirm the animal in its fear. The horse's fear is easiest allayed by the rider behaving as if nothing unusual were going on, keeping the horse well "between legs and reins" and in an unchanged direction towards or past the dreaded object; soothing words and caresses are, under such circumstances, the rider's surest helpmates; if possible, the horse should be brought so close to the object that excites his fear that he may smell it. When the animal has obeyed the rider, it should be rewarded with approving address, caresses and-if such are at hand-with some oats, carrots, apples, etc., but not with sugar.

Punishment is sure to increase the animal's fear.

If the horse tries to whirl himself round, he should be brought into "versing-position" in a way that his head is bent away from the object of his fear; at any rate, the rider must, with might and main, try to prevent the animal from twisting himself round; punishment with spurs and whip (see pages III-II3) is, in such a case, fully justified. If, nevertheless, the horse should succeed in turning aside, he must always be turned back from that side to which he turns. If he cannot be made to turn back, but rears or sweeps off sideways from what has caused his fear, he should be made to stand for a short while and meantime be calmed down; then he 
should be backed towards the place where he turned, then left alone for a while, talked to in a soothing way and again backed close to the place where the trouble began, when a sudden turn on forehand, by the strong use of leg and rein on the same side to which he is turned, will unexpectedly bring the animal face to face with the object of its fear. This behavior on the part of the rider will scarcely fail to confuse the horse to such degree that he will stand as if paralyzed on the spot, and the reward should then instantly follow.

To turn back, to dismount, or to go a long way about, will generally result in a shy horse becoming restive.

A common fault with inexperienced riders is to suggest beforehand where the battle should take place, and then arrange oneself in the saddle, tighten the reins with convulsively clenched hands and hold on by the legs, as if notifying the animal: "Now we will see!" Challenging the horse in this manner will scarcely fail to be met with acceptation.

Restive and stubborn horses should be handled much the same as shy ones. The cause of the restiveness should, as soon as possible, be found out and, if possible, be removed - the horse may, for instance, be wrongly bridled or saddled, through which something or other pains him. If viciousness be the cause, the rider must, if gentleness be of no use, act energetically; in such a case, forcible use of spurs and whip may be made, also backing in the same direction in 
which the animal will not advance, or repeatedly turning round on the spot. If it be a deeply rooted fault of the animal, most frequently arising from rough handling in its youth, a thorough breaking by an experienced trainer is required in order to re-establish the lost confidence in men, and the remedy is longeing, which, however, lies beyond the limits of this book.

Restive horses frequently try, in different ways, to dispose of their tormentor, "the rider;" if not sufficiently firm in the saddle, one should then dismount as soon as possible and leave the cure to a professional trainer; for if the horse once gets into the habit of ridding himself of the rider, it is almost past belief what the animal may take into its head to do in that respect, and what difficulties this may give even the ablest rider to overcome.

A common trick of the horse is to lean up against an object, such as a wall, a tree, etc., and there to try rubbing the rider off; the horse's head and neck should then be bent much to the side where the object is, and at the same time the spur applied on the same side.

If the horse tries to lie down with the rider, and punishment with spurs and whip be fruitless, one must immediately free oneself from the animal and inflict a regular drubbing on it with the whip, at the same time trying to hold it down on the ground.

If a horse rears, the upper part of the rider's body should be inclined forward, the reins in- 
stantly slackened, and, if the fault be not from fright, punishment with spurs and whip should directly follow (see pages I I I-I I3). If the animal goes up very high, the rider may grasp its neck with both arms (besides see Fig. 60); but if it

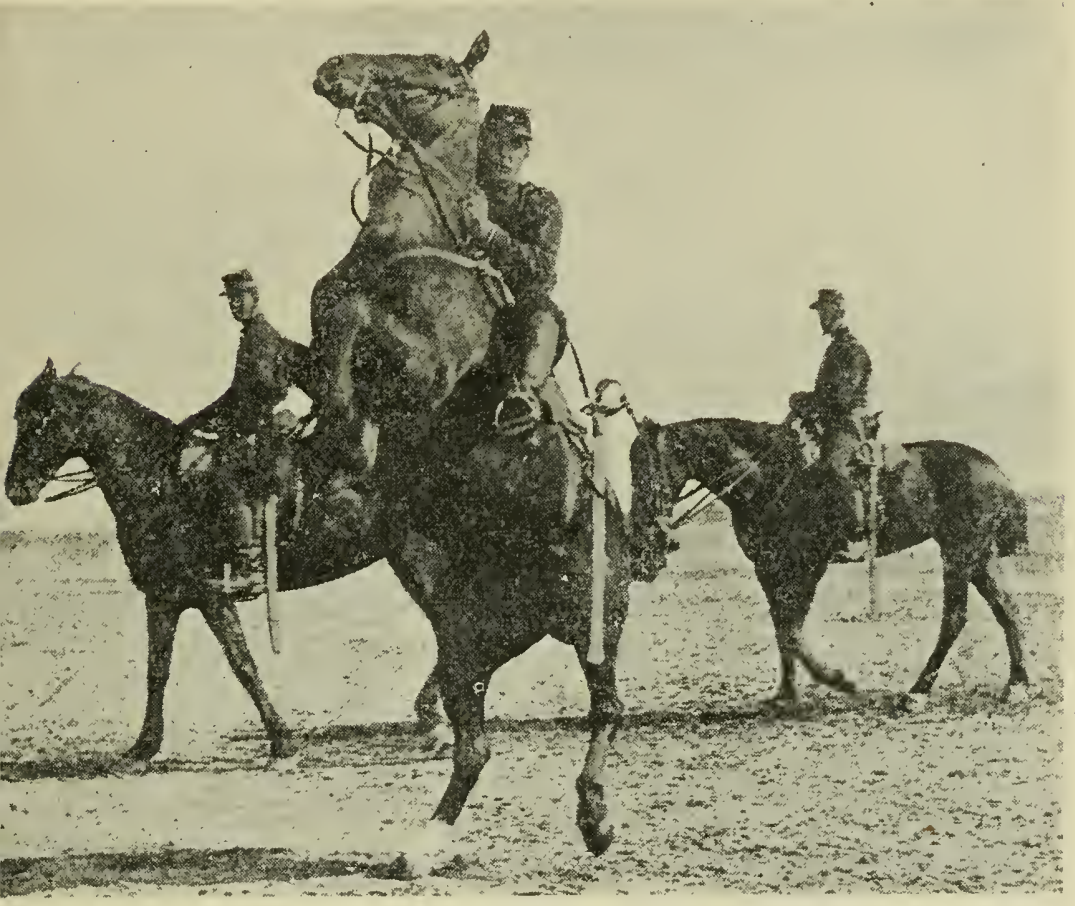

Fig. 6o.

At well equipped Cavalry Schools of Equitation one or two horses are schooled to rear at a sign from the Instructor in order to teach the pupils how to act in such a case.

is felt that the horse is tottering backwards, the stirrups should be released, and, shoving off from the saddle with both hands, the rider should throw himself off, out to the side. 
To strike the horse with the whip on the head should not be done, as it may often have the reverse effect of that desired; besides, using the whip in front of the horse's shoulder is not considered civilized, and it is cruel.

The most incorrigible rearers may often be cured in the following manner: The rider provides himself with a bottle, or glass-balloon, made of very thin glass and with a long neck (the same as for chemical use); it is filled with water and corked; the rider holds it by the neck in his right hand. When the horse rears, the bottle is smashed by a quick blow between the horse's ears; the water, pouring down over his head, makes him immediately lower the forehand. If the blow be applied quickly and suddenly, the splinters of glass will rarely or never injure the horse; and even if they do, the injury is so slight that it is of no consequence. By applying this treatment once, maybe twice, the horse will, as a rule, forever be cured of rearing; at all events, any such further attempts may be prevented by the rider merely placing his hand on the horse's neck, near to the ears, and he will remember the breaking of the object from which. the water poured.

If the horse kicks, the rider should throw his upper body back, according to how high the horse's croup is raised, and observing the general rule of keeping the upper body perpendicular to the horizontal ground. Raising the horse's neck and head, and making him advance by pressure 
of the legs may diminish or, if applied at the right moment, even prevent any raising of the croup.

Side-leaps may be prevented by forcible use of leg, spur and whip (see pages III-II3) on the same side to which the horse throws himself; the horse's head should also be bent much to this side, while the rider's hands are brought over to the opposite side (besides see pages 83 and ro8).

With regard to the rider's "sticking on," bucking is almost the worst fault a horse can have, especially if he be not saddled with a "cowboy" saddle, from which it is almost impossible to be thrown. The rider should not make the situation worse by clinging with his calves and heels; but, on the contrary, he should try to keep his balance by supporting himself forward in the stirrups. In bucking, the horse shoves off from the ground with all four legs almost at the same time, his back being curved upward and his head down between his fore-knees and, when grounding, his fore legs are stiff and stretched forth. In violent bucking, the saddle-girths may often break. If one does not succeed in getting the horse's nose quickly enough pulled up, even the best rider may then be thrown, especially as in such cases, the horse does not generally content himself with that one plunge.

If the horse does not stand quietly when being mounted, and soothing address and caresses prove useless, or if then he strikes at the rider with the fore legs, he should be punished by backing $16-$ Handbook for Riders. 
until he leaves off; in the latter case cuts of the whip on the fore legs may also be applied.

If the horse kicks forward with a hind leg (so-called cow-kick), for instance, after the rider's foot, when mounting, the horse should be punished by backing.

When, in riding, the horse kicks after the rider's leg or spur, it should be punished by a sharp cut of the spur.

If the horse puts his tongue over the bit and lets the tongue hang out of the mouth, he must not be hit with the whip on the tongue. The fault may occasionally be prevented by placing the bit higher in the mouth; but, after all, the surest remedy is a kind of curb-bit with a stop-plate fixed on to the mouth piece. In putting this bit into the mouth of the horse, it should be strictly observed that the tongue gets under the bit. 


\section{Supplement.}

\section{Outdoor Riding.}

The first ride out-of-doors should be taken in a large open space and under the instruction of the teacher; if there is opportunity, riding over various obstacles should be practised at the same time.

The pupil should take his first road lesson on a steady, quiet horse and in company with the teacher or with another experienced rider, and then all unusual occurrences should be avoided, for instance, riding on very crowded promenades or roads, equipping oneself with new saddlery or riding garments, tight fitting gloves, cigar in the mouth, etc.

Proceeding in this manner, and by gradually increasing the difficulties, the rider will soon acquire the self-reliance which every sportsman needs.

The rider should always observe the road on which he rides, and in such a manner that, by looking forward over the horse's head, he may know what lays between his horse and the spot where his line of vision meets the ground; for, in 
looking down just in front of the horse's fore legs, he will not be able to get out of the way of obstacles in time, or be able to leap over them.

On beaten roads, the rider generally keeps to the right side, if the rider's safety or the care of the horse's legs should not demand otherwise; and only then, if space be at one's disposal, the softest and least stony part of the road should be chosen. In meeting anybody, one keeps to the right side, * whereas in passing by, it is done to the left of the one in front, and it should be observed that nobody is inconvenienced by it, either by being soiled, hustled, or by causing their horses to shy, which last mentioned may often occur when riding at a too rapid pace while passing.

When riding in company, the pace should be kept so that everybody can keep up with it, and should one or more of the horses become unmanageable, or in trotting break into a gallop, the others should be pulled up until quiet is again restored. It should also be strictly observed that roads, public promenades and streets are not the right places for horse-racing.**

When riding in company with others to whom respectful consideration should be shown or who may need protection or assistance, such persons should have the privilege of riding to the opposite side of any one they meet.

* In England, Sweden and a few other countries, in meeting, one keeps to the left side.

** About the pace, generally used in outdoor riding, see the chapter about "The various paces." 


\section{$-245-$}

When riding in company, two or more abreast, if the breadth of the road does not offer sufficient room for meeting anybody, then the one or those nearest to the meeting side should pull the horse up and let the rider on the outside pass in front, the others following one by one, exactly behind the leader. If, under such circumstances, anybody has to be passed from behind, one acts in like manner, inasmuch as the one on the inside passes in front.

When a rider is accompanied by a mounted servant, the latter should ride about 20 yards behind his master.

When on a long ride the horse needs a rest, the rider should dismount and loosen the girths a little. If, in such case, the horse be put up in a strange stable, it should be ascertained beforehand as to whether there be or have been sick horses in it, if the floor is safe, if there be outstanding nails or anything on which the horse is likely to injure himself, if manger and drinking-vessel be clean, if there be proper contrivances for tying the horse up, etc.

When riding in company, no one should start before all are mounted.

In riding on stony, uneven and swampy ground, in deep snow or when it is dark or foggy, the horse should be kept well "between legs and reins," though in the last two mentioned cases it may be advisable to let the horse choose the way himself, for, as a rule, he can see or perceive better than the rider. When in swampy land or in snow, the 
animal sinks deeply and becomes nervous, the rider should try to calm it down by dismounting and leading it.

On ice, on narrow roads (mountain-paths) and in passing over frail bridges, and altogether on such places where the horse may be liable to slip or fall, the rider must sit lithely and steadily in the saddle, supporting himself lightly in the stirrups and not influencing the horse too much, unless he should slip or stumble, and then sustaining him in a quiet and controlled manner but not abruptly. If, nevertheless, the horse should fall, the stirrups are released, the rider grasps the mane and, providing the animal does not fall over to the side, it should be encouraged in recovering its legs (see page 233), observing that the reins do not prevent it from stretching forth its neck and head. If the animal should fall over to the side, the rider tries to bring his leg so far out to the side to where the animal is falling, that he may reach the ground with his foot and, in endeavouring to keep his body erect, throw his other leg quickly over to the same side.

In riding up or down hill (see pages Io7-108), the rider's legs may be brought backward or forward (i.e., slight support in the stirrups), the reins should be slightly eased or tightened, and the rider's body kept perpendicular to the horizontal ground. In riding up very steep hills, the rider may grasp the mane or he may dismount and lead the horse. Ground with steep acclivities, not being slippery, may be ridden zig-zag. With- 
out any special reason, hills should not be riảanen over at any other pace than the walk.

Fences and ditches, the latter not being broader than the horse can walk or jump over, are taken according to the rules for high and broad jumping (see "Obstacle-Riding"). Over broad stone walls and banks, the horse is made to climb or to leap upon the top and down again on the other side. If a ditch be so broad that the horse cannot clear it by jumping, one may, if the slopes are not too steep, ride a bit down the side of the ditch and from thence make the horse jump across to the opposite slope and then climb up to the edge. One may also ride slowly and slantways down into the ditch and in the same manner up again on the other side. If the bottom of the ditch be broad and firm, the sides steep and the ditch not too deep, one simply jumps down on the bottom and up again.

In jumping obstacles, slippery or soft ground should be carefully avoided.

Not being sure that the horse can clear the obstacle (with his rider), it is better not to try, but to dismount at once and lead the horse over; for, when rid of the rider's weight, the thing becomes considerably easier.

In crossing water by fording, the horse is kept well "between legs and reins" and is ridden, without hesitation, into the water at a place where the bottom is even and firm, in order to prevent the animal from stumbling, falling or sinking down, which might give it a permanent fear of 
passing through water. Being so unfortunate as to hit upon a place where the horse sinks, he will become nervous and start to work fiercely with his legs; the rider should then dismount at once and lead the horse over or turn back, according to circumstances. Passing through flowing water, it should be done obliquely against the current, the rider looking towards the other bank and not down at the water, lest he turn dizzy. If the horse begins to paw in the water with his fore legs, it is generally a sign that he intends to lie down; he must then be forced forward with legs or spurs.

Many horses have such a great dislike of passing through water that one may have to temporize with them for hours; everything then depends on having patience and not giving in. Under such circumstances it is advisable to leave the horse by the edge of the water alone for a while or to ride him up and down along the water side. The reins should be eased sufficiently now and then to allow the animal to smell the water and, if he likes, to take a drink. With soothing words and caresses, one may at last succeed in getting the horse at least a few steps into the water, after which he should be rewarded by again being ridden slowly back to terra firma. By repeating this method with calmness and perseverance, the animal's fear of the water may vanish forever. If the water be very shallow, backing the horse may also be tried.

Railroad tracks should be crossed with care and 
always at a walk and at a right angle to the rails, otherwise the horse may slip, stumble or fasten his foot in the rails, thus tearing off the shoe and even the outside wall of the hoof.

In riding under low superstructures or trees the body should be bent down towards the right shoulder of the horse without displacing the seat; the right hand may take a lock of the mane, the reins are eased sufficiently to allow the horse to stretch out neck and head, and he is urged forward by the aid of voice and legs. If, during such passage, the horse gets frightened, stops, tries to turn round or possibly attempts to rear, then the rider throws himself quickly off to the right (or to the left, according to the rule of the road for meeting).

\section{The Full Gallop. \\ (The Carrière.)}

This pace (see pages II $5^{-I I} 6$ and I $2 \mathrm{I}$ ) is practised only on straight lines, and when the rider has acquired a sure and correct seat at the other paces and in jumping. There are no paces at which the horse requires such intense support on the reins as in carrière, though the rider's hand and elbow must be pliant so as to follow the greater movements of the horse's neck and head, and not to interfere with the speed by unintentional nudges of the bit. The immense bending and stretching of the horse's back require a supple and quiet seat, i.e., the body of the rider "goes with" the motions of the horse 
so as not to interfere with the movements of the muscles of his back.

During the carrière the body is held slightly forward without raising the seat too much from the saddle. With firm support in the stirrups and with thighs and knees fitting closely to the sides of the horse, he is urged forward with legs or spursaccording to the animal's temper-and kept well on the reins, which are given sufficiently not to prevent the extended position of the horse's neck and head.

In practising the carrière, the horse is put from the walk into the short trot, which is increased to the middle trot from which the horse is put on a quiet gallop right or left, which by degrees is increased to the carrière, observing that the horse does not break into a cross gallop (see pages I 2 I and I92) and does not "slip out of one's hand," i.e., the obedience to the tensions upon the reins must not be lost. The cross-gallop is easiest mended by changing the fore legs (see page r93). If the rider perceives that the obedience to the tensions on the reins is lost, the horse is either not let out into the carrière or he is directly pulled up and-if necessary - he should be backed (see page I 52). Sometimes the lost respect for the bit may be re-established by alternate takings on the snaffle-reins, i.e., by pulling the bit from one side of the mouth to the other. When at this pace it is necessary to ride on a curve, it should be taken very wide, and even then the horse should be pulled in a little. 
When the carrière is to be stopped, it is done by degrees in passing first over into the extended gallop, then into a trot and walk. Immediately after a carrière, the horse should be made to walk for a good while, but not be allowed to rest at the stand.

\section{Method of Swimming a Horse.}

The horse being used to pass deep water by fording and taught to swim without rider, the swimming with rider may be practised if the latter can swim.

In teaching the horse to swim alone, he is provided with a halter to which a longe is fastened, the longe being held by a person who-according to the breadth of the water-stands on the opposite shore or accompanies the animal in a boat. The horse is then led by another person as far as possible out into the water; the one, who holds the longe, tries to guide the horse and prevent him from turning back.

When swimming a horse with the rider on, the rider should press his legs firmly to the sides of the animal and grasp a lock of the mane in his right hand; without looking down at the water, the rider guides the horse to a place on the opposite shore, where the landing can be made. If the horse is saddled, the girths should be loosened, the curbchain taken off and the stirrups drawn up, before he is ridden into the water.

If the water is flowing, the horse is guided a 
trifle obliquely with the current. When the horse has landed, he is put into a trot for awhile in order to get him dry and warm. When feeling that the horse is sinking, the rider loosens his legs and holds on to the mane with both hands, and in this way swims with the horse on his downstream side.

\section{Long Distance Rides.}

Making a long ride, according to a previously made out scheme, either in a fixed time or in the shortest possible one, is what is termed a long distance ride. Such rides must not be mistaken for racing.

Besides the qualities of the rider, for instance, his endurance, weight, horsemanship and knowledge of horseflesh, it is particularly the qualities of the horse together with the previous training and feeding, which are decisive as to the length and the speed of the ride. What otherwise may influence the ride are the condition of the roads and those of the weather and-in case of the ride lasting a whole day or more-the accommodation and fodder, which may be procured for the horse while on the way.

The endurance of the horse depends upon the activity of the muscles and that of the lungs, and it is always the lungs which give out first at all paces except at the walk.

It is of great importance for a rider, who intends making a strenuous ride, to possess some knowledge of the respiration of the animal, this 
being the only means of utilizing the horse's strength to the utmost without breaking him down.

The following observations have been made with regard to the respiration of a horse with the rider on and at the different paces:

At rest the respirations are 8 to $\mathrm{I} 2$ in a minute.

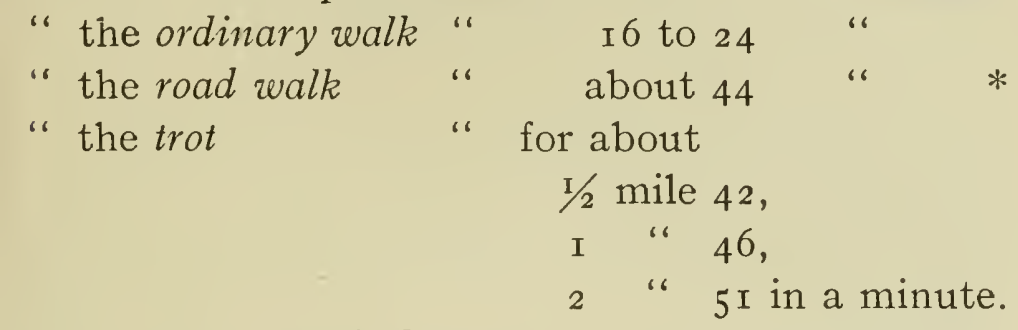

and at the stretched trot the respirations may increase to 65 and even more.

At the gallop the respirations are

for $5 / 8$ mile 55 in a minute.

At the carriere the respirations are

$$
\text { " } 2 \text { " } 72 \text { to } 84 \text { “" }
$$

$$
\begin{aligned}
& \text { for } \mathrm{I}^{\mathrm{T} / 2} \text { fuŕlong } 5^{8} \\
& \text { " } 5 / 8 \text { mile } 60 \text { to } 72 \text { “" }
\end{aligned}
$$

In the carrière at a long stretch (racing), the respirations may increase to $\mathrm{I} 30$ in a minute, but then the pace must be diminished, unless the animal is to be suffocated. Over-exertion of the lungs becomes apparent first by rapid and short respiration; later on the horse stretches out his neck and throws his head forward and finally respiration becomes deep and groaning and the rider feels that his legs no longer touch the sides of

* This proves how important the fast walk must be for developing the functions of the horse's lungs. 
the horse on account of the spasms of the chest; then the speed must be stopped, as another furlong would cause congestion.

It has been stated that 2 miles at a fast walk make the horse as much out of breath as about $1 / 2$ mile at a trot; 2 miles at a trot as $1 / 2$ mile at a gallop; about $1 / 2$ mile at a gallop as one furlong at the carrière.

Training the horse for long distance rides is principally accomplished at the walk and the trot, and it takes from 4 to 6 weeks. It is preferable to do the training in the open if the ground be soft and level.

The first week the horse is ridden from 2 to 3 hours a day and at the road walk; between each hour Io minutes' rest at the ordinary walk. A period of trot for 5 minutes each half hour would not hurt, the pace to be the short trot.

The second week the horse is ridden 3 hours a day and in the same manner as the first week, only the periods of trot are increased to ro minutes; henceforth the pace being middle trot.

The third week the horse is ridden 4 hours a day and in the same manner as the two previous weeks, only the periods of trot are increased to 15 minutes.

The fourth week the periods of trot are increased to 20 minutes.

The fifth and sixth weeks the horse is ridden 5 hours daily and then the periods of trot may be increased even up to 30 minutes. During this time 


\section{$-255-$}

one may make a trial-ride of 30 to 40 miles with $1 / 2$ hour's rest mid-way.

It must be particularly observed that the last Io to 5 minutes, before the horse is placed in a stable, are ridden at a walk.

As to feeding and watering, see pages 27 and 30 .

To bring the horse "in condition" by sweating* him should only be done, if the animal be very fat and if the time be short for the training.

As a first practice at a long distance ride a trip of about 60 miles is made in one day, using about one hour to every 6 miles and a rest of two hours mid-way.

A favourable alternation between trot and walk is 6 minutes at the trot and 5 minutes at the walk, and after a ride of 55 minutes, dismounting and resting for 5 minutes. At such a rate one rides 6 miles and 520 yards an hour.

Up and down steep hills one should not trot.

At long distance rides the most frequently used alternation between trot and walk is I mile at the trot and $1 / 2$ mile at the walk;** by changing too frequently from the trot to the walk and vice versa, the horse as well as the rider becomes fatigued. The trot should be the middle trot. If very long distances are travelled, the walk should be kept at a rate of about $1 / 2$ mile in 9 minutes; at such a walk the respirations are about 20 in a minute.

* The horse, while ridden, being covered with several blankets and then ridden until he gets into a good sweat.

** With regard to the calculation of time see "The Various Paces." 
At a gallop, if not too fast, one may, on a welltrained horse, do periods of about 2 miles, for the length of the road fatigues less than the speed"it is the pace that kills."

On long rides, of which the point is to utilize the strength of the horse to the utmost without wearing the animal out, the rider must pay attention to his own position; he should sit quiet and supple, and not dangle hither and thither, especially so at the end of his ride when he begins to get tired. It is a poor achievement for a strong rider to make a long ride in an incredibly short time, when, in so doing, he rides his horse to pieces; but the science of it consists in being able to judge, what he may demand of the animal, and in not going beyond the limits of possibility.

Riding during the night should be avoided; during rest the horse should be provided with all attainable comforts. A long rest is preferable to several short ones. When, after a long ride, the horse is put up, he should be well groomed and cared for in every respect (see pages $58-67$ ).

\section{Exercising and Longeing.}

"Stand-still and fat are the worst enemies of the horse," says an Arabian proverb.

By examining the legs of a well-cared-for work-horse, they will, as a rule,-even in animals of rather advanced age,-appear to be normal, which is principally due to daily and regular exercise, taken most frequently in the open. 
By this the muscles and sinews are kept elastic; the fat, which weighs upon the legs of the horse, is kept away and the whole of his inner organism is put into full activity. It is different with the wellfed private riding horse; he often stands still for days at a time, and when he is occasionally taken out of the stable, he is then to have "a thorough, good exercise." Great knowledge of horses is not required to be able to understand what such methods lead to; the limbs, which are loaded with the weight of the fat body and have become stiffened from want of exercise, are easily overstrained, causing inflammation and subsequently chronic ulcers in the leg; for instance, wind-gall, spavin, splint, etc., may arise; but one does not always get off so easily, for the animal may by such unreasonable treatment often sustain serious internal injuries, from which it never recovers; in other words the strength of the horse and-what in this animal is so highly appreciated-his stayingpower are broken forever.

The health and the working capacity of the horse depend on judicious and sufficient exercise together with strengthening, but not too fattening food; for this reason one should not listen to the advice of "ignorant" friends of the horse, by whom it is often considered as cruelty to animals to take the horse out from the suffocating air of the stable and from the well-provided manger more than once a day, even if it be no more than an hour, and when the horse does not look like a fattened pig ready for butchering.

17 - Handbook for Riders. 
If a sound and well-fed riding horse is to be kept "in good condition," he ought not to be without exercise any day, and never less than two hours per day, preferably the hours divided between morning and afternoon and-if the condition of the roads and the weather are favourablespent in the open.

Not having time to exercise the horse oneself, it should, if possible, be done by an experienced rider. Having a groom, who is sufficiently conversant with riding and also conscientious enough to be trusted with the horse by himself, one is well off; but, even then, it may be of benefit to take some precautions, for instance, to have the groom ride on blanket and with snaffle and to provide the horse with boots; as a rule, a groom should not be allowed to exercise at any other paces than at a walk and trot. If the groom be not sufficiently experienced in riding, he should lead the horse when dismounted and at a walk (see pages 77-79); while so doing, care should be taken that the horse is led an equally long time to the right as to the left side; in the riding-school the one leading the horse should always walk to the inner side.

In case the horse feels good on account of standing still a long time, he should be ridden, as one is then more master of the animal than in leading it on foot, and is consequently more able to prevent it from making violent jumps and plunges which may injure its legs. If, under such circumstances, for one reason or another, the horse cannot be ridden, but has to be led by hand, it 
should be done in a riding-school or in an enclosed place and at a time when things are quiet. As soon as the horse enters the place, he should be led towards one of the walls and be kept there during the whole time of exercising. If, during this, the horse is to be changed from one hand to the other, the person leading him places himself in front of the animal and tries cautiously to turn it on the forehand by directing its head towards the wall, while moving himself between the horse's head and the wall, thus getting over to the other side of the animal. Horses that rear or strike with their forelegs should not be turned in this manner, but by being led on a small circle in from the wall.

Longeing means leading the horse on a long rein (longe) and with the aid of whip and voice. Ordinarily the horse is longed on a circle, while the person holding the longe remains in the centre or moves on a smaller circle, which is concentric to the one on which the horse is moving: Longeing, applied as a means of breaking, requires great skill in horsemanship and long practice, but as a means of exercising horses one may, if possessing composure, patience and a little handiness, easily attain the necessary accomplishment. Longeing should never be put in charge of persons who are utterly ignorant of it; for in such hands the longe becomes a dangerous implement, with which the horse is easily ruined.

Horses that are wanton from long rest should not be exercised in longe; as the freedom of move- 
ment, which the leading in longe allows, makes the animal more disposed to cut capers, which may result in serious injuries to the legs. If, in such a case, longeing is used, it should be done with the horse well reined in, but then the longeing must be in the hands of a skilled trainer.

As longeing, applied as means of breaking, would require a book to itself, I shall in the following only discuss it as a means of exercising.

For the longeing of a quiet horse, there are only needed a halter with a ring at the back of the noseband in which to fasten the longe, a longe and a so-called longeing-whip.

The longe should be made of the same kind of flat woollen web that is generally used for driving-reins; it should be about an inch broad and about nine yards long and provided with a buckle and leather strap in one end, or with a snap-hook; the other end should be made into a loop for holding; moreover, it is a good plan to have a few knots stitched on part of the longe, beginning from the loop, at distances of about I 4 inches, to provide a better grip in shortening the longe.

The longeing-whip should have a light and flexible handle about 2 yards long and a cord with lash about 5 yards in length.

For horses that are very spirited or of which the neck and head are to be held in correct carriage during the longeing, the halter is replaced by a snaffle-bridle with two pairs of divided reins; there should also be two bearing-rings with straps, 
which are provided with holes for the purpose of buckling one to each side of the throatlatch.

The longeing-girth should have a pad with a ring fastened on the middle and one on each side, the latter, each about 4 inches from the former. An ordinary surcingle may easily be thus arranged.

After passing the upper pair of reins (bearingreins) through the bearing-rings, one of them is passed through the middle ring of the girth and buckled to the other one, which is made somewhat shorter and provided with a buckle for this purpose. The lower pair of reins are fastened to the lower rings of the girth. By shortening and lengthening the reins, the raising of the neck and the bending of the head may be regulated.

The longe, which should be fastened to the inner ring of the bit and underneath the reins, is first made quite short and is held, coiled up, together with the whip (the point of which is turned backward with its cord dragging along) in the inner hand, the arm hanging straight down, while the horse is led out on the circle by the outward hand holding the inner rein; the horse being thus brought out upon the circle, the outward hand takes hold of the whip from behind the back and holds it with the point toward the inner side of the horse; then, moving himself little by little toward the centre of the circle, the trainer lets out the longe, coil by coil, at the same time trying to urge the horse forward and keeping him on the circle by continually pointing the whip towards the middle of the horse. The person in charge of 
the longe should, when in the centre, keep his inner foot on this spot and move the outward one forward, as the horse moves round on the circle. If the person is moving on a circle, he should always be on the same diameter as the horse.

The point of the whip, held in the direction of the horse's inner hock-joint, urges the horse forward; by directing the point of the whip towards the horse's shoulder, he is urged outward. A more forcible use of the whip is produced by flinging the cord forward in one of these directions. The cord is flung forward by a movement of the wrist. The handle of the whip, with the point turned somewhat backward and downward, is held firmly by the thumb and the first finger, the hand slightly closed, the nails turned half upward, and the arm somewhat bent at the elbow; then, in throwing the point of the whip forward by bending the wrist, the other fingers are tightened, by which the forward movement of the point is checked and the cord runs straight out in the intended direction, generally with a slight crack. To bring the handle of the whip first forward and then backward, as is done by cabmen, is wrong.

The longe is held in the inner hand by the thumb and the first finger, the position of the arm and the hand as in riding. Tensions upon the longe are made by imparting a wavy motion with the wrist, the wrist to be limber.

The eyes of the person in charge of the longe should always be directed towards the animal's 
eyes and ears, keeping his shoulders turned half way towards the horse or at a right angle to the length of the horse, in the former case by moving his inner shoulder back and the outer one forward.

If the horse is to be started or the pace to be increased, the words, "March," "Trot," "Gallop" or "Fort" (faster) are spoken in a sharp and peremptory tone. If the movement is to cease, or the pace is to be slackened or is to be changed from a gallop into a trot, the words-" Halt," "Walk," "Slow" or "Trot"-_-are spoken in a sluw and drawling tone.

To quiet a fiery horse that rushes about wildly, the words, "Foa! Foa! or Ho! Ho!" are spoken soothingly; if this has no effect, "Fy!" is shouted out sharply and threateningly while moving a little forward and towards the horse, at the same time throwing the inner hand suddenly up in the air (during which movement the longe is taken in the outer hand).

During the first longeings the voice should be assisted with signs from longe or whip.

\section{Transportation of Horses.}

In transporting horses, it is of the greatest importance to secure an experienced and reliable person to take charge of the animal and one who will carry out the orders given him. Moreover, it must be seen to that the horse is provided with everything necessary to ensure a successful journey. 
During transportation of any kind, the horse should be provided with boots (see page 43) and knee-caps on the fore legs, a strong halter with a chain or rope (see Fig. I9, page I9), a horse-cloth (see page 57) and a surcingle. A separate bridle is unnecessary, as a snaffle-bit may be buckled to the rings on the sides of the halter by means of two loose straps.

If the horse is to be ridden or led along the road, the shoeing and saddling should be strictly looked into; if necessary, interfering boots (see page 44) are put on. If the person in charge be unacquainted with the route, he should, if possible, try to obtain some information about the best places for rest at noon and at night beforehand; instruction should also be given for feeding on the way. In hot weather one should rest during the warmest part of the day; travelling at night should be avoided. Feeding is restricted to three times a day-in the morning before departure, at noon, and in the evening after the arrival at night-quarters. Before the horse is put up, the stable should be examined. If the animal is ridden, the saddling should be examined frequently while on the road.

In travelling by rail, injuries to the horse's tail, back of the thighs, and the points of the hocks may be prevented by supplying an ordinary four-bushel sack which is sewn together lengthways by three seams at equal distances, thus forming four separate bags, which are stuffed with straw and then fastened on the wall of the 
car behind the horse. Plaiting straw into the tail is often done. The wagon-floor and the ramp should be covered with sand and straw. It is also necessary, during long journeys, to take along a pail for watering and feeding.

Before entraining the horse, the car should be carefully examined to see if the bar, to which the animals are tied, is in order, and that the ventilating shutters may not knock to and fro while en route. The ramp must be examined to see if it is properly fastened and lies steady. If possible, a person should be placed on each side of the ramp to prevent the hind part of the horse from stepping aside. The man leading the horse into the car should go in front (see page 77). If the horse does not follow willingly, one may sometimes succeed in making him back into the car; but the surest way is to place a thick rope, held by two persons, behind the horse just above the hocks; when the horse stops or balks, a pressure from the rope forces him forward. When the horse is in the car, he is placed with his head in the direction in which the train is moving and in the middle of the space set apart for horses; then the bar is fastened and the horse tied with the rope quite short; the bridle (or the bit) is not taken off before the train has started and the animal proves to be quiet; during this the person in charge remains standing in front of the animal, holding it by the reins, and quieting it by caresses and soothing words, giving fodder from the hand. If the horse be very nervous, a strong rope should be placed 
over his neck and fastened to the bar on each side, preventing him from raising his forehand, and placing the fore legs over the bar, or from knocking his head against the roof.

If more than one horse is to be put in the same car, the first one should be placed along the wall opposite to the entrance, the other ones, in succession, by the side of the first. In this way both spaces of the car are filled; the heads of the horses are turned towards the middle of the car, and the most nervous animals with their heads in the direction in which the train is moving.

The best cars for horses are those with partitions, i.e., a stall for each animal. A single horse should be placed in the middle stall. Usually the partition-walls are arranged to move on hinges placed on the short walls of the car. Before entraining, one or more of the partition-walls are thrown back towards the entrance, according to the breadth of the car and the number of animals to be shipped. When the horse is in his place, the partition-wall is bolted.

In detraining, the same precautions are observed with regard to the ramp, etc., as in entraining. The horse being bridled, he is loosed from the bar which is brought out of the car. With more than one horse, the one furthest from the entrance should be taken out first. In cars with partitions, these are opened and thrown back as the horses are taken out.

While on the way, the horse is fed principally with hay from the hand. Oats and water are 
given only when the journey is longer than one day and then during the longest stops which the train makes.

The risk involved in transporting horses by water is far greater than it is by rail, because, in addition to the external injuries which the rolling of the ship may cause, the animal is subject to the risk of taking cold and to stoppage of the bowels-to say nothing of sea-sickness, which often kills a horse.

On long sea voyages and when a heavy sea is to be feared, the horse should be placed in a strong and well padded stall, which may be constructed for the occasion, or be a shipping-box of separate parts put together, and in which the horse may be hoisted on board. As the padding of such boxes is usually too hard and scant, they should be provided at the front and back with a sack, stuffed and arranged as before mentioned. A strong rope, padded in the middle, is stretched just in front of the horse's withers from the one wall of the stall to the other, and a sling is put under his belly. The best position for a horse aboard ship is amidships, and so situated that the smell from the engine-room and galley is minimized and there is as little draught as possible. On sea voyages in particular, the horse should be well covered up; a tarpaulin placed over the stall will shelter him from draughts and sea-spray.

If the horse is led on board, the same precautions are taken as in entering a train. When hoisted on board in a sling, the sling must not be 
detached as soon as the horse's feet touch the deck, but be kept under him for a while, until he stands firmly on his legs.

In order to prevent stoppage of the bowels $4 \frac{1}{4} \mathrm{lbs}$. of bran should be given daily, otherwise hay is the principal fodder; 4 qts. of oats a day are sufficient, but the horse needs more water than when travelling by land.

During long sea passages, the legs of the horse need rubbing at least two hours a day.

\section{Treatment of Sick Horses.}

As veterinary assistance cannot be obtained everywhere and at all times, all riders should know a little about the most ordinary ailments of the horse, their symptoms and the precautions to be taken against them.

Diseases are called external or internal, according to their nature; as a.m. of c., the former are easier to understand as regards symptoms and treatment, I shall confine myself principally to them.

Lameness is known by the horse not supporting himself evenly on all four legs, by which the pace becomes irregular. The first thing to do is to find out in which leg the horse is lame, next the cause of the lameness.

In order to decide on which leg the animal limps, it is moved along at a walk and a slow trot. The leg upon which the horse leans most lightly and for shortest time is the lame one. If the horse 


\section{$-269-$}

be lame on a fore leg, he throws his head upward when he treads upon the sore foot; in limping on a hind leg, he lowers his head when the lame foot is planted. If the lameness be considerable, it often shows itself when the horse is standing, as he will lean lightly or not at all on the affected leg.

If the horse goes lame suddenly during riding, the lameness will often pass away after riding for a short time at a walk or by letting the horse stand still for a short while. If the lameness does not cease, or if it grows worse, one dismounts and examines the lame limb closely. Such examination should start with the under surface of the hoof and, if necessary, be continued upward all along the leg.

If it be only a stone or the like which has stuck fast in the hoof, the lameness will, as a rule, cease when the object is removed. If some pointed object, such as a nail, has penetrated into the sensitive part of the hoof and the lameness does not cease when the object is drawn out, the shoe should be taken off, the hole made in the hoof cleansed and filled up with tow or cotton saturated with aloetic tincture, and the hoof placed in a bag filled with pieces of ice or sawdust wetted with cold water. When the shoe is replaced, no nail must be put near the sore place.

When bruising of the sole of the foot happens, the sore place becomes apparent as a dark spot which arises from extravasation of blood or matter. By having the farrier pare the horn over 
the diseased place and make an opening in the sole, the blood and matter will flow out, after which the same treatment is applied as in the case of pricking by a nail. Horses suffering from bruising or pricking of the foot will show pain when the sore spot is tapped with a hammer or pressed with pincers; such animals may, as a rule, be used after being treated as mentioned, when the shoe is so arranged as not to press the diseased place.

Thrush means that the frog of the hoof decays, becomes soft and shreddy and secretes a gray malodorous humour. The disease is generally caused by dirt coupled with want of exercise. By washing with a solution of carbolic acid, and afterward filling the furrows of the frog with oakum or tow, the latter being saturated with carbolic alcohol ( 1 part of carbolic acid with Io parts of alcohol), the disease may be cured.

Among other diseases most frequently found in the hoof may' be mentioned hoof-fissure, that is, a crack in the wall from the edge upward or from the coronet downward; and cavity under the walls, that is, a hollowness underneath the external crust. By proper shoeing the evil may be partly remedied and the animal made fit for use.

Founder is an inflammation in the quick of the foot which becomes very warm and sore. The animal stretches its legs forward and rests on the quarters. Very frequently the cause is overfeeding or drinking too much cold water when 
the horse is exerted and warm. The patient should be placed on soft, cold and moist ground, be fed only with hay, and be given water with the chill off. The shoes must not be taken off immediately.

Ring-bone is a bony enlargement in front of and at the sides of the coronet; it is due to inflammation in the coronary-joint, from which exostosis form around the coronet. The treatment should be the same as in the case of spavin.

Grease appears at the back of the pastern and fetlock and shows itself in the shape of vesicles, cracks or ulcers from which a malodorous humour flows and which forms scabs. It is most frequently caused by uncleanliness, dampness and cold, or by having the fetlock clipped, thus exposing the back of the pastern to slush from sloppy roads. To prevent the disease, the pastern is kept clean and dry, the use of peat moss for bedding has also proved effective. The treatment of grease consists in washing the diseased place with lukewarm soapsuds, then rinsing and wiping it well off and rubbing with oil or cerate, added to a little carbolic acid. Iodine ointment is also frequently used. To prevent the recurrence of the disease, the same treatment should be given every time the horse is taken out on dirty and wet roads.

Wind-gall, which is an inflammation in the fetlock joint or in the sheath of the tendon at the lowest part of the shank, shows itself as soft swellings full of humour and which in time may turn hard as bone. If wind-gall does not appear to a great extent, the animal rarely goes lame 
from it. Massage (see page 64) or bandaging (see pages $6_{5}$ and 66 ) is the best way to prevent and remove the disorder. If the horse is not lame, wind-gall will increase rather than diminish by too much rest.

Inflammation of the tendinous tissues appears as swelling, soreness and heat in the back tendons; it is easily discovered by passing the finger tips lightly along the tendons. The disease is due to overwork, strains or blows. By complete rest with massage and cooling fomentations, the evil may be removed. A compound of $1 / 4$ alcohol and $1 / 4$ vinegar with $\frac{2}{4}$ of water may be used as a fomentation having a discutient effect.

Splint is the name of a bony enlargement of the canon bones; it arises from inflammation in the periosteum (periostitis), caused by blows or kicks. On the inside of the shank it is, as a rule, due to the fact that the horse knocks one leg against the other while in motion. By the immediate use of cooling fomentations and massage, the formation of splint may be prevented. If, on the other hand, the splint is fully developed but not too old, an acrid ointment ( $I$ part of biniodide of mercury with ro parts of purified fat) may be applied. After the hair has been clipped off, the splint is rubbed for about ro minutes with the ointment. In case the horse does not walk lime, he may be used if the following treatment is carried out: The splint is rubbed once a day on two consecutive days; during the next six days no rubbing is applied, after which the 
treatment is repeated on two consecutive days, and it is thus continued, until the splint is completely removed. In order to prevent the acrid ointment from flowing down on the leg, it is oiled below the diseased place. When the horse is in use, "shin-boots" should be used.

Malanders is situated at the back of the knee and in front of the hock. The signs, the cause, and the treatment of the disease are the same as for grease.

Spavin (bone-spavin) is an exostosis caused by inflammation in the hock joint, sometimes called spavin-protuberance. If the inflammation cannot be checked, it will most frequently result in a symphysis of the small bones of the hock. Bone-spavin is situated on the inside of the hock joint and is felt as unevenness, when passing the fingers along the inside of the hock joint. The lower down on the joint the spavin is situated, the less serious it is. In most cases the cause of the disease is over-exertion, but it may also be due to heredity. Not being sure whether the horse be spavined or not, he is put to the so-called spavin-test, which is carried out by taking hold of the shank and lifting it forward in a way that the hock joint is bent forcibly; in this position the leg is kept 2 or 3 minutes and is then dropped, after which the horse is immediately put into a trot. If it be spavin, the animal will, during the first few steps, show considerably more lameness than before. The inflammation being discovered at its very beginning, it may be removed by 18 - Handbook for Riders. 
cooling fomentations and rest. Recently formed spavin-protuberances may be removed by rubbing with acrid ointments. Old spavin is incurable.

Bog-spavin is a soft tumour on the front and inner part of the hock joint; as a rule, it does not prevent the use of the horse.

Curb is a hard protuberance at the back of the hock about $2 \frac{1}{2}$ inches below the point of the hock. On aged horses, curb is generally of no consequence.

Jardes are exostosises on the outside of the hock; they do not interfere with the horse's useful ness, but are unsightly.

Capped hock is a swelling on the point of the hock, generally caused by blows or knocks, which the horse may either have inflicted upon himself or may have contracted during transportation by rail or by ship. As long as the inflammation lasts, cooling fomentations are applied. The swelling not being warm, discutient salve is applied. Capped hock rarely causes lameness.

Capped elbow is a swelling on the point of the elbow, generally caused by pressure of the shoe or of the hoof when the animal lies down with its knee much bent. This tumour being soft and warm, cooling remedies are applied, but if it is cold and hard, it should be fomented with spirit of soap or rubbed with green soap. If the swelling breaks, it should be kept open by stuffing the hole with tow or the like until the substance of the tumour is evacuated. In order to prevent capped elbow from re-forming, a thick padded leather ring 
should be placed about the pastern, by which the hoof (or the shoe) is prevented from touching the elbow when the animal lies down. Instead of such a ring about the pastern, a pad well stuffed with straw may be placed underneath the animal's chest and fastened with a broad strap across its back; in adding a breast-plate, the pad is kept close to the elbow.

Capped hock and capped elbow may, at their very beginning, be removed by rubbing with claysilt (clay mixed with vinegar or Goulard's extract), which is left on until it drys.

A condition, found not infrequently in riding horses, is the so-called knuckling over; that is a sprain or wrong bending of the fetlock-joint, caused by the horse making a false step or by being pulled up too suddenly and, perhaps, in a wrong manner. Slight knuckling over does not, as a rule, cause any lameness, at any rate not of longer continuance than will pass away by riding at a walk or by making a stop for a while. If the horse, after knuckling over, does not lower the fetlock properly and if it be warm and sore, a bandage is put tightly around the joint and constantly soaked with cold water.

If the horse has swellings or bruises caused by any part of the saddlery, he is said to be galled. Swellings are treated with cooling remedies, for instance, fresh cut green turf, which is placed with the grassy side on the swelling and constantly soaked with cold water. Bruises are cleansed with a solution of carbolic acid and smeared with 
zinc-salve or cerate prepared with carbolic acid (or carbolic oil). The gall being caused by wrong saddling or by defects in the saddlery, the defect should be adjusted and, if the horse must be used, a strip of linen soaked in melted tallow is placed on the injured place. Galls on the withers are among the most serious and are slow in healing.

In wounds that are only bleeding slightly, the bleeding may be staunched with cold water, snow or vinegar. The wound should be cleansed and disinfected by syringing with solution of carbolic acid (or of sublimate) and be smeared with carbolic oil (or iodic powder), after which the edges of the wound are pressed well together and a dressing is put on. If a wound is bleeding profusely and is deep a wad of clean tow, immersed in cold water and vinegar, may be pressed firmly into the wound; the bleeding not decreasing, more tow is put on, while constantly fomenting with cold water until the bleeding is stopped, after which, if possible, a bandage is put on. Being sure that the bleeding is arrested, the bandage may be taken off, the wound cleansed, disinfected and stitched up. Deep wounds in the joints must be immediately stopped up and bandaged, as it is very dangerous to expose such wounds to the influence of the atmosphere for any length of time.

Internal diseases disclose themselves most frequently by certain external symptoms, as, for instance, drooping of the head, of the ears and of the under lip, dim and half-closed eyes, pinched together nostrils and roughness of the coat. 
Amongst other symptoms of internal diseases may be mentioned: want of appetite, much thirst, short and rapid breathing, discharge from the nostrils with their mucous membrane yellowish or very dark red, profuse sweating, abnormal droppings, obstruction, frequent passing of water, etc. In such cases and until veterinary aid can be obtained, the following measures of precaution are taken: the quantity of fodder is lessened, especially oats, the drinking water is given with the chill off, plenty of straw for bedding, rubbing with wisps of straw and covering the horse well.

Colic is a sickness that every rider should know about; it arises suddenly, progresses quickly, and must be attended to speedily, otherwise it may prove fatal. The most ordinary causes of the ailment are bad food, cverfeeding, especially when the animal is much exerted, change of food, and sudden exposure; cold drink, when the horse is warm, may also cause colic. Horses may have more or less tendency to this trouble on account of the digestive organs being out of order; horses that are windsuckers are particularly disposed to this ailment. The external symptoms of the sickness become apparent in the animal getting suddenly restless, wanting to lie down and immediately springing to its feet again or rolling over on its back, in placing all four legs in under itself, pawing with the fore feet, kicking itself under the belly with the hind feet, whipping the tail, looking back towards the belly and biting itself at the skin of the belly. Besides treating the animal as 
prescribed for internal diseases in general, it should be well rubbed with wisps of straw under the belly and be moved at a walk and at a slow trot without making it warm. As a remedy, give 0.28 ounce of chlorat barycum dissolved in 3 qts. of water with the chill off. If there is no relief within a short time, an injection of oil and warm water should be given. For some time after recovering from colic, measures of precaution should be taken in the feeding of the horse.

The pulse of the horse may be felt in the easiest way at the inside of the lower jaw, near the jowl, by placing the first and middle finger on the inside of the jaw, the thumb on the outside. If the glands at the throttle be swollen, the pulse should be felt at the temple or at the elbow. In a healthy and full-grown horse, the average pulsation is from 32 to 40 per minute; in stallions from 28 to 30 .

The temperature of the horse is taken by a thermometer, which is put into the rectum and left there for 3 minutes. The normal temperature is about $100^{\circ} \mathrm{F}$.

The normal respiration of the horse is from ro to I 2 per minute.

\section{Quadrille Riding.}

When the various figures and exercises, which have been taught in school-riding, are performed by several riders in pairs and in a class, they are called quadrille riding. Such riding should be 
performed at the collected paces but so that marching up, forming line and changing of places are done at a faster pace. An even pace with precision in the performance of figures and exercises gives elegance to this kind of riding, which is still further enhanced by ladies taking part in it and when ridden to music. Quadrille riding may be performed at the sides of the school as well as on the great circle or on both. The distance between the horses should be arranged according to the number of riders and the size of the school.

The following very easy figures are examples:

I. An equal number of pairs of riders are arranged in line at one of the short sides of the school, facing the other short side, the ladies to the left and the gentlemen to the right of the

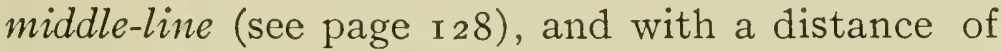
I step between the horses.

Words of command:

I. "Salute!"

All salute. Ladies with the tops of their whips to their hats; gentlemen taking their hats off down to their right sides, their right arms perpendicular.

2. "Advance by Twos, from the middle (and the pace)-March!

The middle pair moves straight forward; the others move, one by one, simultaneously from both sides of the leading pair and half turn to the right and left towards the middle-line, where they continue at a horse's length from the pair in front and straight behind the one leading. 
3. "Leading Pair, Right and Left TurnMarch!"

Performed when the leading pair has advanced to the short side of the school, and by parting in turning right and left and continuing, one by one, along the sides of the school; thus pair by pair follow.

4. "In Travers, Right and Left, Half TurnMarch!"

The riders in the rear having passed the first corners, all move their horses by a half turn and in travers parallel to the long side of the school until meeting each other at the middle-line, whereupon they ride by pairs straight ahead.

5. "Leading Pair, Right and Left TurnMarch!"

Performed the same as no. 3 .

6. "Long-Passade!" (See page I8o.)

Performed when both the leading riders have passed the long sides of the school.

7. "Long-Passade!"

Performed when both the leading ridersafter the first passade, and after having advanced at the long side of the school-have reached the corners.

8. "Great circle-March!"

Performed when both the leading ridersimmediately after the passade-have reached the "marks" of the great circle situated opposite to each other (the great circle touching the short side). The riders to the left hand keeping a little inside the track of the great circle, thus passing 
with the right side towards the riders moving to the right hand.

9. "Chain!"

Performed while on the great circle by alternately turning the right and the left side towards each other, the leading riders beginning with the right side towards each other.

Io. "The Chain Ceases!"

Riding on the great circle is resumed in the manner described in no. 8.

I I. "Straight on, Turn Across the SchoolMarch!"

Performed when both front riders are by the "marks" of the great circle at the long sides. The central point of the school is first passed by the rider in front coming from the left hand and then alternately by one from the right and one from the left hand.

I2. "Leading Riders, Right and Left TurnMarch!"

Performed when both front riders, after having passed across the school, have advanced to the middle of the short side, whereupon they ride by pairs along the middle line of the school.

I 3. "Circle Right and Left-March!"

Performed when all the pairs are on the middle-line; those on the right side making a small circle to the right and those on the left side to the left.

\section{I4. "Change!"}

Performed when, in accomplishing the small circle, all are oblique to the right or to the left of 
the middle-line; when, meeting each other, they ride by pairs straight along the middle-line.

\section{I5. "Circle Right and Left-March!"}

Performed before the front pair has reached the short side and otherwise the same as no. I3.

I6. "Change!"

Same as no. I 4.

I7. "By Pairs, Alternately Right and Left Turn-March!"

Performed when the leading pair has advanced to the short side of the school, the front pair turning to the right, the next one to the left, etc., then moving along the sides of the school, the front pairs keeping abreast of each other.

18. "Leading Pairs, Right and Left TurnMarch!"

Performed when, after the foregoing exercise, both front pairs have passed the long sides and have advanced to the middle of the short side. In this manner, two pairs ride side by side along the middle-line, thus forming lines of four.

I9. "By Pairs, Right and Left TurnMarch!"

Performed when the front pairs have advanced to the short side. Pairs on the right side turn to the right and those on the left side to the left, all moving along the sides of the school.

2o. "Even Pairs, Left Half Turn-March!"

Performed when the pairs are at the long sides. Second, fourth, etc., pair turn half to the left, thus moving obliquely across the school 
towards the opposite long side, where they resume their places behind first, third, etc., pair.

21. "Leading Pair, Right Turn-March!"

Performed when the front pair has advanced to the middle of the short side.

22. "Right and Left Form Line-March!"

Performed when, after having accomplished no. 2I, all the pairs are on the middle-line. The front pair continues moving at a walk or goes into a walk, if the pace be a faster one; riders on the right side ride at the extended gallop and, in half turning to the right, form in line with the front pair, and pass into a walk. Those on the left side do the same to the left.

23. "Halt!"

When the line is formed.

24. "Salute!"

Same as no. I.

II. Christmas tree quadrille.

In the centre of each great circle (the circles touching the short sides) a high fir tree is placed with a solid foundation, trimmed like a Christmas tree and hung round with small presents at a suitable distance from the ground, and without candles on the lower limbs.

An equal number of pairs of riders are arranged in the same manner as described in I. Pairs of riders, moving along the middle-line, part in passing the trees in a half small circle, each on their side of the tree. In meeting, the riders pass each other with the right side towards each other. When single riders pass the trees along the middle- 
line, it is performed in a half small circle with the right side towards the trees. The ladies wear bows of silk ribbon on their right shoulders, and the gentlemen on their left shoulders, each pair wearing a different colour. The riders may also carry on their right hip a bag with bandoleer over the left shoulder, both being of the same colour as the bow. The bags are intended to hold the presents that may be snatched from the trees.

Words of command:

I. "Salute!"

Performed the same as I, no. I.

2. "Advance by Single Riders from Right and Left, Short Trot-March!"

The riders trot, one by one, simultaneously from both flanks and half turn to the right or left, with a horse's length between each other on each long side of the school.

3. "Leading Riders, Left and Right TurnMarch!"

Performed when the front riders meet at the middle of the next short side, whereupon they ride by pairs along the middle-line and pass the trees.

4. "Leading Pair, Right and Left TurnMarch!"

Performed when the front pair, having passed the middle-line, is by the short side of the school, where the pairs part, then moving, one by one, along the sides.

5. "Turn Across the School-March!"

Performed when, after the foregoing turn, 
the riders have passed the first corner of the school. The central point of the school is passed same as I, no. II.

March!"

6. "Leading Riders, Left and Right Turn-

Performed same as no. 3 . March!'”

7. "Leading Pair, Right and Left Turn-

Performed same as no. 4.

8. "Ladies, Great Circle-March!"

Performed when, after the foregoing turn, the leading lady is by the "mark" of the first great circle at the long side. The gentlemen continue riding along the other long side of the school.

9. "Gentlemen, Great Circle-March!"

Performed when the leading gentleman has reached the "mark" of the other great circle by the other long side.

го. "Diminish the Circle-March!"

All the riders move their horses towards the trees and try to snatch the presents from them, keeping distance and pace.

I I. "Half Circle-March!"

All ride a half circle out to the track of the great circle, by which they all come over to the other hand, when the former front rider will be in the rear.

I 2. "Diminish the Circle-March!"

Like no. Iо.

I3. "Half Circle-March!"

Same as no. I I. 
I4. "Straight on, Leading Riders, Right and Left Turn-March!"

Performed by both front riders at the same time and from the middle of the short sides. All ride along the middle-line with the right side towards the trees and towards each other.

I5. "Leading Riders, Diminished CircleMarch!"

Performed by the front riders, after having passed one of the trees, riding a "diminished" circle to the right around the other tree. The other riders follow the front rider, and the presents are again snatched from the trees.

16. "Half Circle-March!"

Same as no. II.

I 7. "Straight on, Leading Riders, Left TurnMarch!"

Like no. I4, only the turn is made to the same (left) side by both parties.

18. "Leading Riders, Diminished CircleMarch!"

Like no. I 5 but not round the same tree.

I9. "Half Circle-March!"

Same as no. II.

2o. "Gallop-March!" (Middle speed.)

2I. "Straight on, Turn Across the SchoolMarch!"

Is performed at the same time by both front riders and from the "marks" of the great circles on the opposite long sides. Riders pass with the right side towards each other.

22. "Jeu de Barre!" 
The gentlemen ride in a faster gallop up to the inner side of their iadies and try to take the bows off their shoulders; when they succeed in doing this, they keep by the side of their ladies.

23. "Leading Pair, Right Turn-March!"

Performed when the front pair is at the middle of the short side.

24. "Right and Left, Form Line-March!"

Performed when the front pair has passed the first tree and then falls into a walk. Riders on the right side (gentlemen) ride in a faster gallop the shortest way up in the line. Those on the left (ladies) do the same. Then all take the same pace as the front riders.

25. "Halt!"

In the middle of the ring.

26. "Salute!"

Same as no. I.

There may be introduced in this quadrille still another figure, by having ladies and gentlemen ride a "half circle," each from their track of the great circles, towards the trees, thereby all moving on the diminished great circle, from whence the track of the great circle may be resumed at the command, "Enlarge the Circle-March!" (see page I87). The same is repeated to the other hand. At a collected gallop with changing à tempo, this figure looks well, but it requires accomplished riders and well schooled horses.

This quadrille may be performed without the Christmas trees, if the centres of the great 
circles be marked, for instance, by poles with flags attached to them.

III. Quadrille on the great circle is performed either by 4 pairs or by 4 single riders.

With 4 single riders, 2 being ladies and 2 gentlemen, they should be placed on the middle line in file at a distance of $\mathrm{r}$ step, the rider in the rear having the hind feet of his horse on the track by the short side of the school. The riders are numbered from the front, No. I being a lady, No. 2 a gentleman, etc.

Those figures which are not performed singly or by all four at the same time, but by each pair vis-à-vis separately, should always be commenced by the odd numbered pair ( $\mathrm{I}$ and 3 ).

Words of command:

I. "Short Trot-March!"

2. "Leading Rider, Right Turn, Great CircleMarch!"

Performed when the leading rider has reached the short side of the school.

3. "Take your Places!"

Performed when rider No. I has ridden once round on the great circle. Rider No. 4 halts with the horse's hind feet on the "mark" of the great circle by the short side of the school, No. 3 in the same manner on the next "mark," No. 2 on the next, etc.

\section{4. "Face!"}

All turn their horses on the haunches until vis-à-vis partners are facing each other.

5. "Vis-à-Vis, Salute!" 
All ride at a walk straight forward towards the centre, halt and salute when at a horse's length distance between the heads of the horses. Having performed the salute, all back their horses simultaneously to their places.

6. "Vis-à-Vis Change Places!"

Riders No. I and 3 put their horses simultaneously on the short gallop left and ride with their left side turned towards each other across the circle, each halting on the other one's place, and turning the horse on his haunches to the left, again facing each other, when the same is performed by Nos. 2 and 4 . In the same order and manner, the figure is then repeated at the gallop right with the right side towards each other and by turning to the right, thus every one resuming his (or her) original place.

7. "On the Circle to the Right, Short TrotMarch!"

All make $1 / 4$ turn on the haunches to the left and pass into a short trot.

8. "Diminish the Circle-March!"

(See page i 86.) On the diminished circle the distance between the horses should be a horse's length.

9. "Right about--March!"

All make $1 / 2$ right turn on the haunches, change the bend of the horse and continue at a short trot on the diminished circle to the other hand.

ıо. "Left about-March!"

Same as no. 9 .

$19-$ Handbook for Riders. 
I I. "Enlarge the Circle-March!"

(See page I87.) In reaching the track of the great circle, the distance between the riders will be the same as before the diminishing of the circle.

I 2. "Resume your Places!"

All halt at their "marks" (see no. 3).

I3. "Face!"

Same as no. 4.

I4. "Vis-à-Vis Half Circle about Centre, Short Gallop-March!" .'

Riders No. I and 3 make $1 / 8$ turn on the haunches to the right-from this position putting their horses on the gallop left-ride with their left side turned towards each other a half small circle about the centre, and return to their original places, where "Halt" and "Face" are made (see no. 6). Then the same is performed by Nos. 2 and 4. In the same order and manner, the figure is then repeated at the gallop right.

I5. "On the Circle to the Right, Short TrotMarch!"

Same as no. 7 .

I6. "Circle-March!"

Performed when all are at their "marks" (otherwise see pages 188 and 189 ).

I 7. "Circle-March! Change!"

Performed when all are at their "marks" (otherwise see pages I 89 and I90).

I8. "Circle-March!"

Same as no. I6.

I9. "Circle-March! Change!"

Same as no. I 7 . 
In changing from small circles made from the track of the great circle, the horses are directed towards the corners of a square, in which the great circle might have been inscribed, the sides of the school partly forming the square.

20. "Resume your Places."

Same as no. I 2.

2 I. "Face!"

Same as no. 4.

22. "Serpentine!"

Performed at the short gallop. Rider No. I makes $1 / 8$ turn on the haunches to the right, and rides at the gallop left in front of and past No. 2, then changes the gallop and rides at the back of No. 3, who has advanced half a horse's length from the track of the great circle while No. I passes. When No. I has passed behind her vis-à-vis, the gallop is again changed and, after passing in front of No. 4, "Resume your Place" and "Face" are performed. Then the same figure is performed in numerical order and in the same manner by the others.

23. "On the Circle to the Right, Short GallopMarch!"

Performed the same as no. 7 , but at the gallop.

24. "Vis-à-Vis Change Places!"

Riders No. I and 3 ride the shortest way across the great circle at a faster pace, with the right side turned towards each other and towards the centre, each taking the other one's place, where 
the original pace is resumed; the same is then performed by Nos. 2 and 4.

25. "Right about-March!"

All halt, make $1 / 2$ right turn on the haunches and change the gallop.

26. "Vis-à-Vis Change Places!"

Performed same as no. 24 , but to the other hand.

27. "Resume your Places!"

Same as no. I 2.

28. "Face!"

Same as no. 4.

29. "Vis-à-Vis Salute!"

Same as no. 5 .

30. "On the Circle to the Left, Short GallopMarch!"

Performed the same as no. 23, but the turn on the haunches is made to the right.

3 I. "Double!"

The ladies (Nos. I and 3) ride at a faster pace up to the inner side of the gentlemen (Nos. 2 and 4 ).

32. "Double!"

Riders No. I and 2 ride at a faster pace up to the inner side of Nos. 3 and 4.

During the doubling, the pace is increased sufficiently at the outer flank to allow the inner one to maintain the original pace (short gallop).

33. "Advance by Single Riders from Right, Extended Gallop-March!"

Rider No. 4 advances at the extended gallop on the track of the great circle; when No. 4 has 
passed the others by $1 / 4$ circle (in the meanwhile the latter moving with their outer flank towards the track of the great circle) No. 3 and the other riders in succession go into the extended gallop, until all are on the track with intervals of $1 / 4$ circle.

34. "Short Gallop-March!"

35. "Left about-March!"

All halt, make $1 / 2$ left turn on the haunches, and change the gallop.

36. "Double!"

The gentlemen (Nos. 2 and 4 ) ride at a faster pace up to the inner side of the ladies (Nos. I and 3 ).

\section{7. "Double!"}

Riders Nos. 3 and 4 ride at a faster pace up to the inner side of Nos. I and 2.

38. "Advance by Single Riders from Left, Extended Gallop-March!"

Performed same as no. 33, but beginning with Rider No. I.

39. "Short Gallop-March!"

40. "Left Form Line, Leading Rider Right Turn-March!"

The line is formed as described on page I 3 I, but facing the short side of the school, the centre of the great circle being between Riders Nos. 2 and 3 , and with I step distance between the horses.

4 I. "Halt!"

When Rider No. I is abreast of the centre.

42. "Salute!"

All salute, making their horses perform a pesade (see page I57). 


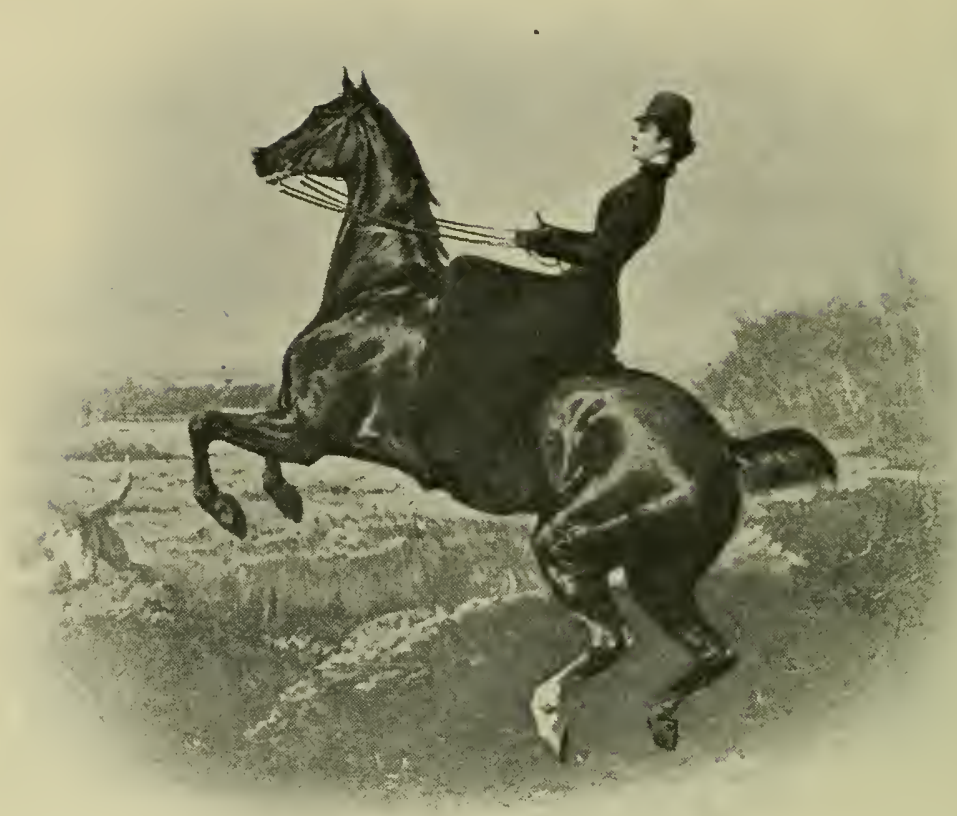

Fig. 6I.

ELIZABETH, THE LATE EMPRESS OF AUSTRIA. A Model Horsewoman.

\section{Ladies' Riding.}

As riding in a side-saddle may be understood from what has been written here about riding astride, I shall, with regard to the former, discuss only what every rider should know in order to be able to lend assistance and a little guidance to ladies, when riding in their company-taking it for granted that the lady is conversant with riding, and mounted on a horse broken to side-saddle. 
A lady's dress for riding requires much care and attention. There is scarcely anything that contributes so much in spoiling a riding lesson, or the pleasure of a ride with ladies, as derangements of dress.

Riding apparel should be simple and comfortable without any trimming of feathers, bows, braids, ornaments, ${ }^{*}$ etc. The habit should be made of a suitable dark cloth. The bodice, with a low upright collar, may be buttoned all the way up to the neck, or with a lay-down collar, it may be buttoned so as to leave an opening for a shirtfront. The sleeves should be without puffs at the shoulders, regardless of fashion. In case shirtcollar and cuffs are used, they should be white.

The length of the skirt should be so as just to cover the left foot of the rider when on horseback, the skirt itself being of the safety type. Two elastic loops are fastened on the inside of the skirt and in a manner that they may each be slipped on a foot, but not at the heel, in order to prevent the skirt from working up during riding. The bodice is fastened to the skirt by hooks and eyes or, better still, by a strap with button-holes at the back of the bodice, and corresponding buttons on the skirt. No other skirts should be worn while riding.

Stiff stays should not be used, an ordinary slip-body, the so-called sanitary stays or the rubber corset are preferable. At any rate, this

* A small veil on the hat and at the neck a small brooch in the shape of a horseshoe or the like should be the only ones. 
article of dress must not reach too far below the hips, or it may cause much discomfort.

The riding pants should be made of dark elastic material and tight-fitting. Riding boots, their tops reaching midway up the calf and with or without a spur buckled on the outside of the left heel, are preferable to ordinary walking boots, which must, at all events, for riding be without buttons.

Black silk hat, a Derby or jockey-cap of the same colour as the habit are the most practical and most becoming head coverings; as a rule, they are fastened with a narrow elastic band under the hair at the back of the neck.

The hair should be well fastened, for which purpose bands of the same colour as the hair are used instead of hair pins. If the hair cannot be fastened properly, it is better to leave it loose, particularly so during the first lessons, when appearance must give way to what is most practical.

The gloves must not be tight, and should be made of buckskin or dogskin.

The riding-whip (the lady's right leg) should be sufficiently long, and neither too thin nor too pliable, because it would then not be able to produce a pressure like that of the leg, and if no influence can be exerted on the horse by the whip, unless by striking him, the animal will become nervous and afraid of the whip, which a lady's riding horse must not be. Besides, a constant use of the whip in this manner does not look well. Consequently, those lady's light riding whips, 
which are usually sold, are not at all fit for lady's riding.

Pins and long hat-pins, on which, while mounting and dismounting, the person in attendance may tear his hands or get his eyes put out, should not be found in a lady's riding apparel.

A lady's riding horse should in every respect be as nearly faultless as possible (see pages 8-io).

The lady's position on horseback, with the considerable length of the side saddle, require that the horse should have a well-marked portage for the saddle, a not too short back, sure and not too low movements of the fore legs, and easy gaits. The horse should also have no bad habits (see page $23 \mathrm{I}$, III), but a lively temper and be well schooled; his mouth should not be too sensitive, that is, a lady's horse must never be behind the bit (see page 99), and must readily obey every influence of the rider's leg, whip and weight.

The side-saddle would neither put horse owners in such fear, nor be so often a hindrance to ladies' riding, if more attention were paid to the convenience of the horse and-pardon me, ladiesa little less to the convenience of the rider; because the galls, unfortunately too often caused by side saddles, would then virtually be avoided. It does not follow, however, that a lady may be placed in any saddle, simply because it fits the horse; on the contrary, side saddles should be adapted to the individual to a much higher degree than crosssaddles.

On the other hand, the side saddle should 
fit the horse still more precisely than the crosssaddle. Thus, on horses with sharp and prominent withers and backbone, saddles with broad and low gullet should not be used; for even if the under

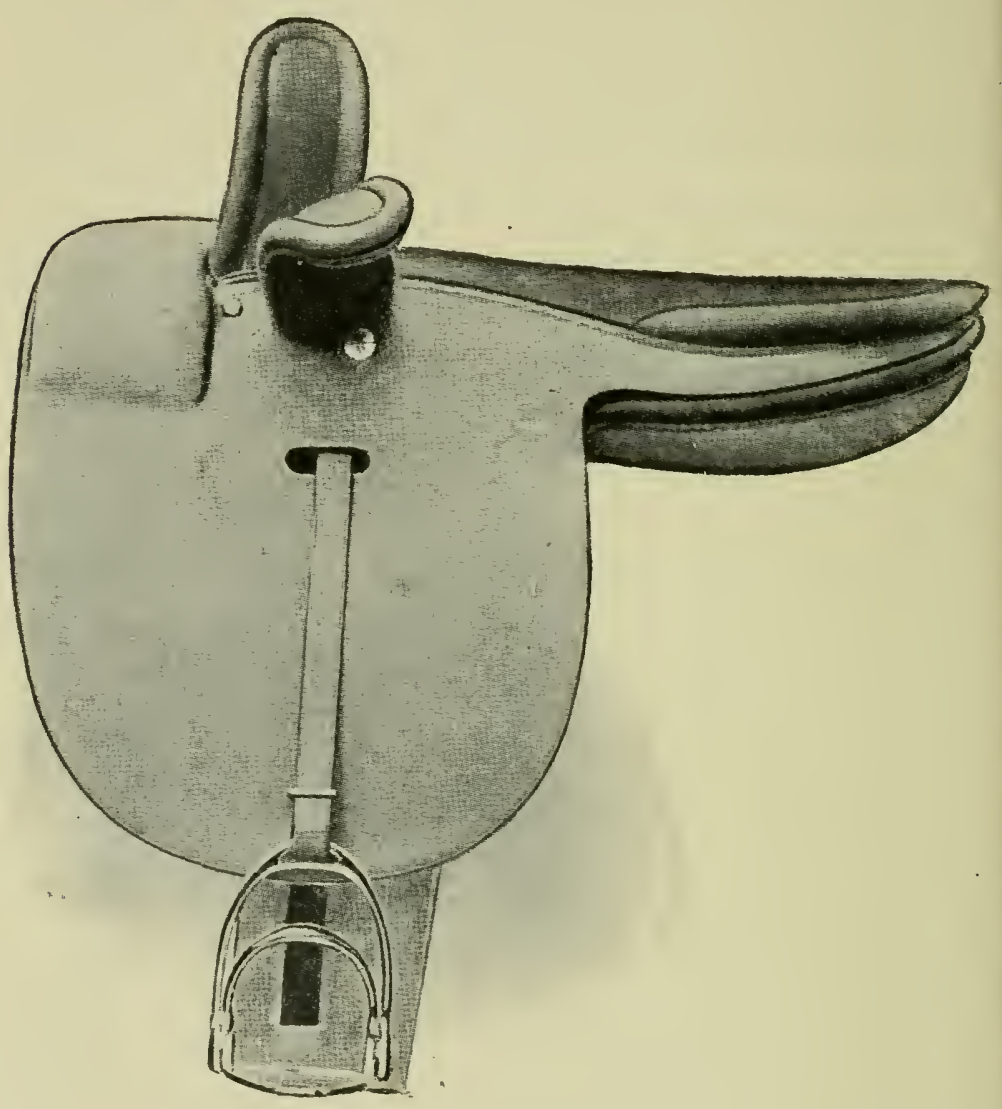

Fig. 62.

part of the pommel does not touch those parts of the animal, the saddle may, nevertheless, during riding, easily cause galls by sliding from one side to the other. The saddle panel (see page 39) 
should be made somewhat thicker on the right side of the pommel than on the left, which may either be done while the saddle is new or with more stuffing after it has been pressed together by use, because the weight of the lady's right leg makes the burden heavier on the left side of the pommel, by which the panel at the right side is pressed against the right side of the withers, causing the stuffing on this side to be pressed together and to become thinner. At the cantle under the seat, the panel should be made thicker on the left side on account of the lady's tendency to lean over to this side. In paying proper attention to these details during the use of a new saddle and as long as the stuffing has not yet settled, saddle galls, otherwise easily caused, may often be avoided; it also enables the rider to keep an equally balanced seat in the saddle more easily.

The best and safest lady's Park saddle is the one with improved level seat, all-over hogskin, with buckskin eave in seat and heads, on French cut back tree, and two hole socket (Fig. 62). The seat of the saddle should be spacious and its length in proportion to the height of the rider.* The stirrup-leather being so arranged as to enable the lady to assist herself in shortening or lengthening it at the right side of the saddle, it must be observed that the leather, which, thus arranged,

* The length from the fore-side of the upper head to the cantle of the seat should be about $3 / 4$ inch more than the distance from the lady's back line to the genuflection of her right leg, when the back is kept vertical and the right thigh horizontal. 
has to pass under the belly of the horse, does not gall the animal at the back of the fore legs (elbow), which "very often happens. To the lady's saddle belongs the safety stirrup and cord girth, the latter having a buckle on its right side for the fastening of the strap on that same side of the saddle seat, thus preventing the saddle from sliding too much over to the left.

The saddle-cloth, being of felt, should be so shaped that the horse may feel the influences of leg and whip.

The reins should be limber and not too broad. Saddling and bridling a lady's horse must be done with exactness, and is carried out in all essentials as described for a gentleman's horse (see pages 46-52); but the girthing is done on the right side. The high position of the hands, which, naturally, must be assumed when riding in a sidesaddle, often necessitates the use of a martingale, and in such case it should either be put to the noseband or its running rings should be brought outside of the curb-reins and placed on the snafflereins (see pages 42-43 and Fig. 26). The girthing and the stirrup-leather are adjusted after the lady is mounted.

If, during mounting, the lady's horse is held by an attendant, it is done with the right hand in the same.manner as in holding a gentleman's horse (sèe pages $81-82$ ), while the left hand, placed against the right side of the horse, prevents the hind part from swerving to this side.

Without a whip in her hand, the lady 
approaches the horse in the same manner as described for gentlemen (see page 83 ), bridling and saddling* are examined, and she places herself with her right side so close to the left side of the horse that she may take hold of the upper head with her right hand. With the left hand, the lady then lifts the skirt a little and raises the left foot sufficiently to permit the attendant to place his right hand under the middle of her foot and the left one under the sole of the foot, after which she leans her left hand upon his right shoulder. At a sign, agreed upon beforehand-i.e., "One, Two, Three" or "Up"-the lady shoves off with her right foot, stretches her left knee, and raises herself by her right arm; at the same time, the attendant arises from his bent attitude, by which she is lifted into the saddle. Then the rider turns herself to the right and passes her right leg over the upper head, against which it rests in an unconstrained position along the safe of the saddle. Then, if the stirrup-leather be "stationary," its length is adjusted and the foot is put into the stirrup. The skirt is now arranged by the attendant, who, in taking hold with both hands at its lower edge-while the rider, with her right hand on the front of the saddle and the left one at the cantle, rises from the saddle-draws it quickly to and fro a few times, after which the elastic loops on the inside of the skirt are placed at her right knee and on her

* In order to ascertain that the saddle does not rest on the withers, the left hand is passed under the safe of the saddle. 
feet. After having given the whip to the rider and, if necessary, assisted her in taking up the reins, the attendant examines the girthing and buckles the surcingle or, on a saddle thus arranged, the stirrup-leather at the right side of the saddle.

If the one, who assists the lady in mounting, has also to hold the horse, he does well to place the animal with its right side towards a wall; the horse is then held by the left snaffle-rein with the left hand, while the lady is lifted in to the saddle by means of the right hand alone.

The lady being so short that, when standing on the ground, she is unable to reach the upper head with her right hand, she places herself with her back to the horse and; while shoving off with both feet, is lifted into the saddle by the attendant placing his hands about her waist.

If a lady has to aid herself in mounting, the horse is placed close to a staircase or another elevated object; reins, whip and the upper head are seized with the left hand, the cantle with the right one, and, with the left foot in the stirrup, she vaults into the saddle. If, in this manner, the rider cannot reach with the foot into the stirrup, the stirrup-leather is lengthened and re-adjusted when she is mounted.

In dismounting, the whip is thrown to the ground, the hold of the reins is released, the foot is taken out of the stirrup and the loops on the skirt set free; the right leg is brought over the upper head and down along the left side of the horse and, in turning herself to the left in the saddle, 
the rider sets the skirt free of the head. Supporting herself with the right hand on the lower head and with the left one in the right hand of the attendant, she jumps down with knees bent.

The horse being very high or disposed to kicking forward with the hind legs (see page 242 ), it is advisable to lift the lady down by seizing her with both hands about the waist-while supporting herself with her hands on the attendants shoulders-she is held on straight arms and brought to the ground in such a manner as to face the side of the horse.

During mounting and dismounting, the whip being held by the rider, it should be taken at the middle and by the right hand.

On horseback, the whip is held in the right hand with point downward. In riding with the reins in one hand, the whip is held between the second and third finger, the back of the right hand being turned so much to the rear as to make arm and whip form a perpendicular line. In riding, the whip is used principally by movements of the wrist. The use of weight, legs, spur and reins is in all essentials the same as in riding astride-the whip replacing the right leg, although gallop right is frequently performed by touching the horse's shoulder with the whip. Sometimes it may be necessary to assist the left leg with the whip by the rider bringing it behind her back and down along the left side of the horse.

The weak point of the rider's position in a side saddle appears mostly in the attitude of the 
shoulders, although it is owing to that of the hip bones which should be kept square to the length of the horse and with a perpendicular but strainless position of the body from the waist up (the spine), that the shoulders will apparently seem motionless. Let me warn the fair rider against the forward and backward swaying movement of the body, so generally seen, at the gallop and also in leaping-somewhat like the top of a tree in a wind. Remember that it is the horse which is to gallop and leap, not the rider. "The hardest thing for a rider to learn to do on horseback is to do nothing."

When escorting a lady riding in side-saddle, one should keep to the side where protection and assistance are mostly needed; consequently, on roads in countries where the rules for passing (in meeting) establish such to be effected to the right, one should ride to the left of the lady and vice versa. In narrow and difficult passages, and when the lady's horse shows signs of restiveness, one acts well in taking the lead.

\section{Schooling the Horse.}

\section{(Breaking.)}

"Haste makes waste."

A broken horse is a horse without any will of his own-whether he be a truck horse or a high school horse.

The common sense, strength and willingness 
of the horse have, from ancient times and in different ways, been taken advantage of by man in applying a training suitable to various purposes.

In order to utilize the animal's strength in the most advantageous manner, the right proportion between strength and labor should be observed, and in the schooling of a riding horse this must be strictly followed.

For the rider to be on good terms with the horse contributes a great deal in advancing the work of schooling, because when once the animal has gained confidence in its teacher, its desire for work will be aroused and it will learn to understand quicker, and also obey him more willingly. This can only be attained by a rational and skilled manner of proceeding.

In the schooling of a riding horse, there is required great skill in horsemanship, a great deal of judgment, a thorough knowledge of the treatment of horses, their structure and natural disposition in other respects, much patience, presence of mind, perseverence, fearlessness and firmness. For this reason, the breaking of a horse may seem an insuperable task to an ordinary rider; but he must not be discouraged, but hopefully set to work, when, in order to get his horse broken, he has no better alternative than to do it himself; even if the result be not so good, it adds to his experience, which is surely the best teacher. In order not to bring too many disappointments upon himself, the rider must not make his 20 - Handbook for Riders. 
plans higher than those he himself and the horse are able to manage.

The time required for the training of a riding horse can hardly be fixed beforehand; the best results are attained by acting cautiously and by letting the schooling lessons follow in succession and in a regular order by which the horse is taught to accomplish the different movements in balance, which should be the principal object of the training.

An ordinary riding horse should, through the training, be taught:

A. quietly to submit to saddling, bridling and unsaddling;

B. to stand still during mounting and dismounting;

C. willingly to obey reins, legs and weight, at the stand and while in motion, and consequently:

a. to stand still and to turn on the spot;

b. to be able to move in all gaits and paces while retaining balance and keeping time-and

c. in so doing, to suffer himself to be turned and stopped;

d. easily to back and also

e. safely and willingly to leap over obstacles.

To this end the schooling lessons are applied in the way they are prescribed in the foregoing riding instruction and in the following order: 


\section{Preparatory Practices.}

I. Accustom the horse to saddle and bridle by letting him look at them and smell them; the girths must not be drawn too tightly and the bit should not be struck against the horse's teeth and lips.

2. Accustom the horse to the manège by leading him round on the track; right and left (at the sides).

3. In order to accustom the horse to carry the rider, one mounts cautiously and slowly (frequently stopping and beginning again) and remains for a while resting on the arms with left foot in the stirrup, then descends again, thus continuing the same operation until the animal quietly submits to it, after which the right leg is brought several times across the horse's croup and again down to his left side. If the horse also stands still during this, the rider may then seat himself gently and must, with might and main, try to stick on. If he be thrown, he must mount again at once. At first, during mounting and dismounting, an assistant should be employed.

\section{With Snaffle.}

I. To put the horse into a walk. The legs used as urging aid is taught by means of voice and whip.

2. Turning by feeling one rein, the rider's weight to co-operate. 
3. The natural trot-in order to attain natural bearing under rider. With a steady and pliant hand support on the bit is attained. The rider keeps as passive as possible; the seatsteady and pliant.

4. To pass from the natural trot to the walk and from the latter to halt. Gradual passings by reins and weight but without the use of legs.

5. Turning corners. Easing the outward rein; whip and leg on the inward side.

6. Turning diagonally across the school at the walk.

7. Leading the horse over a bar. The reins so long as not to exert any influence on the horse's mouth during the leap. The rider either jumps over the bar or lets go the reins just in front of the bar. Leaping, dismounted or mounted, according to progress, should henceforth be practised at the end of each following lesson.

8. Voltige on horseback, by which the horse is taught further to submit to the movements of the rider.

9. Bending the horse's neck at the stand and while in motion, when the horse takes support on the bit. Short periods; chewing on the bit.

Io. The medium trot, when the purpose of the natural trot is attained. Whip and legs urge the horse on against a passive and pliant hand; firmer seat in the saddle. By developing the medium trot, the horse is brought into better balance.

I I. Turning on forehand with horse's head 
to the front. At first the inward leg is assisted by the whip and the inward rein.

I2. To pass from the medium trot to the natural trot and vice versa. In passing from the medium trot to the natural one, the legs are closed quietly; the reins are felt by degrees. The horse should yield to the bit and press his neck together. In passing from the natural trot to the medium one, the reins are not relaxed, whip and legs urge the horse forward, by which he learns to push off better with his hind legs and at the same time retaining his bearing.

I3. Bending the horse's head at the stand and while in motion, when the horse yields to the bit and pays attention to the legs, and also has attained steadiness and bearing of the neck.

I4. The extended trot, when the object of the medium trot has been achieved and the pace has become steady. The reins must not be relaxed more than necessary in order to retain support on the bit. With horses that have a weak back and hind quarters, the rider should sit lightly in the saddle.

15. To pass from the extended trot to the medium trot, and vice versa. Same as no. I2. By passing from the extended trot to the medium, the horse is taught to bring his haunches under. Gradual passing over with cautious influence of legs should be observed.

I6. To gather the horse while in motion. The head is placed perpendicular and the neck is raised, by which the bearing and the gaits of the 


\section{$-3 \mathrm{IO}-$}

horse are improved. The horse must not go behind the reins. At first practised at the medium trot, then at the walk. If the pace slackens, the gathering has then been too forcible.

I7. To gather the horse at the stand. The horse should pay such precise attention to the rider's legs, weight, and to the reins that hewith his neck raised and his head as near to the perpendicular position as his structure allowsstands still with light support on the bit.

I8. To regulate the walk should not be practised until after the gathering has been accomplished.

r. Backing can only be executed correctly, following a previous gathering of the horse.

20. Collection. After gathering, the horse is made to bring his haunches under him, i.e., further improvement of the balance.

$2 \mathrm{I}$. The halts have already previously been applied (see nos. 4, I 2 and I5), but they cannot be accomplished correctly until the necessary carriage and the removal of the weight to the hind quarters have been conveyed to the horse through gathering and collection.

22. Bending the horse. For the attainment of correct turnings, side-gaits and gallop.

23. Turning on forehand with horse's head bent sideways. Preparatory practice for versing (shoulder in).

24. The great circle. As a practice in bending the horse and as the introduction to correct turning while in motion. 
25. Turning while in motion. Introduction to change in crossing the great circle.

26. Change in crossing the great circle is performed on a serpentine line.

27. To pass from the great circle to "straight on," and vice versa.

28. Yielding sideways to the rider's leg, when the horse can keep on the great circle.

29. Side-gaits with horse's head to the front (see page I7I, etc.).

30. Side-gaits with horse's head bent sideways (see pages I $7 \mathrm{I}-\mathrm{I} 82$ ).

31. Turning on haunches (see page 184 ).

32. Change in crossing the great circle is performed by sharper turnings than are described in no. 26 .

33. Diminishing and resuming the great circle. Introduction to small circles.

34. Precise turning of corners (see page 137)

35. To turn diagonally across the school at the extended trot (see pages I 38 and I 53).

36. Small circles (see pages 188-190).

37. Small circles on one track from versing. A stronger pressure of the rider's outward leg, easing the outward rein and the rider's weight inwards.

38. To change during turnings while in motion (see page I67).

39. To pass from one side-gait to another one (see page 182) and turning on haunches while in side-gaits.

40. Bringing the haunches more under is 
practised at the stand and consists in a higher degree of collection by which a raising of the forehand may be effected (see page $\mathrm{r}_{57}$ ). It is applied in quick turnings on haunches and in taking the gallop from the stand.

4r. The gallop. From trot on the great circle (see page I92) with even and easy gallop strides. It depends on the horse and on the preceding work of schooling, if the gallop should be taken from the short or the medium trot.

42. To pass from the gallop to the trot, and vice versa. On the great circle.

43. At the gallop on the great circle to pass "straight on," when the horse has learned to maintain an even and quiet tempo at the gallop on the great circle.

44. Collected gallop. On the great circle, when the horse at the medium gallop has commenced to lower his croup and to bring the hind legs under the mass.

45. To pass from the gallop to the walk, when the horse in bearing takes gallop from the trot. At first practised on the great circle.

46. The extended gallop, when the horse goes closely collected in the short gallop (see page 198 ).

47. To pass from the extended to the short gallop, and vice versa.

48. To change from gallop right (or left) to gallop left (or right) by an interval of a few trotting steps (see page I97).

49. Turnings and small circles at the gallop.

50. To halt from the gallop (see page 197). 
51. The gallop from the stand (see page I96).

52. Changing the gallop "à tempo" (see pages $197-198)$.

\section{With Curb.}

The double or curb bridle is taken into use when, during the preceding lessons with snaffle, the horse has been taught to "carry himself." At first the horse should be accustomed to having two bits placed in his mouth-the snaffle-reins only to be used. Later on the four reins are to be held in both hands, the same as in riding with double snaffle-reins; then, by gradually feeling the curb-bit, the horse is also made to yield to gentle pressures on his mouth, when the reins are taken and held as explained in "Riding with Curb," and the schooling lessons repeated in the same consecutive order as "With Snaffle."

I. Yielding to the bit (champing the bit.)

2. Unbent lessons.

3. After attaining to a quiet, light and steady support on the bit, bending of the horse's head, turnings, side-gaits, etc., are practised.

4. With the four reins held in one hand.

5. With the curb-reins alone.

6. Carrière (see page 249).

Concluding remarks: As the training advances, the early and easier exercises must not cease, but be repeated daily.

The schooling lessons are always commenced and finished with the least fatiguing exercises, 
and the exercises should not be continuous, but be alternated with long periods of easy walking when horse and rider should be doing nothing. It is a good policy not to attempt to do any schooling when you are out of sorts, and also to scrutinize yourself when your work does not seem to prosper with you; for it is a poor trainer who is always ready to lay the blame on the animal.

\section{Horse Gymnastics.}

(The Modern Equine High School.)

Although this branch of horsemanship may be considered as being beyond the limits of this work, the book would be incomplete without some mention of it, as there are comparatively very few riders who have any idea of the real scientific "Haute Ecole" of to-day, and by confounding it with circus trick riding, they consequently despise it, which is a matter for extreme regret, as the knowledge of its practical use can but add to their accomplishments.

- The "Old School"--quite suitable for circus horses which are to be trained in great haste for "high school"-is represented by the so-called "Baucher System," and is, taking our modern ideas into consideration, restricted too much to work "at the stand." Of this system the Duke of Nemour said: "Je ne vəux pas d'un systeme, qui prend sur l'impulsion des chevaux" (I do not approve of a system which tends to diminish the 


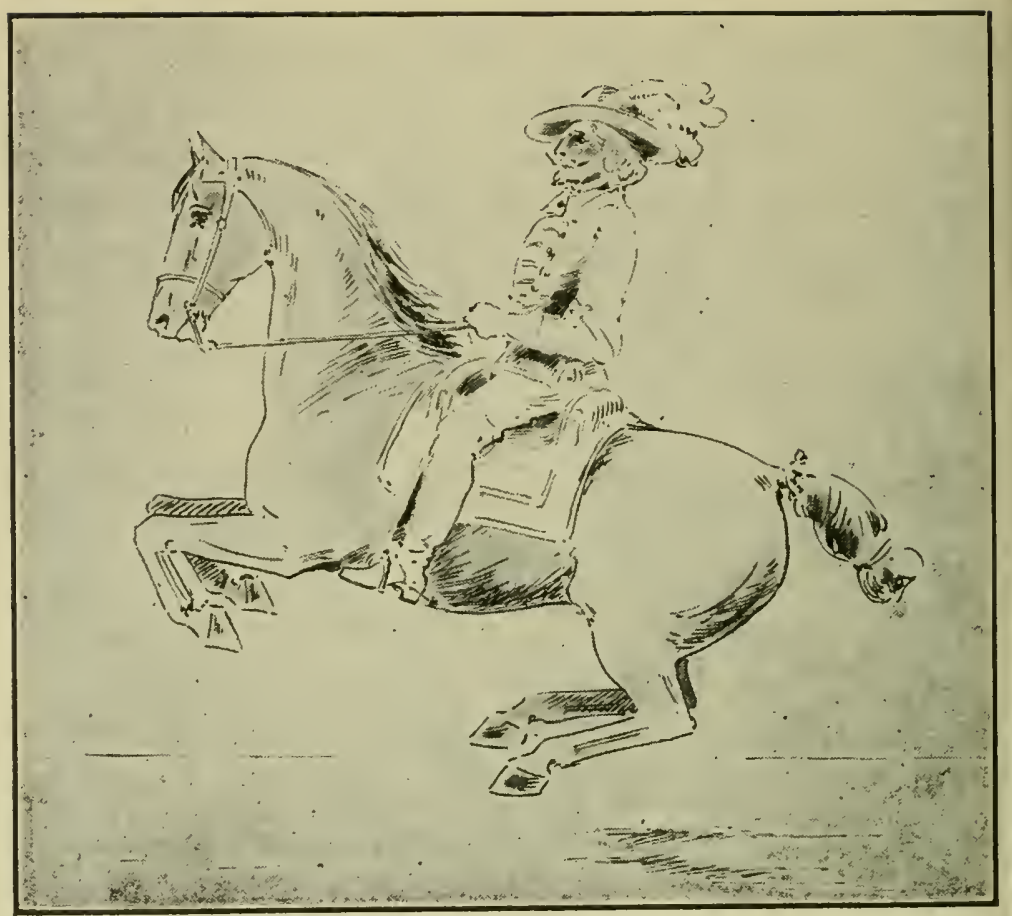

Fig. 64. THE CROUPADE.

with hind hoofs raised with their under-surface turned upwards).

School-jumps on the spot enter little into modern high school work, as their practical use is small compared with the strain to back and limbs which they entail. The only school-jump occasionally practised is the Lançade. This is not a jump "on the spot," but one "from the spot," the horse-by shoving himself forward by the spring of the haunches-landing considerably in advance of the spot at which he left the ground, in the same way as in a standing jump. 


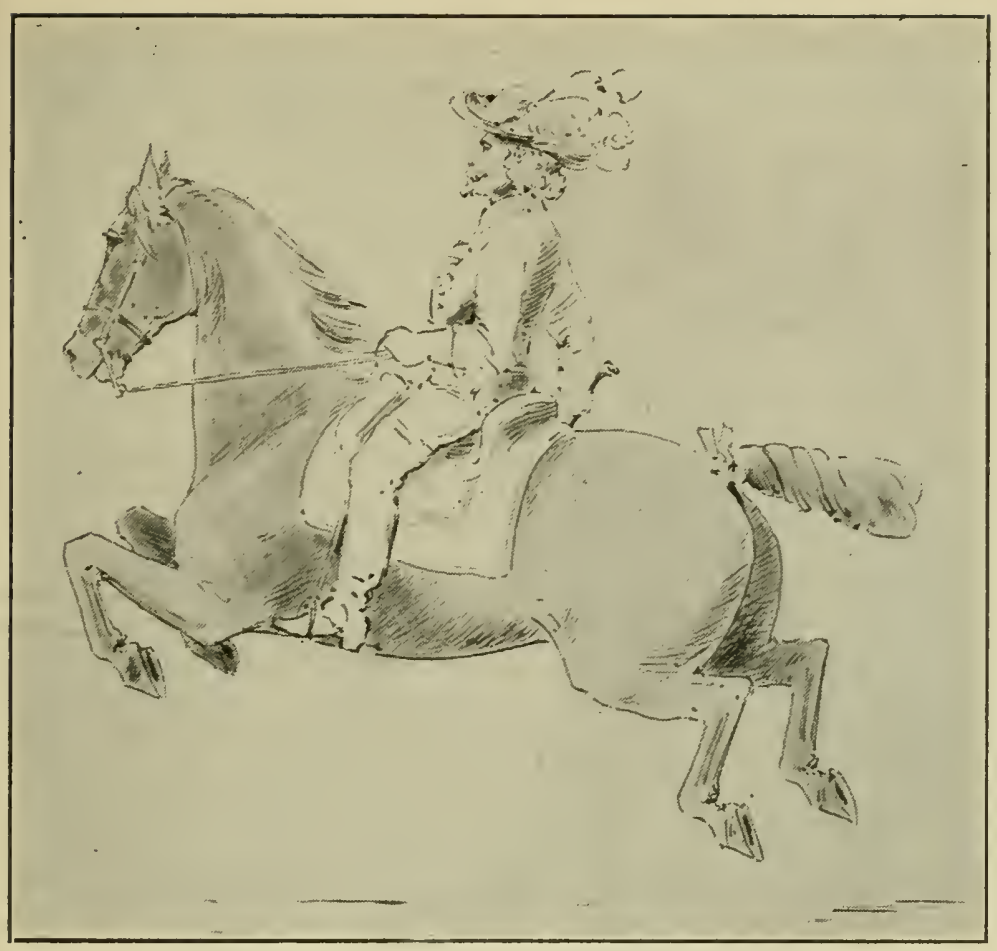

Fig. 65. THE BALLOTADE.

The Pesade (Figs. 67, 68 and 69) is the introduction to them all, and in it the back-line of the horse should form an angle of $45^{\circ}$ with the ground.

The Levade is similar to the pesade only the raising of the forehand is of shorter durationsuch as precedes the school-gallop when taken from the stand. For this reason one may hear mentioned "Levade right" or "Levade left" according to which of the fore legs is in advance; for instance, in "Levade left" the left fore leg should be advanced by the horse being bent to the left. 


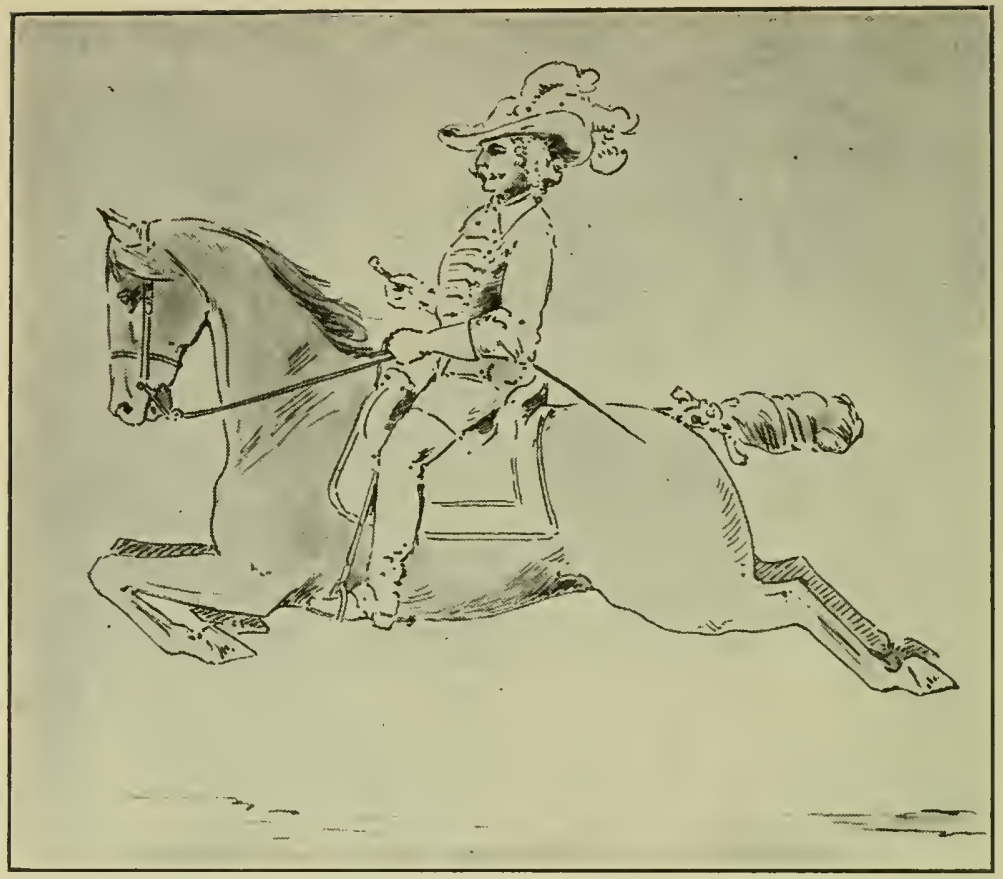

Fig. 66. THE CAPRIOLE.

The Terre à Terre is a school-jump executed with all four legs and while in the school-gallop. The Mézair is somewhat the same, only in it the horse raises the forehand higher and raises the croup less and later than in the terre à terre.

The school-jumps may be considered as a very severe test of the rider's firmness in the saddle.

Even to-day, the school-jumps are taught at the "Spanish Court Riding-School" in Vienna and have no equal, as far as correctness, grace, beauty and elegance are concerned; they are also the specialty of this institution, its horses (Fig. 69) being especially adapted to this work and, as 


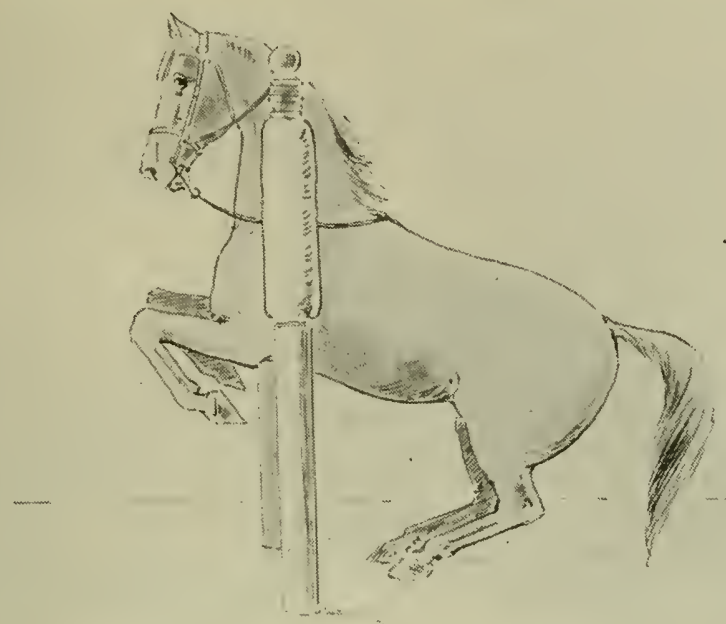

Fig. 67. THE PESADE BETWEEN THE "PILLARS."

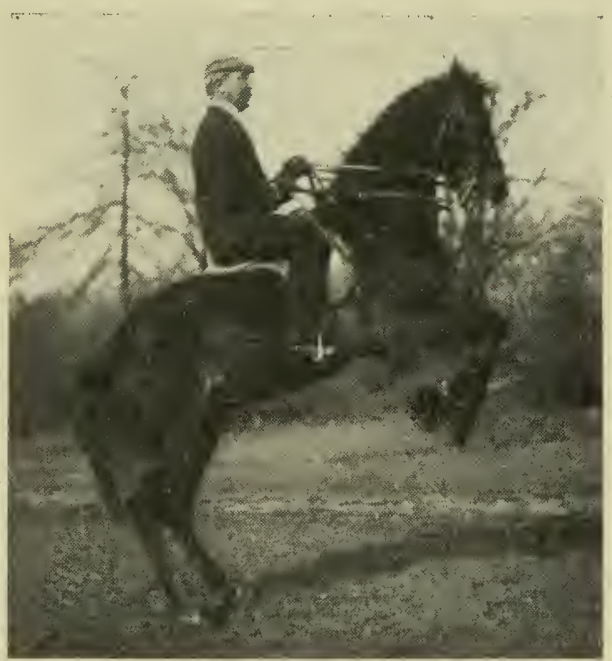

Fig. 68. THE PESADE.

Performed by a Pupil of the Author. (Central Park, New York, December, I908). 


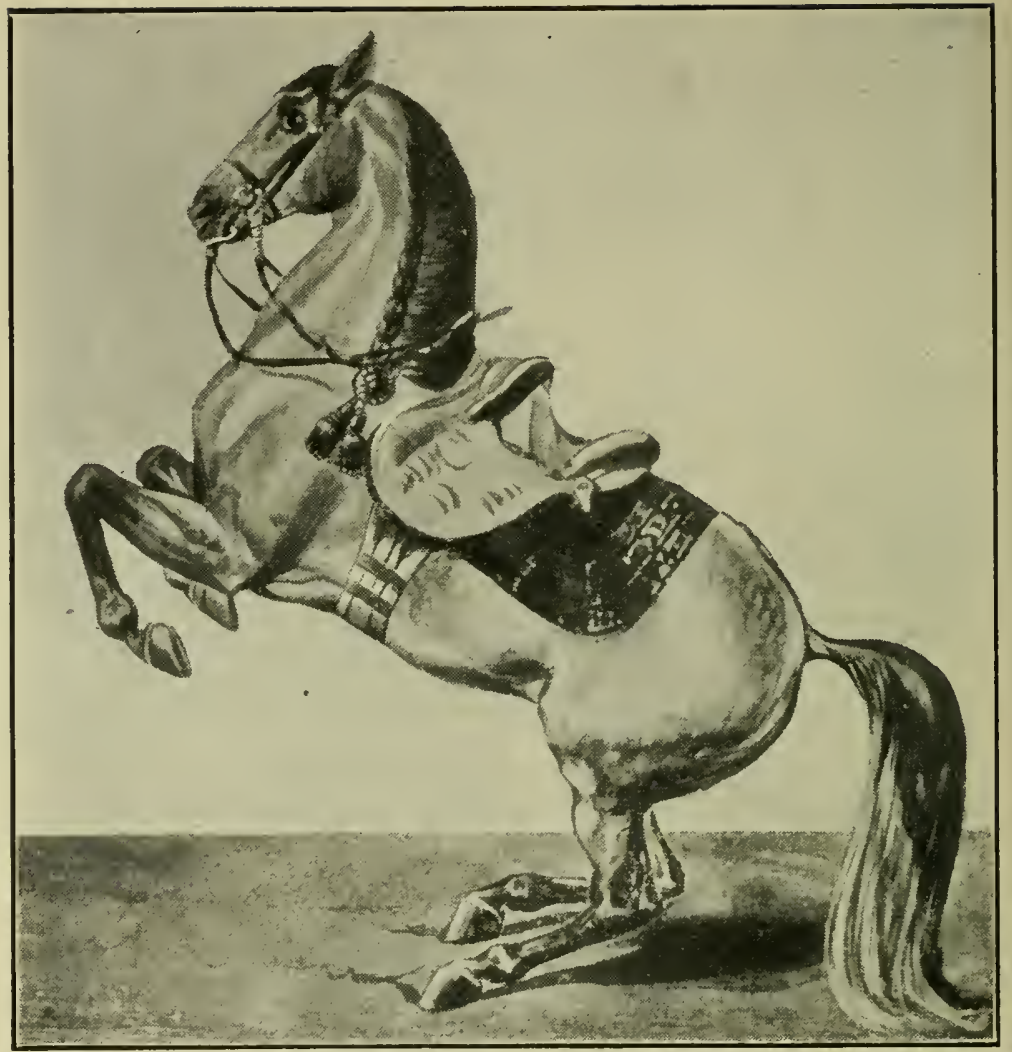

Fig. 69. THE PESADE.

"MUESTOSO-MOSCHINA," A LIPIZZA STALLION, One of the Eight Famous Stallions at the Imperial-Royal Spanish Court Riding-School in Vienna, Austria.

compared with other breeds, easily broken to high school.

The modern high school work is principally performed from the horse's back, and it lays extreme stress upon the action of the hind part. The practical high school trainer scarcely wastes a thought or a glance on the fore legs, for he knows 


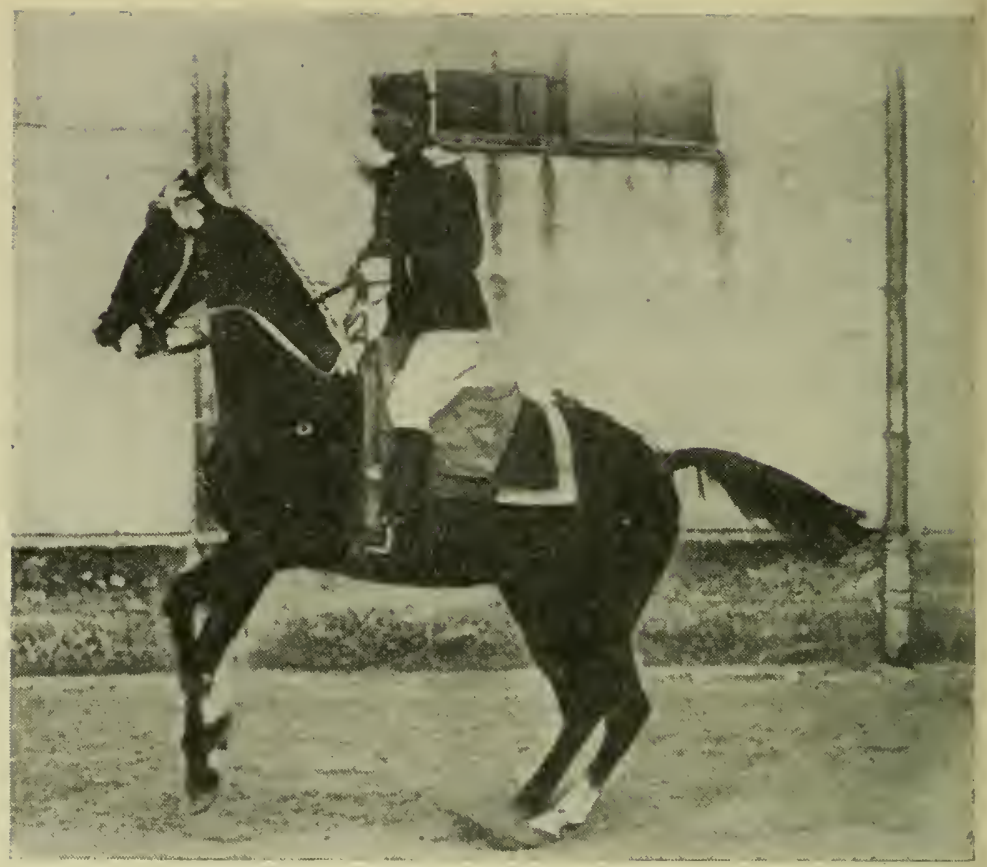

Fig. $7 \mathrm{I}$.

ECOLE DE CAVALERIE DE SAUMUR.-LE PAS ESPAGNO

The Spanish Step, Performed according to the "Baucher System" at the Cavalry School in Saumur, France.

ment of the horse's activity for practical riding, and upon the same principle as gymnastics are used in schools and gymnasiums; therefore it would be better explained by calling it "Horse Gymnastics." This is why it is not infrequently found, that such schooling, whole or in part, is used for animals the natural bearing and paces of which are deficient.

The high-schooling is not commenced before the horse has been trained in longe and ridden; and thereby broken for ordinary school riding. 


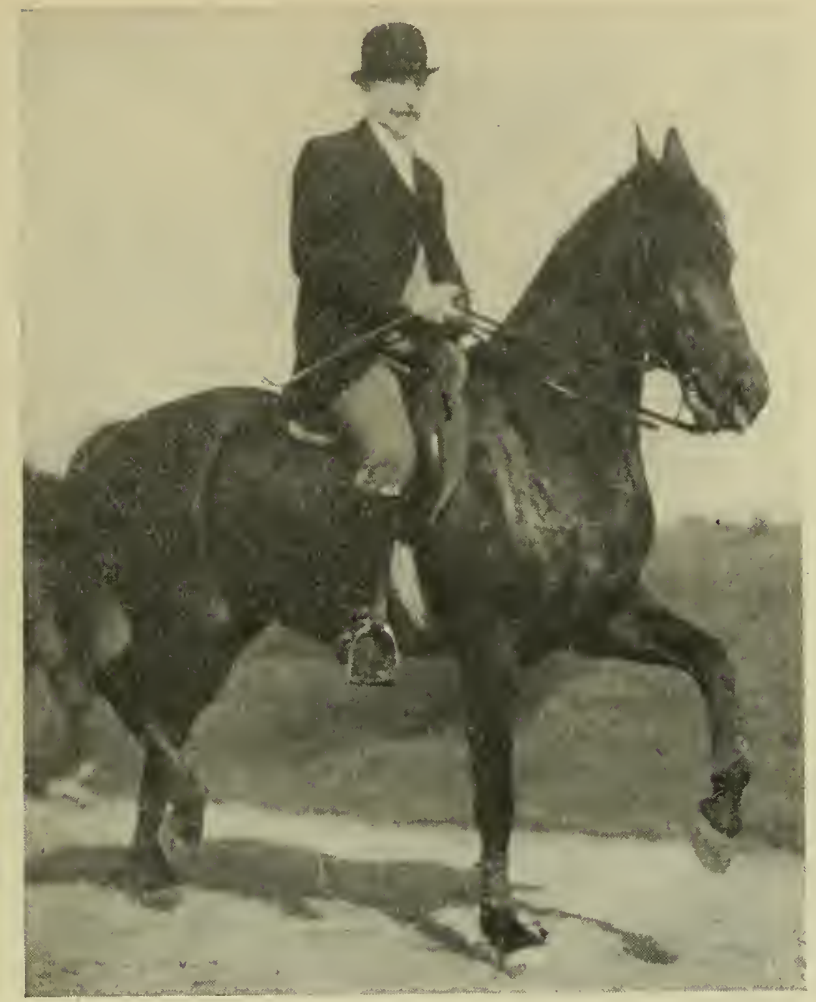

Fig. 72. THE "SPANISH STEP" AT THE TROT.

Performed according to the "Author's System."

(Central Park, New York, May, I9Iо.)

This is the gait that the French call "Le Passage"-an extremely rhythmical trot and one in which the horse signifies a momentary pause on each diagonal by keeping the lifted legs of the other diagonal in their position in the air for a moment. "Le Passage" is not considered elegant unless the lifted forearm be horizontal and the lower part of the leg vertical. The lifted hind leg should be bent at the hock joint so much that the toe becomes level with the top of the pastern of the other hind leg or is even lifted a little higher; but never so that the "two lifted legs" of a diagonal are level with each other, as this would make it look as if the horse were falling on his nose, instead of conveying the impression that the horse is pushing himself forcibly forward, which is what gives elegance to the movement. 


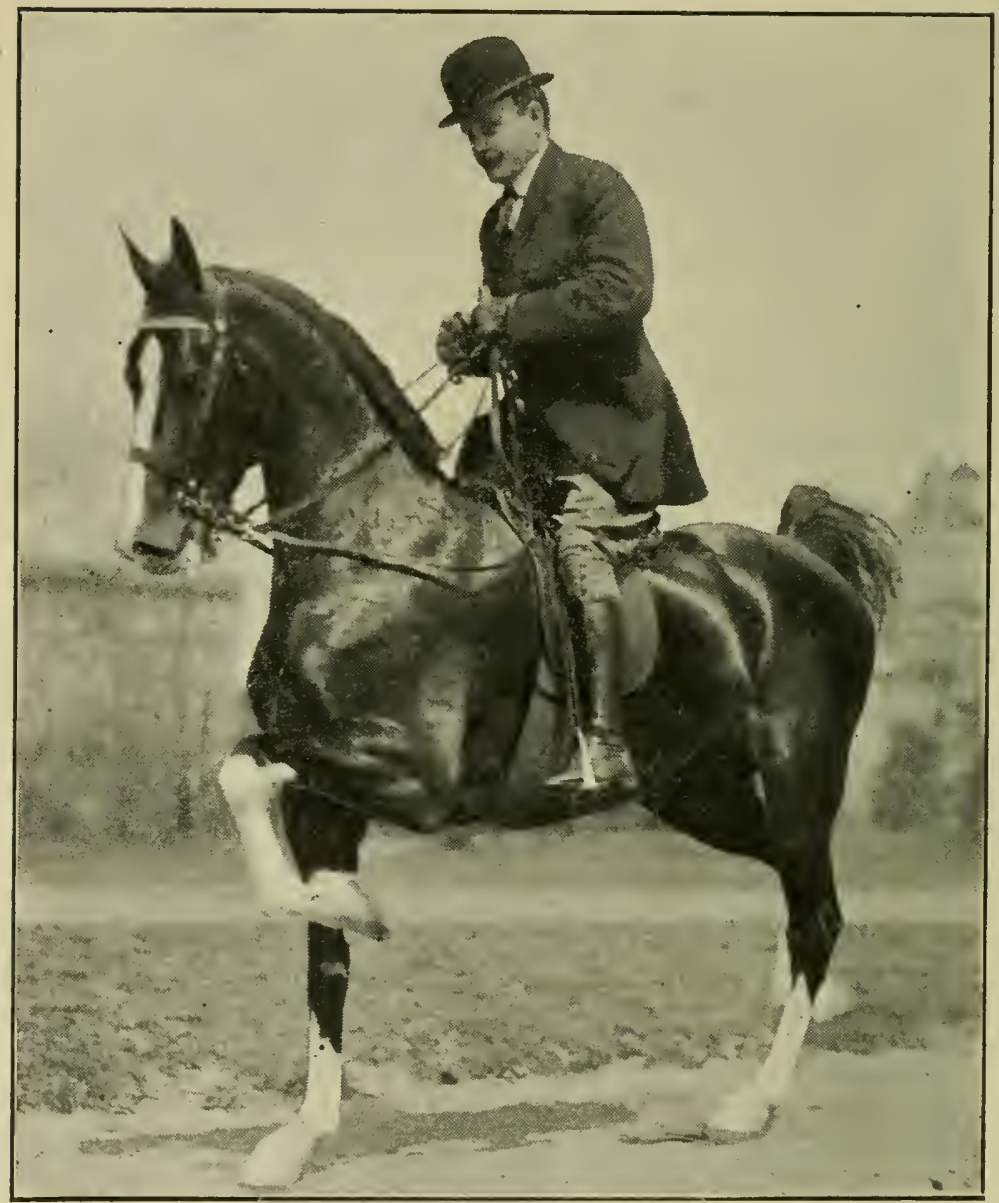

Fig. 73. THE "AMERICAN TRAINED" HIGH STEPPING HORSE.

The paces and gaits taught in high school practices were (besides the school-jumps) formerly restricted to side-gaits (see pages $\mathrm{I}_{7 \mathrm{I}-\mathrm{I} 83}$ ) at a closely collected trot, the school-gallop (gallopade, Fig. 70) with its different evolutions, the Spanish step (Figs. $7 I$ and 72), and the piaffe (Figs. 74, 


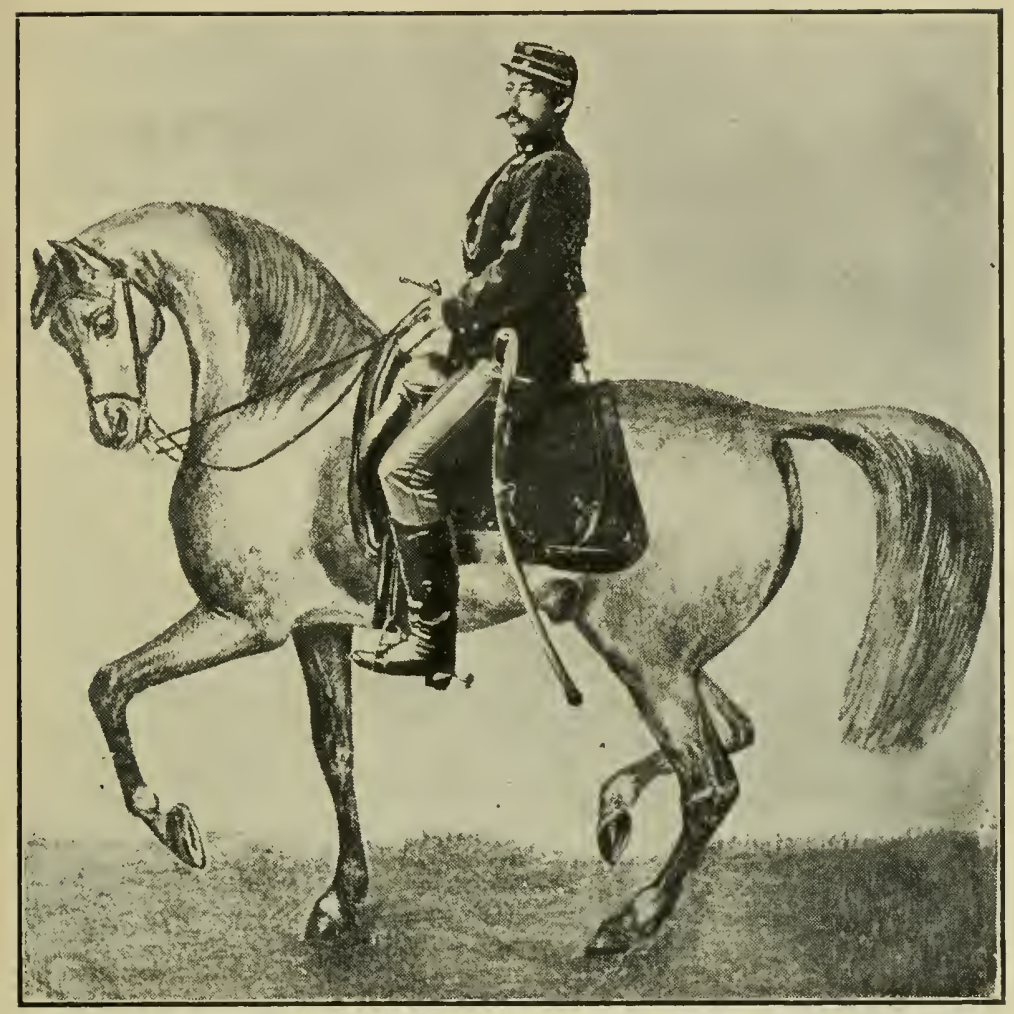

Fig. 74. THE PIAFFE (Le Piaffer).

75, 76 and 77), the last-mentioned being the "Spanish trot on the spot."

By comparing Fig. 72, the Spanish Trot (Le Passage), with Fig. 73, the high-stepping horse, the reader may draw his own conclusions with regard to the action of the horse's legs, etc.

The Great Napoléon said: "Pour devenir grand capitaine il faut lizer et relizer les vieux capitaines." $\mathrm{A}$ This great man could have had no other reason for saying so than by studying 


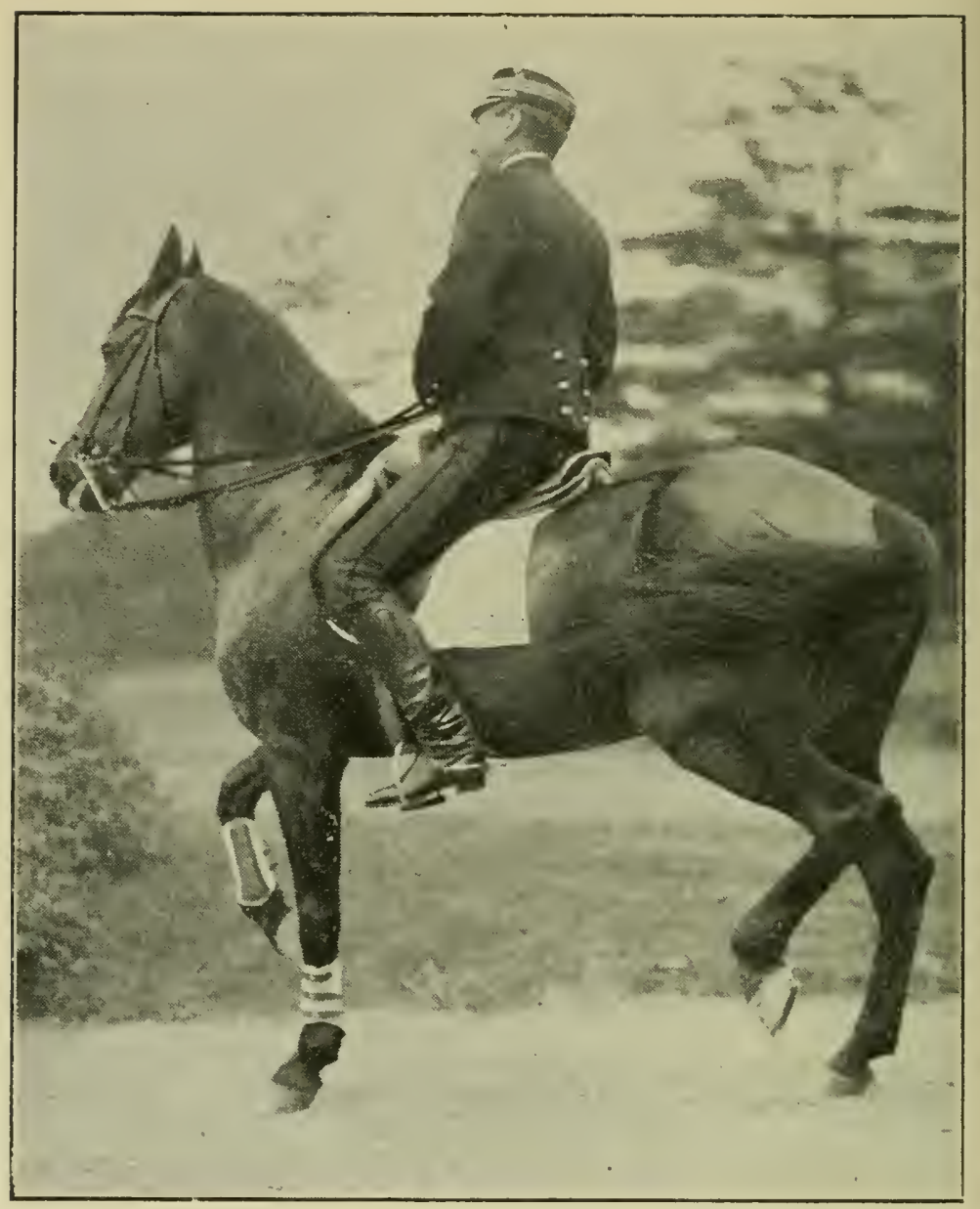

Fig. 75. THE PIAFFE.

Developed Entirely by Work on the Horse's Back.

(Central Park, New York, May, Igıo.)

the old masters and seeing the results of their ideas, the masters of later periods have been enabled to improve on and even to alter the old systems into-we may say-quite new ones, which satisfy the requirements of later periods. We must 


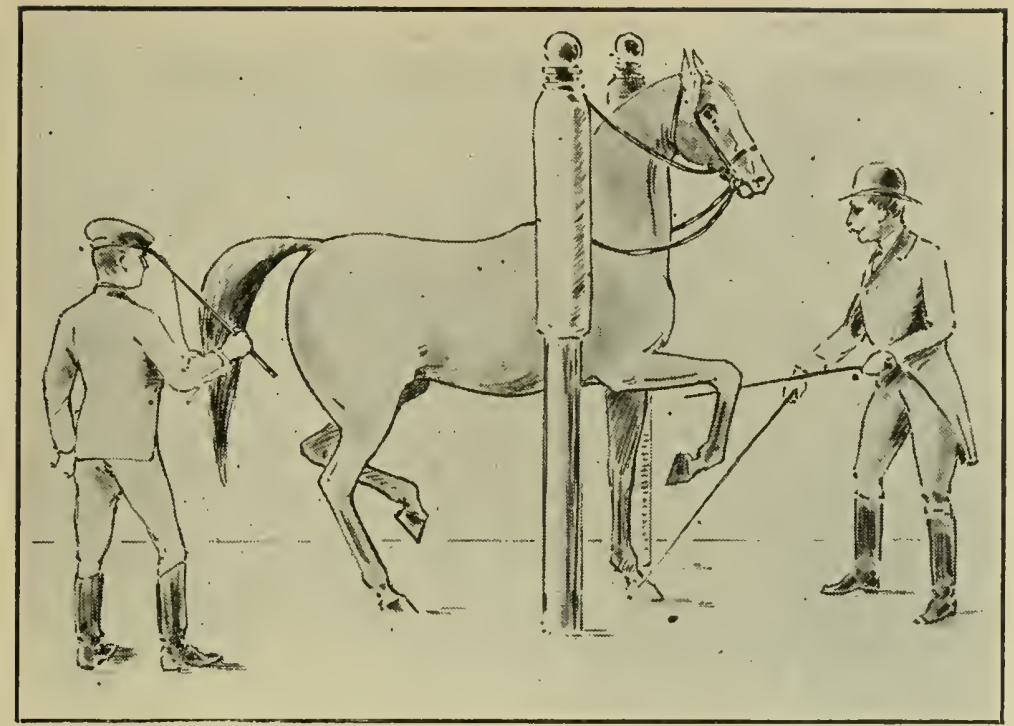

Fig. 76. THE PIAFFE BETWEEN THE "PILLARS."

also read the written works of the old masters on equitation in the same spirit-thus, the modern school, in some respects, acknowledges and utilizes the fundamental principles of the Old School, and has developed them in a higher degree:

I. By adding new paces, for instance, the extended trot with its greater spring from the hind legs and well extended action of the fore legs, the marching step at the walk* (Figs. 78,79 and 80) and the floating trot (Figs. $8 I, 82$ and 83 ) (or as it is called in Germany, the "Swim-trot," and in France the "Spanish trot"). In the two last

* When in marching the horse is made to execute two beats (the first one being in the air) with the lifted fore leg at each step, it is called Double Marching ( $\mathrm{Pas}$ espagnol doublé). 


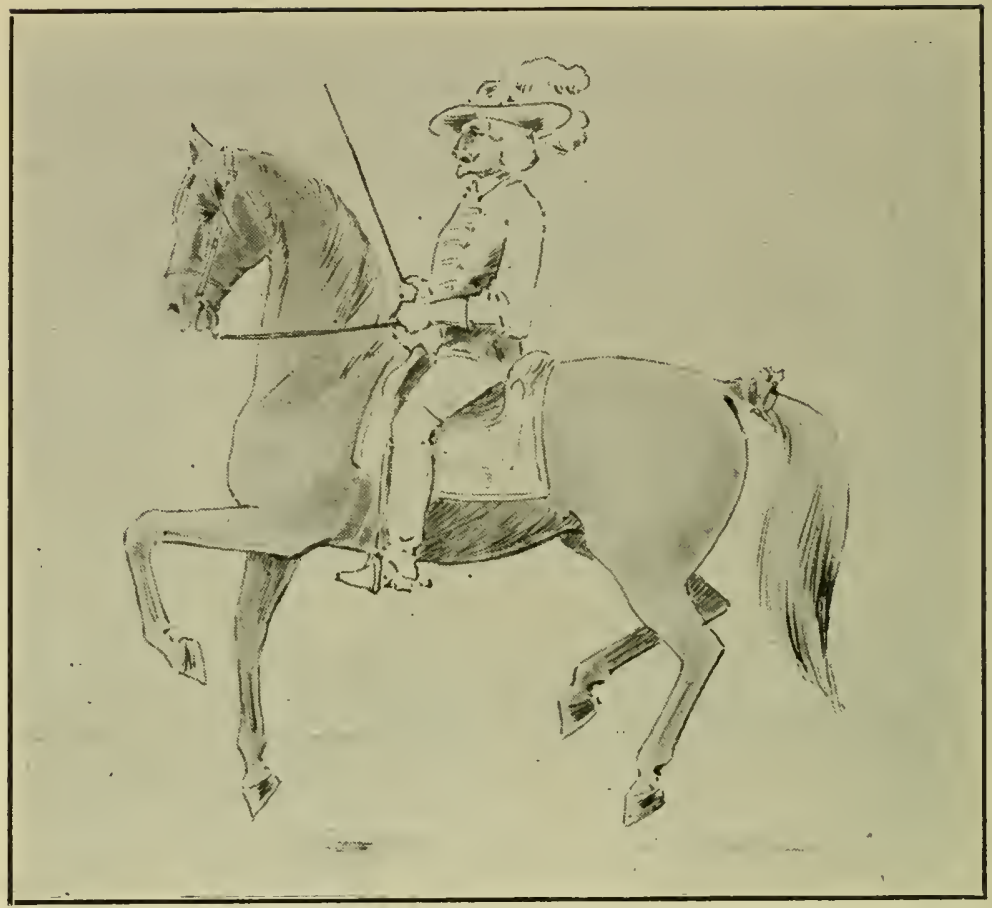

Fig. 77. THE PIAFFE OF THE "OLD SCHOOL."

mentioned gaits the fore legs are stretched forward and brought into an almost horizontal position; thus enabling the horse to cover more ground with each step than in the Spanish trot (see Fig. 72). In marching and in the floating trot the stretching forward and the high position of the fore legs should not be produced by striking the horse with the whip on the fore legs, but by using the outward leg more forcibly and farther back (see Fig. 82) than in the Spanish trot, also by conveying the rider's weight more over on the 


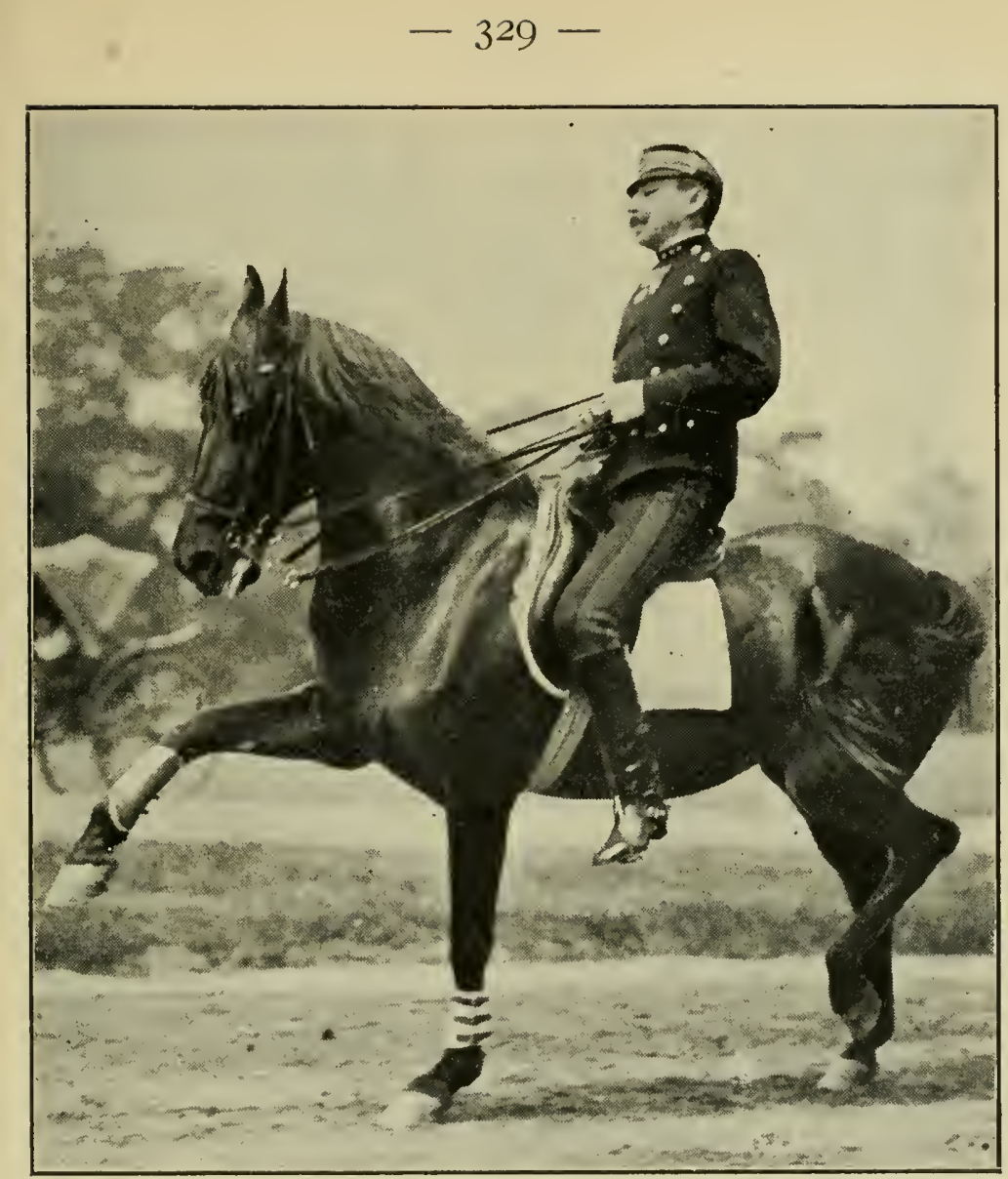

Fig. 78. THE MARCHING STEP AT THE WALK. According to the "Author's System," accomplished entirely by work on the horse's back.

(Central Park, New York, May, rgro.)

outward hind leg; the reins should not be needed for this purpose.

2. By requiring a more rapid performance of some of the Old School's evolutions, as for instance, the pirouette and the half pirouette (two methods of turning around and half around on one 

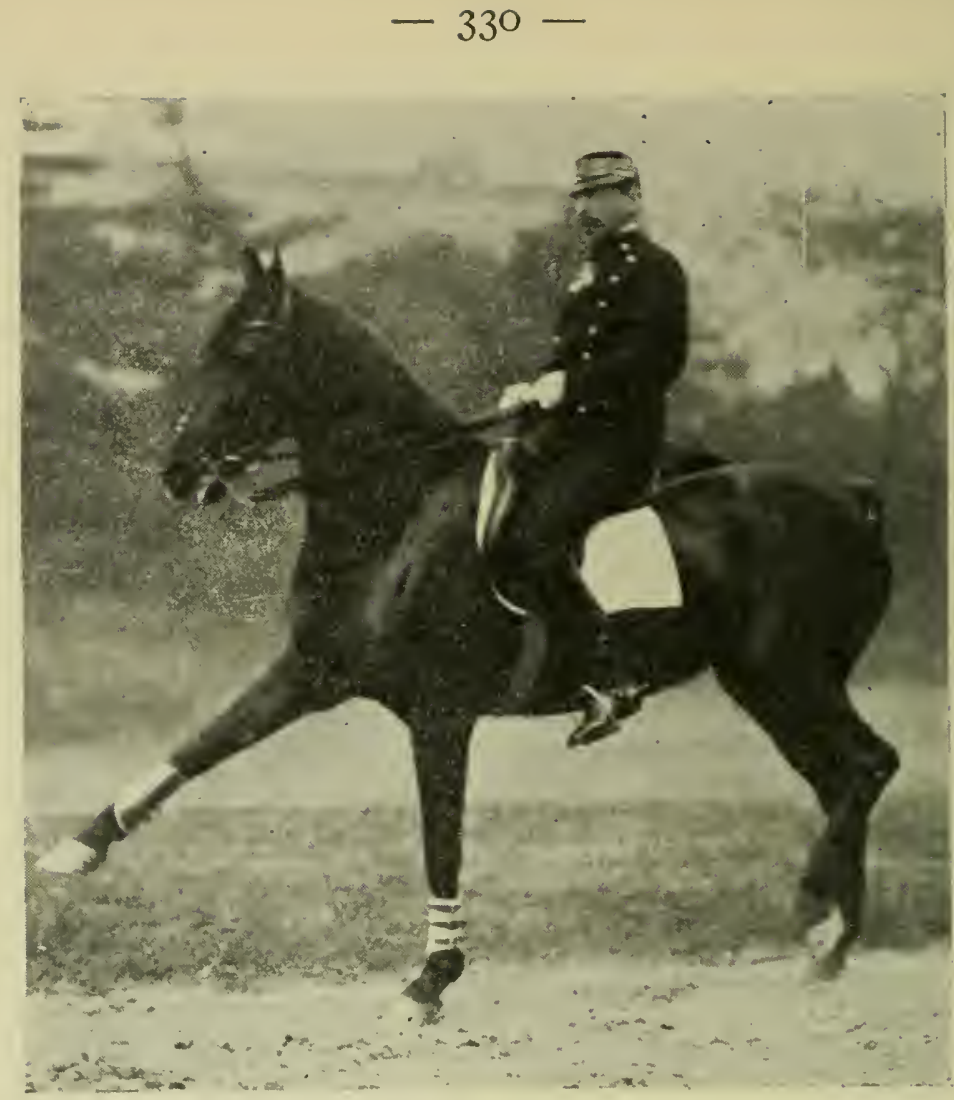

Fig. 79. THIE MARCHING STEP

(Central Park, New York, May, igı)

illustrating the third movement (planting the previously horizontally stretched fore leg). The movement comprises three distinct actions: Ist. The lifting of the forearm into horizontal position. 2nd. The strctching forward of the lower part of the leg to be in line with the horizontally placed forearm. 3 rd. Bringing the leg obliquely to the ground. This movement tends to develop free shoulder action for practical riding, apart from the benefit obtained from the action of the haunches.

hind foot at the school gallop), which are executed by the Old School in six, or three, slow, but high and beautiful gallop strides. The modern school demands that such turnings be made in less time than it takes to accomplish one gallop stride. 


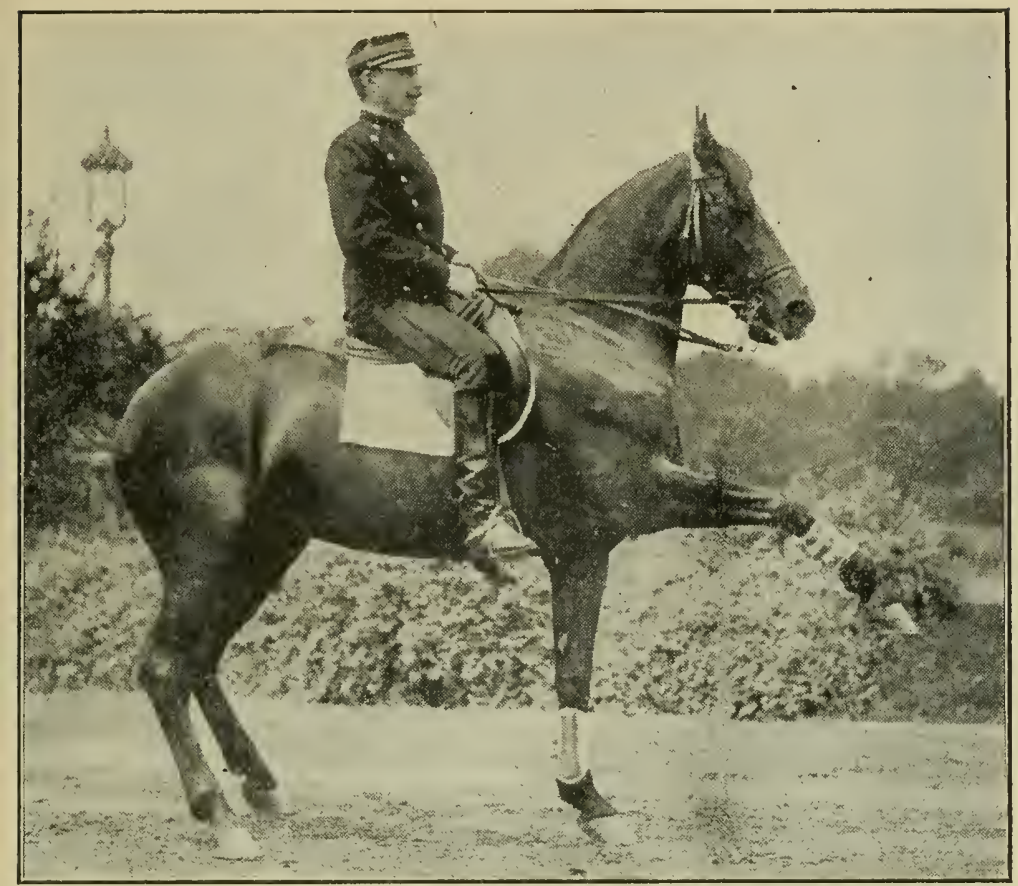

Fig. SO. THE HALT FROM MARCHING AT THE WALK, KEEPING FORE LEG IN AIR.

(Central Park, New York, May, Igro)

Another feature of the modern style is the "free gallop" with its changings à tempo at every third or second stride.

3. Again, by having introduced more variations in the movements, which means passings over from one school gait to another direct and without intermission; for example, from school gallop right and left into Spanish trot and vice versa, and with a certain number of strides and steps in each gait, say three gallop-strides left; four steps Spanish trot; three gallop-strides right, and so on. Another feature is the direct passing 


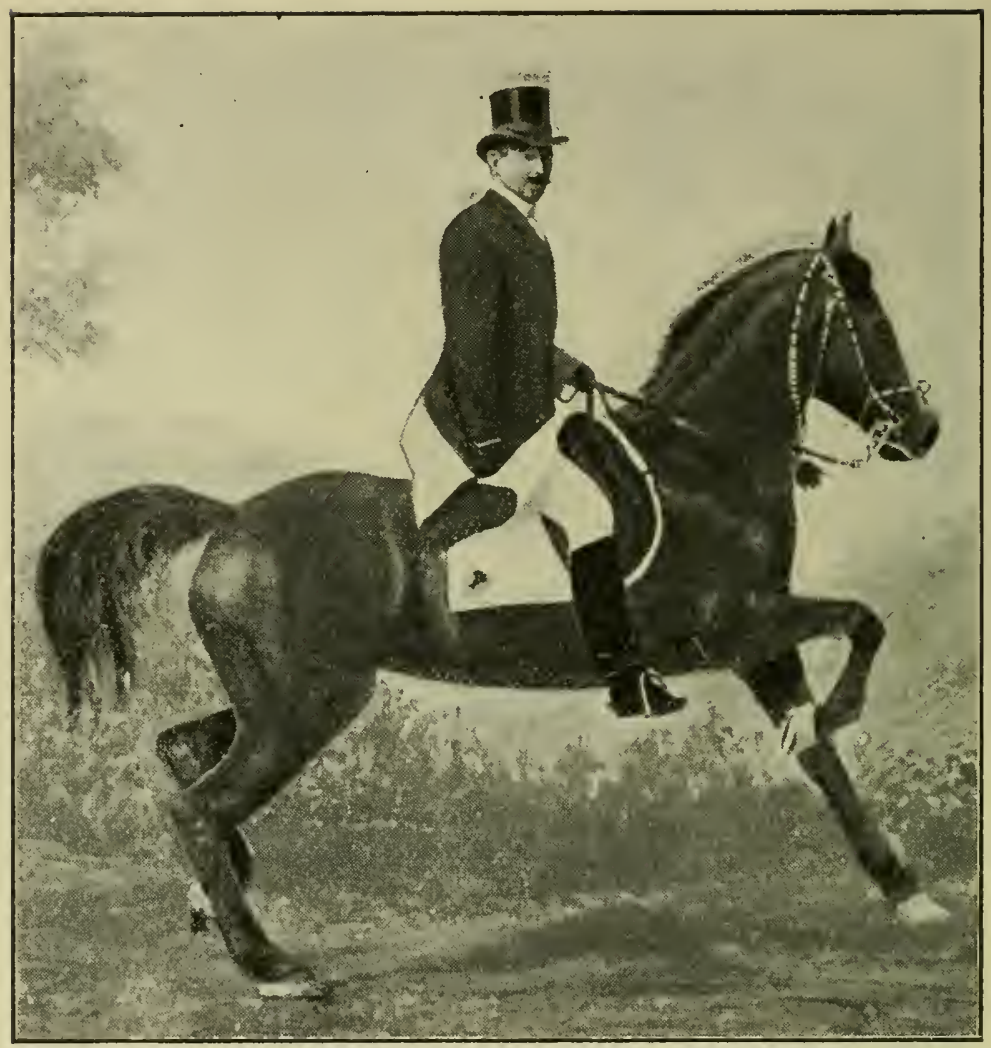

Fig. Sr. THE FLOATING TROT. Illustrating the First Movement.

over from the floating trot into the piaffe and then again into the same trot.

4. Finally, the modern school demands that the high school horse shall be taught to jump as we understand it, and to do it with the highest degree of precision and correctness. The devotees of the modern school insist that a horse shall not only be able to get over an imaginary obstacle gracefully, but that he shall be able just as grace- 


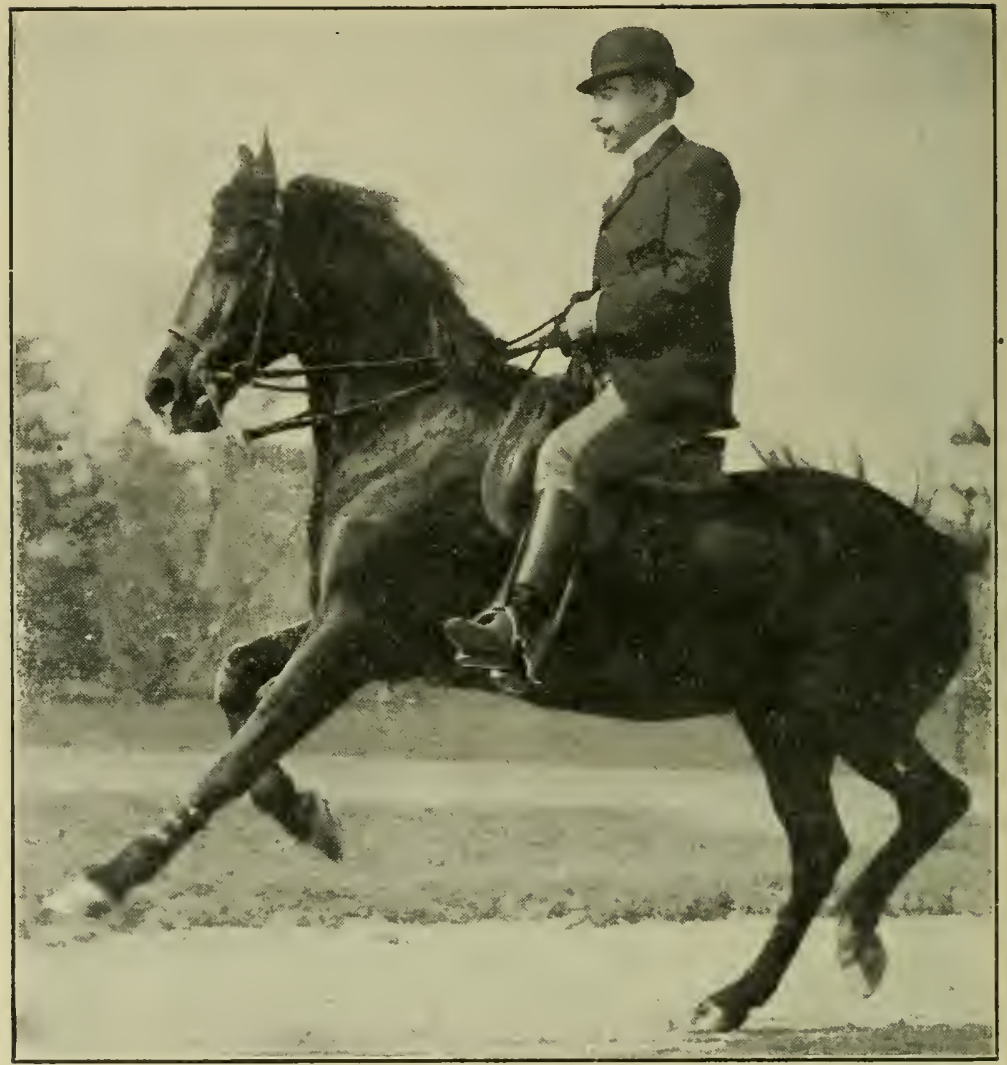

Fig. 83. THE FLOATING TROT.

Illustrating the Third Movenent.

(Central Park, New York, May, rgro)

The equerry of Louis the Fourteenth took three-quarters of an hour at the school gallop to advance one hundred and fifty steps, that being the distance between the riding-school and the dairy at Versailles-which is at the rate of just three and five-seventh steps per minute!

This was the gallop record of those days; in ours it goes in another direction. There would be 


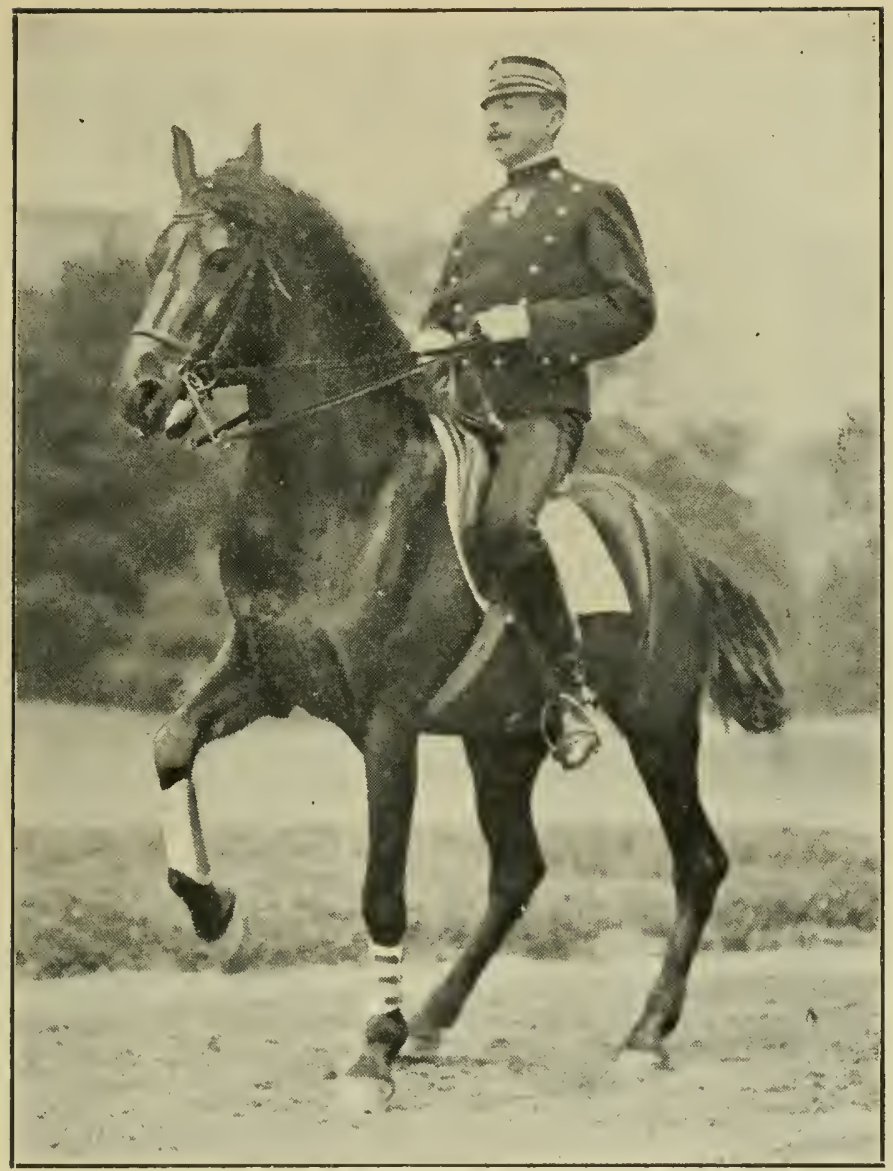

Fig. 84. THE HALT ON THREE LEGS FROM SCHOOLGALLOP RIGHT.

(Central Park, New York, May, igro.)

very little risk of such a highly schooled horse running away, unless it were tail first!

Apart from what has been already said about the manner in which the different features of the high school are taught and afterwards practised, a minute explanation of the subject would be too 


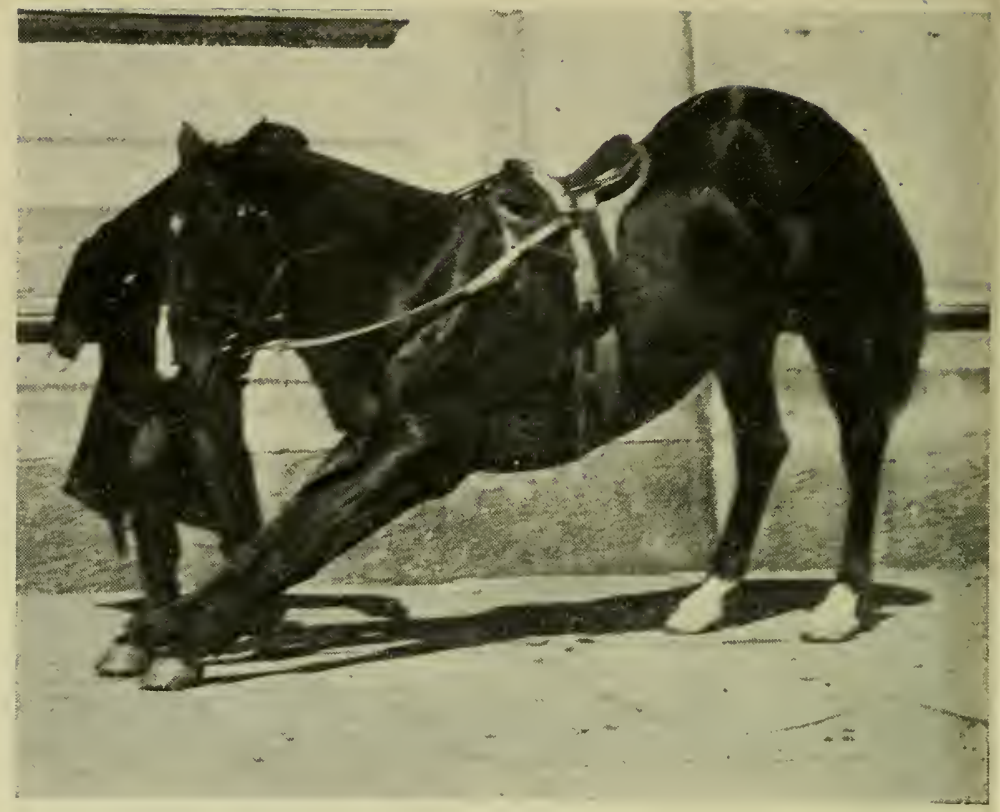

Fig. 85. LOWERING OF THE FOREHAND (Au Bas)

The exercise of the horse in this position tends to develop free shoulder action. It should not be done with hind legs "backward placed" but be commenced by first bringing the haunches under and then stretching the fore legs gradually forward by which latter movement the forchand slowly becomes lower. With a rider mounted it must be especially observed that collection precedes the lowering of the forehand, otherwise the animal's back will be strained.

elaborate and of too little interest to the ordinary rider (for whom this work is intended) to be introduced here; besides, the detailed study of scientific high school work and its practice takes nearly a man's lifetime and requires special equestrian gifts.

Circus tricks, such as kneeling, rearing and walking on the hind legs, etc., have nothing to do with this question, and should be absolutely 
barred from high schooling, as they may prove fatal to the ordinary rider and injurious to the horse, whereas there is no safer animal to ride than the finished high school horse.

On account of the greater mobility of the modern high school methoas, special emphasis must be laid upon the harmony that should exist between the movements of the rider and those of the horse. The stiffened position-riding with long stirrups and straight legs-is no longer considered correct. "Elasticity" is the best word to describe the attitude of a high school rider. The elasticity of an easy rider, who has a good seat and a natural position, will communicate itself to the movements of the horse; for the horse will always be a mirror of the rider.

Besides what has already been stated in favour of the high school training, it has the practical advantages of making the animal more obedient in proportion to the higher training and also making the movements of its legs more nimble i.e., it enables the horse, with safety and without causing injuries to his legs, to perform the quickest movements-a quality that should not be despised but sought for.

From an artistic point of view there is the regrettable drawback that the masterpieces of the art vanish with their great masters, and neither "snap-shots," paint, marble nor bronze can replace the poetry, rhythm and music which inspire us when watching the beautiful, graceful and harmonious movements of the living work 22 - Handbook for Riders. 
of art, though in the eyes of a true horseman there is no more pitiful sight than that of a crippled high school performance.

The following list of exercises for the performance of which the rider was awarded a Gold Medal for Equestrianism, may serve as an illustration of modern high school work:

All exercises performed on or within the track of a great circle and equally to both hands.

I and 2. Pesade and Au Bas.

3. The Extended Trot-performed in the figure 8.

4. The Side-Gaits (Versing, Traversing, Contra-Versing and Reversing) at the Collected Trot with passing direct from one side-gait to another, changing hands by half Pirouettes.

5. The School-Gallop with five changes of lead (à tempo) in crossing the circle; small circles with changes, the same in Contra-Gallop; changes of lead at every third and at every second stride on the track of the great circle-to change hands by half Pirouettes. Diminishing the circle at the Renvers-Gallop until hind feet are in centre, then, by a whole Pirouette and immediate change of lead, resuming the track of the circle at the renvers-gallop to the other hand, etc. Gallop from the Stand at the Closing Travers with halts on three legs, leading fore leg in air- 
alternately gallop right and left. Gallop on the spot with changement à tempo.

6. The Spanish Trot, forward and backward, performed in the figure 8 , and alternately on the spot, i. e., the high piaffe.

7. Marching forward and changing to backward as a fore leg is in the air.

8. Double Marching.

9. The Floating Trot with direct passings over to "Spanish trot on the spot" and again to the floating trot, finally from the former "Halt" on three legs (a fore leg in air).

Io. Direct Changing from the School-Gallop to the Spanish Trot and vice versa, by three strides gallop right, four steps Spanish trot, three strides gallop left, etc.

II. The Piaffe with turning on haunches at the "piaffe-tempo," finally Halt on three legs with the last lifted fore leg stretched horizontally.

\section{Jeu de Barre,}

This being the game on horseback which, more than any other, requires great skill in riding and agility of body, it should not be unknown to the "educated" rider.

The origin of the name "jeu de barre" is jouer aux barres, which means "to play at war."

It is hardly possible to give any practical rules and advice for carrying out the movements of 
horse and rider, as the game is entirely individualsome showing their superiority in skilful management of their mount, others by the agility of their own bodies and limbs, and experts, indeed, by both. Quietly awaiting the movements of the aggressors, no rushing and, when attacks are made on the rosette, trying to escape them by swift and small movements, keeping the aggressor on one's right side, should be the principal policy of the defender of the rosette. He will find that "turning on haunches" at the stand and while in motion (pironette) will prove the most effective movements on his part. The policy of the aggressors should be more active, trying to confuse and bewilder the defender so as to tempt him into a wrong position, then, by a sudden rush, making a grab at the rosette.

The rules of the game-as they have been practised for the last forty years at Officers' riding competitions on the European Continent and as they are still maintained by "The Austrian Kampagnereitergeselschaft" in Vienna, at its annual public competitions,--are in short as follows:

I. A rosette to be pinned on the right shoulder of each of the players in turn.

2. All reins to be held in the left hand; a short aid of the right hand being allowed.

3. In each round both aggressors shall try to take the rosette. No one acts as another's assistant.

4. If the defender gets outside the territory marked out for the game, he loses the rosette, which is then passed over to the next player. 
5. The game to be played by only three at a time-one being the defender of the rosette and the two others the aggressors-each player to be placed in a corner of an equilateral triangle as starting-point (Fig. 86); the arena for the combat is generally a square, which in the riding-school

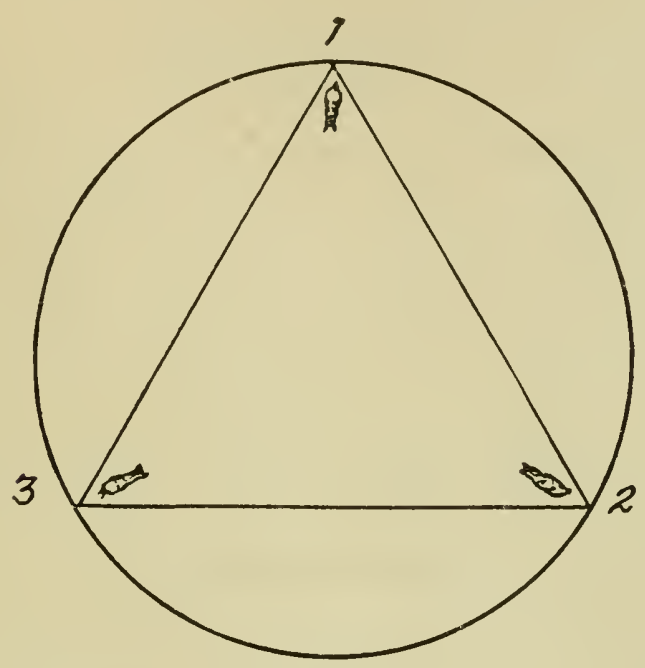

Fig. 86

may be marked out by placing a white tape on the ground across the manège and in such a way that one of the great circles lies within the square.

7. The defender is allowed a certain time in which to defend the rosette-from one to three minutes according to the condition of horse and rider. The combat is finished after the time, set for it, has expired if the rosette has not been taken within that space of time.

8. The one, who takes the rosette, defends it in the next round, though it must only be defended 
once by each of the three players. If nobody takes the rosette, it is given in turn to Nos. I, 2 and 3 .

9. The counting up of the result for each game, consisting of three combats (one for each of the three bearers of the rosette), is as follows:

Taking the rosette counts 2 ,

Holding " " " " I,

Losing " " "

For instance No. I in a game, holding his rosette during the fixed space of time and then taking the rosette from Nos. 2 and 3 , gets $I_{2}+$ $2=5$ marks, the highest number he can get. If, at the finish, two players stand even in number of marks, both will have to defend the rosette once more in the fixed space of time. The player who then holds the rosette the longer time, for instance, I minute and 5 seconds, wins from the one who loses the rosette after a combat of, say, 30 seconds. In the same manner the time is calculated for taking the rosette; the player who takes the rosette, say, in I minute, wins from the one who takes it after a combat of 1 minute and 5 seconds. 


\section{Memorandum.}

\section{Dear Reader:}

Before laying down my pen, I should like to impress upon you that modesty is the "hall mark" of the true horseman; for when on a horse "you don't know where you are," or rather, "where you may be the next moment." In any case, give your "dumb friend" the credit of having inspired you with the ideas that made you his master, and do not-you the one on whom Providence has bestowed its rarest gift, "intellect"- degrade yourself by misusing your supremacy.

Your obedient servant,

Tile Autrior. 




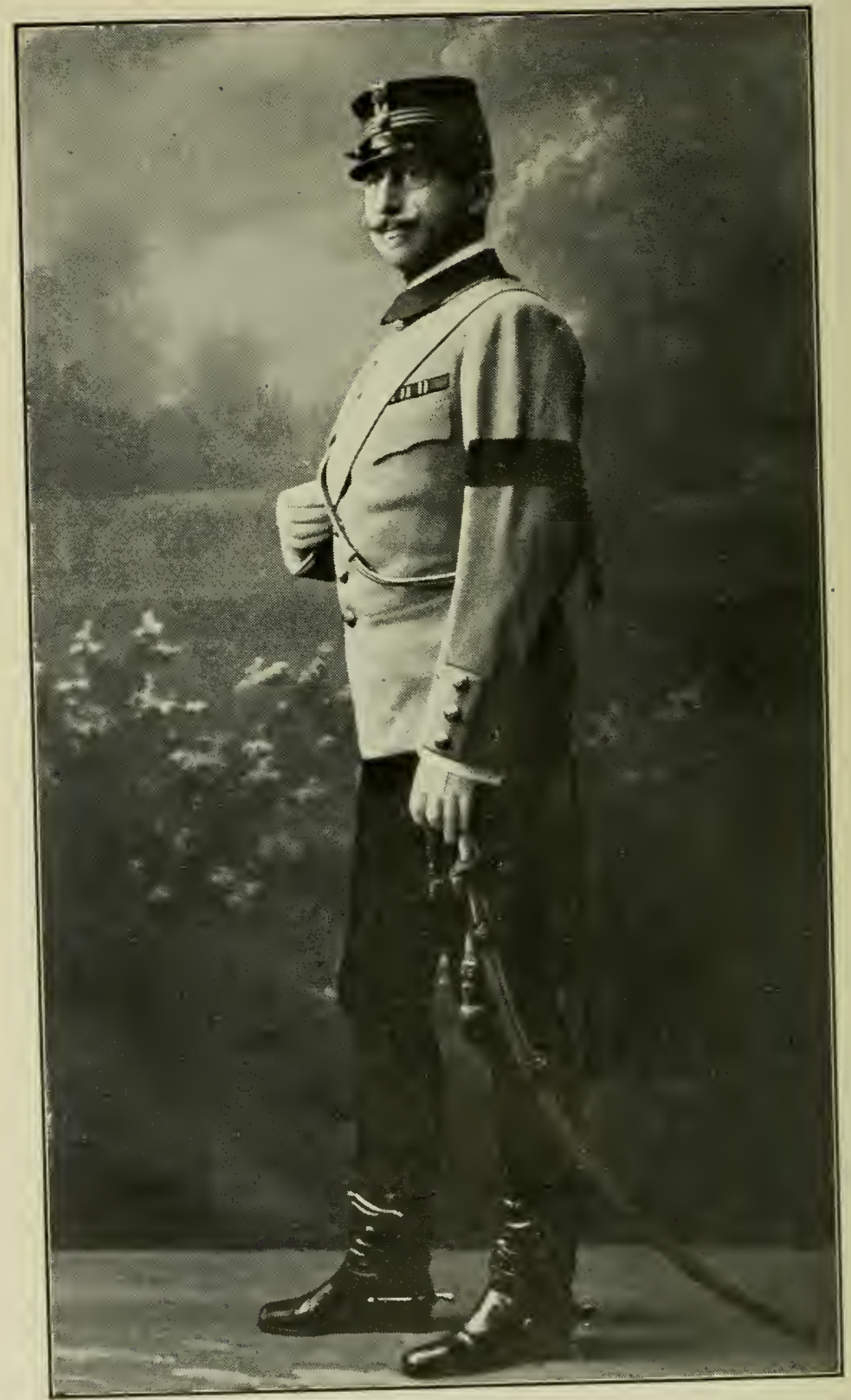

Norway, 1904

THE AUTHOR. 


\section{ARE YOU A LOVER OF HORSES?}

IF SO, YOU SHOULD READ

\section{THE RIDER AND. DRIVER EDITED BY \\ SAMUEL WALTER TAYLOR}

A weekly publication devoted to every branch of the horse's interests: Horse Shows; Polo Games; Hunt Meetings; Riding Clubs and Schools; and other forms of Outdoor Sport.

EQUITATION IN ITS HIGHEST FORM Fully illustrated

Price 10 Cents Weekly $\$ 5.00$ Yearly $\$ 6.00$ Foreign

Edward Bach

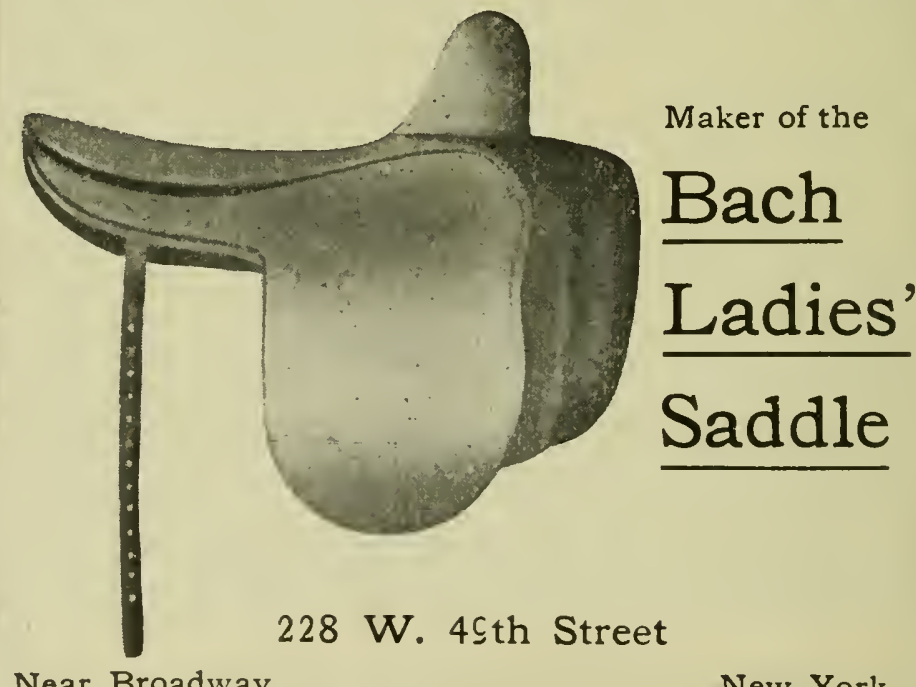




\section{(jin GRIMSGAARD'S
Park Saddle}

\section{AND \\ CAPTAIN GRIMSGAARD'S Training Saddle}

Impart to the Rider a Firm and Elegant Seat

The outlines and curves of a saddle conbribute greatly to the comfort, firmuess and elegance of the rider's seat. Through a profund study, long experience and numerous experiments, the author of this book has solved the problem of imparting to the saddle the necessary attributes required.

The saddles are imported, of best English make, and are only made to order, from customers' measurements; they are also VERY CHEAP.

\section{Lady's Astride Saddle}

with Buckskin Scat and of the Fark-Saddle Style-also in sizes for children-may be ordered.

The Shin-Boots and the Rubber Curb-Chain Guard, which have been recommended in this book, may be ordered through the author.

For particulars address: Captain Grimsgaard, care of The Winthrop Press, 4 I9 Lafayette Street, New York, N. Y. 


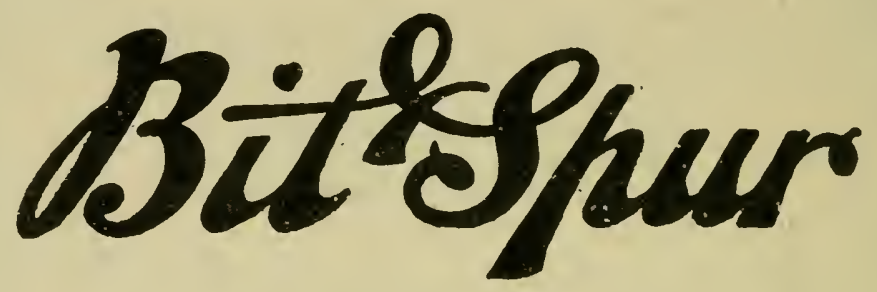

America's foremost Publication in the Horse World and the Field of Fashionable Sports.

Handsomely and profusely illustrated Covers a wide range, including

\section{Horse Shows,}

Breeding, Hunting, Polo, Equestrianism, Hunt

\section{Club Racing}

Kennel and Sporting Notes

Issued monthly

$\$ 3.00$ yearly
On best news-stands 25 cents a copy

\section{WILFRED JAY, Editor}

Sample copy may be had upon request

\section{Bit \& Spur}

389 Fifth Avenue, New York 


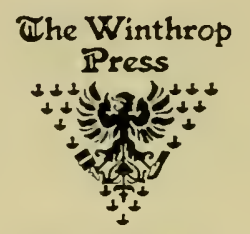

New Ulork

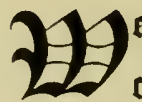

$\mathfrak{e}$ make a specialty

of prize=lists and beautiful catalogs for borse sbows, anoprograms for equestrian entertain: ments. We babe experts to rebise and carrect.

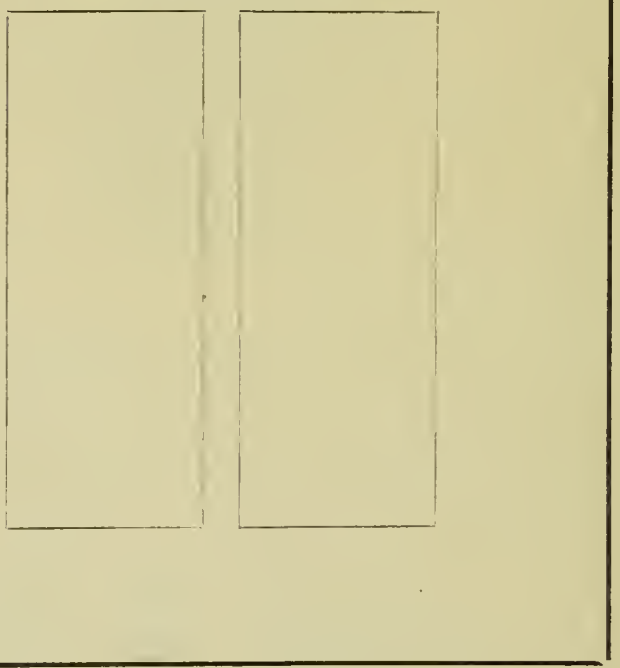




\section{FREE BOOK}

500 Page Book free, on the Treatment and Care of Horses, Cattle, Sheep, Dogs, Hogs and Poultry, also Stable Chart to hang up, mailed free.

For Every Living Thing on the Farm Humphreys' Veterinary Specifics.

A. A. For FEVERS, Milk Fever, Lung Fever.

B. B. For SPRAINS, Lameness, Rheumatism.

C. C. For SORE Throat, Epizootic, Distemper.

D. D. For WORMS, Bots, Grubs.

E. E. For COUGHS, Colds, Influenza.

F. F. For COLIC, Bellyache Diarrhea.

G. G. Prevents MISCARRIAGE.

H. H. For KIDNEY and Bladder disorders.

I. I. For SKIN DISEASES, Mange, Eruptions. J. K. For BAD CONDITION, Indigestion.

At druggists or sent prepaid on receipt of price. $60 \mathrm{cts}$. each.

HUMPHREYS' HOMEO. MEDICINE CO. Corner William and Ann Streets, New York. 


\title{
The Safety-Hygienic Bit
}

Invented by Capt. Giov. Ciammaichella, of the Italian Army.
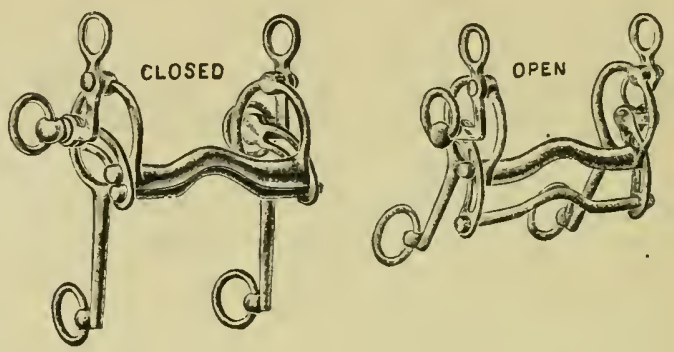

The Best all around Bit on the market. Has, all the good points of the Bit you are now using with additional features. Insures absolute safety to the Rider or Driver by giving perfect control at all times and in any emergency. Never becomes displaced in the mouth. No head pressure. No torture, no chafing, no callous formation.

Makes This Bit the Most Perfect and Practical for Riding, Driving, Hunting, PoloPlaying, Cavalry and Mounted Police.

\section{Safety-Hygienic Horse Bit Co.} 51 Chambers Street, New York, N. Y.

\author{
At all first-class Saddlery Dealers. \\ WRITE FOR BOOKLET
}




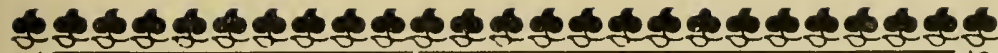

Horse

Shows

\section{Riding Academies}

\section{AMERICA'S}

leading journal devoted to the interest of the HORSE in harness and under saddle

SPORTS of the TIMES The Journal of Outdoor America BEAUTIFULLY ILLUSTRATED

depicting all the horse shows, hunt meets and saddle horse news, with a little dash of dogs and the stage.

Subscription price $\$ 4.00$ per year

Sample copy mailed upon application Address

SPORTS OF THE TIMES

22 Thames Street

New York

Harness

Saddle

Horses

Horses 



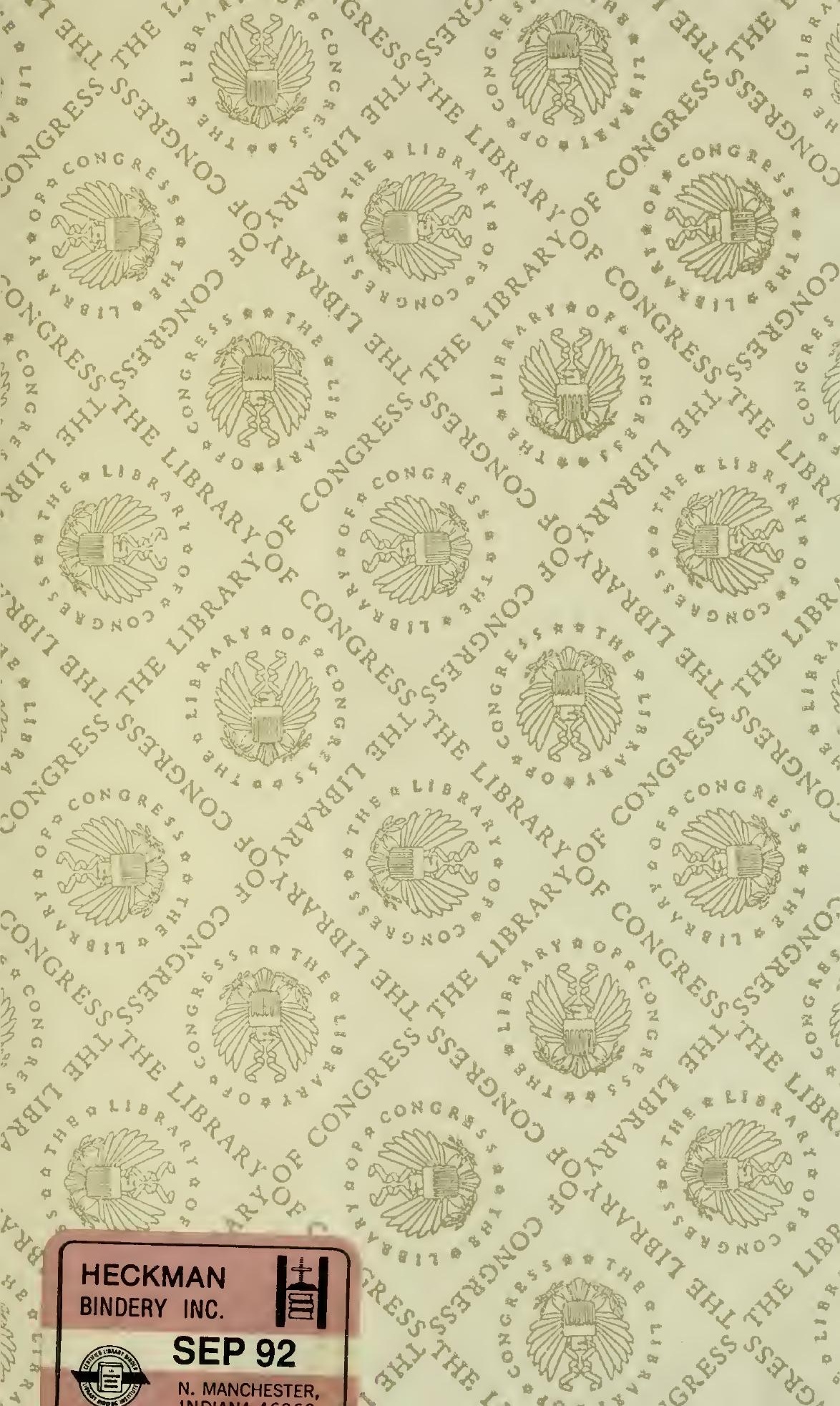




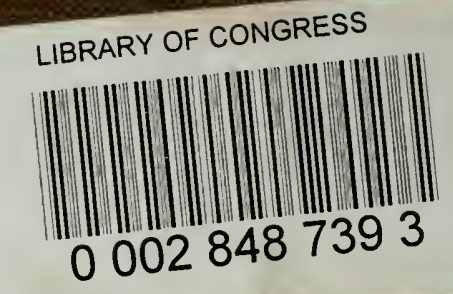

